\title{
Pulse-Jet Baghouse \\ Performance Improvement With Flue Gas Conditioning
}

Topical Report

Stanley J. Miller

Dennis L. Laudal

Work Performed Under Contract No.: DE-FC21-86MC10637

\author{
For \\ U.S. Department of Energy \\ Office of Fossil Energy \\ Morgantown Energy Technology Center \\ P.0. Box 880 \\ Morgantown, West Virginia 26507-0880 \\ University of North Dakota \\ Energy and Environmental Research Center \\ Box 8213 \\ University Station \\ Grand Forks, North Dakota 58202-8213
}

October 1992 


\section{ACKNOWLEDGMENT}

The authors wish to acknowledge that the work reported in this document was jointly funded by the U.S. Department of Energy (DOE), the Electric Power Research Instirute (EPRD), and the Canadian Electrical Association (CEA). We thank Dr. Perry Bergman of DOE PETC, Dr. Ramsay Chang of EPRI, and Delip Deshpande of Alberta Power for their helpful technical input throughout the study.

The authors also wish to thank TU Electric for supplying the Big Brown coal, Alberta Power for supplying the Milner coal, and the ARCO Coal Company for supplying the Black Thunder coal. 


\begin{abstract}
A pilot study was conducted at the Energy and Environmental Research Center (EERC) at the University of North Dakota to evaluate the effectiveness of flue gas conditioning in reducing tube sheet pressure drop and fine particulate emissions from a pulsejet fabric filter. The project was jointly funded by the U.S. Department of Energy (DOE), the Electric Power Research Institute (EPRD), and the Canadian Electrical Association (CEA). The work was completed with EERC facilities consisting of a pulverized coal-fired combustor and pilot baghouse. Full-scale pulse-jet bags were employed under conditions similar to large-scale baghouses. The investigation included baseline tests and tests in which ammonia and $\mathrm{SO}_{3}$ were injected upstream of the baghouse to determine the effect of conditioning on baghouse performance. The primary independent variables included coal type, conditioning agent concentrations, air-to-cloth $(\mathrm{A} / \mathrm{C})$ ratio, and fabric type. The main dependent variables were particulate emissions, baghouse pressure drop, and cohesive properties of the fly ash. Results demonstrated significant benefits of using conditioning with a pulse-jet baghouse, including a substantial reduction in particulate emissions and a substantial reduction in pressure drop (or the ability to operate at a higher AVC ratio without increasing pressure drop or bag-cleaning frequency). The improvements in fabric filter performance correlate strongly with a shift in the tensile strength and with increases in the aerated and packed porosity of the fly ash. Conditioning appears to be applicable to a wide range of coals and fabrics. Applications for this technology are where there is a need to reduce pressure drop and/or particulate emissions in existing baghouses, to reduce fineparticle air toxic emissions which may be required in the future, and for new baghouse installations to allow operation at a higher A/C ratio while providing an ultrahigh fineparticle collection efficiency.
\end{abstract}




\section{TABLE OF CONTENTS}

Page

IIST OF FIGURES $\ldots \ldots \ldots \ldots \ldots \ldots \ldots \ldots \ldots \ldots \ldots \ldots \ldots$

IIST OF TABLES $\ldots \ldots \ldots \ldots \ldots \ldots \ldots \ldots \ldots \ldots \ldots$

1.0 PROJECT SUMMARY $\ldots \ldots \ldots \ldots \ldots \ldots \ldots \ldots \ldots \ldots \ldots \ldots \ldots$

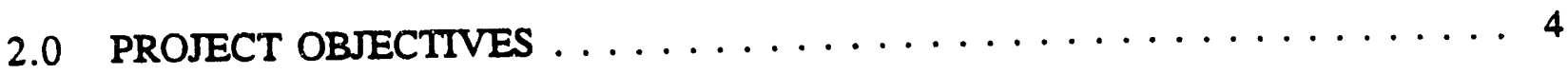

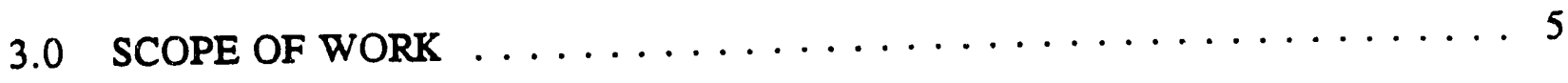

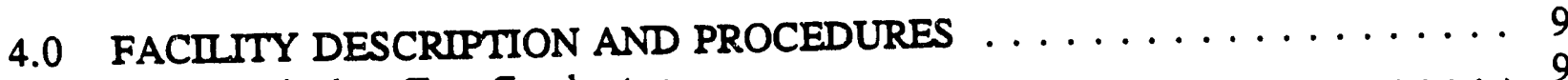

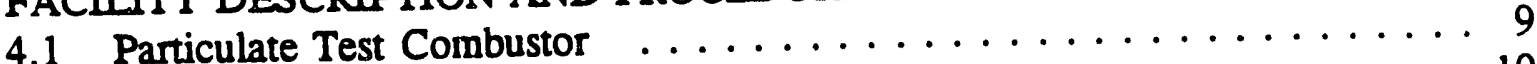

4.2 Particulate Sampling and Measurement . . . . . . . . . . . . . . . 10

4.3 Sulfur Trioxide and Ammonia Injection $\ldots \ldots \ldots \ldots \ldots \ldots$

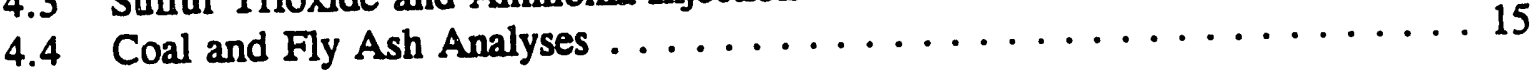

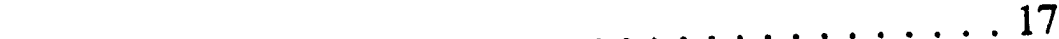

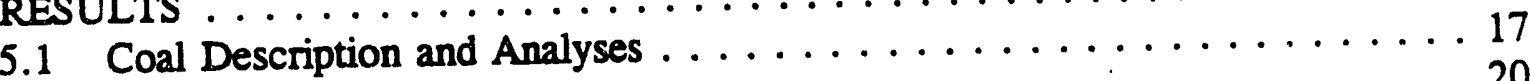

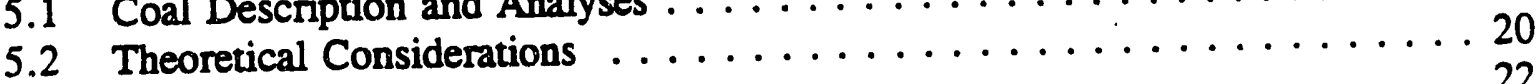

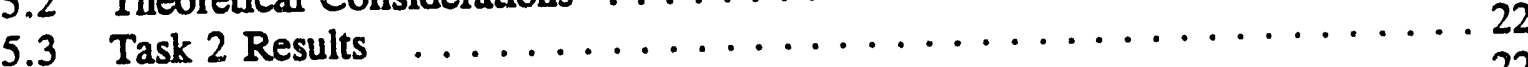

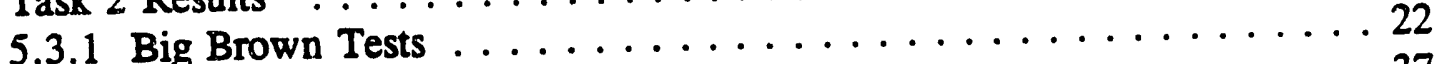

5.3 .2 Milner Tests $\ldots \ldots \ldots \ldots . \ldots \ldots$

5.3 .3 Cohesive Properties and Ash Analyses . . . . . . . . . . . . 42

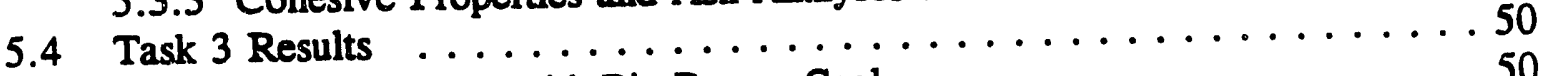

5.4 .1 100-hour Tests with Big Brown Coal $\ldots \ldots \ldots \ldots \ldots$

5.4 .2100 -hour Tests with Milner Cazl . . . . . . . . . . . . . . 59

5.4 .3100 -hour Tests with Rlack Thuniler Coal . . . . . . . . . . . 65

$5.4 .416-\mathrm{ft} / \mathrm{min}$ Tests with Big Browr Coal . . . . . . . . . . . . 72

5.4 .5 Cohesive Properties and Ásin Analyses . . . . . . . . . . . 81

5.4 .5 .1 Particle Size . . . . . . . . . . . . . . . . . . . . . . . . . . . . . . . . . .

5.4 .5 .2 Tensile Strength . . . . . . . . . . . . . . . . . . 84

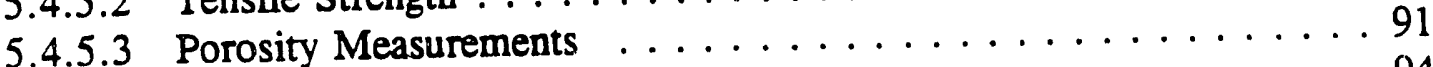

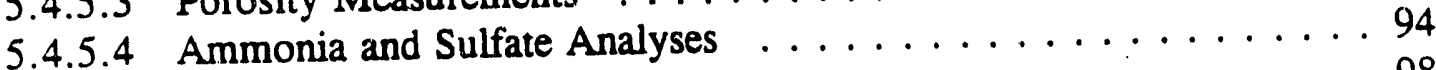

5.4.5.5 Residual Dust Cake Weight . . . . . . . . . . . . . . . 98

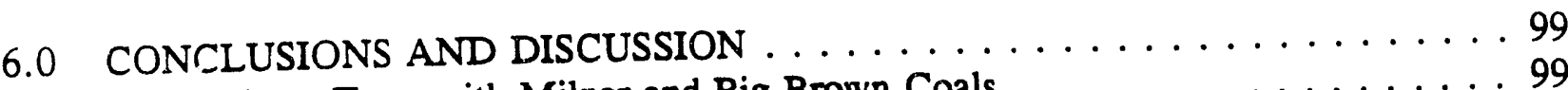

6.18 -hour Tests with Milner and Big Brown Coals . . . . . . . . . . . . . . 99

15.2 100-hour Tests with Big Brown, Milner, and Black Thunder Coals . . . . 110

6. $316-\mathrm{ft} / \mathrm{min}$ Tests with Big Brown Coal . . . . . . . . . . . . . . . 111

6.4 Unresolved Issues and Areas for Future Research . . . . . . . . . . . . . 111

7.0 REFERENCES 


\section{LIST OF FIGURES}

Firure

Page

1 Combustion system used for tests, showing the PTC and baghouse $\ldots \ldots \ldots 10$

2 Schematic of aerodynamic particulate sizer. . . . . . . . . . . 12

3 Schematic of the particulate-sampling system (APS 33, DMPS, and dilution system) ............................ 14

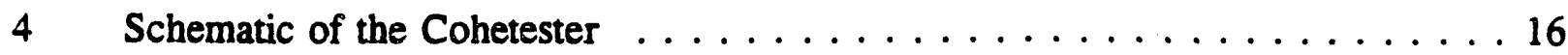

$5 \quad$ Log-probability plot of coal particle-size distribution based on sieve

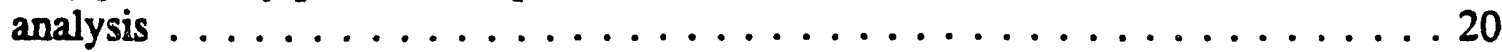

6 Respirable mass emissions and pressure drop as a function of time for Big Brown coal at an AVC ratio of $4 \mathrm{ft} / \mathrm{min}$, Ryton fabric, and no conditioning. Bags were cleaned every 60 minutes after an initial 180-minute period

7 Respirable mass emissions and pressure drop as a function of time for Big Brown coal at an A/C ratio of $4 \mathrm{ft} / \mathrm{min}$ with Ryton fabric and 50/25 ppm of $\mathrm{NH}_{3} / \mathrm{SO}_{3}$. Bags were cleaned every 60 minutes after an initial 180-minute period . . . . . . . . . . . . . . . . . . . . . . 27

8 Respirable mass emissions and pressure drop as a function of time for Big Brown coal at an A/C ratio of $4 \mathrm{ft} / \mathrm{min}$ with Ryton fabric and 24/12 ppm of $\mathrm{NH}_{3} / \mathrm{SO}_{3}$. Bags were cleaned every 60 minutes after an initial 180-minute period

9 Respirable mass emissions and pressure drop as a function of time for Big Brown coal at an A/C ratio of $4 \mathrm{ft} / \mathrm{min}$ with Ryton fabric and $12 / 6 \mathrm{ppm}$ of $\mathrm{NH}_{3} / \mathrm{SO}_{3}$. Bags were cleaned every 60 minutes after an initial 180-minute period

10 Pressure drop for baseline and conditioning tests with Big Brown coal with Ryton fabric at an $\mathrm{A} / \mathrm{C}$ ratio of $4 \mathrm{ft} / \mathrm{min}$. Bags were cleaned every 60 minutes after an initial 180 -minute period . . . . . . . . . . . 30

11 Respirable mass emissions and pressure drop as a function of time for Big Brown coal at an A/C ratio of $6 \mathrm{ft} / \mathrm{min}$ with Ryton fabric and no conditioning. Bags were cleaned every 30 minutes during the last 4 hours

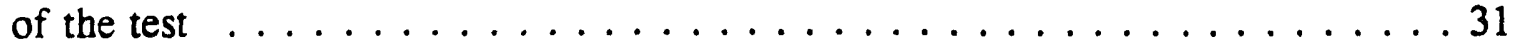




\section{IIST OF FIGURES}

Figure

12 Respirable mass emissions and pressure drop as a function of time for Big Brown coal at an A/C ratio of $6 \mathrm{ft} / \mathrm{min}$ with Ryton fabric and $24 / 12 \mathrm{ppm}$ of $\mathrm{NH}_{3} / \mathrm{SO}_{3}$. Bags were cleaned every 30 minutes after an initial 90 -minute

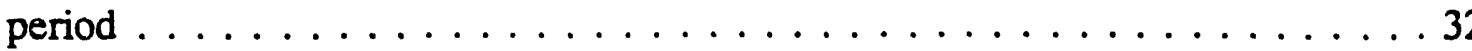

13 Respirable mass emissions and pressure drop as a function of time for Big Brown coal at an AVC ratio of $8 \mathrm{ft} / \mathrm{min}$ with Ryton fabric and $24 / 12 \mathrm{ppm}$ of $\mathrm{NH}_{3} / \mathrm{SO}_{3}$. Bags were cleaned every 30 minutes after an initial so-minute

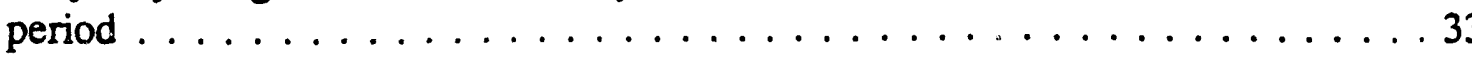

14 Pressure drop for baseline and conditioning tests with Big Brown coal with Ryton fabric at an A/C ratio of $6 \mathrm{ft} / \mathrm{min}$. Bags were cleaned every 30 minutes during the last 4 hours of tests $\ldots \ldots \ldots . \ldots \ldots$

15 Pressure drop for conditioning tests with Big Brown coal with Ryton fabric at $\mathrm{A} / \mathrm{C}$ ratios of 4 and $8 \mathrm{ft} / \mathrm{min}$. After initial filtration periods, bags were cleaned every 30 minutes at $8 \mathrm{ft} / \mathrm{min}$ and every 60 minutes at $4 \mathrm{ft} / \mathrm{min} \ldots \ldots 34$

16 Comparison of submicron emissions measured with the CNC for Big Brown coal with Ryton fabric for the baseline and conditioning tests at an

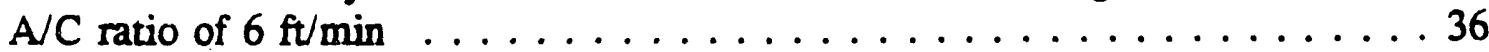

17 Respirable mass emissions and pressure drop for baseline and conditioning tests with Big Brown coal with woven glass fabric at an A/C ratio of $4 \mathrm{ft} / \mathrm{min}$. Bags were cleaned every 45 minutes after an initial 90 -minute period

18 Respirable mass emissions and pressure drop as a function of time for Milner coal at an A/C ratio of $4 \mathrm{ft} / \mathrm{min}$ with Ryton fabric and no conditioning. After an initial 90-minute filtration period, bags were cleaned every 30 minutes, except that the last two cleaning cycle intervals were 60 minutes

19 Respirable mass emissions and pressure drop as a function of time for Milner coal at an A/C ratio of $4 \mathrm{ft} / \mathrm{min}$ with Ryton fabric and $24 / 12 \mathrm{ppm}$ of $\mathrm{NH}_{3} / \mathrm{SO}_{3}$. After an initial 90-minute filtration period, bags were cleaned every 30 minutes, except that the last two cleaning cycle intervals were 60 minutes . . . . . . . . . . . . . . . . . . . . . . 40

20 Respirable mass emissions and pressure drop as a function of time for Milner coal at an A/C ratio of $4 \mathrm{ft} / \mathrm{min}$ with Ryton fabric and $12 / 6 \mathrm{ppm}$ of $\mathrm{NH}_{3} / \mathrm{SO}_{3}$. After an initial 90-minute filtration period, bags were cleaned every 30 minutes, except that the last two cleaning cycle intervals were 60 minutes 


\section{LIST OF FIGURES}

Figure

Page

21 Respirable mass emissions and pressure drop as a function of time for Milner coal at an AVC ratio of $8 \mathrm{ft} / \mathrm{min}$ with Ryton fabric and 24/12 ppm of $\mathrm{NH}_{3} / \mathrm{SO}_{3}$. After an initial 40-minute filtration period, bags were cleaned every 20 minutes . . . . . . . . . . . . . . . . . . . 43

22 Respirable mass emissions and pressure drop as a function of time for Milner coal at an A/C ratio of $4 \mathrm{ft} / \mathrm{min}$ with P84/Ryton fabric and no conditioning. After an initial 90-minute filtration period, bags were cleaned every 30 minutes $\ldots \ldots \ldots \ldots \ldots \ldots$

23 Respirable mass einissions and pressure drop as a function of time for Milner coal at an AVC ratio of $4 \mathrm{ft} / \mathrm{min}$ with P84/Ryton fabric and 24/12 ppm of $\mathrm{NH}_{3} / \mathrm{SO}_{3}$. After an initial 90 -minute filtration period, bags were cleaned every 30 minutes . . . . . . . . . . . . . . . 45

24 Particle-size distribution of Big Brown and Milner fly ash based on multicyclone results

25 Tensile strength as a function of porosity for baseline and conditioned fly ash with Big Brown and Milner coals with Ryton fabric at an A/C ratio of $4 \mathrm{ft} / \min \ldots \ldots \ldots \ldots \ldots \ldots \ldots \ldots \ldots \ldots$

26 Tensile strength as a function of porosity for Task 2 Big Brown tests . . . . . 48

27 Tensile strength as a function of porosity for Task 2 Milner tests . . . . . . 48

28 Effect of conditioning on baghouse pressure drop for 100-hour Big Brown tests for Runs 403, 404, and 405. Bags were pulsed once per hour . . . . . . . 53

29 Effect of conditioning on average respirable mass emissions for 100-hour Big Brown tests for Runs 403, 404, and $405 \ldots \ldots \ldots \ldots$

30 Respirable mass emissions before and after bag cleaning for the 100-hour baseline Run 403 with Big Brown coal . . . . . . . . . . . . . . . 55

31 Respirable mass emissions before and after bag cleaning for the 100-hour conditioning Run 404 with Big Brown coal . . . . . . . . . . . . . 56

32 Respirable mass emissions before and after bag cleaning for the 100-hour conditioning Run 405 with Big Brown coal . . . . . . . . . . . 56

33 Range of submicron particle emissions for the 100-hour baseline Run 403 with Big Brown coal . . . . . . . . . . . . . . . . 57 


\section{LIST OF FIGURES}

Figure

$\underline{\text { Page }}$

34 Range of submicron particle emissions for the 100-hour conditioning Run 404 with Big Brown coal . . . . . . . . . . . . . . . . . . . . . . 57

35 Range of submicron particle emissions for the 100-hour conditioning Run 405 with Big Brown coal . . . . . . . . . . . . . . . . . . . 58

36 Effect of conditioning on baghouse pressure drop for 100-hour Milner tests for Runs 406, 407, and 411. Bags were pulsed every 30 minutes . . . . . . . 60

37 Effect of conditioning on average respirable mass emissions for 100-hour Milner tests for Runs 406,407 , and $411 \ldots \ldots \ldots \ldots$. . . . . . . . 61

38 Respirable mass emissions before and after bag cleaning for the 100-hour baseline Run 406 with Milner coal . . . . . . . . . . . . . . . . 61

39 Respirable mass emissions before and after bag cleaning for the 100-hour conditioning Run 407 with Milner coal

40 Respirable mass emissions before and after bag cleaning for the 100-hour conditioning Run 411 with Milner coal $\ldots \ldots \ldots \ldots . \ldots \ldots 2$

41 Range of submicron particle emissions for the 100-hour baseline Run 406 with Milner coal $\ldots \ldots \ldots \ldots$. . . . . . . . . . . . . . 63

42 Range of submicron particle emissions for the 100-hour conditioning Run 407 with Milner coal . . . . . . . . . . . . . . . . . . . . . . . . 64

43 Range of submicron particle emissions for the 100-how ? conditioning Run 411 with Milner coal . . . . . . . . . . . . . . . . . . . . . . . . . . . 64

44 Effect of conditioning on baghouse pressure drop for 100-hour Black Thunder tests for Runs 409, 410B, and 413. Bags were pulsed once every hour . . . . . 66

45 Effect of conditioning on baghouse pressure drop for Black Thunder test with $24 / 12$ ppm of $\mathrm{NH}_{3} / \mathrm{SO}_{3}$ for Run $410 \mathrm{~A}$. Bags were pulsed once per hour for the first 8 hours and once every 30 minutes for the remainder of

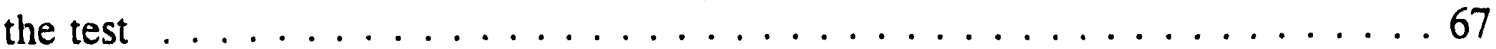

46 Effect of conditioning on average respirable mass emissions for 100-hour Black Thunder tests for Runs 409, 410B, and $413 \ldots \ldots$. . . . . . . . 68

47 Respirable mass emissions before and after bag cleaning for the 100-hour baseline Run 409 with Black Thunder coal 


\section{LIST OF FIGURES}

Figure

Page

48 Respirable mass emissions before and after bag cleaning for the 100 -hour conditioning Run 410B with Black Thunder coal . . . . . . . . . . . . . . 69

49 Respirable mass emissions before and after bag cleaning for the 100-hour conditioning Run 413 with Black Thunder coal . . . . . . . . . . . . . . . 69

50 Range of submicron particle emissions for the 100-hour baseline Run 409 with Black Thunder coal . . . . . . . . . . . . . . . . 70

51 Range of submicron particle emissions for the 100-hour conditioning Run 410B with Black Thunder coal . . . . . . . . . . . . . . . . . 70

52 Range of submicron particle emissions for the 100-hour conditioning Run 413 with Black Thunder coal . . . . . . . . . . . . . . . . . . 71

53 Respirable mass emissions for Black Thunder test with 24/12 ppm of

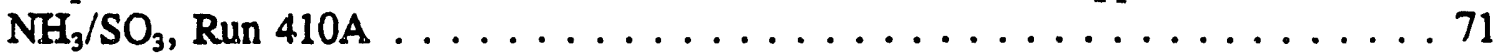

54 Range of submicron particle emissions for Black Thunder test with $24 / 12 \mathrm{ppm}$ of $\mathrm{NH}_{3} / \mathrm{SO}_{3}$, Run $410 \mathrm{~A} \ldots \ldots \ldots \ldots \ldots \ldots$

55 Effect of conditioning on baghouse pressure drop for 8-hour Big Brown tests with a full dust loading at an A/C ratio of $16 \mathrm{ft} / \mathrm{min}$ for Runs 399 and 400. Bags were pulsed every 5 minutes during the last 2 hours of each test . . 73

56 Effect of conditioning on average respirable mass emissions for 8-hour Big Brown tests with a full dust loading at an AVC ratio of $16 \mathrm{ft} / \mathrm{min}$ for

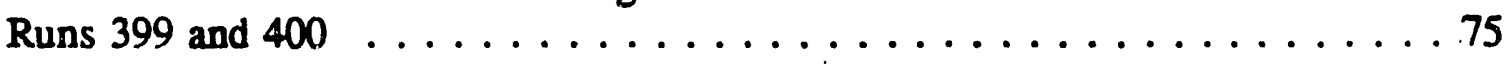

57 Respirable mass emissions before and after bag cleaning for the 8-hour baseline Big Brown test with a full dust loading at an $\mathrm{A} / \mathrm{C}$ ratio of $16 \mathrm{ft} / \mathrm{min}$ for Run $399 \ldots \ldots \ldots \ldots \ldots \ldots$

58 Respirable mass emissions before and after bag cleaning for the 8-hour Big Brown test with conditioning and with a full dust loading at an $\mathrm{A} / \mathrm{C}$ ratio of $16 \mathrm{ft} / \mathrm{min}$ for $\operatorname{Run} 400 \ldots \ldots \ldots \ldots \ldots \ldots \ldots$

59 Respirable mass emissions before and after bag cleaning for the 8-hour baseline Big Brown test with a reduced dust loading at an AV ratio of $16 \mathrm{ft} / \mathrm{min}$ for Run $401 \ldots \ldots \ldots \ldots \ldots \ldots$ 


\section{LIST OF FIGURES}

Figure

$\underline{\text { Page }}$

60 Respirable mass emissions before and after bag cleaning for the 8-hour Big Brown test with conditioning and a reduced dust loading at an $\mathrm{A} / \mathrm{C}$ ratio of $16 \mathrm{ft} / \min$ for Run $402 \ldots \ldots \ldots \ldots \ldots$. . . . . . . . . . . . . . . . . . . . . . .

61 Particle-size distribution of Big Brown fly ash based on multicyclone sampling . 82

62 Particle-size distribution of Milner fly ash based on multicyclone sampling . . . 82

63 Comparison of particle-size distributions of Big Brown, Milner, and Black Thunder fly ash based on multicyclone sampling $\ldots \ldots \ldots . \ldots 3$

64 Comparison of particle-size distributions for normal and reduced dustloading tests for Big Brown, based on multicyclone sampling . . . . . . . 83

65 Effect of conditioning on fly ash tensile strength for 100-hour Big Brown

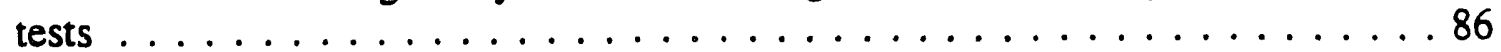

66 Effect of conditioning on fly ash tensile strength for 100-hour Milner tests . . . 86

67 Effect of conditioning on fly ash tensile strength for 100-hour Black

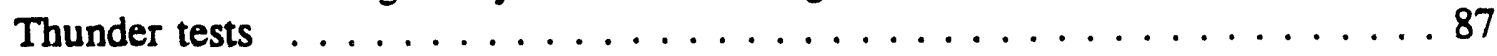

68 Comparison of fly ash tensile strengths for conditioned tests with Big Brown, Milner, and Black Thunder coals . . . . . . . . . . . . 87

69 Comparison of fly ash tensile strengths for baseline tests with Big Brown, Milner, and Black Thunder coals . . . . . . . . . . . . . . . 89

70 Fly ash tensile strengths for 100- and 8-hour Big Brown tests . . . . . . . . 89

71 Fly ash tensile strengths for 100 - and 8 -hour Milner tests $\ldots \ldots \ldots$. . . . 90

72 Comparison of tensile strengths of hopper ash and residual dust cake ash from the bags for Black Thunder tests . . . . . . . . . . . . . . . 90

73 Laboratory measurement of $\mathrm{K}_{2}$ as a function of porosity with CarmanKozeny equation fit to data for Big Brown tests . . . . . . . . . . . 92

74 Laboratory measurement of $\mathrm{K}_{2}$ as a function of porosity with CarmanKozeny equation fit to data for Milner tests . . . . . . . . . . . . . . . . 92

75 Laboratory measurement of $K_{2}$ as a function of porosity with CarmanKozeny equation fit to data for Black Thunder tests . . . . . . . . . . . . . . 93 


\section{LIST OF FIGURES}

Figure

Page

76 Comparison of $\mathrm{K}_{2}$ curves for Big Brown, Milner, and Black Thunder tests . . . 93

77 Correlation between initial $\mathrm{K}_{2}$ and aerated or packed porosity 95

78 Correlation between effective $\mathrm{K}_{2}$ and aerated or packed porosity ....... 95

79 Residual dust cake at the end of the 100-hour baseline test with Big Brown coal for Run $403 \ldots \ldots \ldots$. . . . . . . . . . . . . . . . . 100

80 Residual dust cake at the end of the 100-hour conditioning test with Big Brown coal at an AVC ratio of $4 \mathrm{ft} / \mathrm{min}$ for Run $404 \ldots \ldots$. . . . . . . 101

81 Residual dust cake at the end of the 100-hour conditioning test with Big Brown coal at an A/C ratio of $6 \mathrm{ft} / \mathrm{min}$ for Run $405 \ldots \ldots$

82 Residual dust cake at the end of the 100-hour baseline test with Milner cual for $\operatorname{Run} 406 \ldots \ldots \ldots$. . . . . . . . . . . . . . . . . . 103

83 Residual dust cake at the end of the 100-hour conditioning test with Milner coal at an AVC ratio of $4 \mathrm{ft} / \mathrm{min}$ for Run $407 \ldots$. . . . . . . . . . . . . . . . . 104

84 Residual dust cake at the end of the 100-hour conditioning test with Milner coal at an AVC ratio of $6 \mathrm{ft} / \min$ for Run $411 \ldots \ldots \ldots$. . . . . . . . . . 105

85 Residual dust cake at the end of the 100-hour baseline test with Black Thunder coal for $\operatorname{Run} 409 \ldots \ldots$. . . . . . . . . . . . . . . . . 106

86 Residual dust cake at the end of the 100-hour conditioning test with Black Thunder coal at an AVC ratio of $4 \mathrm{ft} / \mathrm{min}$ for Run $410 \mathrm{~B} \ldots \ldots . . . . . . . .107$

87 Residual dust cake at the end of the 100-hour conditioning test with Black Thunder coal at an A/C ratio of $6 \mathrm{ft} / \mathrm{min}$ for Run $413 \ldots \ldots$. . . . . . . 108 


\section{LIST OF TABLES}

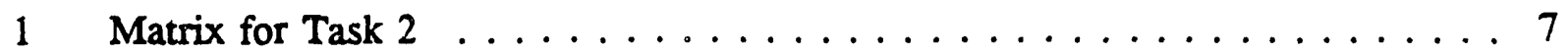

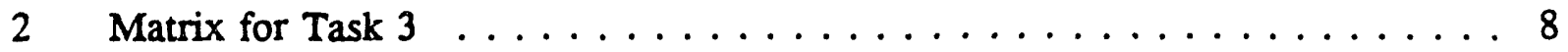

3 Pulse-Jet Fabric Filter Specifications $\ldots \ldots \ldots \ldots \ldots \ldots \ldots$

4 ACGIH Respirable Mass Definition . . . . . . . . . . . . . . 13

5 Summary of Coal Analyses . . . . . . . . . . . . . . . 19

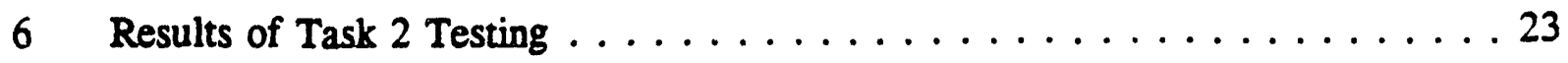

7 Physical and Chemical Fly Ash Characteristics from Task 2 . . . . . . . . 24

8 Results from Task 3 Testing $\ldots \ldots \ldots \ldots \ldots \ldots$

9 Physical and Chemical Fly Ash Characteristics from Task $3 \ldots \ldots \ldots$

10 Ammonia and Sulfate Balances from Task $3 \ldots \ldots \ldots$ 


\section{PULSE-JET BAGHOUSE PERFORMANCE IMPROVEMENT WTTH FLUE GAS CONDITIONING: FINAL PROJECT REPORT}

\subsection{PROJECT SUMMARY}

This project was jointly funded by the U.S. Department of Energy (DOE), the Electric Power Research Institute (EPRD), and the Canadian Electrical Association (CEA), with approximately $50 \%$ of the funding from DOE and $25 \%$ each from EPRI and CEA. The purpose of this project was th evaluate the effectiveness of flue gas conditioning in improving the performance of pulse-jet baghouses. The work was conducted at the Energy and Environmental Research Center (EERC) at the University of North Dakota.

The project was divided into three tasks. Task 1 included facility preparation, procurement of supplies, project management, and report preparation. Task 2 consisted of 15 screening tests of about 8 hours each for initial evaluation of the test parameters. Task 3 consisted of five 8-hour tests at an A/C ratio of $16 \mathrm{ft} / \mathrm{min}$ and 9 longer-term tests of about 100 hours each to establish the effect of conditioning over multiple cleaning cycles. Task 2 results were presented in a Task 2 Summary Report in September 1991, and Task 3 results were presented in a Task 3 Summary Report in May 1992. This final report includes the results from both Tasks 2 and 3.

Previous research with shaker-cleaned and reverse-air baghouses has shown that particulate emissions and baghouse pressure drop are significantly reduced when small amounts of ammonia and $\mathrm{SO}_{3}$ are injected into the flue gas just upstream of the baghouse (1-10). This concept also appears to have significant potential to improve the performance of pulse-jet baghouses. The benefits of using flue gas conditioning with pulse-jet baghouses may be even more significant than with reverse-gas baghouses because pulse-jet baghouses typically operate at higher air-to-cloth $(\mathrm{A} / \mathrm{C})$ ratios, are more subject to high particulate emissions, and are more subject to a combination of high pressure drop, frequent bag cleaning, and short bag life. There are at least four advantages of conditioning, all of which are desirable for pulse-jet baghouses:

1. Particulate emissions are substantially reduced, which enhances the ability of the baghouse to meet regulatory standards at high $\mathrm{A} / \mathrm{C}$ ratios. 
2. A more porous dust cake is formed, leading to reduced pressure drop. This means that the baghouse can be operated at reduced pressure drop while keeping the same cleaning cycle, or the pressure drop can be held constant at a reduced bag-cleaning frequency, or the baghouse can be operated at a higher $\mathrm{A} / \mathrm{C}$ ratio without increasing either pressure drop or bag-cleaning frequency.

3. The dust cake is kept on the surface of the fabric. Fabric blinding by seeping and packing into the fabric structure is prevented.

4. Dispersion of the ash after pulsing is minimized because the dust cake is more cohesive. The dust is dislodged from the bag in larger agglomerates which easily fall to the hopper instead of being recollected on the bags.

The work was completed with EERC facilities consisting of a pulverized coal-fired combustor and pilot baghouse. Full-scale pulse-jet bags were employed under conditions similar to large-scale baghouses. Tests included baseline runs to establish performance without conditioning and similar runs with conditioning agents to quantify performance improvement. The primary independent variables included coal type, conditioning agent concentrations, A/C ratio, and fabric type. The main dependent variables were particulate emissions, baghouse pressure drop, and cohesive properties of the fly ash.

Results from the fifteen 8-hour tests completed in Task 2 showed that:

- Conditioning significantly reduced pressure drop and corresponding $\mathbf{K}_{2}$ at all concentrations tested. Concentrations of 24/12 ppm of $\mathrm{NH}_{9} / \mathrm{SO}_{3}$ provided significant performance improvement for the coals, fabrics, and A/C ratios tested.

- Conditioning did not reduce particulate emissions for either the Ryton or P84/Ryton faurics at an A/C ratio of $4 \mathrm{ft} / \mathrm{min}$ with a constant bag-cleaning interval. However, collection efficiency was already high at $99.99 \%$, and some additional reduction in particulate emissions would be likely if the bags were cleaned on a pressure drop basis. The 8-hour tests were apparently not long enough in duration to detect differences in particulate emissions with the felt fabric; however, the 100hour tests resulted in significantly reduced emissions with conditioning. A small reduction in particulate emissions was seen with conditioning for the Ryton fabric operated at an A/C ratio of $6 \mathrm{ft} / \mathrm{min}$. Conditioning resulted in a significant reduction in particulate emissions for the woven glass fabric. 
- With conditioning, reasonable pressure drop and excellent particulate collection efficiency were achieved for both the Big Brown and Milner coals when operating the pulse-jet baghouse with Ryton fabric at a high A/C ratio of $8 \mathrm{ft} / \mathrm{min}$. Results imply that operation at even higher $\mathrm{A} / \mathrm{C}$ ratios should be possible when using ammonia and $\mathrm{SO}_{3}$ conditioning.

- The primary effect of conditioning on ash properties appears to be a significant increase in aerated and packed porosity. Conditioning also produces an increase in the tensile strength at constant porosity. It appears that reduced particulate emissions arid pressure drop are a direct result of the change in the cohesive nature of the ash that occurs with conditioning.

Results from the 100-hour tests at AVC ratios of 4 and $6 \mathrm{ft} / \mathrm{min}$ and the 8-hour tests at an $\mathrm{A} / \mathrm{C}$ ratio of $16 \mathrm{ft} / \mathrm{min}$ completed in Task 3 showed that:

- Conditioning significantly reduced pressure drop and the corresponding specific dust resistance coefficient, $\mathrm{K}_{2}$, for the Big Brown and Milner coals at concentrations of $24 / 12 \mathrm{ppm}$ of $\mathrm{NH}_{3} / \mathrm{SO}_{3}$. With a constant bag-cleaning frequency, the bagiuuse $\Delta P$ was lower with conditioning at an $A / C$ ratio of $6 \mathrm{ft} / \mathrm{min}$ than for the corresponding baseline tests at $4 \mathrm{ft} / \mathrm{min}$.

- Conditioning reduced particulate emissions for the Big Brown and Milner coals at concentrations of $24 / 12 \mathrm{ppm}$ of $\mathrm{NH}_{3} / \mathrm{SO}_{3}$ using Ryton or P84/Ryton fabrics at $\mathrm{A} / \mathrm{C}$ ratios of 4 and $6 \mathrm{ft} / \mathrm{min}$ with a constant bag-cleaning interval.

- The effects of conditioning on ash properties for the Big Brown and Milner coals were significant shifts in the tensile strength-porosity curves and increases in the aerated and packed porosities. There were no obvious problems with bag cleanability.

- Conditioning reduced pressure drop and corresponding $\mathrm{K}_{2}$ for the Black Thunder coal at concentrations of $12 / 6 \mathrm{ppm}$ of $\mathrm{NH}_{3} / \mathrm{SO}_{3}$. Particulate emissions were not reduced, but emissions were already very low for the baseline test.

- The ammonia slip was typically 1 ppm or less for the Big Brown and Milner tests, but was 5 ppm for the Black Thunder tests. The higher ammonia slip and smaller changes in the tensile strength and porosity of the fly ash indicate that achieving 
optimum performance improvement with conditioning may be somewhat more difficult with the Black Thunder coal.

- For Big Brown coal with a normal dust loading and off-line cleaning at an A/C ratio of $16 \mathrm{ft} / \mathrm{min}$, conditioning will lower the $K_{2}$. However, a more energetic pulse may be required to sufficiently dislodge the dust.

- Big Brown tests with a dust loading of approximately $1 / 20$ th of normal at $16 \mathrm{ft} / \mathrm{min}$ with off-line pulsing resulted in bag blinding. Neither conditioning nor the use of Neutralite precoating was successful in preventing the bag blinding. The combination of very low dust loading and high velocity may allow the dust to pack tightly into the fabric structure, or the particulate properties may change because of different combustion conditions.

These results demonstrate the significant benefits of using conditioning with a pulse-jet baghouse: a substantial reduction in particulate emissions and a substantial reduction in pressure drop (or the ability to operate at a higher AVC ratio without increasing pressure drop or bag-cleaning frequency). The improvements in fabric filter performance correlate strongly with a shift in the tensile strength-porosity curves and with increases in the aerated and packed porosity of the fly ash.

Conditioning appears to be applicable to a wide range of coals and fabrics. Applications for this technology are where there is a need to reduce pressure drop and/or particulate emissions in existing baghouses, to reduce fine-particle air toxic emissions which may be required in the future, and for new baghouse installations to allow operation at a higher AVC ratio while providing an ultrahigh fine-particle collection efficiency.

\subsection{PROJECT OBJECTIVES}

The primary objective of the work was to evaluate the effectiveness of flue gas conditioning in reducing tube sheet pressure drop and particulate emissions from a pulse-jet fabric filter. Specific goals of the work included the following:

1. Evaluate the effectiveness of conditioning with pulse-jet cleaning for three different coals 
2. Determine the effect of conditioning agent concentrations on baghouse pressure drop and particulate emissions

3. Evaluate the potential to increase air-to-cloth ratio with flue gas conditioning

4. Determine the effectiveness of conditioning for two different fabrics

5. Demonstrate the effectiveness of conditioning over multiple cleaning cycles in 100 hour tests

\subsection{SCOPE OF WORK}

The wurk was intended to be sufficient in scope to provide data that could serve as a basis to determine the advantages of using flue gas conditioning with full-scale, pulse-jet baghouses. The primary independent variables in the test program, in order of importance, were:

1. Coal Type: While conditioning was previously shown to be effective for several coals, the level of performance improvement will likely be coal-specific. The first test coal was Big Brown Texas lignite. The second coal was from the Alberta Power Milner Station. The third coal was from the Black Thunder mine in Campbell County, Wyoming.

2. Conditioning Agent Concentration: Previous tests at the EERC have shown that, for several coals, 25-ppm ammonia and 12-ppm $\mathrm{SO}_{3}$ are adequate to provide substantial reductions in pressure drop and particulate emissions. These concentrations, however, have not been optimized for any coal and are likely to be different for different coals. Therefore, three initial $\mathrm{NH}_{3} / \mathrm{SO}_{3}$ concentrations of $50 \mathrm{ppm} / 25 \mathrm{ppm}, 24 \mathrm{ppm} / 12 \mathrm{ppm}$, and $12 \mathrm{ppm} / 6 \mathrm{ppm}$ were tested in Task 2. Concentrations of conditioning agents were not a primary variable in Task 3, but were tested at two levels for the Black Thunder coal.

3. Air-to-Cloth Ratio: Since the economics of baghouses are highly dependent on $\mathrm{A} / \mathrm{C}$ ratio, a goal of the work was to determine if $\mathrm{A} / \mathrm{C}$ can be substantially increased with conditioning. A/C ratios of 4,6 , and $8 \mathrm{ft} / \mathrm{min}$ were tested in 
Task 2. The 100-hour tests included AVC ratios of 4 and $6 \mathrm{ft} / \mathrm{min}$, and additional 8-hour runs included tests at $16 \mathrm{ft} / \mathrm{min}$.

4. Fabric Type: Ryton felted fabric ( $18 \mathrm{oz} / \mathrm{yd}^{2}$ with Ryton scrim) was the main test fabric. Some 8-hour tests were also conducted with 22-oz/yof woven glass (JPS Style 7577 with acid-resistant finish). For the 8-hour Milner coal tests, P84/Ryton felted fabric was used as the second test fabric in place of the woven glass fabric. All of the 100-hour and additional 8-hour tests in Task 3 were conducted with either Ryton or P84/Ryton needled felt material. New bags were used for each test.

The original plan was to conduct fifteen 8-hour tests in Task 2 and nine 100-hour tests in Task 3. Following the completion of the Task 2 tests, a review meeting was held at the EERC to discuss initial results and plan any modifications to the originally proposed scope of work. One of the requested changes discussed in the review meeting was to conduct additional 8-hour tests at an AVC ratio of 16-ft/min with Big Brown coal. To achieve an A/C ratio of $16 \mathrm{ft} / \mathrm{min}$, only one 10-ft Ryton bag was used in the pilot baghouse. The 16-ft/min tests included baseline (no conditioning) and conditioning tests at the normal dust loading and with a reduced dust loading. One of the purposes of these tests was to simulate conditions where a high-ratio pulse-jet baghouse is installed downstream of an ESP as in the EPRI Compact Hybrid Particulate Collector (COHPAC) concept. The normal dust-loading tests were conducted in a manner similar to the other tests, except the AVC ratio was $16 \mathrm{ft} / \mathrm{min}$ and the bag was pulsed off-line instead of the normal on-line pulsing. To achieve a reduced dust loading, the combustor was fired with both natural gas and coal with about 1/20th of the normal coal feed rate, while maintaining the same flue gas. flow rate.

The test matrix for the 8-hour, Task 2 tests is shown in Table 1, and the test matrix for the Task 3 tests is shown in Table 2. Originally, nine 100-hour tests were planned, with four additional 8 -hour tests at $16-\mathrm{ft} / \mathrm{min}$. The last 100-hour test was to bave been a run with woven glass fabric. However, because of remaining questions from the first four 16- $\mathrm{ft} / \mathrm{min}$ tests, additional 16-ft/min tests were attempted in place of the run with woven glass. When the last $16-\mathrm{ft} / \mathrm{min}$ tests were unsuccessful, the remainder of the run was used to perform one additional test with the Black Thunder coal using Ryton fabric. 


\section{TABLE 1}

Matrix for Task 2 (8-hour tests)

\begin{tabular}{|c|c|c|c|c|c|c|}
\hline $\begin{array}{l}\text { Test } \\
\text { No. }\end{array}$ & Run & Purpose & Coal & $\begin{array}{l}\mathrm{NH}_{3} / \mathrm{SO}_{3} \\
\text { (ppm) }\end{array}$ & $\begin{array}{c}\text { A/C } \\
\text { Ratio } \\
\text { (ft/min) }\end{array}$ & Fabric \\
\hline 1 & 379 & $\begin{array}{l}\text { Establish Initial } \\
\text { Baseline }\end{array}$ & Big Brown & None & 4 & Ryton \\
\hline 2 & 380 & $\begin{array}{l}\text { Evaluate Conditioning } \\
\text { Agent Concentration }\end{array}$ & Big Brown & $50 / 25$ & 4 & Ryton \\
\hline 3 & 381 & $\begin{array}{l}\text { Evaluate Conditioning } \\
\text { Agent Concentration }\end{array}$ & Big Brown & $24 / 12$ & 4 & Ryton \\
\hline 4 & 382 & $\begin{array}{l}\text { Evaluate Conditioning } \\
\text { Agent Concentration }\end{array}$ & Big Brown & $12 / 6$ & . 4 & Ryton \\
\hline 5 & 383 & A/C Tests & Big Brown & None & 6 & Ryton \\
\hline 6 & 384 & A/C Tests & Big Brown & $24 / 12$ & 6 & Ryton \\
\hline 7 & 385 & A/C Tests & Big Brown & $24 / 12$ & 8 & Ryton \\
\hline 8 & 386 & Fabric Tests & Big Brown & None & 4 & $\begin{array}{l}\text { Woven } \\
\text { Glass }\end{array}$ \\
\hline 9 & 387 & Fabric Tests & Big Brown & $24 / 12$ & 4 & $\begin{array}{l}\text { Woven } \\
\text { Glass }\end{array}$ \\
\hline 10 & 388 & $\begin{array}{l}\text { Establish Initial } \\
\text { Baseline }\end{array}$ & Milner & None & 4 & Ryton \\
\hline 11 & 389 & $\begin{array}{l}\text { Evaluate Conditioning } \\
\text { Agent Concentration }\end{array}$ & Milner & $24 / 12$ & 4 & Ryton \\
\hline 12 & 390 & $\begin{array}{l}\text { Evaluate Conditioning } \\
\text { Agent Concentration }\end{array}$ & Milner & $12 / 6$ & 4 & Ryton \\
\hline 13 & 391 & A/C Tests & Milner & $24 / 12$ & 8 & P84/Ryton \\
\hline 14 & 392 & Fabric Tests & Milner & None & 4 & P84/Ryton \\
\hline 15 & 393 & Fabric Tests & Milner & $24 / 12$ & 4 & P84/Ryton \\
\hline
\end{tabular}


TABLE 2

Matrix for Task 3 (100-hour and 16-ft/min tests)

\begin{tabular}{|c|c|c|c|c|c|c|}
\hline $\begin{array}{l}\text { Test } \\
\text { No. }\end{array}$ & Run & Purpose & Coal & $\begin{array}{c}\mathrm{NH}_{3} / \mathrm{SO}_{3} \\
\text { (ppm) }\end{array}$ & $\begin{array}{c}\text { A/C } \\
\text { Ratio } \\
\text { (ft/min) }\end{array}$ & Fabric \\
\hline 16 & 399 & Baseline, High A/C & Big Brown & None & 16 & Ryton \\
\hline 17 & 400 & $\begin{array}{l}\text { Conditioning, High } \\
\text { A/C }\end{array}$ & Big Brown & $24 / 12$ & 16 & Ryton \\
\hline 18 & 401 & $\begin{array}{l}\text { Baseline, Low Dust- } \\
\text { Loading }\end{array}$ & Big Brown & None & 16 & Ryton \\
\hline 19 & 402 & $\begin{array}{l}\text { Conditioning, Low } \\
\text { Dust-Loading }\end{array}$ & Big Brown & $6 / 3$ & 16 & Ryton \\
\hline 20 & 403 & Baseline & Big Brown & None & 4 & Ryton \\
\hline 21 & 404 & Coal Effects & Big Brown & $24 / 12$ & 4 & Ryton \\
\hline 22 & 405 & A/C Effects & Big Brown & $24 / 12$ & 6 & Ryton \\
\hline 23 & 406 & Baseline & Milner & None & 4 & P84/Ryton \\
\hline 24 & 407 & Coal Effects & Milner & $24 / 12$ & 4 & P84/Ryton \\
\hline 25 & 409 & Baseline & $\begin{array}{l}\text { Black } \\
\text { Thunder }\end{array}$ & None & 4 & Ryton \\
\hline $26 A$ & $410 A$ & Coal and A/C Effects & $\begin{array}{l}\text { Black } \\
\text { Thunder }\end{array}$ & $24 / 12$ & 6 & Ryton \\
\hline $26 B$ & $410 B$ & Coal Effects & $\begin{array}{l}\text { Black } \\
\text { Thunder }\end{array}$ & $12 / 6$ & 4 & Ryton \\
\hline 27 & 411 & A/C Effects & Milner & $24 / 12$ & 6 & P84/Ryton \\
\hline 28 & 412 & High $A / C$, Neutralite & Big Brown & $6 / 3$ & 16 & Ryton \\
\hline 29 & 413 & A/C Effects & $\begin{array}{l}\text { Black } \\
\text { Thunder }\end{array}$ & $12 / 6$ & 6 & Ryton \\
\hline
\end{tabular}




\subsection{FACILTYY DESCRIPTION AND PROCEDURES}

\subsection{Particulate Test Combustor (PTC)}

The pilot furnace, known as the particulate test combustor (PTC), is a $550,000-\mathrm{Btu} / \mathrm{hr}$ pulverized coal-fired unit designed to generate fly ash representative of that produced in a full-scale utility boiler. The combustor is oriented vertically to minimize wall deposits. A refractory lining helps to ensure adequate flame temperature for complete combustion and prevents rapid quenching of the coalescing or condensing fly ash. The mean residence time of a particle in the combustor is approximately three seconds, based on the superficial gas velocity. The coal nozzle of the PTC fires axially upward from the bottom of the combustor, and secondary air is introduced concentrically to the primary air with turbulent mixing. In addition, tertiary air is supplied above the base of the combustor. Coal is introduced to the primary air stream via a screw feeder and ejector. An electric air preheater is used for precise control of the combustion air temperature. Water-jacketed heat exchangers provide flue gas temperature control to the baghouse. The PTC instrumentation permits system temperatures, pressures, flow rates, flue gas constituent concentrations, and baghouse operating data to be monitored continuously and recorded on a data logger. Figure 1 illustrates the PTC schematically.

Flue gas samples were taken at three system sample points: the furnace exit and the baghouse inlet and outlet. After passing through sample conditioners to remove the moisture, the flue gas was analyzed for $\mathrm{O}_{2}, \mathrm{CO}_{2}, \mathrm{SO}_{2}, \mathrm{NO}_{\mathrm{x}}$, and $\mathrm{CO}$. Except for the $\mathrm{CO}_{2}$ and $\mathrm{CO}$, each constituent was normally analyzed at both the furnace exit and outlet of the baghouse simultaneously, using two analyzers. The concentration values from all of the instruments were recorded continuously using circle charts. In addition, all data were manually recorded at set time intervals. $\mathrm{NO}_{\mathrm{x}}$ was determined using two Thermo Electron Chemiluminescent $\mathrm{NO}_{x}$ analyzers. The $\mathrm{O}_{2}, \mathrm{CO}$, and $\mathrm{CO}_{2}$ analyzers are made by Beckman, and the $\mathrm{SO}_{2}$ analyzers are manufactured by DuPont. Each of these analyzers is regularly calibrated aild maintained to provide accurate flue gas concentration measurements.

The baghouse vessel is a 20 -inch- $\mathrm{DD}$ chamber that is heat-traced and insulated. Flue gas is introduced near the bottom of the baghouse. Since the combustor produces about $200 \mathrm{acfm}$ of flue gas at $300^{\circ} \mathrm{F}$, three 13 - $\mathrm{ft}$ by 5 -inch bags were used for tests at an A/C ratio of $4 \mathrm{ft} / \mathrm{min}$. For tests at an $\mathrm{A} / \mathrm{C}$ ratio of $6 \mathrm{ft} / \mathrm{min}$, one bag was removed to provide the correct filtration area. For tests at an $\mathrm{A} / \mathrm{C}$ ratio of $8 \mathrm{ft} / \mathrm{min}$, two 10 - $\mathrm{ft}$ by 5 -inch bags were used. and one 10 -ft by 5 -inch bag was used for the $16-\mathrm{ft} / \mathrm{min}$ tests. Each bag was cleaned 


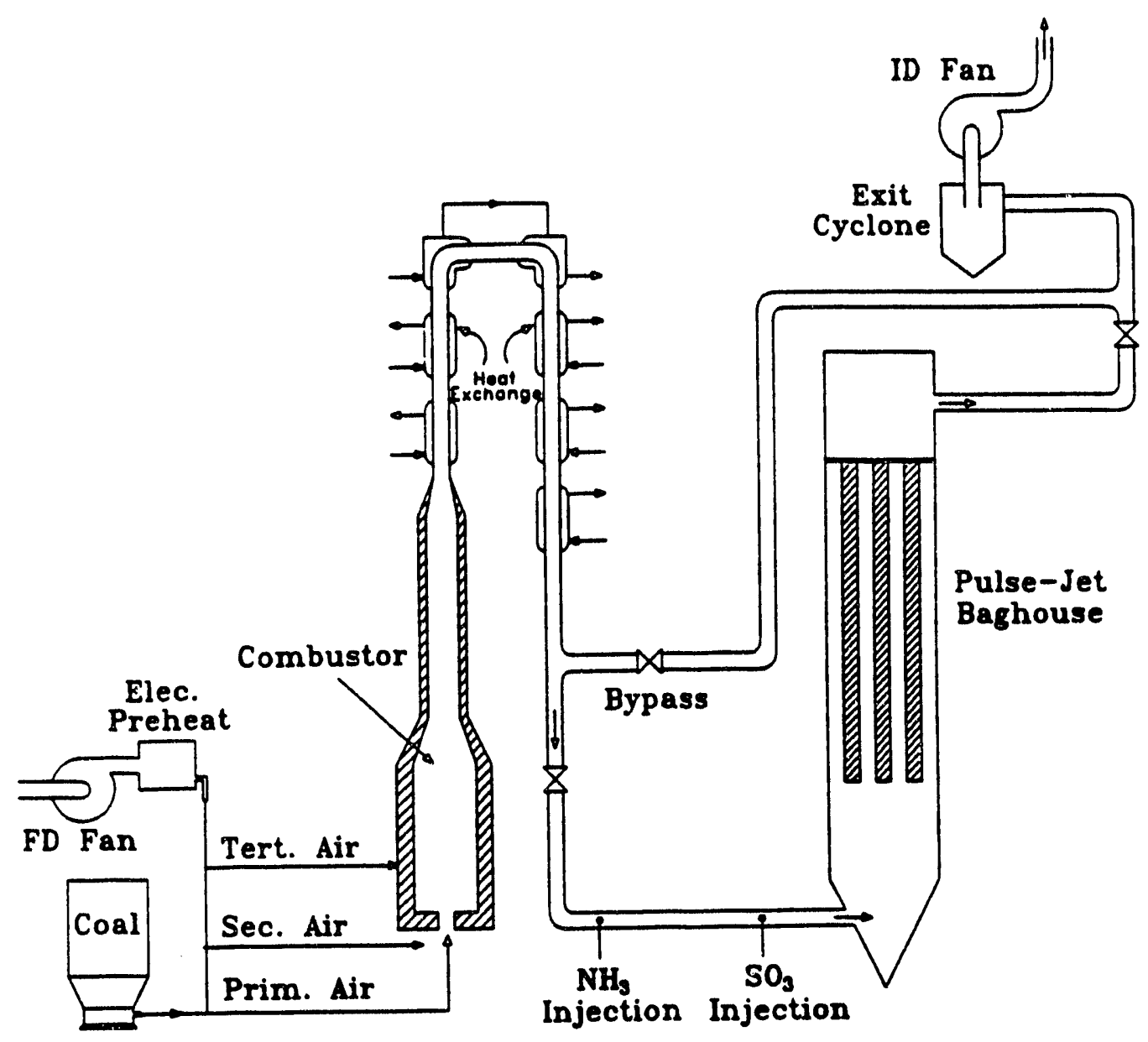

Figure 1. Combustion system used for tests, showing the PTC and baghouse.

separately with its own diaphragm pulse valve. The bags were cleaned on timed intervals, rather than cleaning initiated by pressure drop, in order to quantify differences in pressure drop with different test conditions. Once bag cleaning was initiated, all three bags (or two at $A / C$ ratios of 6 or $8 \mathrm{ft} / \mathrm{min}$ ) were pulsed in rapid succession on-line. Baghouse specifications are given in Table 3.

\subsection{Particulate Sampling and Measurement}

Near real-time particulate measurements were conducted with an aerodynamic particle sizer (APS 33) manufactured by TSI, Inc., shown schematically in Figure 2. The primary 
TABLE 3

Pulse-Jet Fabric Filter Specifications

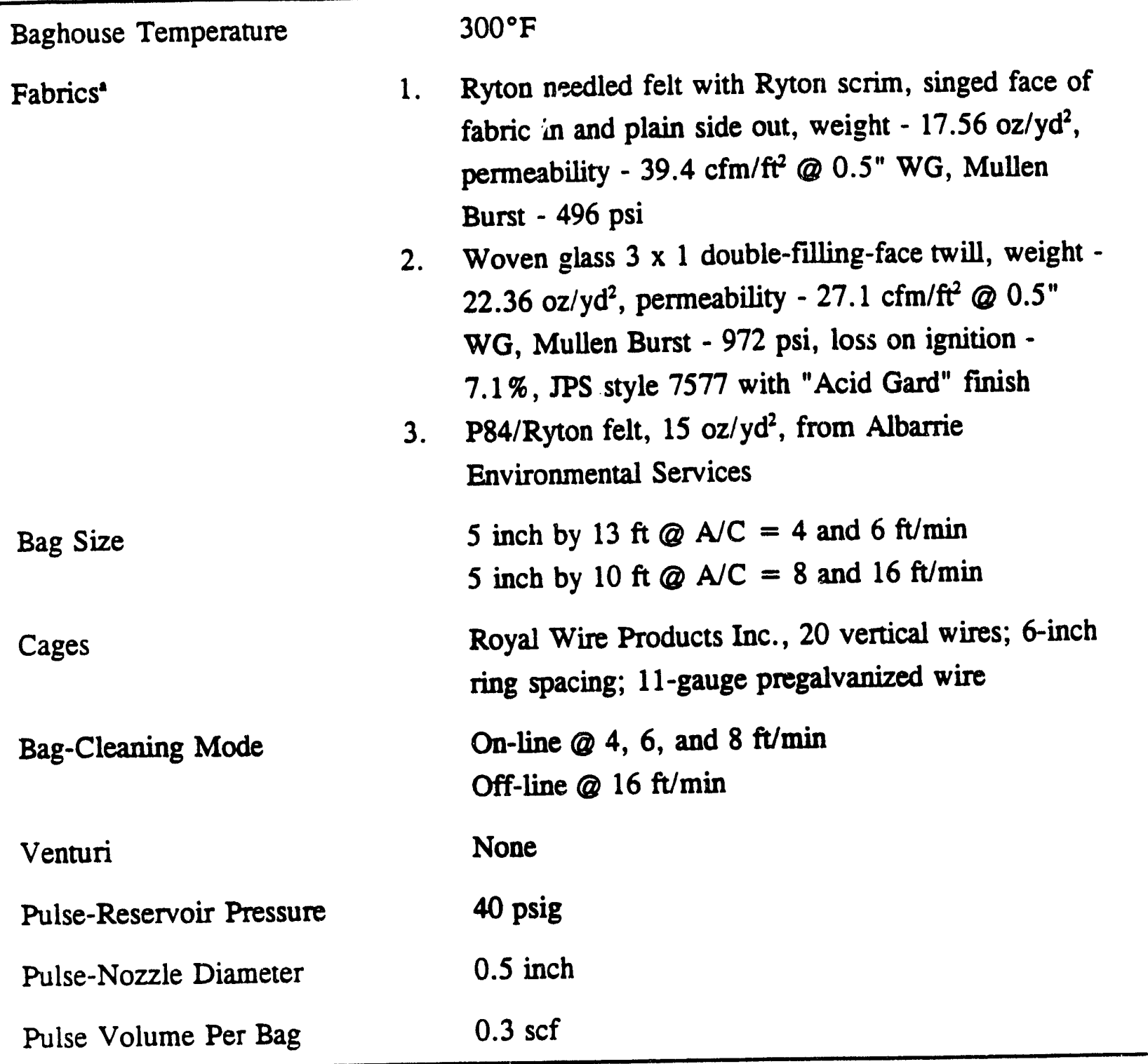

${ }^{a}$ Properties of Fabrics 1 and 2 were measured by Grubb Filtration Testing Services, Inc.

advantages of this system are high resolution and short sampling time. In the APS, particleladen air is passed through a thin-walled orifice, and because of their higher inertia, the particles lag behind the gas. The velocity lag is uniquely related to the aerodynamic diameter of the particles. Therefore, the aerodynamic diameter of a particle can be determined by measuring the particle velocity as it exits from the orifice. To measure the 


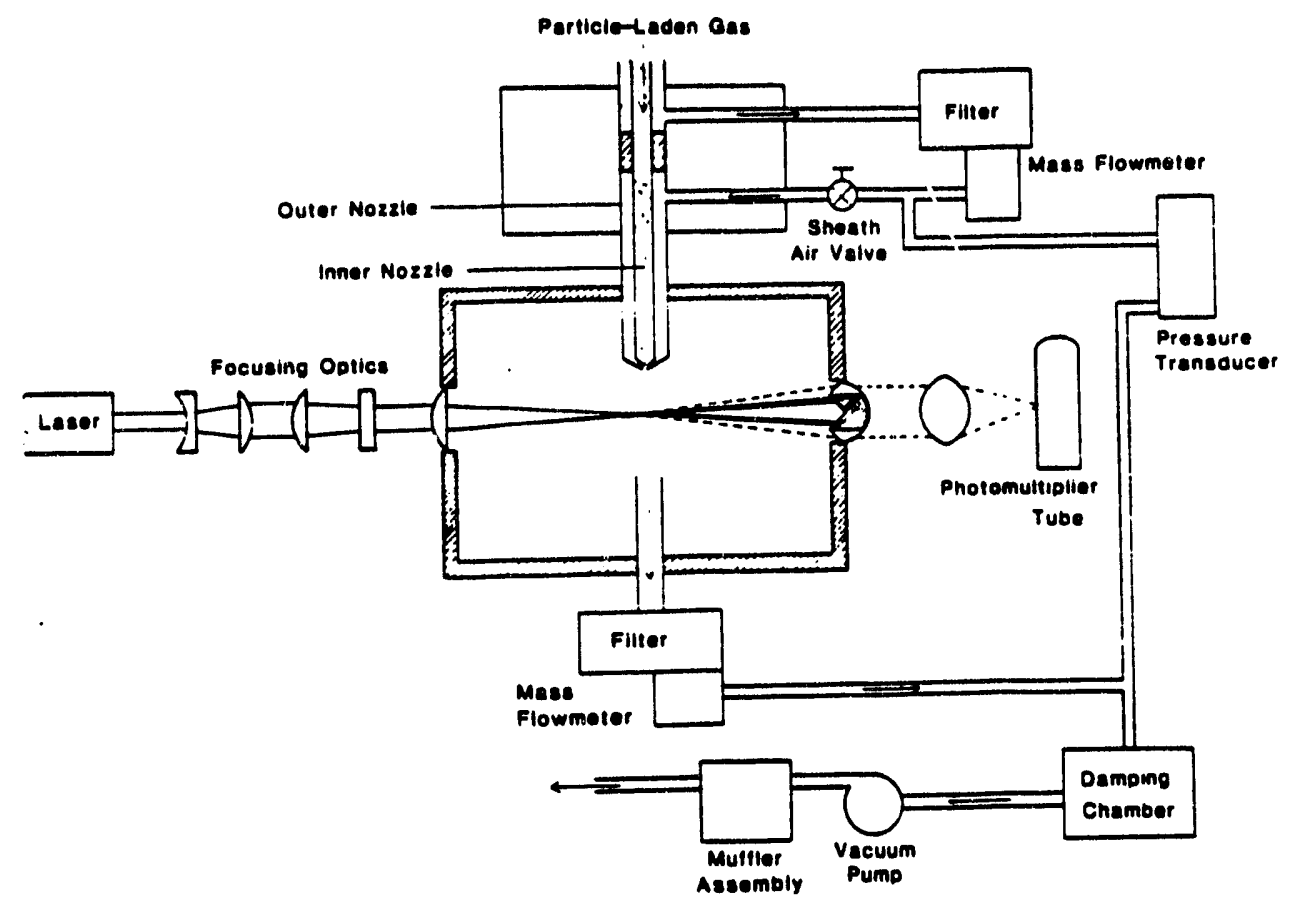

Figure 2. Schematic of aerodynamic particulate sizer.

particle velocity, the APS employs a laser which is split into two beams. The light scattered by a particle passing through these beams is collected, and two pulses are emitted, separated by the time taken for the particle to cross the distance between the two beams. From this time interval, which is measured electronically, the aerodynamic diameter is calculated. For most applications, the particle-size distribution for particles ranging in size from 0.5 to $30 \mu \mathrm{m}$ can be obtained within 20 seconds, givi ig near real-time measurements. The particlesize distribution can be obtained on the basis of either a number or mass concentration. However, rather than looking at emissions of several particle sizes, fine-particle emissions can be combined by using a calculated value of respirable mass. The American Council of Governmental and Industrial Hygienists' (ACGIH) definition of respirable mass, as given in Table 4, was used. The ACGIH definition was extrapolated and interpolated to calculate the percentage at the midpoint of each channel for that particle size. The respirable mass from all of the channels was added to obtain the total respirable mass. This provides a convenient and effective method of plotting fine-particle emissions as a function of time. 
TABLE 4

ACGIH Respirable Mass Definition

\begin{tabular}{cc}
\hline $\begin{array}{c}\text { Aerodynamic } \\
\text { Diameter } \\
(\mu \mathrm{m})\end{array}$ & $\begin{array}{c}\text { Respirable Mass Fraction } \\
(\%)\end{array}$ \\
\hline 2.0 & 90 \\
2.5 & 75 \\
3.5 & 50 \\
5.0 & 25 \\
10.0 & 0 \\
\hline
\end{tabular}

To determine the concentration of submicron particles $(0.01$ to $1.0 \mu \mathrm{m})$, a condensation nucleus counter (CNC) was used. The CNC measures particle number concentration by using the light-scattering technique. Since the dry submicron particles are too small to be easily detected by light scattering, the particles pass through an alcohol vapor which condenses on the particle, forming a droplet. Each droplet is large enough to scatter a detectable amount of light when it passes through a light beam. The droplet size is nearly independent of the size of the original particle over a wide range of particle sizes, so the light scattered is a function of number concentration only, not of size distribution. This instrument was used independently as a continuous real-time monitor of the number of fine particles present in the flue gas. An impactor, prior to the gas stream entering the CNC, removed the particles larger than $1 \mu \mathrm{m}$, so the CNC measured the concentration of submicron particles.

For both the APS 33 and CNC particle analyzers, a dilution system was employed. Dilution of the flue gas is necessary to prevent moisture condensation in the sensors and to reduce particle concentration, which, if too high, may exceed the maximum output of the CNC and may cause coincidence error in the APS. A schematic of the particulate-sampling system with diluter is shown in Figure 3. The APS pump draws the sample into the diluter volume. A second pump is used to draw off a portion of the flue gas to recycle it back as dilution gas after it has been cleaned and the moisture removed. As shown in the figure, both the APS and CNC were operated simultaneously using this dilution syster The maximum 


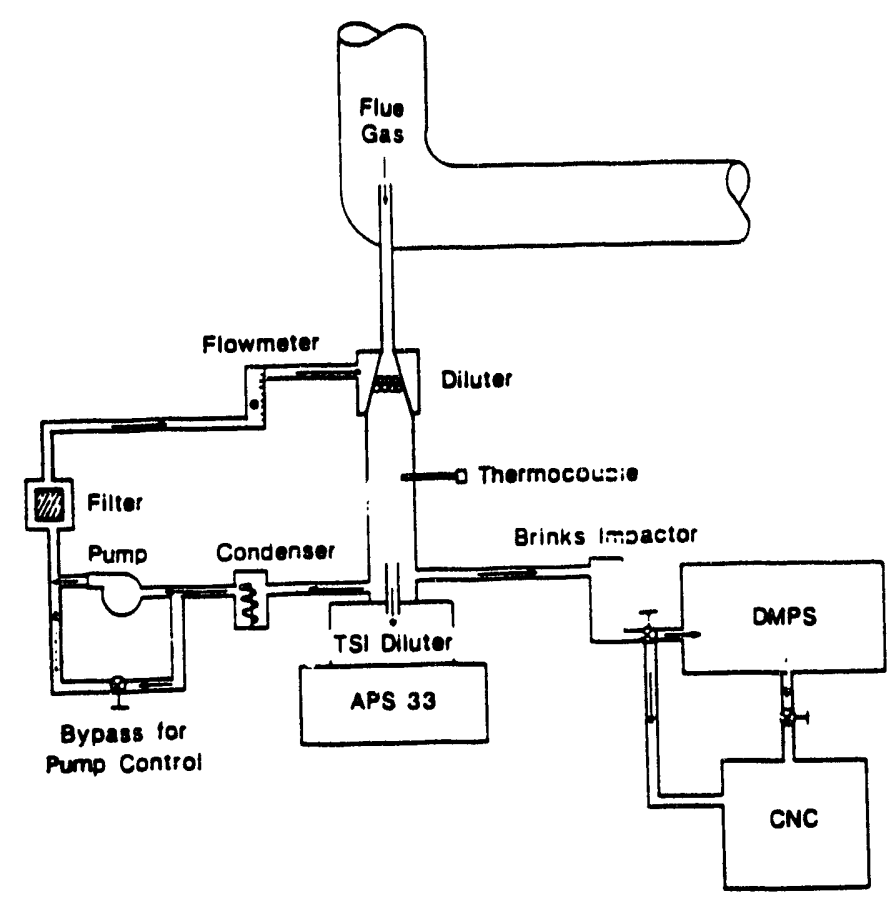

Figure 3. Schematic of the particulate-sampling system (APS 33, DMPS, and dilution system).

dilution that can be obtained with this system is about 10 to 1; if higher dilutions are needed, the system is operated in conjunction with a model 3302 TSI diluter. With both systems operating, dilutions up to 1000 to 1 can be obtained. Typically, a differential mobility particle sizer DMPS (shown in Figure 3 ) is also used in conjunction with the CNC to provide the submicron particle-size distribution. A DMPS sample requires approximately a 25minute period when the particulate emissions are fairly constant. Since the APS and CNC data indicated changes in dust concentrations during the last 25 minutes of most cleaning cycles, valid DMPS measurements were not possible. However, the CNC was operated on a continuous basis during most of the APS sampling periods. During a test, APS and CNC readings were taken at least every 10 minutes and more often during the first few minutes after bag cleaning.

In addition to the CNC and APS, a modified EPA-Method 5 was used to provide dust loadings at the inlet and outlet of the baghouse to determine the overall particulate collection efficiency. Two outlet dust loadings were typically completed for each 8 -hour test, and 7 
outlet dust loadings were typically completed for each 100-hour test. Each outlet dustloading was conducted over at least two complete cleaning cycles and, therefore, included the spike in emissions just after pulsing the bags. One EPA-Method 5 inlet dust loading was taken for each 8-hour test, and 4 inlet dust-loading measurements were completed for each 100-hour test. In addition, one inlet multicyclone sample was taken for each 8- and 100-hour test. The multicyclone provided another inlet dust loading measurement as well as a determination of the particle-size distribution for particles smaller than $10 \mu \mathbf{m}$.

\subsection{Sulfur Trioxide and Ammonia Injection}

Sulfur trioxide $\left(\mathrm{SO}_{3}\right)$ was produced with a catalytic $\mathrm{SO}_{3}$ generator in which air and $\mathrm{SO}_{2}$ are passed through a vanadium-catalyst-filled reactor that is heated to $850^{\circ} \mathrm{F}$, thereby oxidizing the $\mathrm{SO}_{2}$ to $\mathrm{SO}_{3}$. Conversion of $\mathrm{SO}_{2}$ to $\mathrm{SO}_{3}$, measured with $\mathrm{SO}_{2}$ analyzers, was determined to be $70 \% \pm 10 \%$. Therefore, the accuracy of the injected $\mathrm{SO}_{3}$ concentration was about $\pm 10 \%$. Ammonia (from a tank of anhydrous ammonia) was injected upstream of the $\mathrm{SO}_{3}$ and controlled using a mass flow controller calibrated $\mathrm{f} n \mathrm{r}$ ammonia. Concentrations of ammonia and $\mathrm{SO}_{3}$ in the flue gas were based on the flue gas flow rate, measured downstream of the baghouse with an Annubar flow element.

\subsection{Coal and Fly Ash Analyses}

For each coal, standard ultimate/proximate/Btu/ASTM ash analyses were completed. In addition, major elemental analyses of the baghouse hopper ash were completed for each test. Conditioning tests included a determination of the amount of ammonia adsorbed on the fly ash and the amount of ammonia in the flue gas downstream of the baghouse.

Physical characterization of the fly ash was necessary to document changes as a result of the conditioning process and to provide an understanding of the mechanisms of the conditioning process. Important properties included the bulk fly ash particle-size distribution, measured by a Coulter counter; particle density, measured by a helium pycnometer; and specific surface area, measured by a BET monosorb instrument. A key physical measurement is the determination of the cohesive properties of the fly ash, since this appears to be one of the main predictors of ash behavior in fabric filtration. Two instruments manufactured by Hosokawa Micron International were used to quantify cohesive properties. A powder characteristics tester was used to measure the aerated and packed porosities of the fly ash, and a Cohetester was used to measure the tensile strength of the bulk ash as a function of compressive force or porosity. A schematic of the Cohetester is 
shown in Figure 4. It consists of a horizontal split cell $5 \mathrm{~cm}$ in diameter, with one-balf of the cell movable and the other half fixed. The cell is suspended so that it can be pulled apart with minimal force when no sample is in the cell, thus minimizing any error due to external frictional forces. When the strain motor is turned on, the powder bed is pulled and extended in the same direction as the tensile force. The displacement (extension) of the powder bed and tensile stress are plotted on an $x-y$ recorder. The maximum value on the vertical axis is the cohesive tensile strength of the powder in grams of force per square centimeter $\left(\mathrm{g}_{\mathrm{f}} / \mathrm{cm}^{2}\right)$ at that compaction force.

The following procedure is used for making a tensile strength measurement using the Cohetester. Because relative humidity may affect the cohesive properties of fly ash, the samples are prepared by sifting them through a 60-mesh screen and storing them overnight in a humidity-controlled chamber at $10 \%$ relative humidity. An amount of sample, based on experience, is weighed, carefully poured into the cell, and compacted by guiding the packing weight carefully into the extension tube. Additional weights (up to a maximum total compaction weight of approximately $5 \mathrm{~kg}$ ) are placed on the first weight until the lip of the packing weight rests on the cell extension tube. With the sample properly compacted, the weights and cell extension tube are removed. After zeroing the recorder pen and releasing the securing knob, the strain motor is turned on, and the fracture curve is recorded.

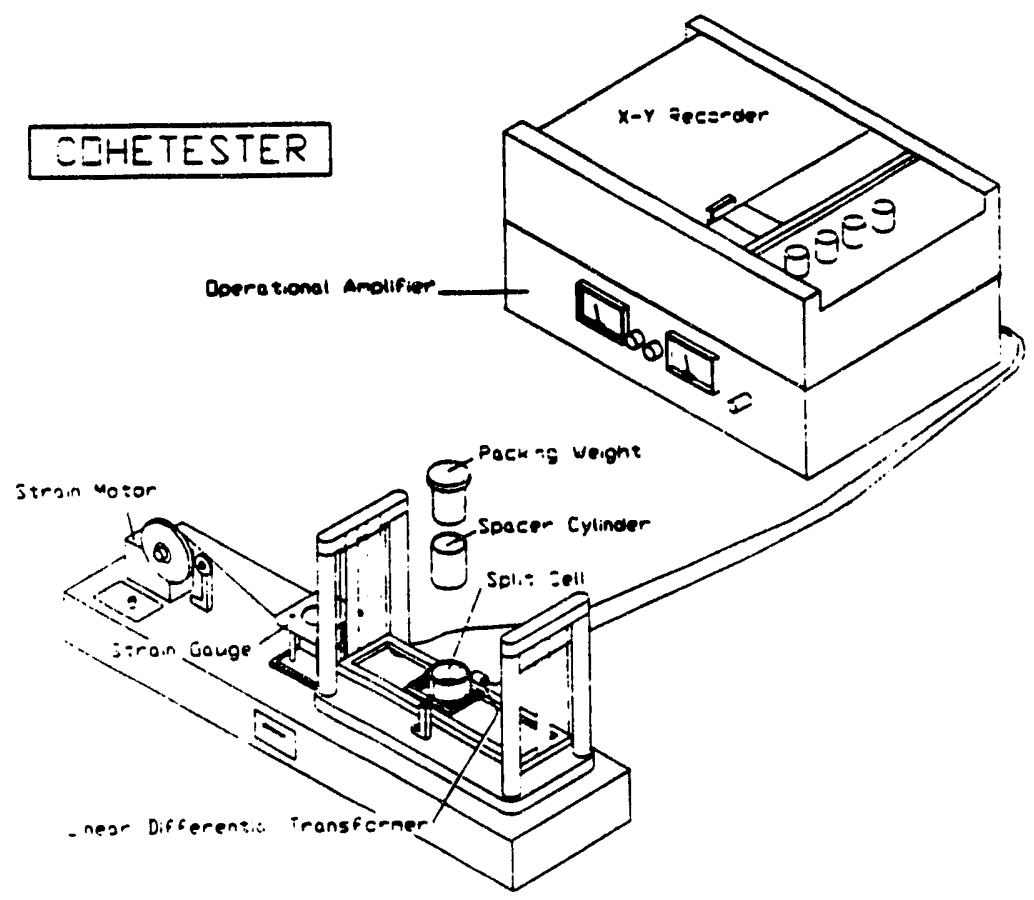

Figure 4. Schematic of the Cohetester. 
Compaction weights ranging from 320 to 5000 grams were used to compress the samples, which corresponds to compaction pressures of 16 to $255 \mathrm{~g} / \mathrm{cm}^{2}$. The upper value of the compaction weight is limited by the structural integrity of the suspended cell. The lower limit is the minimum weight necessary to compact the ash so that it will break along a plane when it is pulled, giving a valid tensile strength measurement. The range in porosity for a given fly ash sample is determined by the range in compaction force, which was the same for each sample. For a particular ash sample, at least five tensile strength measurements over the full range of compaction force are required to plot the tensile strength as a function of porosity. The percent porosity of the powder cake for each test was determined from the particle density (measured by helium-air pycnometry), the sample weight, and the cell volume occupied by the compacted powder (supplied by the manufacturer).

The aerated bulk density is obtained by sifting an ash sample through a vibrating 22 mesh screen into a $100-\mathrm{cm}^{3}$ cup, so that dust overflows the cup edge. The excess dust is scraped off with a knife edge, and the weight of the known volume of dust is measured to determine the bulk density. The packed density is determined by adding an extension to the cup and filling the extension with additional sifted ash. The cup with the extension is then placed in a mechanism that raises the cup about $1 / 2$ inch and lets the cup fall against a stop. This is done once per second for a period of 3 minutes. The cup extension is then removed and the excess dust scraped off as before. There is no external compaction force on the dust layer. Compaction is caused by the natural settling that occurs as the dust is shocked. Since particle density is available, aerated and packed bulk densities are reported as aerated and packed porosities.

\subsection{RESULTS}

\subsection{Coal Description and Analyses}

Three different coals were used for the test program: Big Brown Texas lignite, Milner coal, and Black Thunder subbituminous coal. A short description of each of the coals is given below:

Big Brown Texas Lignite: The Big Brown station, owned and operated by TU Electric, is a minemouth facility located near Fairfield, Texas, in Freestone County. The plant consists of two 575-MW pc-fired boilers. Big Brown lignite is part of the 
Wilcox Formation found in east Texas and is characterized by relatively low heating value and high moisture content. In addition, past experiences at the EERC and at the Big Brown Station indicated that this coal produces a fly ash that is somewhat difficult to collect in a fabric filter.

Milner Coal: The H.R. Milner Station, owned and operated by Alberta Power Ltd., is located in Grand Cache, Alberta. The plant has a 150-MW pc-fired boiler that burns a unique coal. The coal consists of rejects and dewatered tailings left over after washing a high-quality metallurgical coal from the McIntyre mine, located near the plant. Although this coal is characterized by a very high ash content ( $>40 \%$ ), the heating value of the coal is still reasonable: $>8000 \mathrm{Btu} / \mathrm{lb}$. The Milner station is equipped with a pulse-jet baghouse and has had a history of poor baghouse performance while firing this coal.

Black Thunder Subbituminous Coal: The Black Thunder mine is located in the Powder River Basin 12 miles east of Wright, Wyoming, in Campbell County. This mine produces more coal than any other mine in the United States, approximately 30 million tons per year. Coal from the Powder River Basin is subbituminous in rank, is very low in sulfur $(<1 \%)$, and is a prime candidate for utilities considering fuel switching to meet $\mathrm{SO}_{2}$ emission requirements.

A summary of the coal analyses is given in Table 5, and a plot of the sieve analyses is shown in Figure 5. The samples were composite samples from the 100-hour bar-1ine runs. The coals were sampled from the coal feeder about once every 4 hours and then combined into a single composite sample for the entire run. The moisture in these samples is typically much less than the run-of-mine coal moisture because some drying occurs during pulverizing and some additional drying may occur during sampling from the warm location near the combustor. The Milner ash content was very high at $42.2 \%$, compared to $14.6 \%$ for the Big Brown coal, and $6.7 \%$ for the Black Thunder coal, on a moisture-free basis. Even though the Milner coal had a much higher ash content, the heating value was similar to the Big Brown. Ash analyses show that there were significant differences in silica and calcium concentrations among the three different ashes. Silica concentration ranged from a low of $31 \%$ for the Black Thunder coal to a high of $59 \%$ for the Niilner coal, while calcium concentrations ranged from a low of $4 \%$ for the Milner coal to a high of $23 \%$ for the Black Thunder coal. The three coals were pulverized to a nominal $70 \%$ minus 200 mesh $(74 \mu \mathrm{m})$; however, the Big Brown and Black Thunder coals were coarser at $52 \%$ minus 200 mesh compared to $70 \%$ minus 200 mesh for the Milner grind. 
TABLE 5

Summary of Coal Analyses

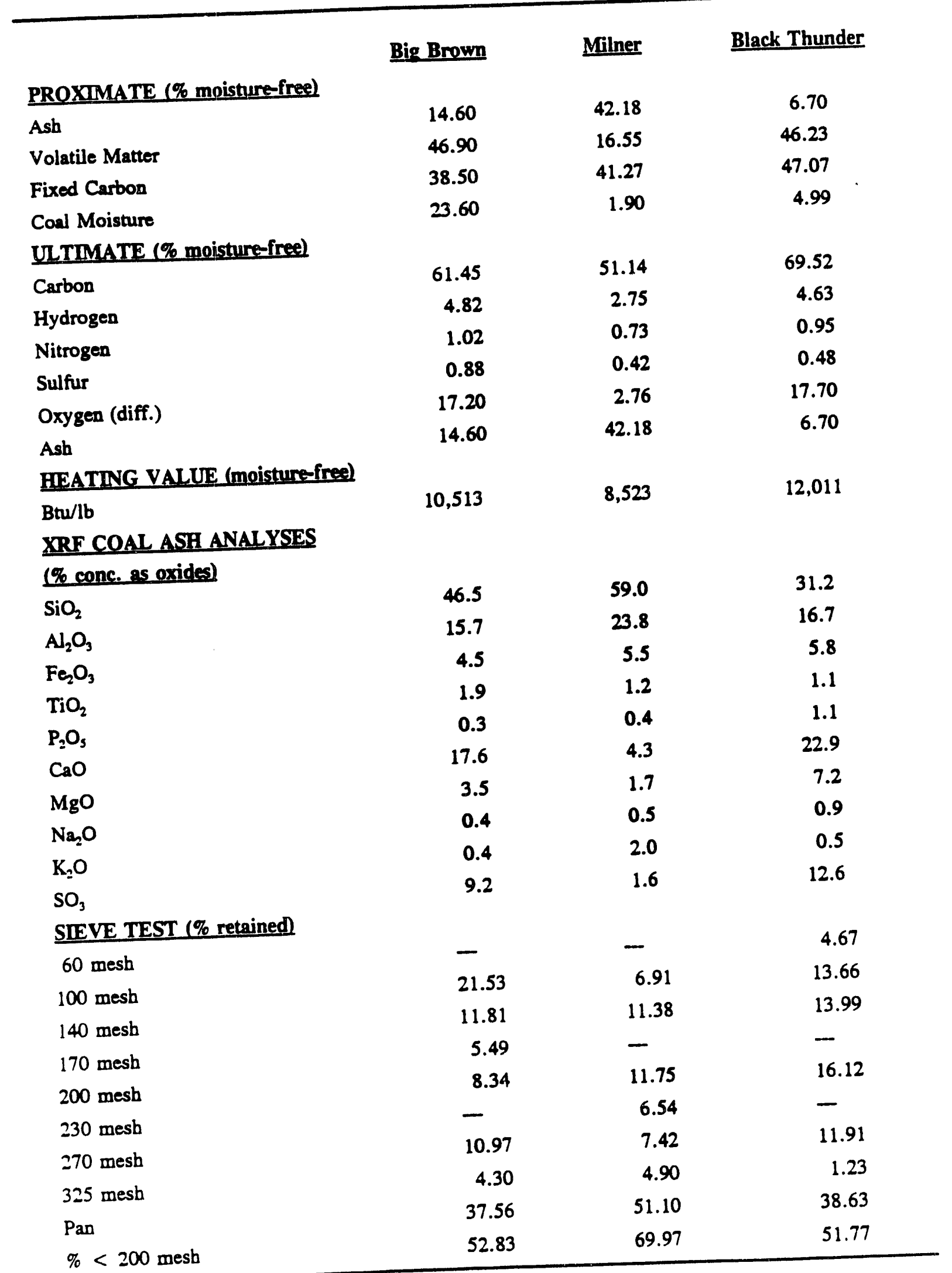




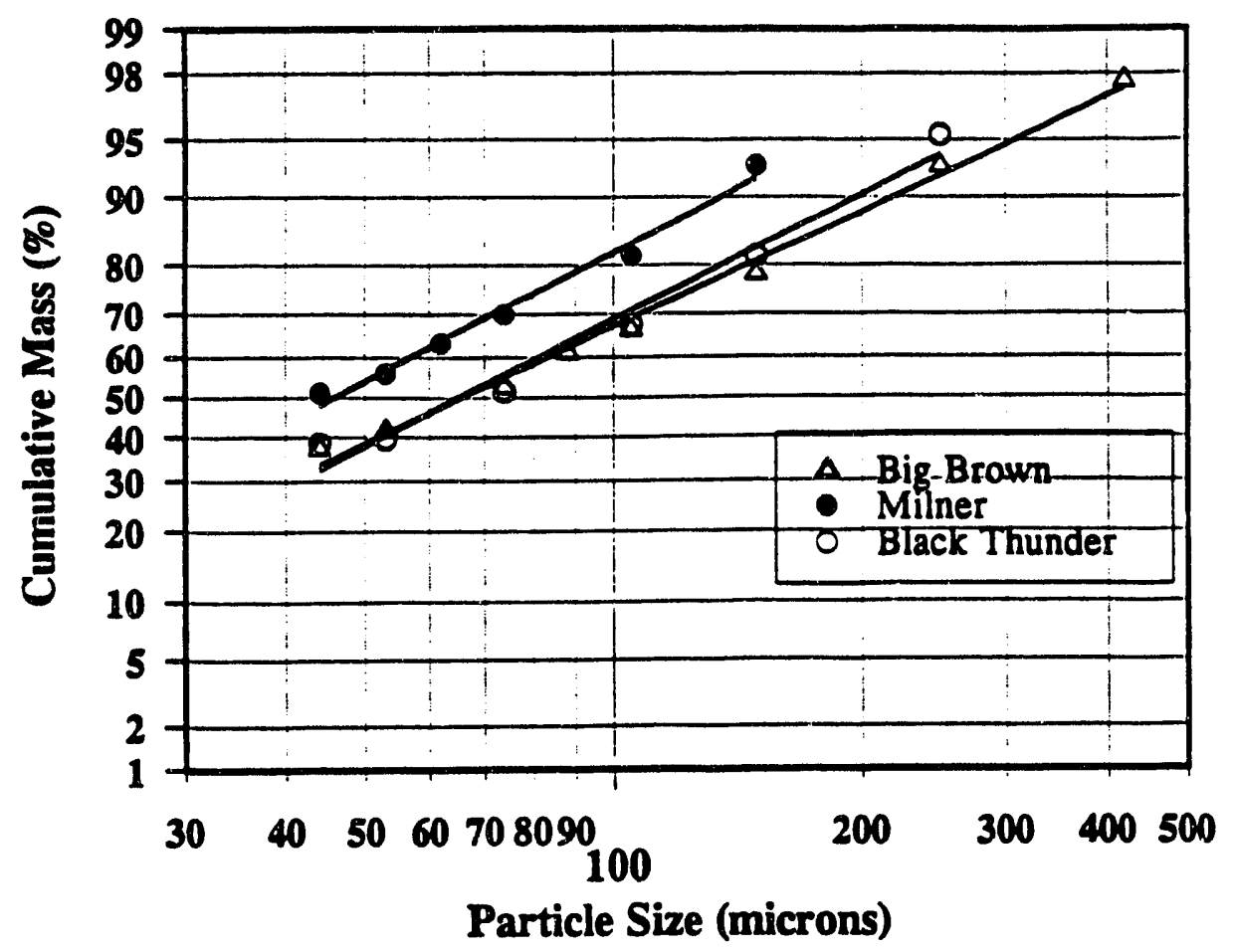

Figure 5. Log-probability plot of coal particle-size distribution based on sieve analysis.

\subsection{Theoretical Considerations}

The size of fabric filters and bag-cleaning frequency are determined by pressure drop. Assuming viscous flow, pressure drop across a fabric filter is given as:

$$
\Delta P=K_{f} V+K_{2} W_{R} V+K_{2} C V^{2} t / 7000
$$

where:

$\Delta \mathrm{P}=$ differential pressure across baghouse tube sheet (inches of water)

$\mathrm{K}_{\mathrm{f}}=$ fabric/dust resistance coefficient (inches of water-min/ $\mathrm{ft}$ )

$\mathrm{V}=$ face velocity or air-to-cloth ratio ( $\mathrm{ft} / \mathrm{min})$

$\mathrm{K}_{2}=$ specific dust cake resistance coefficient (inches of water- $\mathrm{ft}-\mathrm{min} / \mathrm{lb}$ )

$\mathrm{W}_{\mathrm{R}}=$ residual dust cake weight $\left(\mathrm{lb} / \mathrm{ft}^{2}\right)$

$\mathrm{C}=$ dust loading (grains/acf)

$\mathrm{t}=$ filtration time between bag cleaning (min) 
The first term in Equation 1 accounts for the pressure drop across the fabric. For a new fabric, pressure drop across the fabric alone is generally negligible, but, in cases where the dust packs permanently into the interstitial spaces of the fabric, this may be a significant term. The second term in Equation 1 accounts for the pressure drop contribution from the permanent residual dust cake that exists on the surface of the fabric. In many cases, after long-term operation, this is a significant term. The third term in Equation 1 accounts for the pressure drop contribution from the dust accumulated on the bags since the last bag cleaning.

All of the dust characteristics that affect pressure drop are combined into a single term $\mathrm{K}_{2}$, the specific dust cake resistance coefficient. The primary factors that affect $K_{2}$ are the fly ash particle-size distribution and the porosity of the dust cake. Prediction of $\mathrm{K}_{2}$ in terms of measurable dust parameters has been attempted, but accurate prediction of the actual operating $\mathrm{K}_{2}$ for any given baghouse is difficult. One of the simpler models is the CamanKozeny relationship, which has a strong theoretical basis and, assuming monosized spherical particles, takes the form:

$$
\mathrm{K}_{2}=36 \mathrm{k} \mu(1-\epsilon) /\left(\epsilon^{3} \rho_{\mathrm{p}} \mathrm{D}^{2}\right)
$$

where:

$$
\begin{aligned}
\mathbf{K}_{2}= & \text { specific dust cake resistance coefficient (sec/ft); note: } \mathbb{K}_{2} \text { can be converted to } \\
& \text { inches of water-ft-min/lb by multiplying by a factor of } 311.6 \\
\mathbf{k}= & \text { Carman-Kozeny constant }(\sim 5) \text { (dimensionless) } \\
\mu= & \text { gas viscosity }\left(\mathrm{b}-\mathrm{sec} / \mathrm{ft}^{2}\right) \\
\epsilon= & \text { porosity (dimensionless void volume fraction) } \\
\rho_{\mathrm{p}}= & \text { particle density }\left(\mathrm{lb} / \mathrm{ft}^{3}\right) \\
\mathrm{D}= & \text { particle diameter }(\mathrm{ft})
\end{aligned}
$$

The Carman-Kozeny equation was fitted to laboratory measurements of $K_{2}$ (presented later in this report). Typical $\mathrm{K}_{2}$ values for pc-fired fly ash range from about 1 to 20 inches of water-ft-min/lb, but may, in extreme cases, cover a wider range. $K_{2}$ values can be reported as an initial value and as the effective value. The initial value is based on the linear part of the $\Delta \mathrm{P}$ versus time curve from the first filtration cycle, starting with new bags. During the first filtration cycle, the $\Delta \mathrm{P}$ contribution from the first term is negligible, and there is no residual dust cake, so $\mathrm{K}_{2}$ can be readily obtained from the third term in Equation 1. The largest source of uncertainty is the dust loading, which will typically fluctuate at least $\pm 10 \%$. An effective $K_{2}$ value is based on a $\Delta P$ that is an average of the difference 
between the before- and after-cleaning $\Delta$ Ps. Effective $K_{2}$ is higher than the initial $K_{2}$ because the bags generally do not clean uniformly. Immediately after cleaning, the gas flow will take the path of least resistance, so a higher velocity will occur in areas that were more thoroughly cleaned. This nonuniform velocity will gradually diminish until there is a complete cake over the entire surface again. The net result is that the $\Delta \mathrm{P}$ increase between bag cleanings will generally be greater than the initial increase in $\Delta \mathrm{P}$ during the first filtration cycle, even though the same amount of dust is added in a given time interval.

The primary factors that determine collection efficiency in a fabric filter are dust properties such as particle size and cohesive characteristics, fabric properties such as the pore size and fiber diameter, bag-cleaning frequency, and face velocity. To achieve high collection efficiency, the pores in the filter media must be effectively bridged (assuming they are larger than the average particle size). However, pore-bridging ability may deteriorate for a given fabric when the face velocity is increased. Recent work that the EERC conducted for DOE, where pore bridging was studied as a function of pore size, velocity, and conditioning, showed that pore-bridging ability was highly dependent on all three of these factors (11). Therefore, increasing the $A / C$ ratio is likely to result in higher particulate emissions unless a superior fabric is employed, or the dust is modified with conditioning agents to improve pore bridging at a higher velocity. When considering the effect of conditioning on dust characteristics, if a very high collection efficiency can be maintained even after increasing the face velocity, it indicates that the ability of the dust to bridge pores and resist reentrainment is greatly improved.

\subsection{Task 2 Results (8-hour tests)}

A summary of the test variables and results from all fifteen 8-hour tests is shown in Tables 6 and 7.

\subsubsection{Big Brown Tests}

The purpose of the first four tests was to evaluate the effect of conditioning agent concentrations on particulate emissions and pressure drop with Ryton fabric at an A/C ratio of $4 \mathrm{ft} / \mathrm{min}$. In addition to a baseline test, identical tests were conducted at conditioning agent concentrations of 50/25 ppm of $\mathrm{NH}_{3} / \mathrm{SO}_{3}, 24 / 12 \mathrm{ppm}$ of $\mathrm{NH}_{3} / \mathrm{SO}_{3}$, and $12 / 6 \mathrm{ppm}$ of $\mathrm{NH}_{3} / \mathrm{SO}_{3}$. For these tests, the bags were cleaned once an hour following an initial 3-hour filtration period. Particulate collection efficiency was high at $99.9+\%$ for all of the $4-\mathrm{ft} / \mathrm{min}$ tests, indicating that the Ryton fabric provides excellent filtration capabilities. No measured 


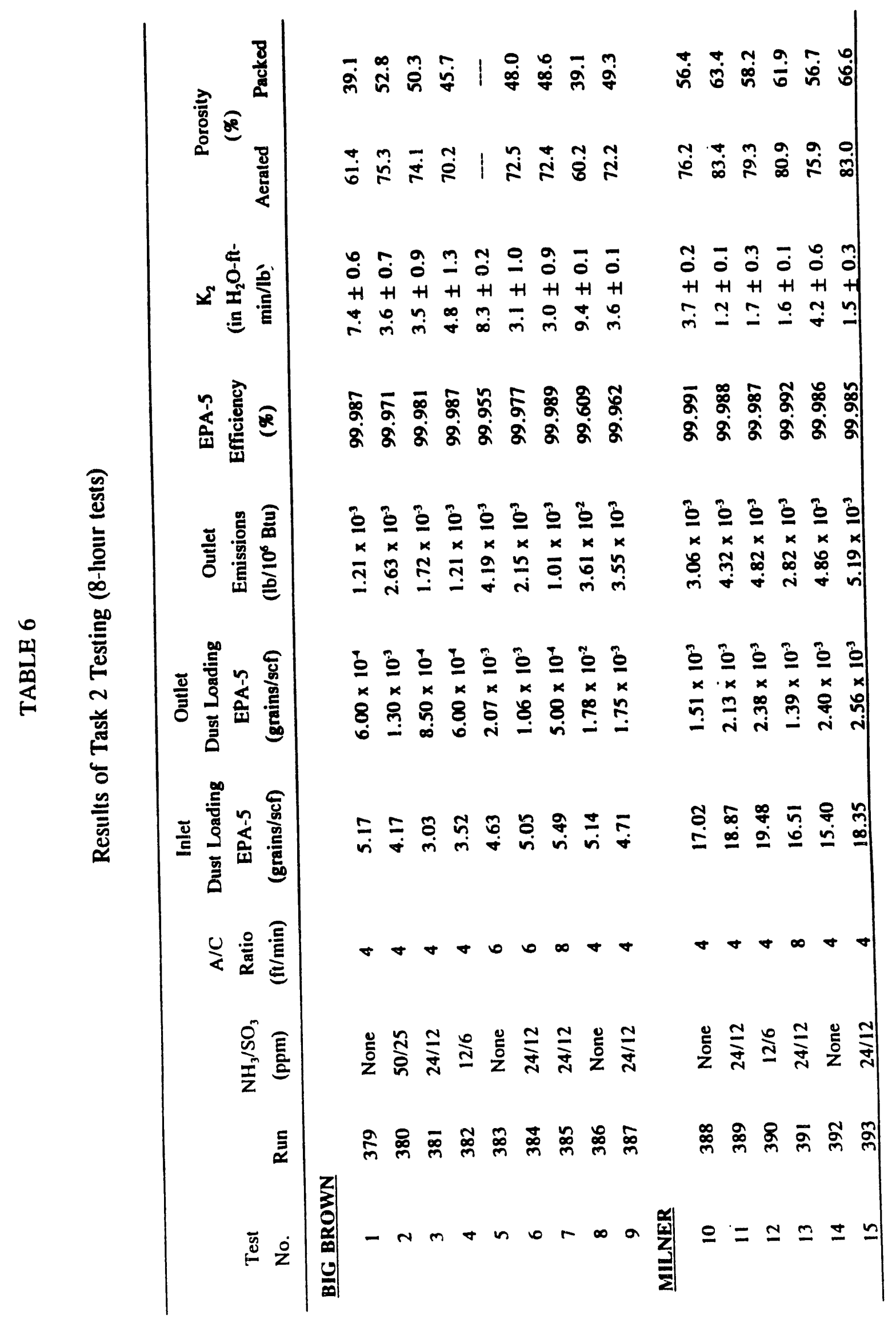




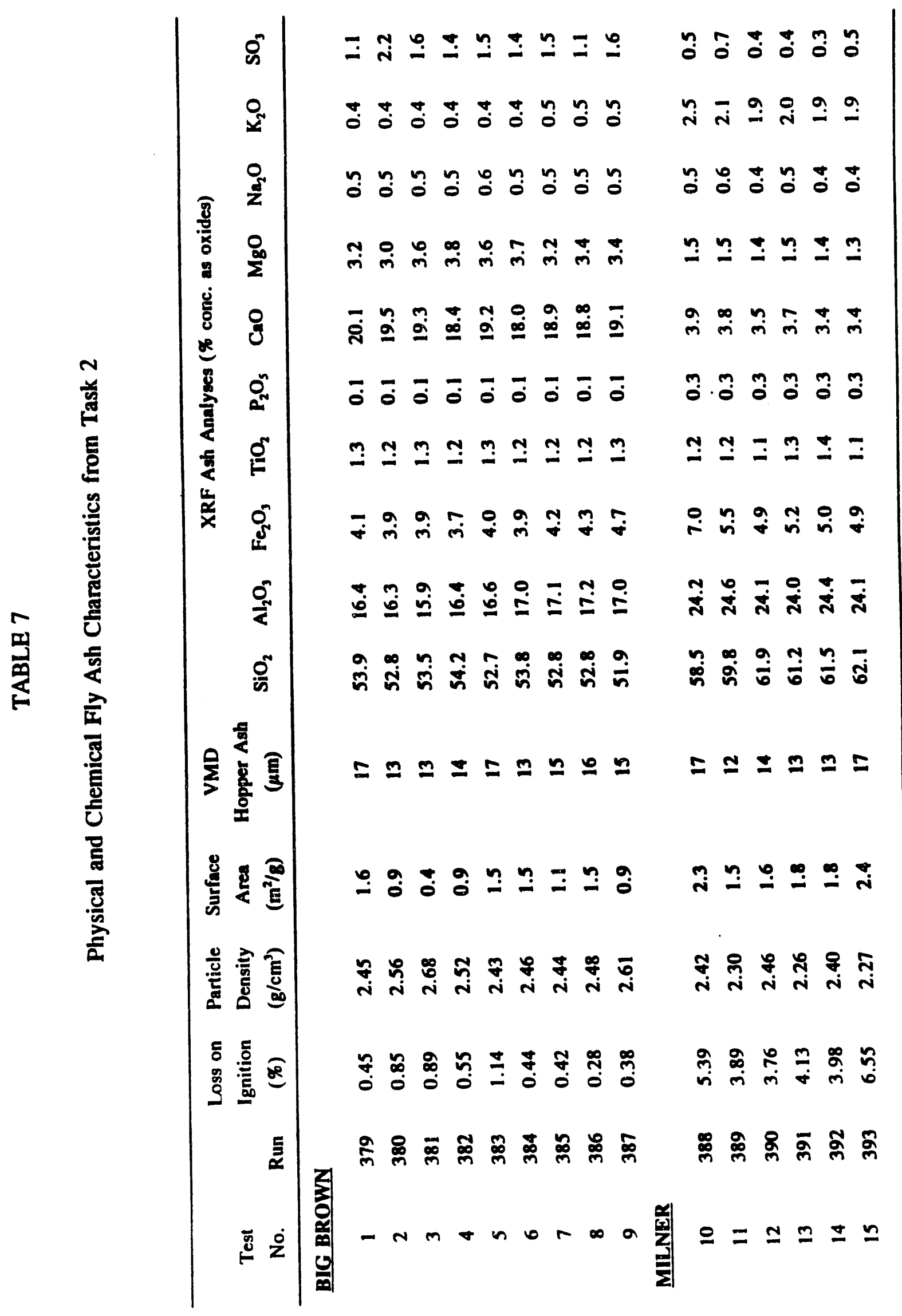


reduction in particulate emissions occurred with conditioning based on the APS, condensation nucleus counter, or EPA-5 results. However, if the bags had been cleaned on a pressure drop basis rather than on a time basis, some reduction would likely have been noted. Plots of respirable mass and pressure drop as functions of time for Tests 1 through 4 are shown in Figures 6 through 9. Pressure drop was reduced approximately 50\% with 24/12 ppm, of $\mathrm{NH}_{3} / \mathrm{SO}_{3}$ compared to the baseline test, as shown in Figure 10. At concentrations of $50 / 25 \mathrm{ppm}$, pressure drop was very close to concentrations of $24 / 12 \mathrm{ppm}$, and at concentrations of $12 / 6 \mathrm{ppm}$, pressure drop was just slightly higher. Since particulate emissions were not significantly different and pressure drop was just slightly different for the three conditioning tests, the concentrations that provided the best performance appeared uncertain. To help assess the differences, $\mathbf{K}_{2}$ values were calculated by three different methods: one calculation was based on the first three hours of filtration time; the second calculation was based on the average $\Delta \mathrm{P}$ increase between bag cleaning during the last 5 hours of the test; the third calculation was also based on the $\Delta \mathrm{P}$ during the last 5 hours, but the dust loading was based on the amount of ash collected in the baghouse hopper rather than on measured inlet EPA-5 dust loadings. Results of these $\mathrm{K}_{2}$ measurements are reported in Table 6 as an average of the three calculations along with the standard deviation. From the $\mathrm{K}_{2}$ value of 4.8 inches of water- $\mathrm{ft}-\mathrm{min} / \mathrm{lb}$ for concentrations of $12 / 6 \mathrm{ppm}$ of $\mathrm{NH}_{3} / \mathrm{SO}_{3}$, compared to $\mathrm{K}_{2}$ values of 3.6 and 3.5 for the other concentrations, it appears that the effectiveness of conditioning is somewhat diminished at concentrations of $12 / 6 \mathrm{ppm}$ of $\mathrm{NH}_{3} / \mathrm{SO}_{3}$. Similarly, the aerated and packed porosity data (shown in Table 6) indicate that the effectiveness of conditioning is reduced at the lower concentrations of $12 / 6 \mathrm{ppm}$ of $\mathrm{NH}_{3} / \mathrm{SO}_{3}$. Therefore, concentrations of $24 / 12 \mathrm{ppm}$ of $\mathrm{NH}_{3} / \mathrm{SO}_{3}$ were chosen for subsequent tests at higher $\mathrm{A} / \mathrm{C}$ ratios.

Tests 5 through 7 consisted of baseline and conditioning runs at an AV ratio of 6 $\mathrm{ft} / \mathrm{min}$ and a conditioning test at an $\mathrm{A} / \mathrm{C}$ ratio of $8 \mathrm{ft} / \mathrm{min}$. Respirable mass and pressure drop plots are shown in Figures 11 through 13. Particulate collection efficiency was slightly reduced for the baseline test at $6 \mathrm{ft} / \mathrm{min}$ compared to the baseline test at $4 \mathrm{ft} / \mathrm{min}$, but was still reasonably high at $99.96 \%$. Collection efficiency was somewhat better, with conditioning at $99.98 \%$ and $99.99 \%$ for the tests at $\mathrm{A} / \mathrm{C}$ ratios of 6 and $8 \mathrm{ft} / \mathrm{min}$, respectively. However, the effect of conditioning on pressure drop was significant, as shown in Figure 14. For the baseline test, after an initial 90-minute filtration period, the cleaning cycle was set at 45 minutes. Pressure drop was not adequately controlled, so the interval was reduced to 30 minutes, which was still not sufficient. The interval was then reduced to 20 minutes, along with a slight increase in pulse duration. After several cleaning cycles, this brought the before-cleaning pressure drop to below 4 inches. Since the pressure drop had 


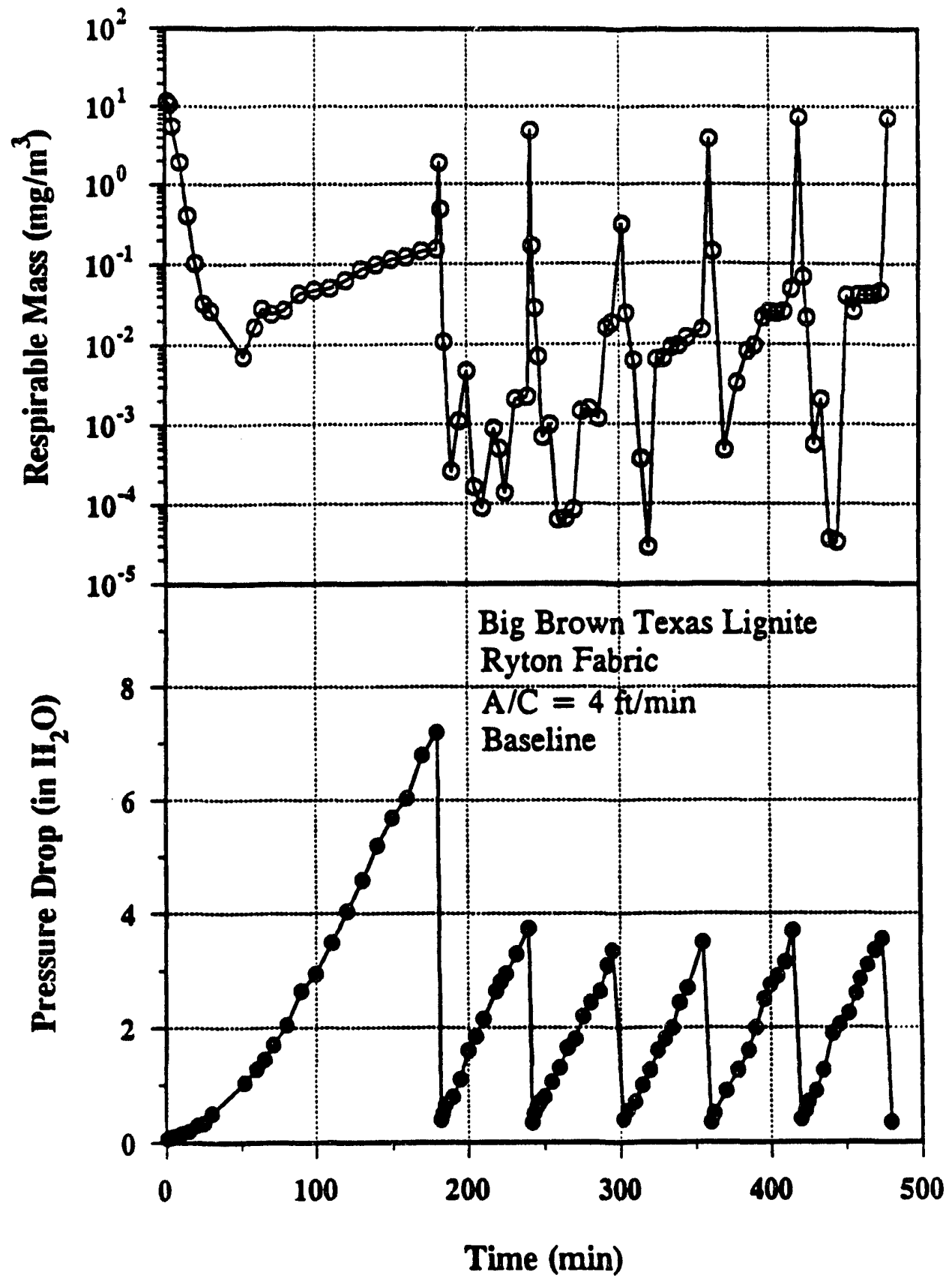

Figure 6. Respirable mass emissions and pressure drop as a function of time for Big Brown coal at an $\mathrm{A} / \mathrm{C}$ ratio of $4 \mathrm{ft} / \mathrm{min}$, Ryton fabric, and no conditioning. Bags were cleaned every 60 minutes after an initial 180-minute period. 


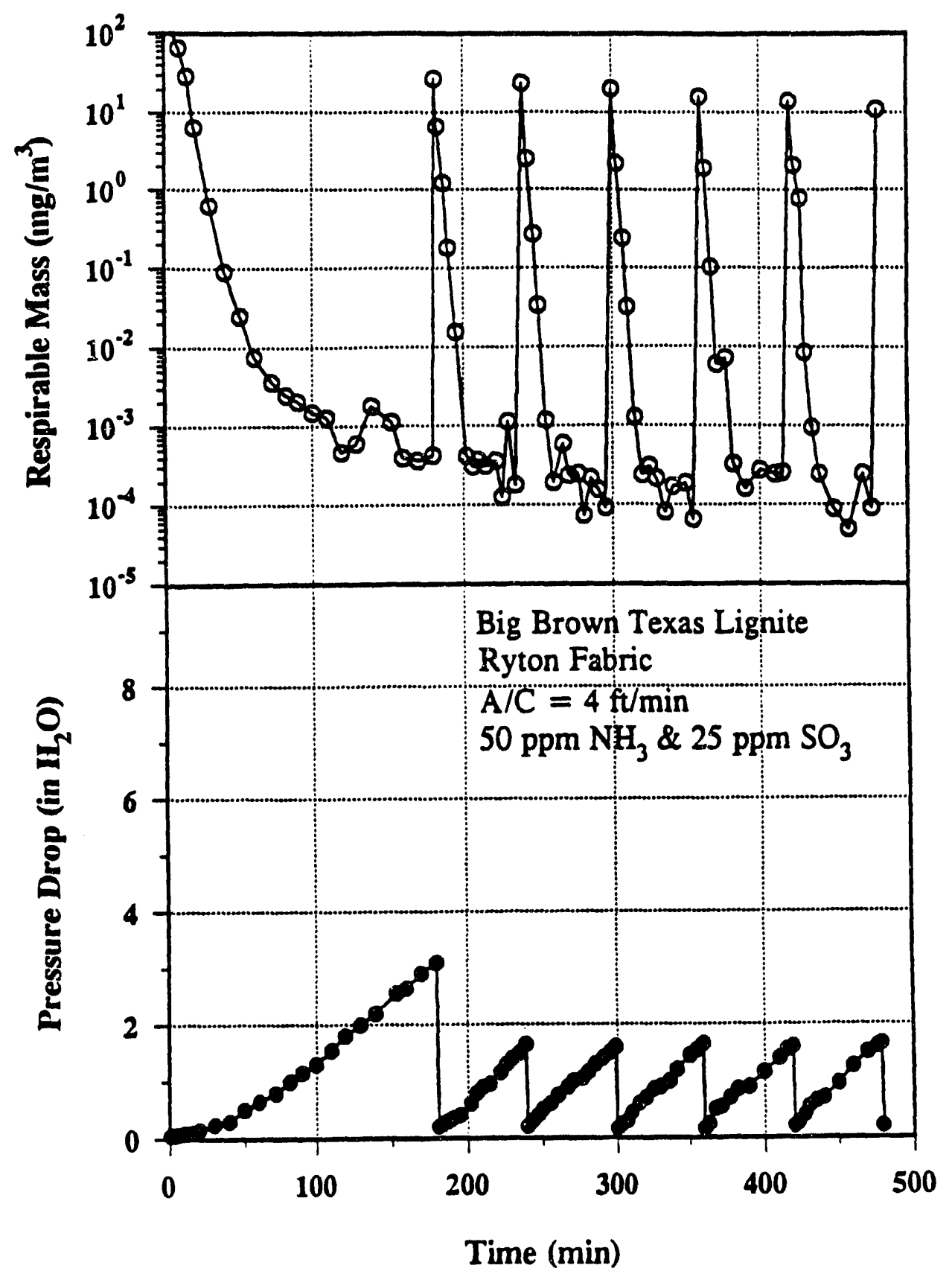

Figure 7. Respirable mass emissions and pressure drop as a function of time for Big Brown coal at an A/C ratio of $4 \mathrm{ft} / \mathrm{min}$ with Ryton fabric and $50 / 25 \mathrm{ppm}$ of $\mathrm{NH}_{3} / \mathrm{SO}_{3}$. Bags were cleaned every 60 minutes after an initial 180-minute period. 


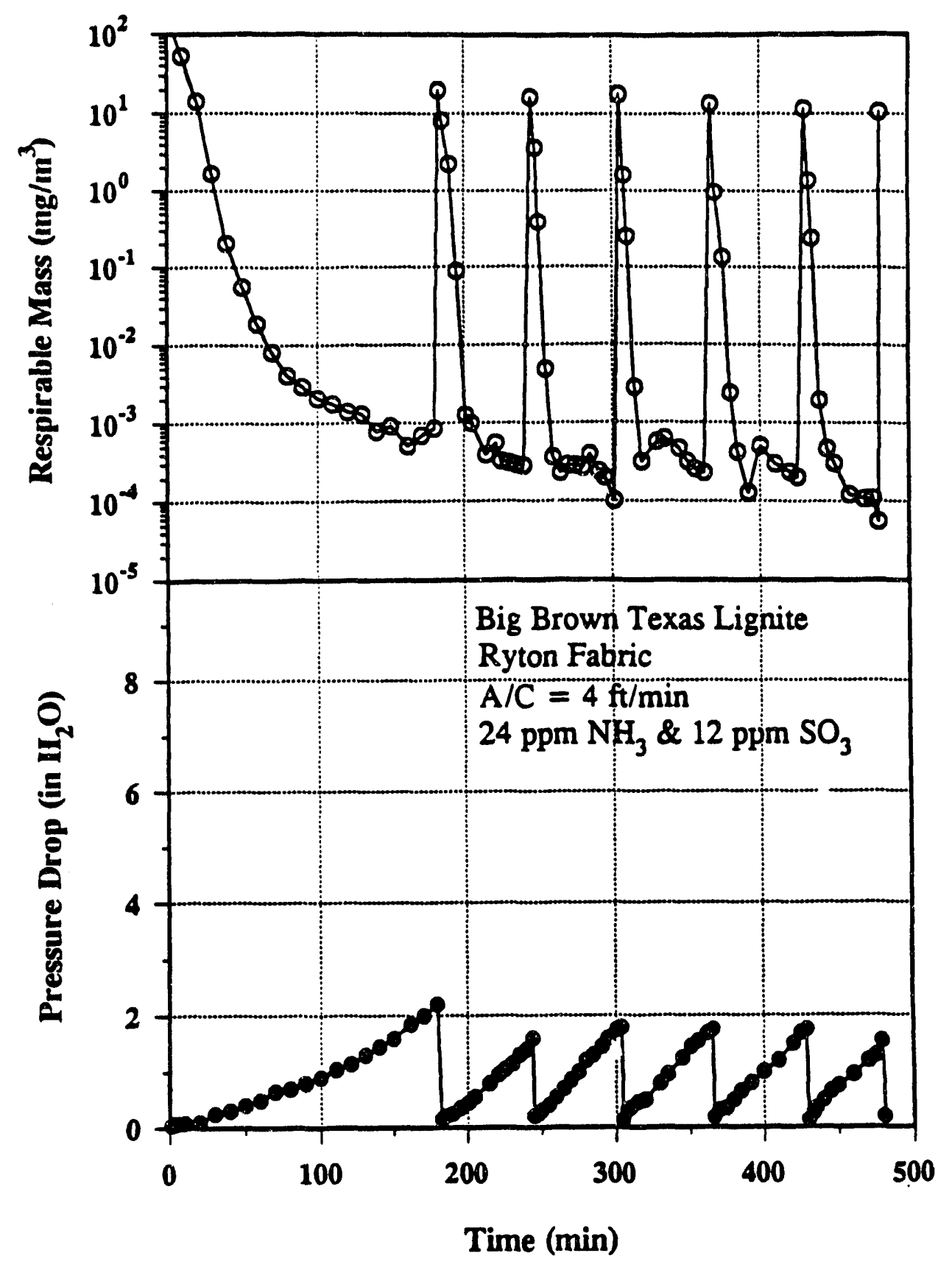

Figure 8. Respirable mass emissions and pressure drop as a function of time for Big Brown coal at an $\mathrm{A} / \mathrm{C}$ ratio of $4 \mathrm{ft} / \mathrm{min}$ with Ryton fabric and $24 / 12 \mathrm{ppm}$ of $\mathrm{NH}_{3} / \mathrm{SO}_{3}$. Bags were cleaned every 60 minutes after an initial 180-minute period. 


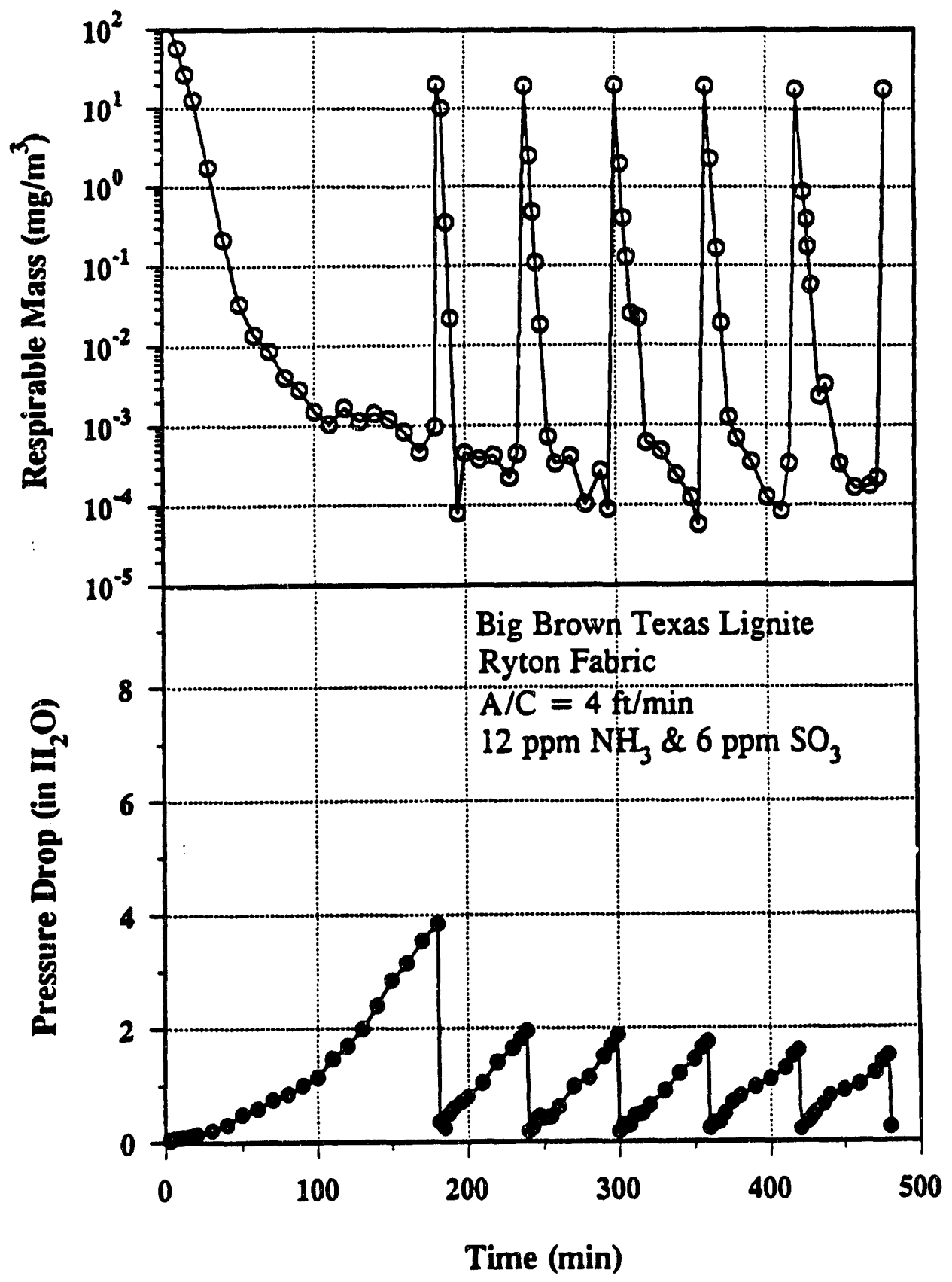

Figure 9. Respirable mass emissions and pressure drop as a function of time for Big Brown coal at an $\mathrm{A} / \mathrm{C}$ ratio of $4 \mathrm{ft} / \mathrm{min}$ with Ryton fabric and $12 / 6 \mathrm{ppm}$ of $\mathrm{NH}_{3} / \mathrm{SO}_{3}$. Bags were cleaned every 60 minutes after an initial 180-minute period. 


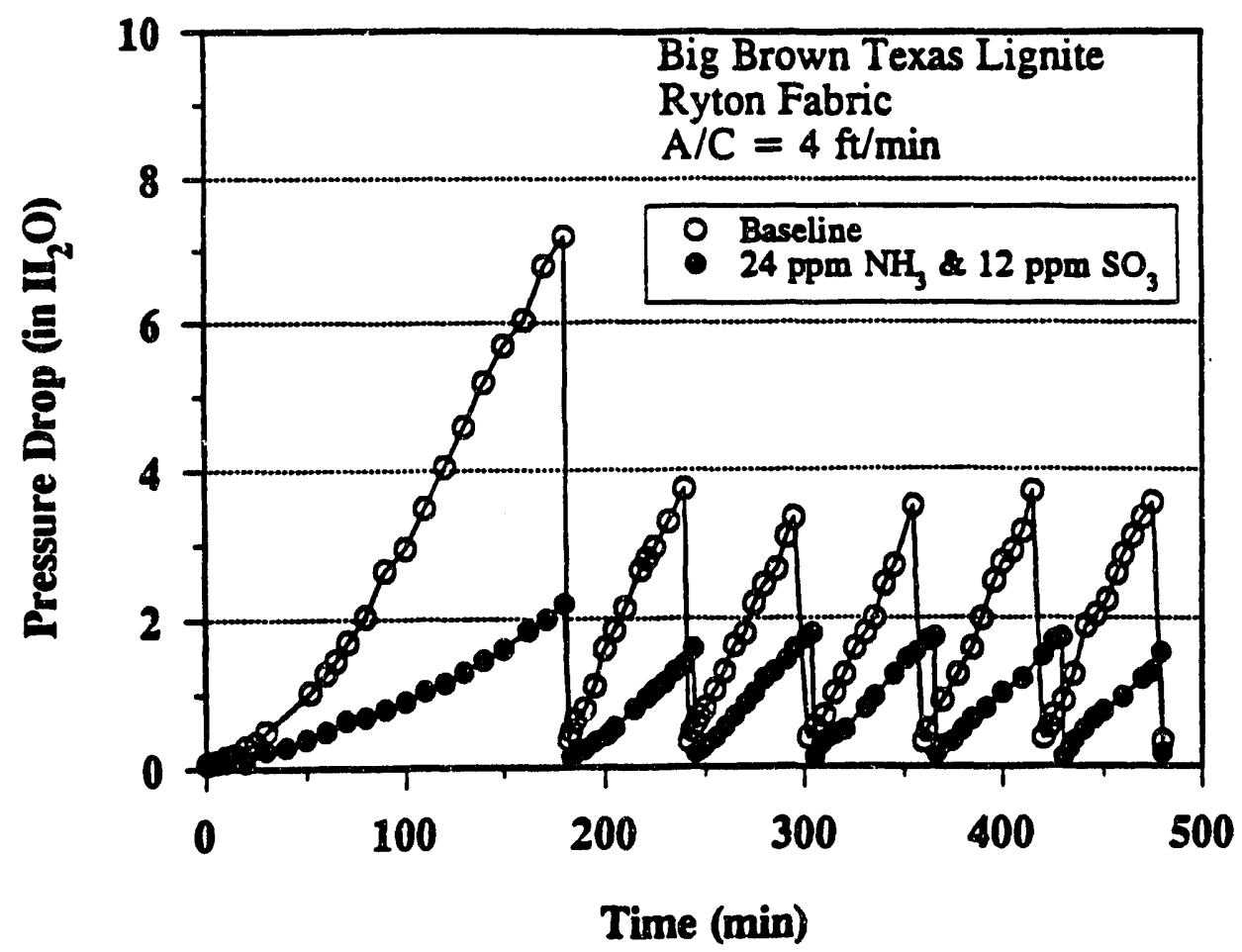

Figure 10. Pressure drop for baseline and conditioning tests with Big Brown coal with Ryton fabric at an A/C ratio of $4 \mathrm{ft} / \mathrm{min}$. Bags were cleaned ever, 60 minutes after an initial 180-minute period.

decreased with successive 20-minute bag cleanings, the interval was increased again to 30 minutes for the last 4 hours of the test. However, pressure drop again increased with successive cleaning intervals and reached a maximum of over 10 inches by the end of the test. This indicated that pressure drop could not be adequately controlled with a 30-minute cleaning interval for the baseline ash at an A/C of $6 \mathrm{ft} / \mathrm{min}$ (see Figure 14). With 24/12 ppm of $\mathrm{NH}_{3} / \mathrm{SO}_{3}$ and the same 30 -minute cleaning cycle, pressure drop was easily controlled at 2.5 inches WC (see Figure 14), which shows that conditioning greatly facilitates operation at high $A / C$ ratios. Since difficulties were encountered for the baseline case at an A/C of 6 $\mathrm{ft} / \mathrm{min}$. no baseline test was attempted at $8 \mathrm{ft} / \mathrm{min}$; however, a test with conditioning was conducted at $8 \mathrm{ft} / \mathrm{min}$. Figure 15 is a comparison of pressure drop for the conditioning tests with $24 / 12 \mathrm{ppm}$ of $\mathrm{NH}_{3} / \mathrm{SO}_{3}$ at $\mathrm{A} / \mathrm{C}$ ratios of 4 and $8 \mathrm{ft} / \mathrm{min}$. At $4 \mathrm{ft} / \mathrm{min}$, pressure drop was about 2 inches with a 60 -minute cleaning interval. Raising the $A / C$ ratio from 4 to $8 \mathrm{ft} / \mathrm{min}$ 


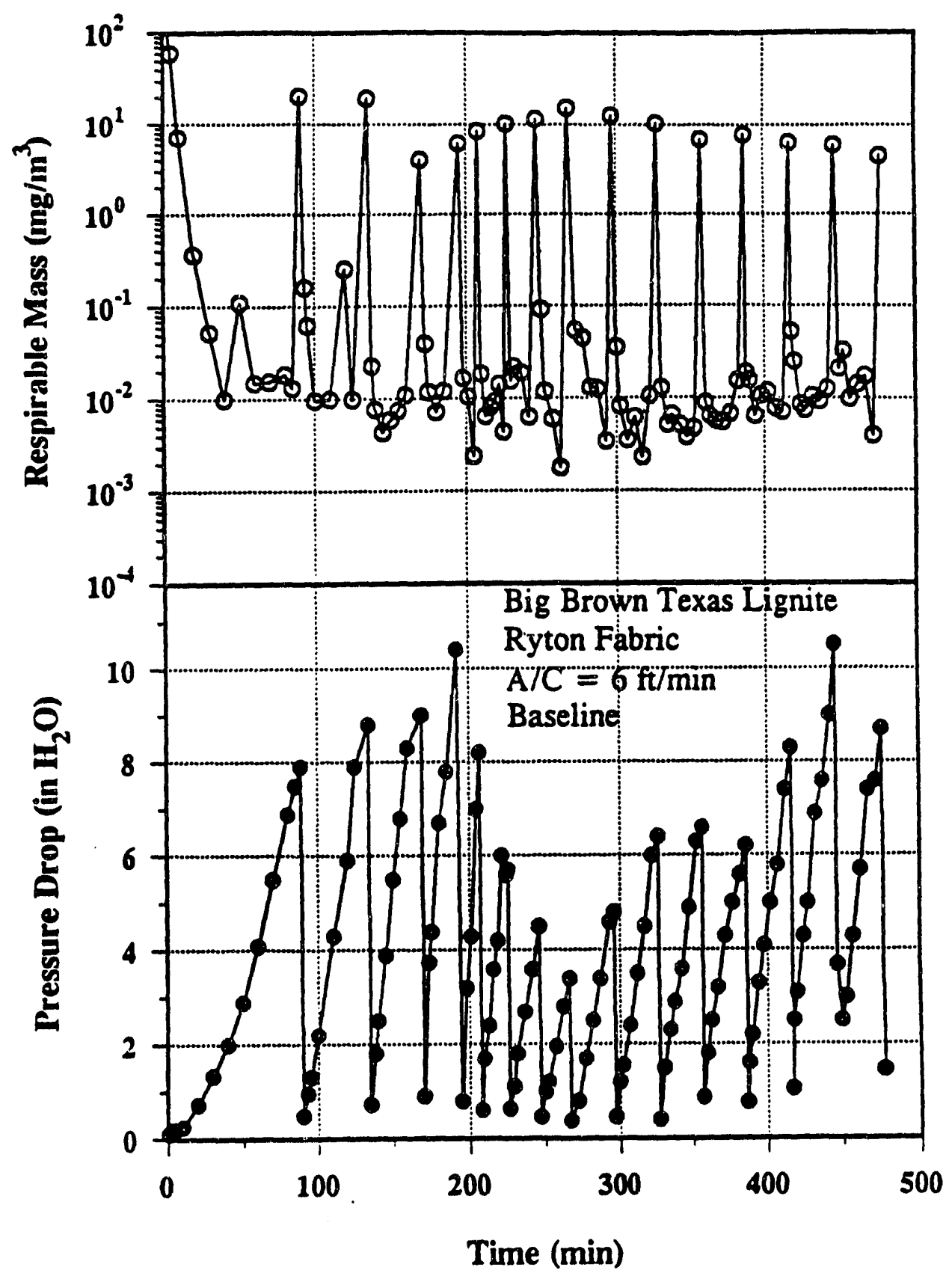

Figure 11. Respirable mass emissions and pressure drop as a function of time for Big Brown coal at an $\mathrm{A} / \mathrm{C}$ atio of $6 \mathrm{ft} / \mathrm{min}$ with Ryton fabric and no conditioning. Bags were cleaned every 30 minutes during the last 4 hours of the test. 


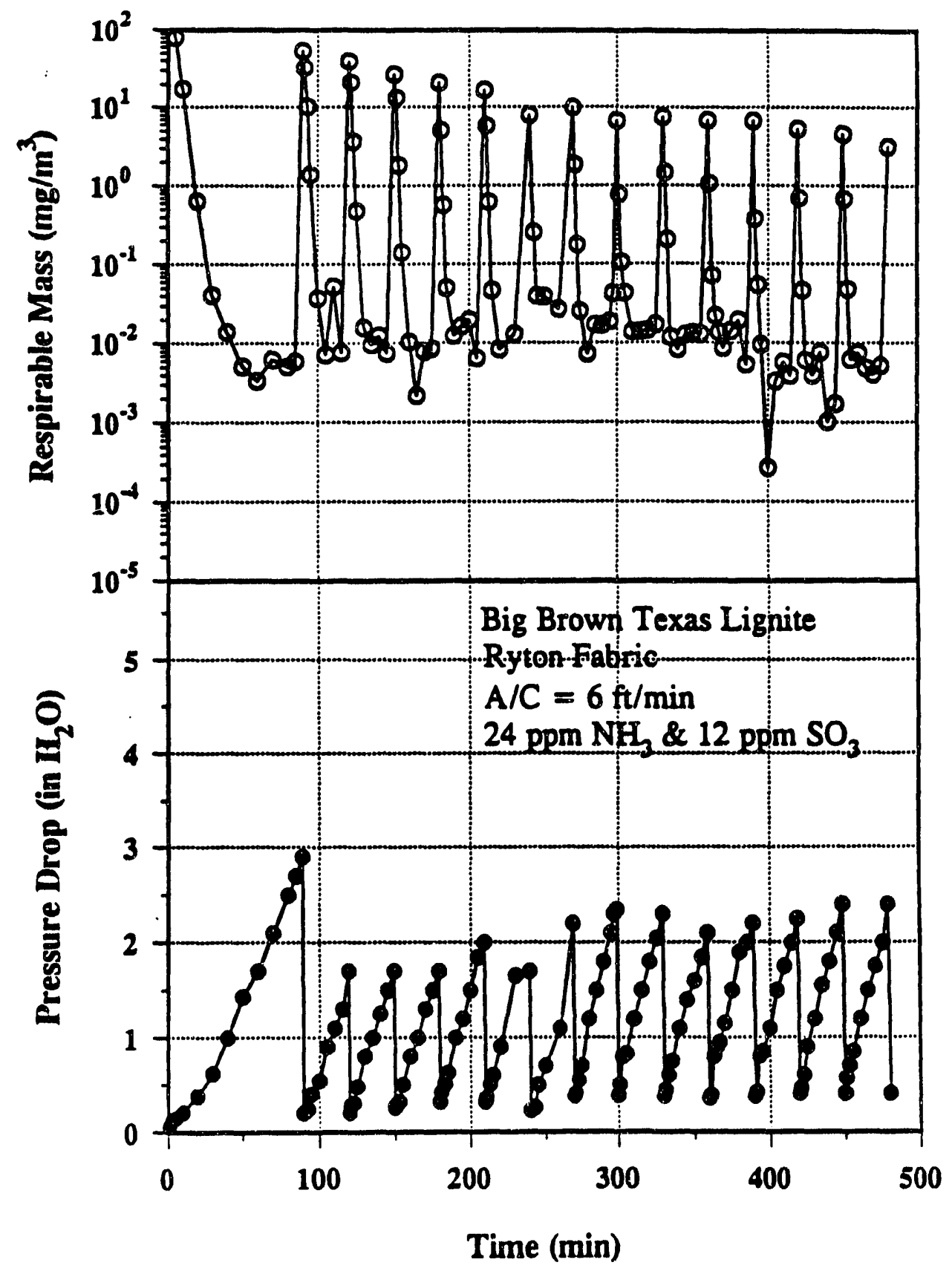

Figure 12. Respirable mass emissions and pressure drop as a function of time for Big Brown coal at an A/C ratio of $6 \mathrm{ft} / \mathrm{min}$ with Ryton fabric and $24 / 12 \mathrm{ppm}$ of $\mathrm{NH}_{3} / \mathrm{SO}_{3}$. Bags were cleaned every 30 minutes after an initial 90-minute period. 


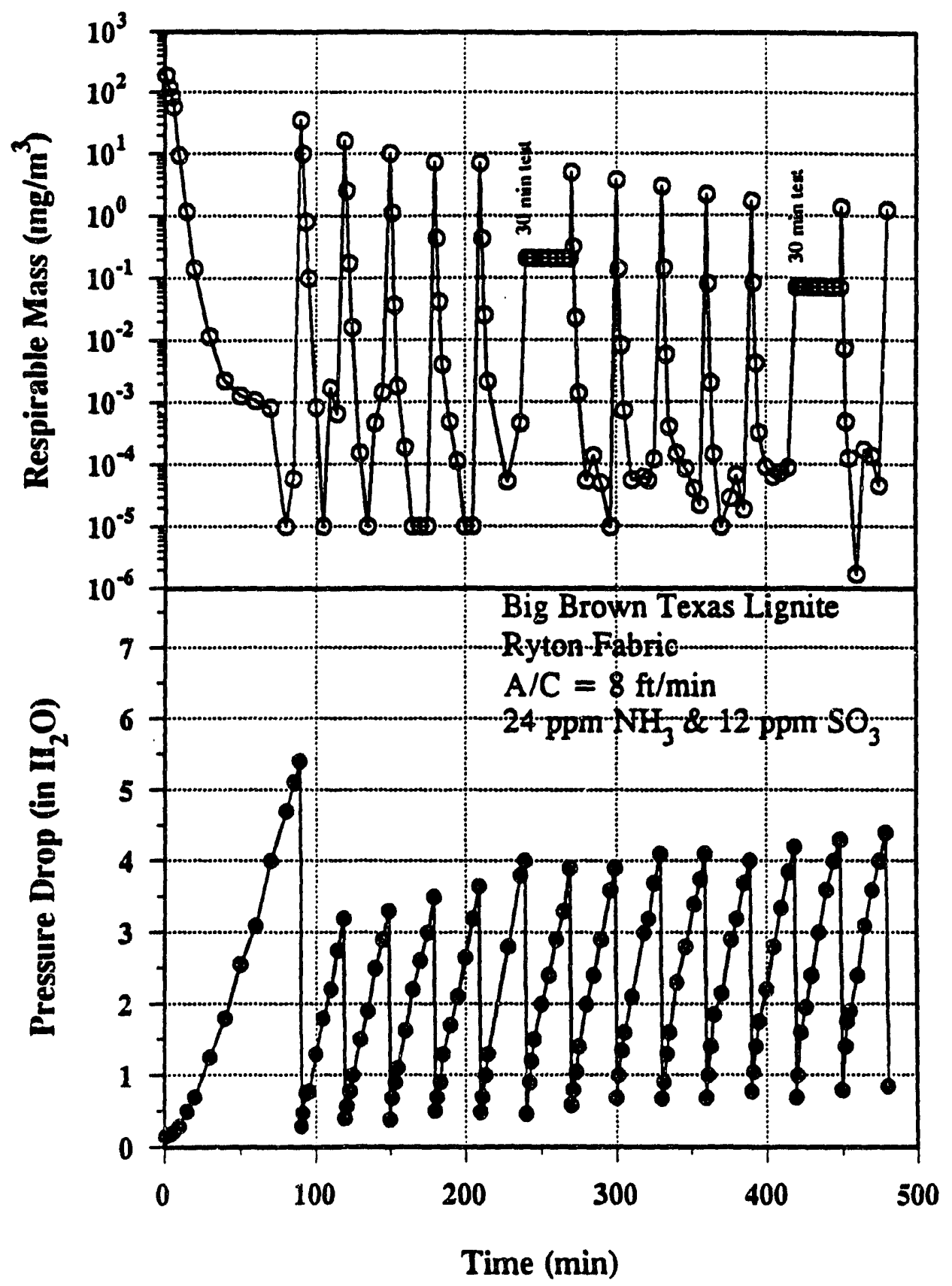

Figure 13. Respirable mass emissions and pressure drop as a function of time for Big Brown coal at an $\mathrm{A} / \mathrm{C}$ ratio of $8 \mathrm{ft} / \mathrm{min}$ with Ryton fabric and $24 / 12 \mathrm{ppm}$ of $\mathrm{NH}_{3} / \mathrm{SO}_{3}$. Bags were cleaned every 30 minutes after an initial 90-minute period. 


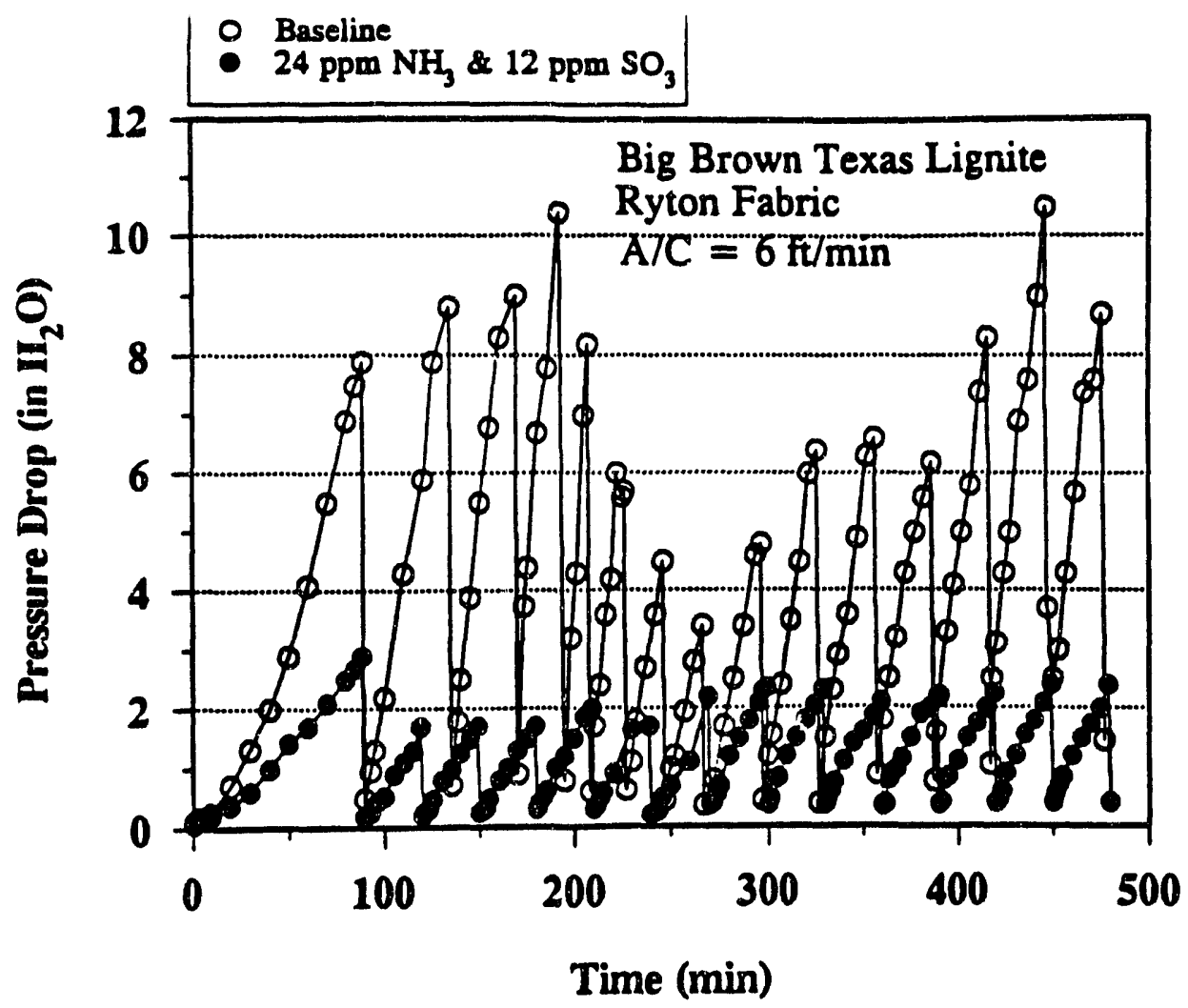

Figure 14. Pressure drop for baseline and conditioning tests with Big Brown coal with Ryton fabric at an A/C ratio of $6 \mathrm{ft} / \mathrm{min}$. Bags were cleaned every 30 minutes during the last 4 hours of tests.

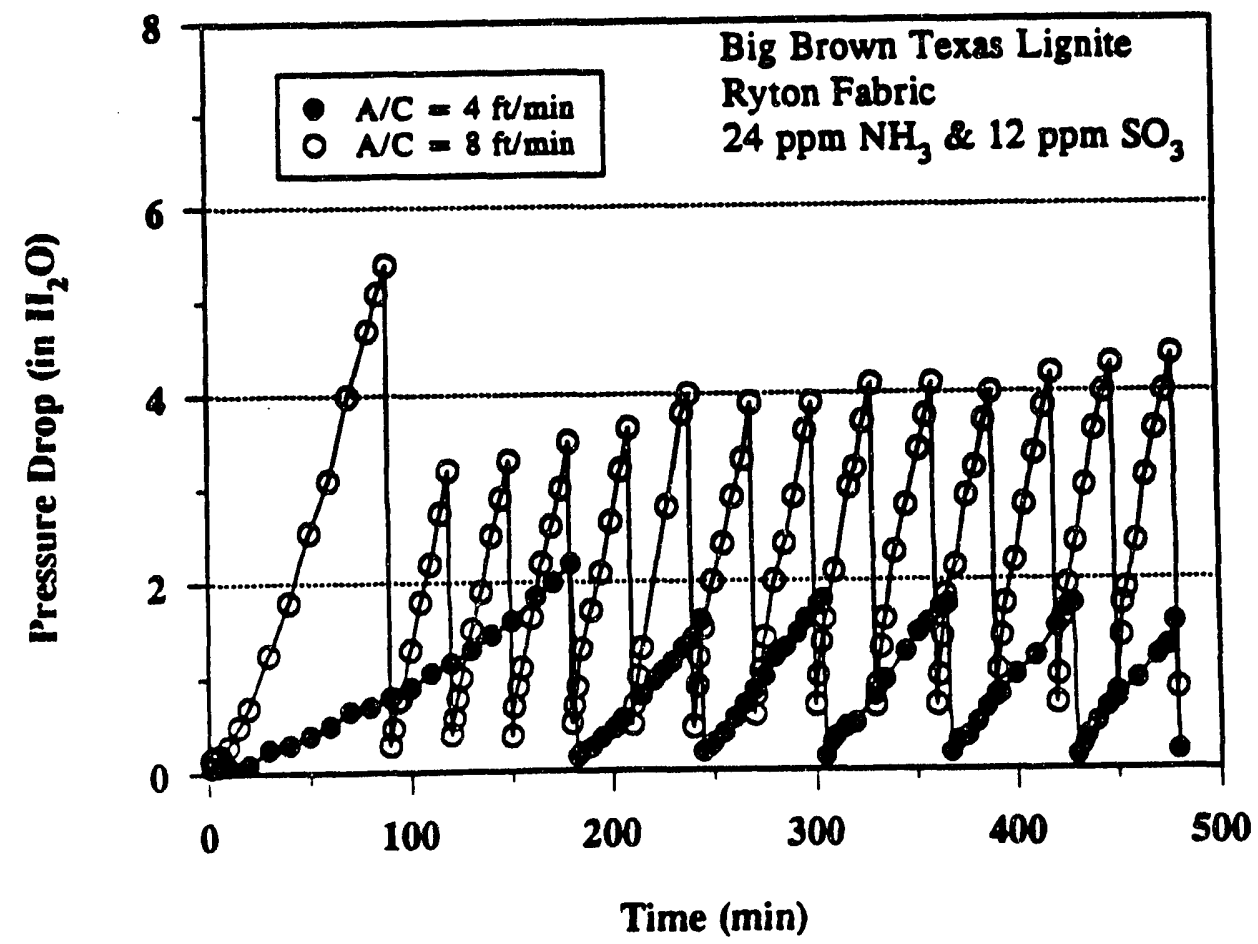

Figure 15. Pressure drop for conditioning tests with Big Brown coal with Ryton fabric at $\mathrm{A} / \mathrm{C}$ ratios of 4 and $8 \mathrm{ft} / \mathrm{min}$. After initial filtration periods, bags were cleaned every 30 minutes at $8 \mathrm{ft} / \mathrm{min}$ and every 60 minutes at $4 \mathrm{ft} / \mathrm{min}$. 
should result in a pressure drop increase to 8 inches WC for the same cleaning interval and $\mathrm{K}_{2}$. If the cleaning cycle interval is reduced by $50 \%$ at the same time, the pressure drop should increase only to 4 inches WC. Figure 15 indicates that, when the A/C ratio was doubled and the cleaning interval reduced by $50 \%$, pressure drop increased from about 2 to 4 inches WC, as predicted by theory. This implies that $\mathrm{K}_{2}$ did not increase with a doubling of velocity and that the bags cleaned well, even at an $A / C$ ratio of $8 \mathrm{ft} / \mathrm{min}$. Actual $K_{2}$ measurements show that $K_{2}$ did not increase, but was in the range of 3.0 to $3.5 \pm 0.9$ inches of water- $\mathrm{ft}-\mathrm{min} / \mathrm{lb}$. Figure 15 does show a slight increase in $\Delta \mathrm{P}$ with time, indicating some increase in residual dust cake weight. The extent of this trend was further evaluated during the 100-hour tests. Figure 13 includes a plot of respirable mass emissions for the test at an $\mathrm{A} / \mathrm{C}$ ratio of $8 \mathrm{ft} / \mathrm{min}$. The large range in emissions from just after bag cleaning to just before bag cleaning covers five orders of magnitude from about $10 \mathrm{mg} / \mathrm{m}^{3}$ to $10^{4} \mathrm{mg} / \mathrm{m}^{3}$. Since the inlet respirable mass was about $600 \mathrm{mg} / \mathrm{m}^{3}$, this corresponds to a respirable mass collection efficiency from $98 \%$ just after bag cleaning to $99.99998 \%$ just before bag cleaning. During two of the cleaning intervals, a continuous 30-minute sample was taken, as shown in Figure 13. Clearly, most of the emissions occur immediately following bag cleaning; however, two encouraging results are evident. The respirable mass spikes are lower with time, indicating that some residual dust cake is developing. This helps to maintain pore bridges and results in a decrease in average emissions with time, indicating that an even higher collection efficiency can be achieved with longer-term operation. During the second 30-minute APS sample, the respirable mass collection efficiency agreed closely with the EPA-5 collection efficiency, both at $99.99 \%$. These results are highly encouraging because they show that, when conditioning is employed with this fabric and coal, a pulse-jet baghouse can be operated at a high A/C ratio of $8 \mathrm{ft} / \mathrm{min}$ with an easily controlled pressure drop and a very high collection efficiency.

Submicron emissions for all of the tests closely followed the APS results. An example of results of submicron emissions for the Big Brown tests with Ryton fabric at an $\mathrm{A} / \mathrm{C}$ ratio of $6 \mathrm{ft} / \mathrm{min}$ is shown in Figure 16. One difference between the APS and CNC results is the peak emissions just after bag cleaning. The submicron emissions with conditioning are slightly higher than for the baseline case. An explanation is that the actual submicron particle count at the inlet to the baghouse is increased with conditioning due to the formation of fine ammonium sulfate particles. Just after bag cleaning, when there is a minimum dust cake, collection efficiency for these particles is low. Therefore, a higher inlet concentration results in a higher level of submicron emissions just after bag cleaning. However, after a shon time, these submicron emissions quickly drop to very low levels and are of no concern. 


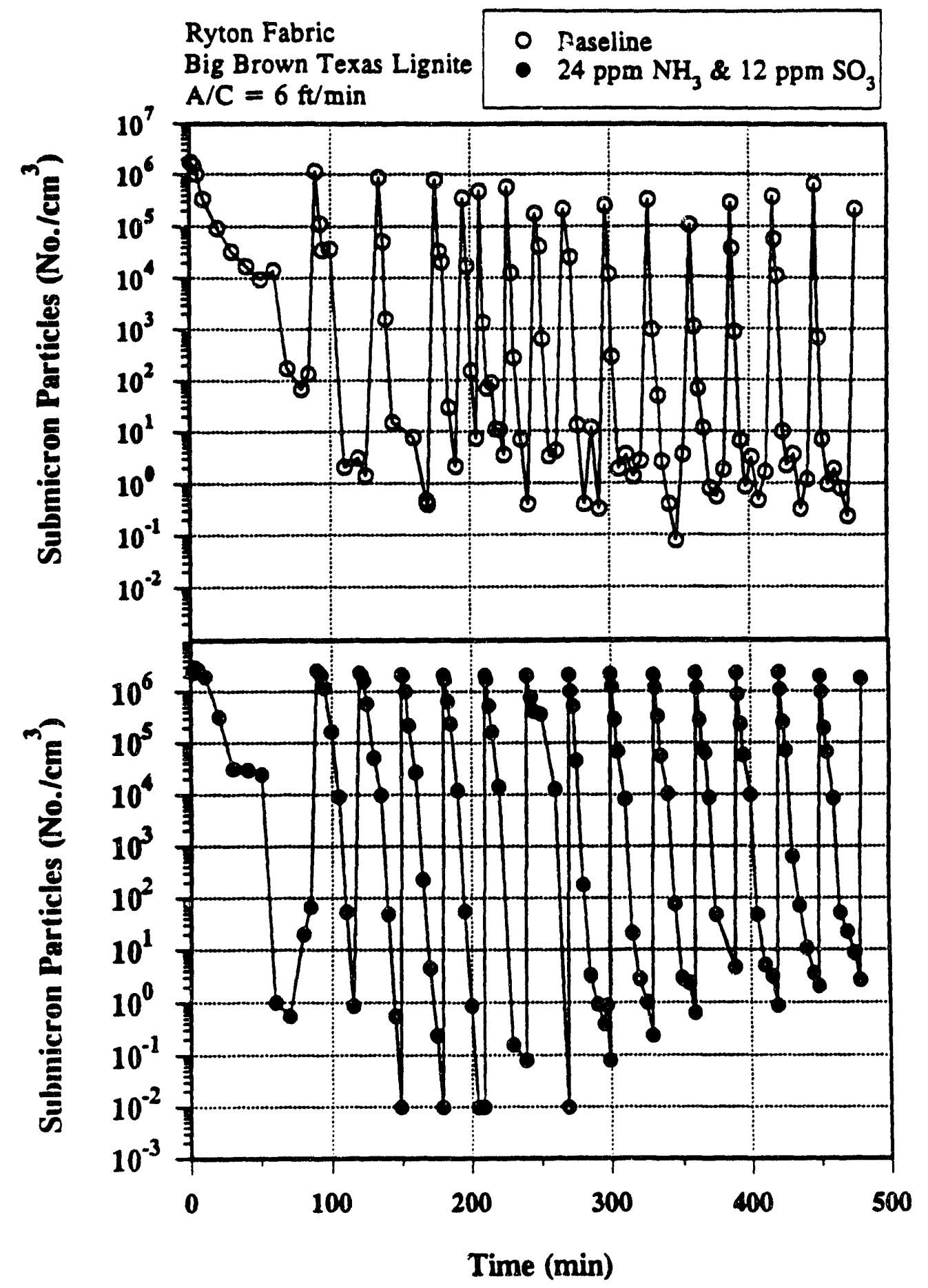

Figure 16. Comparison of submicron emissions measured with the CNC for Big Brown coal with Ryton fabric for the baseline and conditioning tests at an $A / C$ ratio of $6 \mathrm{ft} / \mathrm{min}$. 
Pressure drop and respirable mass results with 22-0z/yd ${ }^{2}$ woven glass fabric at an AVC ratio of $4 \mathrm{ft} / \mathrm{min}$ are shown in Figure 17. The effect of conditioning with woven glass fabric is even more pronounced than with Ryton felted fabric. Pressure drop was reduced from about 6 inches WC for the baseline test to about 2 inches WC with conditioning for the same cleaning interval. The outlet EPA-5 dust loading was reduced by a factor of ten with conditioning. The peak respirable mass emissions were also about ten times lower with conditioning, and the minimum emissions were about three orders of magnitude lower with conditioning. For the baseline test, minimum emissions were high at about $1 \mathrm{mg} / \mathrm{m}^{3}$, which is an indication that complete pore bridging did not occur and that pinholes were likely present. The much lower minimum emissions with conditioning indicate that conditioning provides superior pore bridging. Although no tests were conducted with the woven glass fabric at higher $\mathrm{A} / \mathrm{C}$ ratios, these results indicate that increasing the $\mathrm{A} / \mathrm{C}$ ratio should be possible when conditioning is used. For the baseline case, on the other hand, results indicate that poor collection efficiency would be a problem if the A/C ratio were increased for this coal and fabric. A collection efficiency of only $99.6 \%$ was achieved at an A/C ratio of $4 \mathrm{ft} / \mathrm{min}$ with the baseline ash, which would not meet the NSPS particulate emission limit of $0.03 \mathrm{lb} / 10^{6} \mathrm{Btu}$. While collection efficiency may improve with longer-term operation, these tests flag the combination of woven glass fabric with the Big Brown coal and pulse-jet cleaning as a potential problem, but indicate the problem can be eliminated with conditioning.

\subsubsection{Milner Tests}

A total of 6 tests were completed with the Milner coal. Compared to the Big Brown tests, notable differences are the much higher inlet dust loading and the higher loss on ignition (LOI) of the fly ash for the Milner coal (shown in Tables 6 and 7). The fly ash LOI for the Big Brown coal was less than $1 \%$ for all but one test, while the LOI for the Milner ash ranged from $3.8 \%$ to $6.6 \%$. This LOI range is typical of the LOI of the baghouse ash that has been observed at the Milner station.

Three initial tests were completed at an A/C ratio of $4 \mathrm{ft} / \mathrm{min}$ with Ryton fabric, a baseline test, and conditioning tests at concentrations of $24 / 12 \mathrm{ppm}$ and $12 / 6 \mathrm{ppm}$ of $\mathrm{NH}_{3} / \mathrm{SO}_{3}$. Respirable mass and pressure drop data are shown in Figures 18 through 20. There was concern that conditioning may not be effective with an extremely high-ash fuel such as the Milner coal. The required conditioning agent concentrations were not known and, theoretically, could be much greater because the inlet dust loading was almost 4 times greater than with Big Brown coal. Nevertheless, starting concentrations were chosen at 


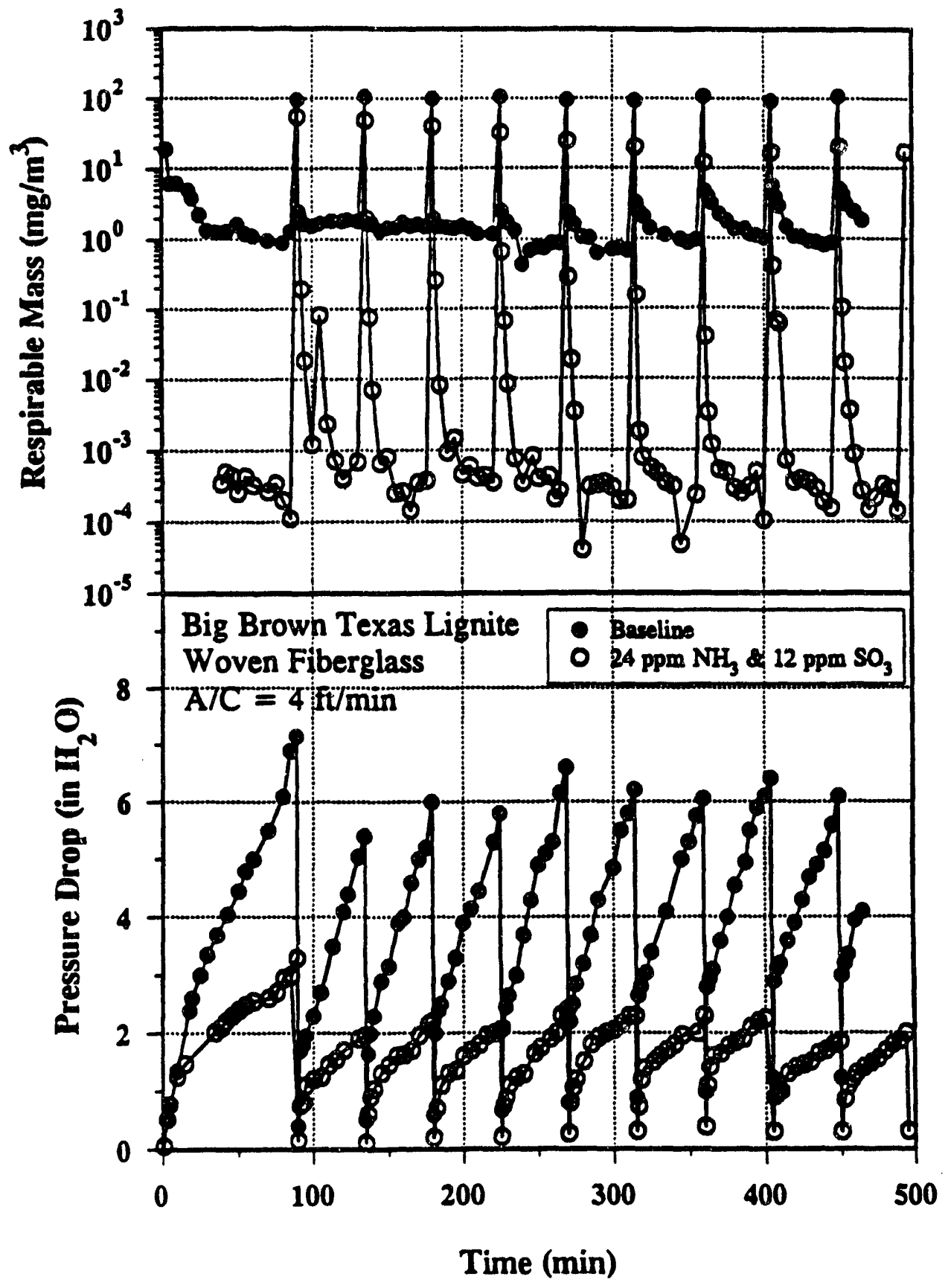

Figure 17. Respirable mass emissions and pressure drop for baseline and conditioning tests with Big Brown coal with woven glass fabric at an $A / C$ ratio of $4 \mathrm{ft} / \mathrm{min}$. Bags were cleaned every 45 minutes after an initial 90 -minute period. 


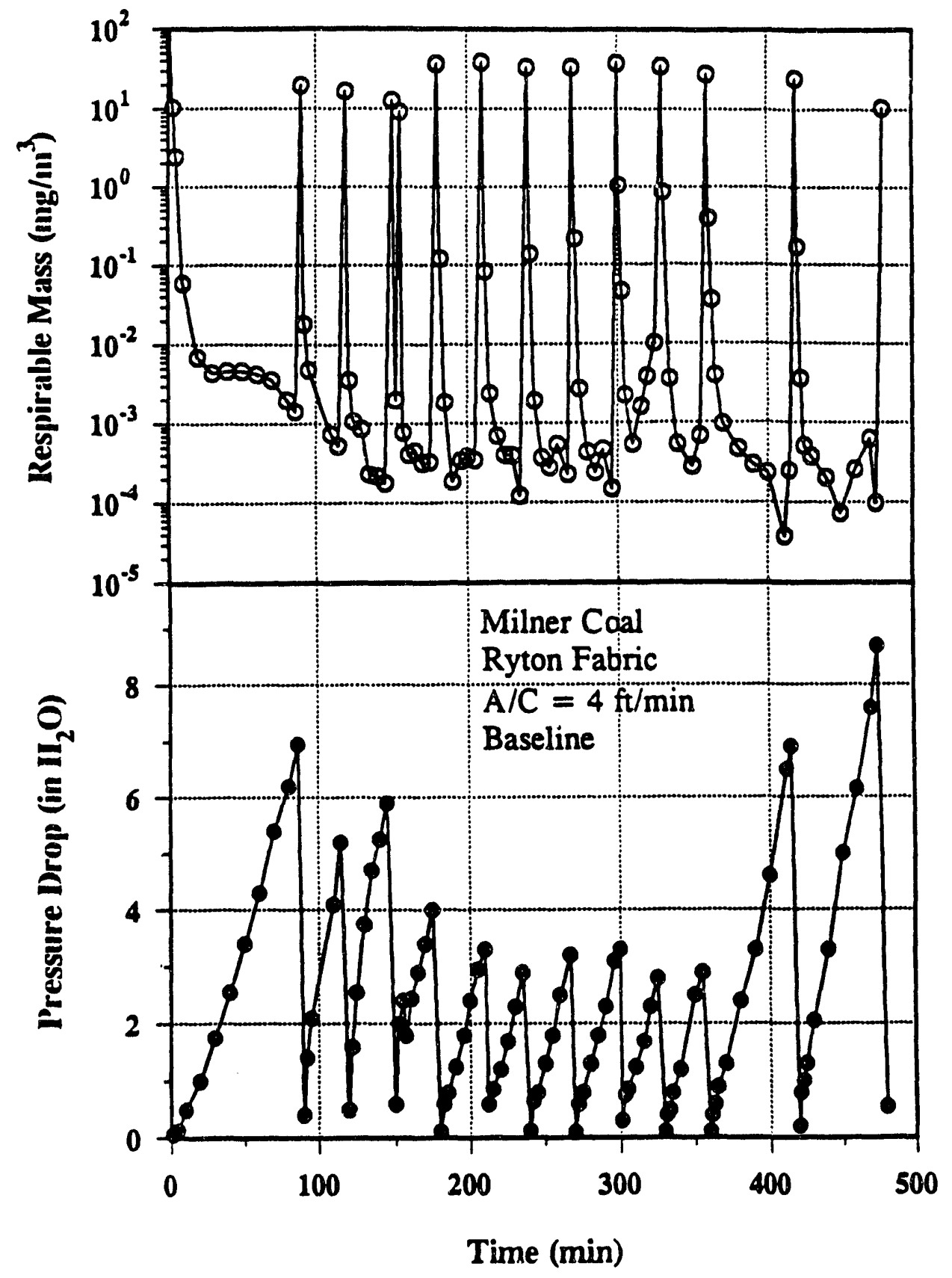

Figure 18. Respirable mass emissions and pressure drop as a function of time for Milner coal at an A/C ratio of $4 \mathrm{ft} / \mathrm{min}$ with Ryton fabric and no conditioning. After an initial 90-minute filtration period, bags were cleaned every 30 minutes, except that the last two cleaning cycle intervals were 60 minutes. 


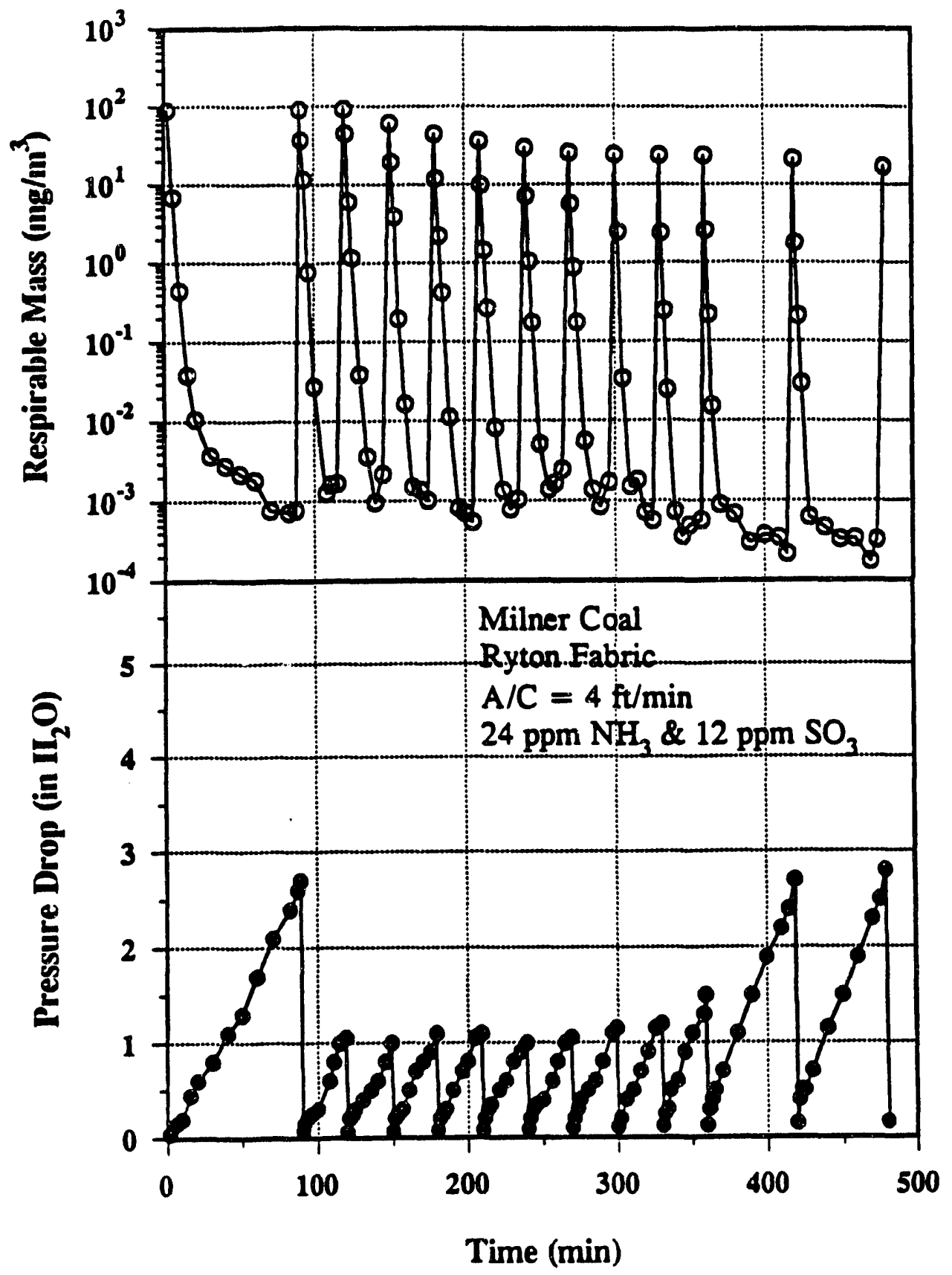

Figure 19. Respirable mass emissions and pressure drop as a function of time for Milner coal at an A/C ratio of $4 \mathrm{ft} / \mathrm{min}$ with Ryton fabric and $24 / 12 \mathrm{ppm}$ of $\mathrm{NH}_{3} / \mathrm{SO}_{3}$. After an initial 90-minute filtration period, bags were cleaned every 30 minutes, except that the last two cleaning cycle intervals were 60 minutes. 


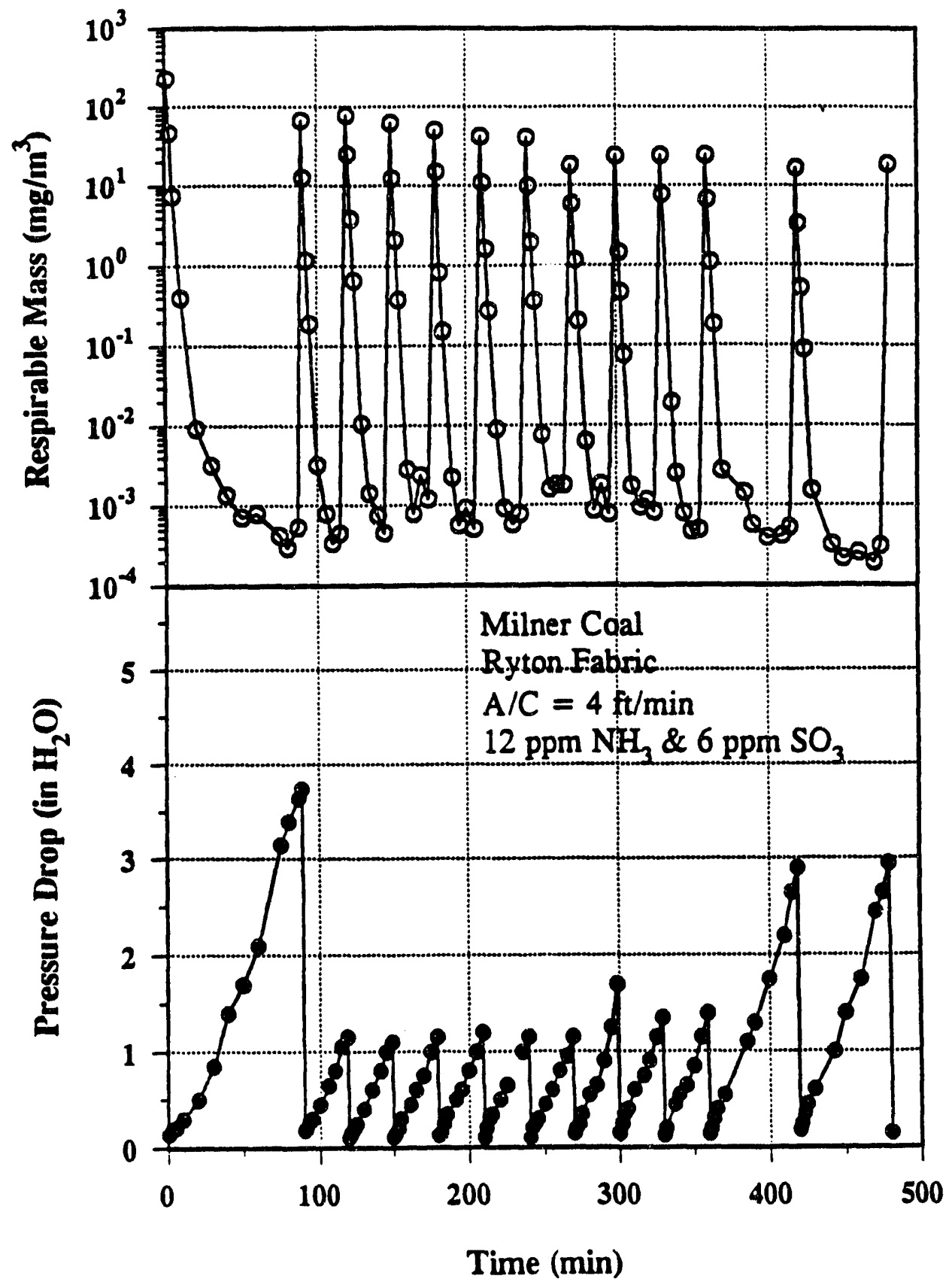

Figure 20. Respirable mass emissions and pressure drop as a function of time for Milner coal at an $\mathrm{A} / \mathrm{C}$ ratio of $4 \mathrm{ft} / \mathrm{min}$ with Ryton fabric and $12 / 6 \mathrm{ppm}$ of $\mathrm{NH}_{3} / \mathrm{SO}_{3}$. After an initial 90-minute filtration period, bags were cleaned every 30 minutes, except that the last two cleaning cycle intervals were 60 minutes. 
$24 / 12 \mathrm{ppm}$ with the idea that they could be increased for the second test if necessary. However, concentrations of $24 / 12 \mathrm{ppm}$ were quite effective, so they were reduced to $12 / 6 \mathrm{ppm}$ for the second conditioning test. Particulate emissions for all three tests were very low, achieving a collection efficiency of $99.99 \%$. Pressure drop and $\mathrm{K}_{2}$ were reduced by a factor of three at concentrations of $24 / 12 \mathrm{ppm}$ compared to the baseline test. At concentrations of $12 / 6 \mathrm{ppm}$, pressure drop and $\mathrm{K}_{2}$ were slightly higher than at concentrations of $24 / 12 \mathrm{ppm}$, but pressure drop was still considerably lower than with no conditioning. Excellent results with $24 / 12 \mathrm{ppm}$ of $\mathrm{NH}_{3} / \mathrm{SO}_{3}$ conditioning agents indicated that operation at a higher $\mathrm{A} / \mathrm{C}$ ratio should be possible, so a subsequent test was conducted at an $\mathrm{A} / \mathrm{C}$ ratio of $8 \mathrm{ft} / \mathrm{min}$ (see Figure 21). Pressure drop was maintained at about 4 inches WC with a 20-minute cleaning interval, and particulate emissions were well controlled at $99.99 \%$ removal efficiency. Achieving superior performance at a high A/C ratio of $8 \mathrm{ft} / \mathrm{min}$ with a dust loading of 17.7 grains/scf again shows the significant benefit of using conditioning with pulse-jet cleaning. Two additional tests, a baseline and a conditioning test at an A/C ratio of $4 \mathrm{ft} / \mathrm{min}$, were conducted with the Milner coal using a P84/Ryton felted fabric in place of the Ryton fabric. Results, shown in Figures 22 and 23, were similar to the Ryton tests in that pressure drop and $\mathrm{K}_{2}$ were reduced by about three times and particulate emissions were low, about $99.99 \%$ collection efficiency in both cases.

\subsubsection{Cohesive Properties and Ash Analyses}

The effect of conditioning on ash properties is of interest to help understand the mechanisms of performance improvement. The reduction of $\mathbf{K}_{2}$ must be attributed to increased porosity of the dust cake because the particle-size distribution of fly ash appears to be unchanged with conditioning. While direct measurement of the dust cake porosity was not attempted, aerated and packed porosity measurements of the baghouse hopper ash (given in Table 6) are an indication of the packing tendency of the fly ash. From Table 6, one of the effects of conditioning on the fly ash is a significant increase in both the aerated and packed porosities, which explains the decrease in $\mathrm{K}_{2}$. As discussed earlier, models, such as the Carman-Kozeny relationship, which relate $\mathrm{K}_{2}$ to porosity, predict that a small change in porosity can account for a significant change in $\mathrm{K}_{2}$.

The $\mathrm{K}_{2}$ of the baseline Milner ash is much lower than the $\mathrm{K}_{2}$ of the baseline Big Brown ash even though the particle-size distributions are similar. Coulter counter results (presented in Table 7) show the volumetric median diameter (VMD) of the Big Brown ash samples to be $14.8 \pm 1.6 \mu \mathrm{m}$ and the VMD of the Milner ash samples to be $14.3 \pm 2.2 \mu \mathrm{m}$. The multicyclone results for the two coals also show the fly ash particle-size distributions smaller 


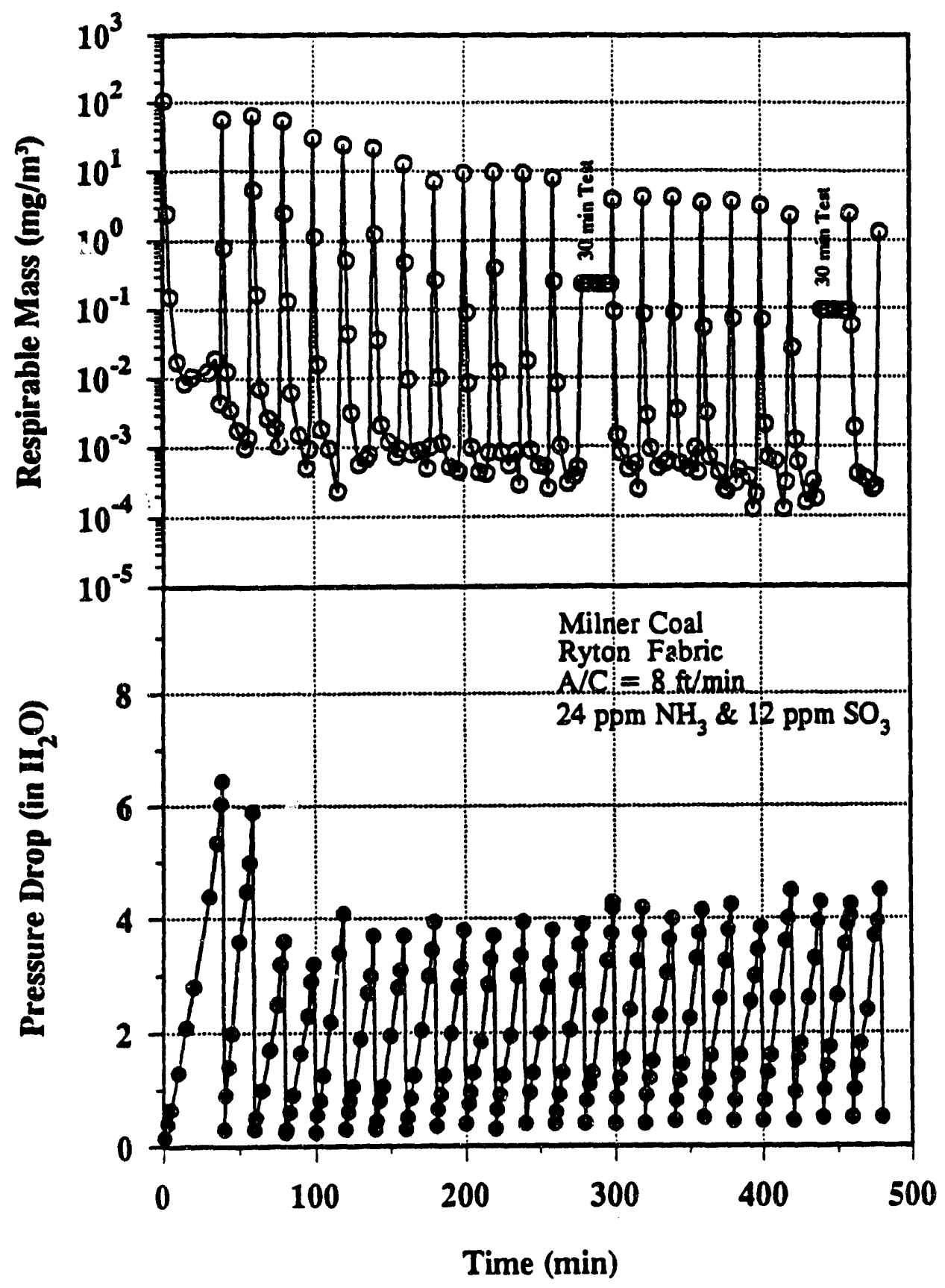

Figure 21. Respirable mass emissions and pressure drop as a function of time for Milner coal at an A/C ratio of $8 \mathrm{ft} /$ min with Ryton fabric and $24 / 12 \mathrm{ppm}$ of $\mathrm{NH}_{3} / \mathrm{SO}_{3}$. After an initial 40-minute filtration period, bags were cleaned every 20 minutes. 


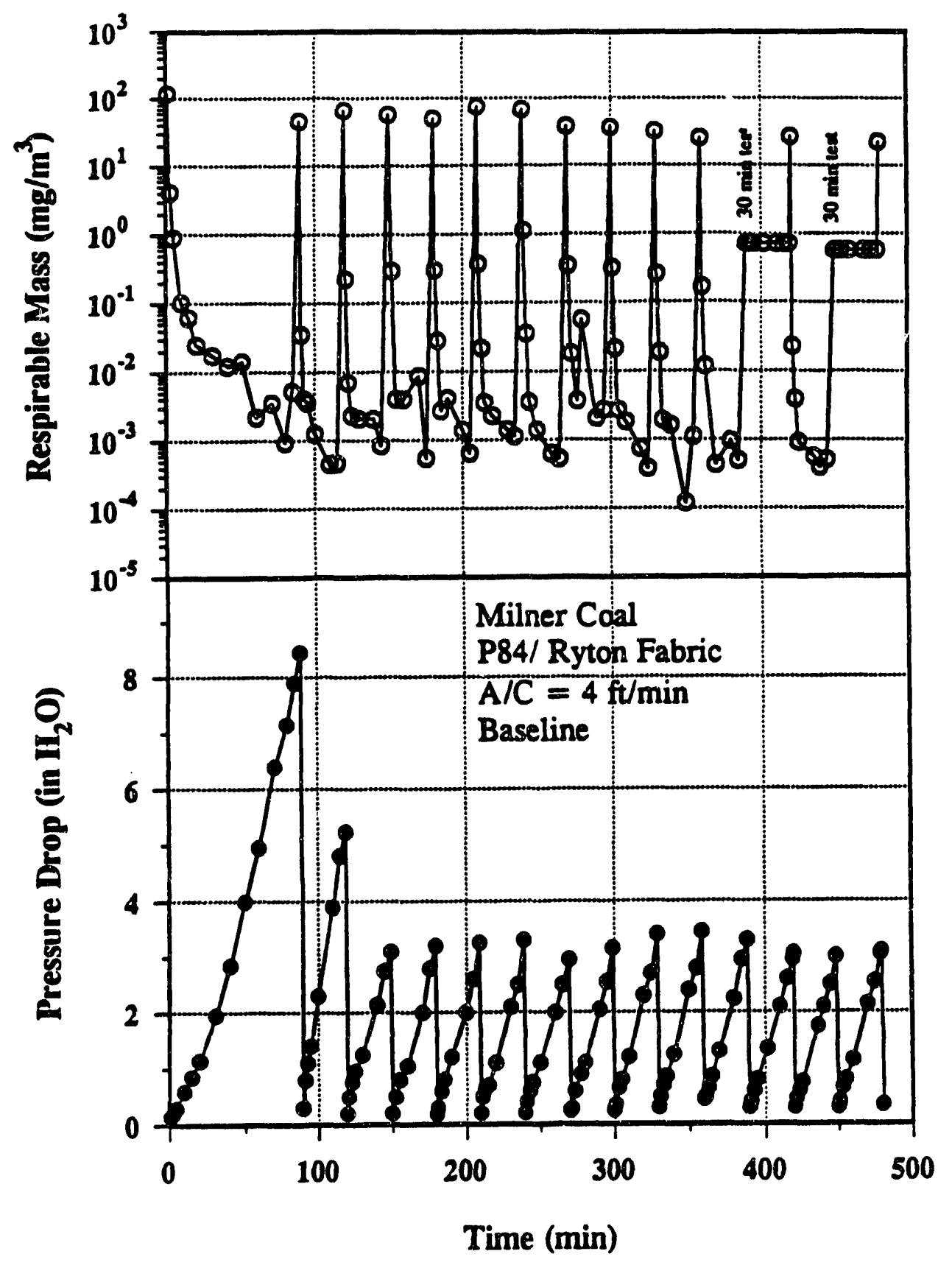

Figure 22. Respirable mass emissions and pressure drop as a function of time for Milner coal at an $A / C$ ratio of $4 \mathrm{ft} / \mathrm{min}$ with P84/Ryton fabric and no conditioning. After an initial 90-minute filtration period, bags were cleaned every 30 minutes. 


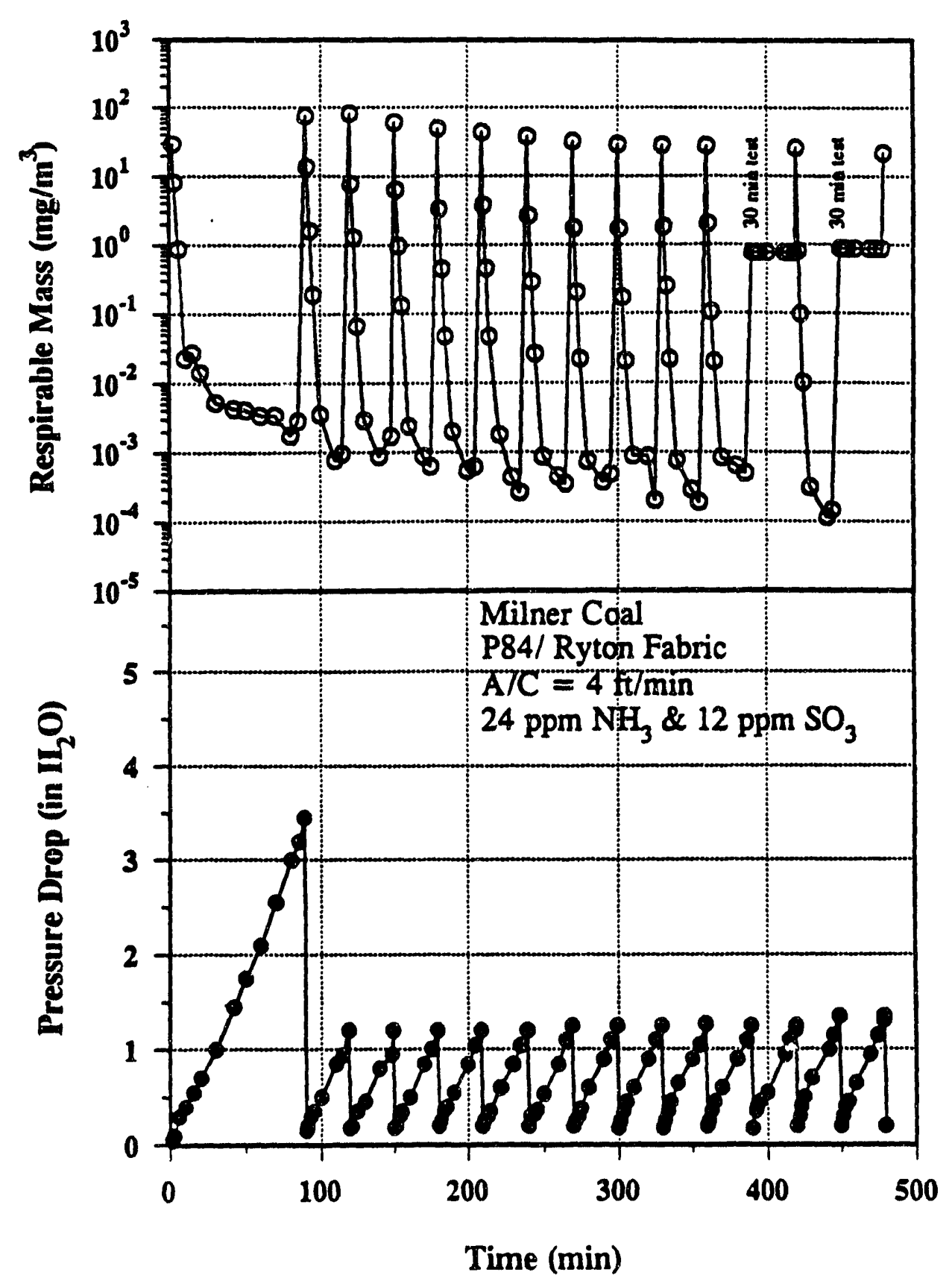

Figure 23. Respirable mass emissions and pressure drop as a function of time for Milner coal at an A/C ratio of $4 \mathrm{ft} / \mathrm{min}$ with P84/Ryton fabric and $24 / 12 \mathrm{ppm}$ of $\mathrm{NH}_{3} / \mathrm{SO}_{3}$. After an initial 90 -minute filtration period, bags were cleaned every 30 minutes. 
than $10 \mu \mathrm{m}$ to be similar (see Figure 24). Therefore, the porosity of the baseline Milner ash must be greater to account for the lower $\mathrm{K}_{2}$. Measured porosities (shown in Table 6) show that, indeed, this is the case. For an ash such as the Big Brown ash, that has a high tendency to pack, an increase in porosity might be expected with conditioning. However, the baseline porosity for the Milner ash was considerably higher than the baseline Big Brown porosity, and conditioning still produced a significant increase in porosity and a corresponding decrease in $\mathbf{K}_{\mathbf{2}}$. This is an encouraging result because it indicates that conditioning is effective for ashes of varying properties--not only in cases where the ash has a high packing tendency.

Tensile strength measurements for the Big Brown and Milner ash samples at an AVC ratio of $4 \mathrm{ft} / \mathrm{min}$ with Ryton fabric are shown in Figure 25. Tensile strength measurements for all of the fly ash samples for each coal are shown separately in Figures 26 and 27. Looking first at the four Big Brown samples, shown in Figure 25, one can see that the effect of conditioning is a shift of the tensile strength vs. porosity curve to the right and sometimes upward. At concentrations of $12 / 6 \mathrm{ppm}$ of $\mathrm{NH}_{3} / \mathrm{SO}_{3}$, the curve shifts primarily to the right and slightly upward from the baseline curve. At concentrations of $24 / 12 \mathrm{ppm}$, the curve shifts further to the right and upward. However, at concentrations of $50 / 25 \mathrm{ppm}$, the shift is further to the right and jownward again. The shift toward increasing porosity with increasing concentrations is in agreement with the aerated and packed porosity measurements. However, there is no obvious explanation for the decrease in tensile strength at the highest concentration of $50 / 25 \mathrm{ppm}$ of $\mathrm{NH}_{3} / \mathrm{SO}_{3}$. The actual tensile strength of the dust cake is of interest because increased tensile strength implies that the dust cake may not be easily removed. Since measurement of tensile strength requires some compaction of the ash, the tensile strength data are generally for a porosity range that is lower than the actual dust cake porosity. For these tests, dust cake porosities were not known, but, for previous conditioning tests with Monticello fly ash, dust cake porosities were inferred based on a comparison of laboratory $K_{2}$ measurements with the dust cake $K_{2}$. From the Monticello tests, the tensile strength of the dust cake with conditioning was actually lower than the baseline dust cake tensile strength. Therefore, even though tensile strength of the fly ash may increase at constant porosity with conditioning, the actual dust cake tensile strength may decrease with conditioning because of increased porosity. In addition, recent pore-bridging tests in the laboratory show that superior pore bridging is achieved with conditioning even though tensile strength of the conditioned ash is reduced under filtration conditions. An explanation is that the particle-to-particle binding forces must be greater with conditioning. 


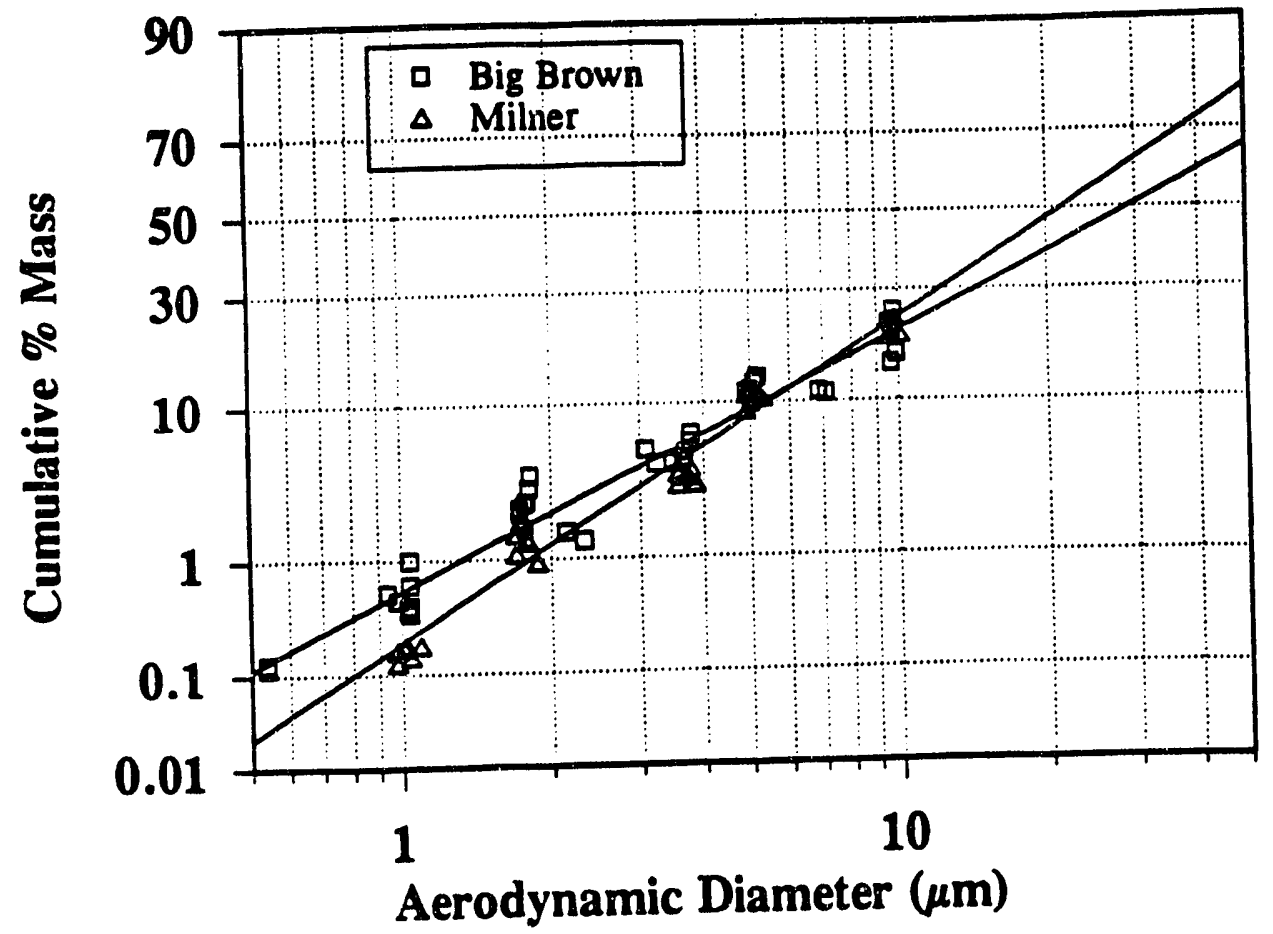

Figure 24. Particle-size distribution of Big Brown and Milner fly ash based on multicyclone results.

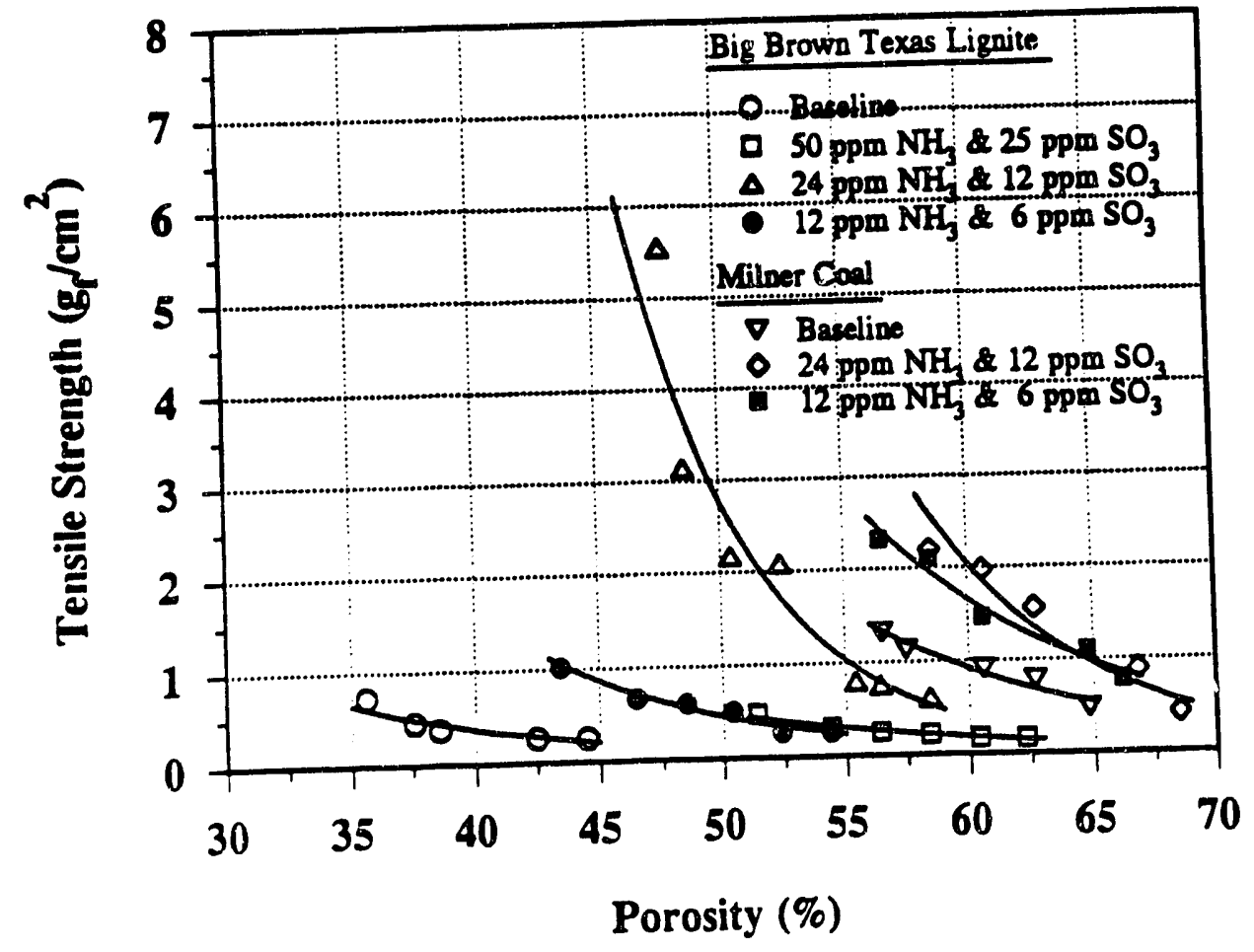

Figure 25. Tensile strength as a function of porosity for baseline and conditioned fly ash with Big Brown and Milner coals with Ryton fabric at an $\mathrm{A} / \mathrm{C}$ ratio of $4 \mathrm{ft} / \mathrm{min}$. 


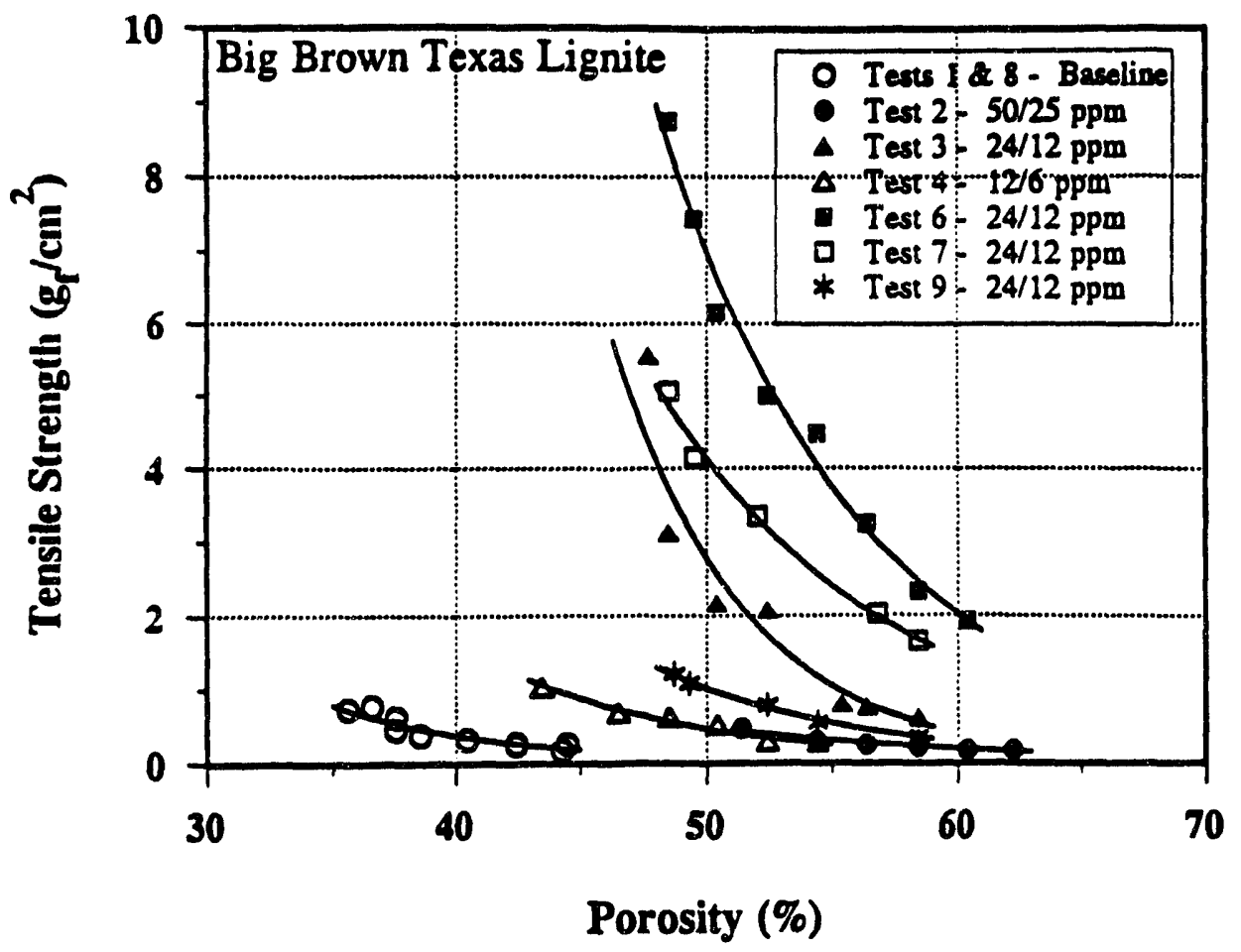

Figure 26. Tensile strength as a function of porosity for Task 2 Big Brown tests.

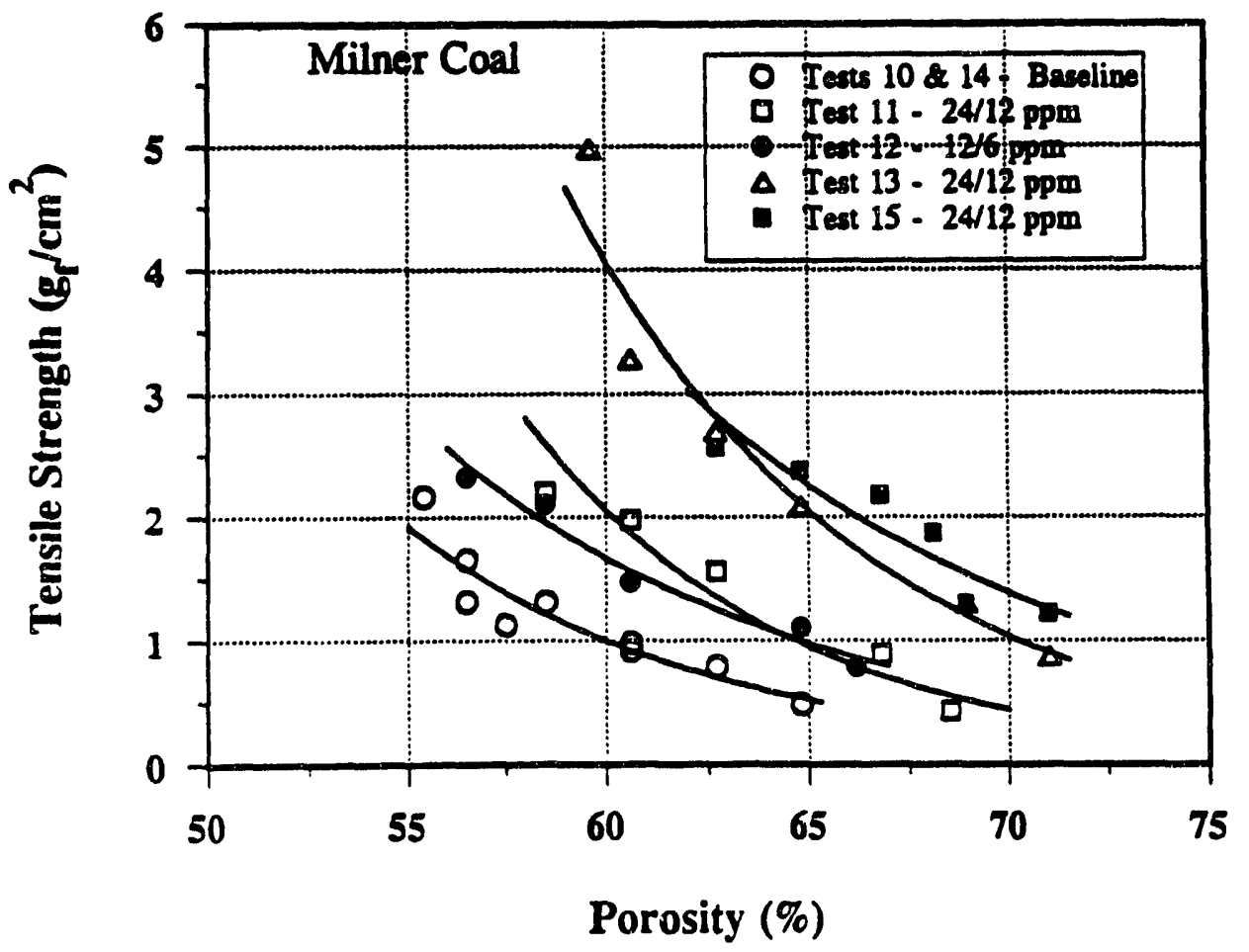

Figure 27. Tensile strength as a function of porosity for Task 2 Milner tests. 
The tensile strength curves for the Milner samples (Figure 25) shift toward higher tensile strength and somewhat toward higher porosity with conditioning. However, since the porosity was higher with conditioning, the data imply that the tensile strength of the conditioned dust cake was no greater than the baseline dust cake. From Figures 26 and 27, it is evident that there is some variability in the tensile strength data. For the Big Brown results, one would expect the four ash samples collected from tests at concentrations of $24 / 12 \mathrm{ppm}$ of $\mathrm{NH}_{3} / \mathrm{SO}_{3}$ to have similar tensile strengths. However, Figure 26 shows a wide range in the tensile strength values at the highest compaction level (e.g., at 50\% porosity). Similarly, Figure 27 shows some variability for the three Milner samples at concentrations of $24 / 12 \mathrm{ppm}$ of $\mathrm{NH}_{3} / \mathrm{SO}_{3}$. The reason for this data spread is not clear. From previous benchscale tests conducted for DOE, relative humidity is known to have an effect on tensile strength, especially for conditioned samples. To minimize this effect, samples are stored for an extended period at $10 \%$ relative humidity prior to the tensile strength measurement. However, there may be some differences in the time the samples are exposed to the ambient laboratory conditions during the measurement process, which could account for some of the variability. To obtain more quantitative data may require conducting the tensile strength tests completely within a controlled humidity chamber. Nevertheless, the tensile strength data show that conditioning produces a shift in the tensile strength vs. porosity curve toward higher porosities and sometimes toward higher tensile strength. However, extrapolating the data to the higher porosities of a dust cake implies that the dust cake tensile strength does not necessarily increase with conditioning, which alleviates concern about bag cleanability because of possible increased tensile strength.

Major elemental concentrations of the baghouse hopper samples measured by $\mathrm{x}$-ray fluorescence analysis are given in Table 7. These data indicate that concentrations of major elements were fairly constant from test to test, as would be expected. A small increase is expected in $\mathrm{SO}_{3}$ because of the amount of $\mathrm{SO}_{3}$ injected. For example, injection of $25 \mathrm{ppm}$ of $\mathrm{SO}_{3}$ with an inlet dust loading of 4.55 grains/scf should increase the fly ash $\mathrm{SO}_{3}$ content by $0.81 \% \mathrm{SO}_{3}$. Injection of $12 \mathrm{ppm}$ of $\mathrm{SO}_{3}$ should result in a $0.39 \% \mathrm{SO}_{3}$ increase. While the data in Table 7 do indicate an increase in $\mathrm{SO}_{3}$ on the order expected, there is some variability in the $\mathrm{SO}_{3}$ concentration for the baseline tests. Therefore, a quantitative determination of the amount of injected $\mathrm{SO}_{3}$ that is transferred to the fly ash is not available. Similarly, for the Milner tests, since the average dust loading was 17.55 grains/scf, $12 \mathrm{ppm}$ of $\mathrm{SO}_{3}$ should produce an increase of $0.10 \% \mathrm{SO}_{3}$ in the fly ash, which does not allow for a quantitative determination of $\mathrm{SO}_{3}$ transfer. 
Two ammonia slip measurements were conducted for each conditioning test as part of the EPA-Method 5 dust loadings. For the Big Brown tests, the indicated ammonia concentration in the flue gas ranged from 0.9 to $5.1 \mathrm{ppm}$ with a mean value of $3.0 \mathrm{ppm}$ and a standard deviation of $1.2 \mathrm{ppm}$. This indicates that most of the ammonia was transferred to the fly ash and that ammonia slip is not a problem. For the Milner tests, the measured ammonia level ranged from 0.1 to $0.7 \mathrm{ppm}$, with a mean value of $0.3 \mathrm{ppm}$ and a standard deviation of $0.2 \mathrm{ppr}$. The lower ammonia slip compared to the Big Brown may be the result of the much higher dust loading with the Milner coal which means that there is much more available surface area for the ammonia to be adsorbed on the fly ash. Ammonia in the fly ash was also measured, but the apparent amount of the injected ammonia that was transferred to the fly ash ranged from only $30 \%$ to $75 \%$. A combination of the ammonia slip and the ammonia transferred to the fly ash should account for all of the injected ammonia. However, the closure was low and the unaccounted-for ammonia ranged from $15 \%$ up to $70 \%$. The ammonia slip values appear to be reasonable, and conditioning had a significant effect on baghouse performance, which implies that the conditioning agents must bave been transferred to the fly ash. This points to the fly ash ammonia analysis as the source of poor closure. The procedure for separating the ammonia from the fly ash may have resulted in some off-gassing of ammonia, or possibly the ammonia was not entirely extracted, either of which could account for lower ammonia concentrations than expected. The extraction procedure was further evaluated for the Task 3 tests in an attempt to improve the closure for the ammonia balance.

\subsection{Task 3 Results (100-hour and 16-ft/min tests)}

A summary of the test variables and results from the Task 3 tests are shown in Tables 8 and 9.

\subsubsection{0-hour Tests with Big Brown Coal}

Three 100-hour tests were completed with Big Brown coal in Task 3. These included a baseline test (Run 403) at an A/C ratio of $4 \mathrm{ft} / \mathrm{min}$ and conditioning tests at $\mathrm{A} / \mathrm{C}$ ratios of 4 (Run 404) and $6 \mathrm{ft} / \mathrm{min}$ (Run 405). All three of these tests employed Ryton fabric, and concentrations for the conditioning tests were $24 / 12 \mathrm{pym}$ of $\mathrm{NH}_{3} / \mathrm{SO}_{3}$, as shown in the test matrix presented in Table 2.

Plots of $\Delta \mathrm{P}$ as a function of time for the three 100-hour Big Brown runs are shown in Figure 28. The bags were pulsed once per hour in each of these tests. Whenever bag 


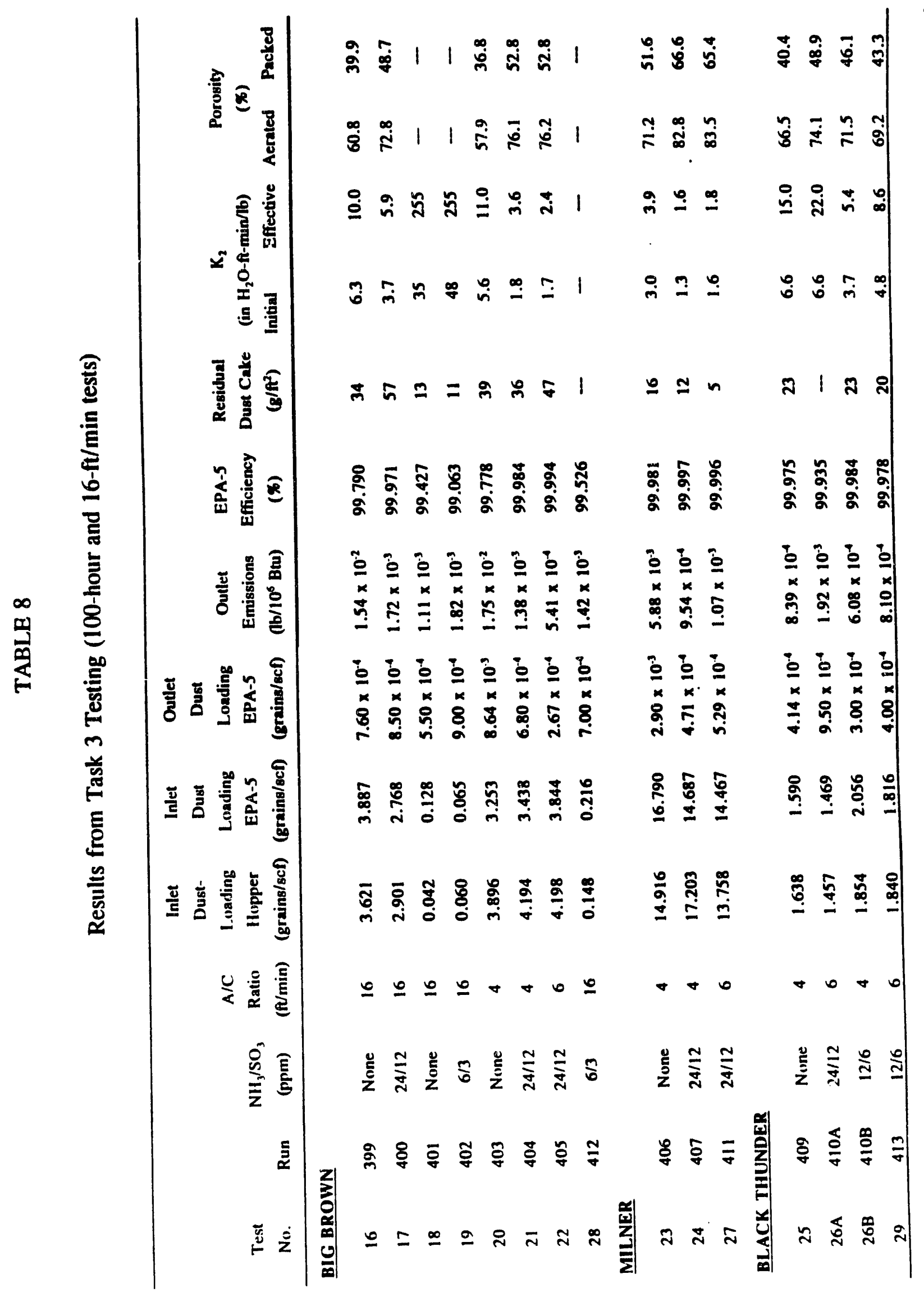




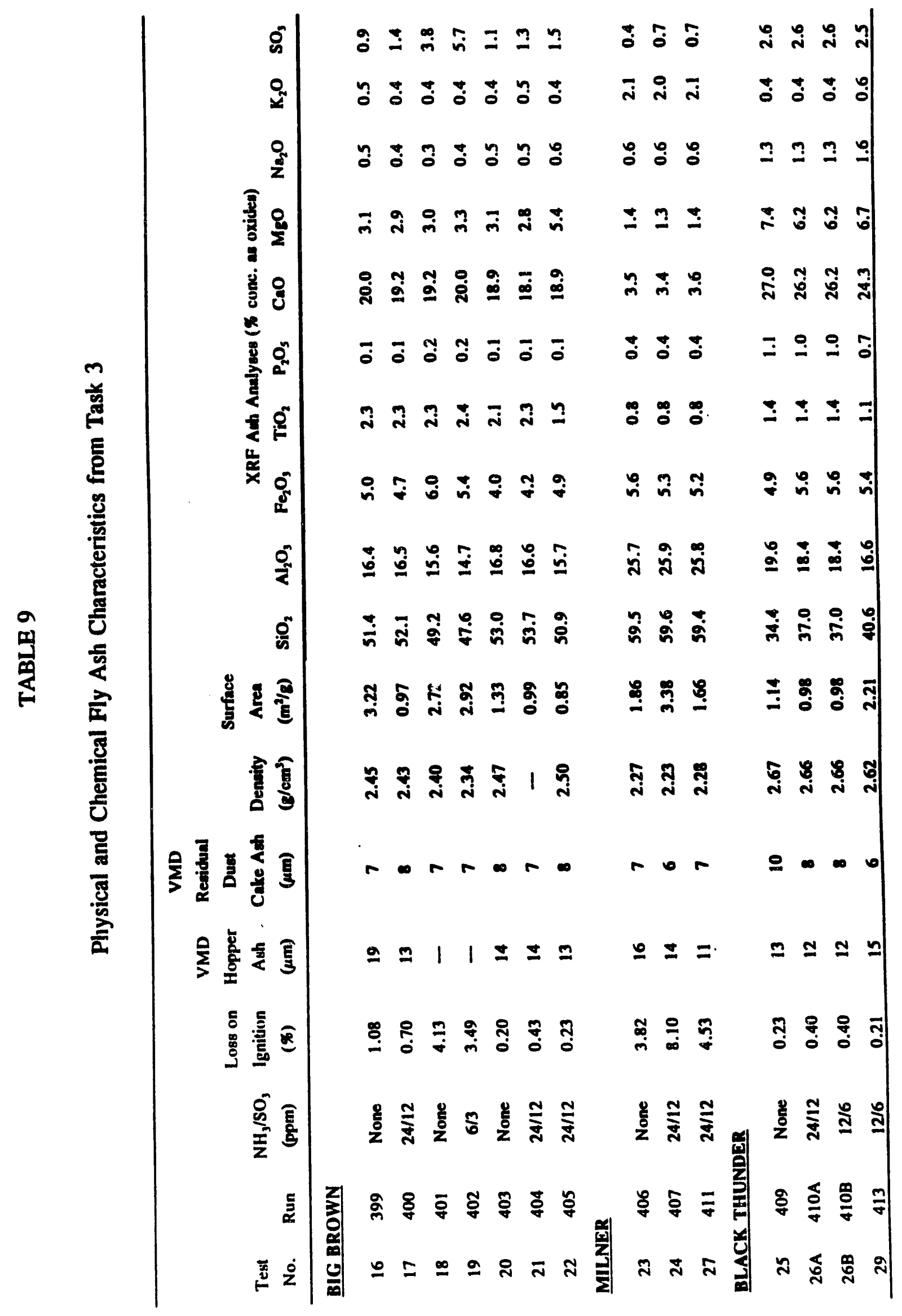




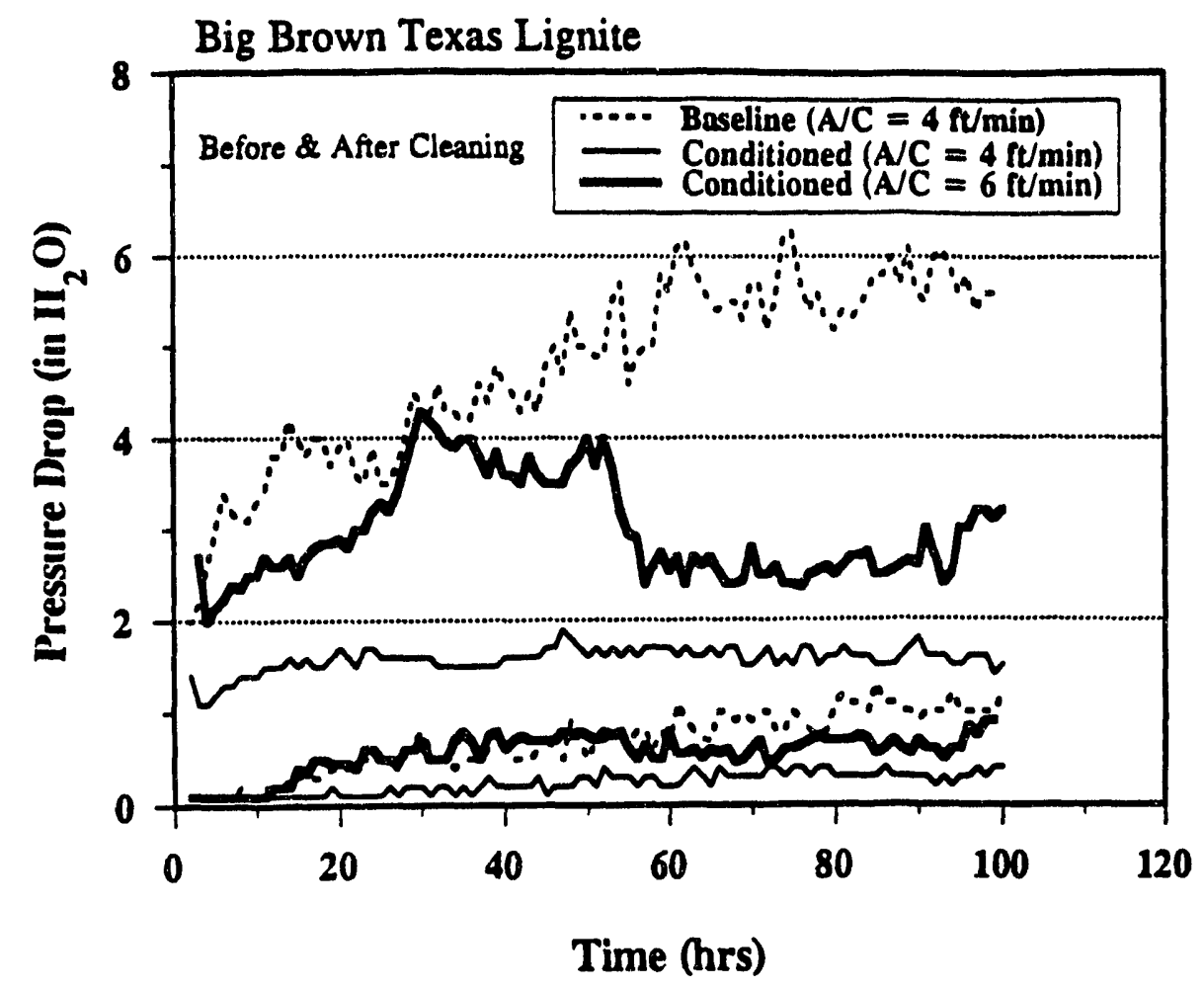

Figure 28. Effect of conditioning on baghouse pressure drop for 100-hour Big Brown tests for Runs 403, 404, and 405. Bags were pulsed once per hour.

cleaning occurred, all of the bags were cleaned in rapid succession (within 6 seconds). Therefore, the $\Delta \mathrm{P}$ before bag cleaning is the tube sheet pressure drop after a 1-hour period of dust cake buildup on all of the bags. The $\Delta \mathrm{P}$ after bag cleaning is the tube sheet pressure drop immediately after cleaning all of the bags and is due to the residual dust on the bags. For the baseline test at an $\mathrm{A} / \mathrm{C}$ ratio of $4 \mathrm{ft} / \mathrm{min}$, the before-cleaning $\Delta \mathrm{P}$ climbed steadily from 2 inches WC at the start of the test to 5.5 inches WC by the end of the test. The aftercleaning $\triangle \mathrm{P}$ also climbed steadily from near zero at the start to about 1 inch WC by the end of the test. For the conditioned test at an $A / C$ ratio of $4 \mathrm{ft} / \mathrm{min}$, the before-cleaning $\Delta P$ reached only 1.7 inches WC, and the after-cleaning $\Delta P$ was only 0.3 inches WC. Twenty hours into the test, the $\triangle \mathrm{P}$ was very steady, which is an encouraging result because it indicates the residual dust cake was not building up excessively as a result of the conditioning. The initial and effective $\mathrm{K}_{2}$ values for these tests, shown in Table 8, are a factor of three lower for the conditioning tests compared to the baseline test. This is also shown in the pressure drop data, which indicate the $\Delta P$ for the baseline test was about three times higher than the $\Delta \mathrm{P}$ for the conditioning test when the $\mathrm{A} / \mathrm{C}$ ratio for both tests was $4 \mathrm{ft} / \mathrm{min}$. 
For the conditioned test at an A/C ratio of $6 \mathrm{ft} / \mathrm{min}$ (Run 405), the before-cleaning $\Delta P$ increased for the first 30 hours and then remained steady. However, 50 hours into the test, the $\Delta \mathbf{P}$ decreased and then was fairly constant again for the remainder of the test. There is no apparent reason for the decrease in $\Delta \mathrm{P}$ at $\mathbf{5 0}$ hours, but it could bave been caused by a small shift in the fly ash particle-size distribution and/or a decrease in the dust loading. Since $K_{2}$ is inversely proportional to the square of the particle diameter (see Equation 2), a small change in diameter (for example, from 14 to $12 \mu \mathrm{m}$ ) could increase $\mathrm{K}_{2}$ by $35 \%$. With a constant bag-cleaning interval and a constant $K_{2}$, the $\Delta P$ at an $A V$ ratio of $6 \mathrm{ft} / \mathrm{min}$ should be 2.25 times greater than the $\Delta P$ at an $A / C$ ratio of $4 \mathrm{ft} / \mathrm{min}$. Since the actual $\Delta P$ at $6 \mathrm{ft} / \mathrm{min}$ was only about 1.5 times greater than the $\Delta P$ at $4 \mathrm{ft} / \mathrm{min}$, the effective $\mathrm{K}_{2}$ values must have been different. The actual measured effective $K_{2}$ value for. Run 404 was 3.6, while the effective $K_{2}$ for Run 405 was 2.4 inches of water-ft-min/lb. Whether this difference was the result of a small change in particle size is not known. Nevertheless, for both conditioned runs, initial and effective $K_{2}$ values were much less than the $K_{2}$ values for the baseline run, which demonstrates the benefit of using conditioning at both AVC ratios.

Particulate emissions for these 100-hour tests with Big Brown coal are shown in Table 8 and in Figures 29 through 35. The effect of conditioning is best shown in Figure 29, which gives the integrated average respirable mass emissions as a function of run tine. These values represent the average respirable mass emissions obtained from sampling during an entire 1-hour filtration cycle. The actual range in respirable mass emissions that occurred for each filtration cycle is shown in Figures 30 through 32. From Figure 29, there is little difference in emissions between the baseline and conditioned tests during the first 8 hours of the test, which is consistent with results from the 8-hour tests conducted in Task 2 with the Ryton fabric. However, by 80 hours into the tests, Figure 29 shows that respirable mass particulate emissions are two to three orders of magnitude lower with conditioning. The EPA Method 5 data (see Table 8) also show emissions to be much lower with conditioning, although the difference is only one to two orders of magnitude. The lowest dust loading measurements were 0.0001 grain/scf, which is the limit of sensitivity that can be achieved with EPA Method 5, unless very long sampling times are employed.

Both the respirable mass and EPA Method 5 data indicate that particulate emissions were lower for the conditioned test at an $\mathrm{A} / \mathrm{C}$ ratio of $6 \mathrm{ft} / \mathrm{min}$ than for the conditioned test at an $\mathrm{A} / \mathrm{C}$ ratio of $4 \mathrm{ft} / \mathrm{min}$. This might appear contrary to expectations, because, typically, emissions increase with an increase in $\mathrm{A} / \mathrm{C}$ ratio. The difference, however, can be explained if one considers that both tests were conducted with a constant cleaning interval rather than at constant pressure drop. At the higher $\mathrm{A} / \mathrm{C}$ ratio, the pores are more rapidly bridged after 


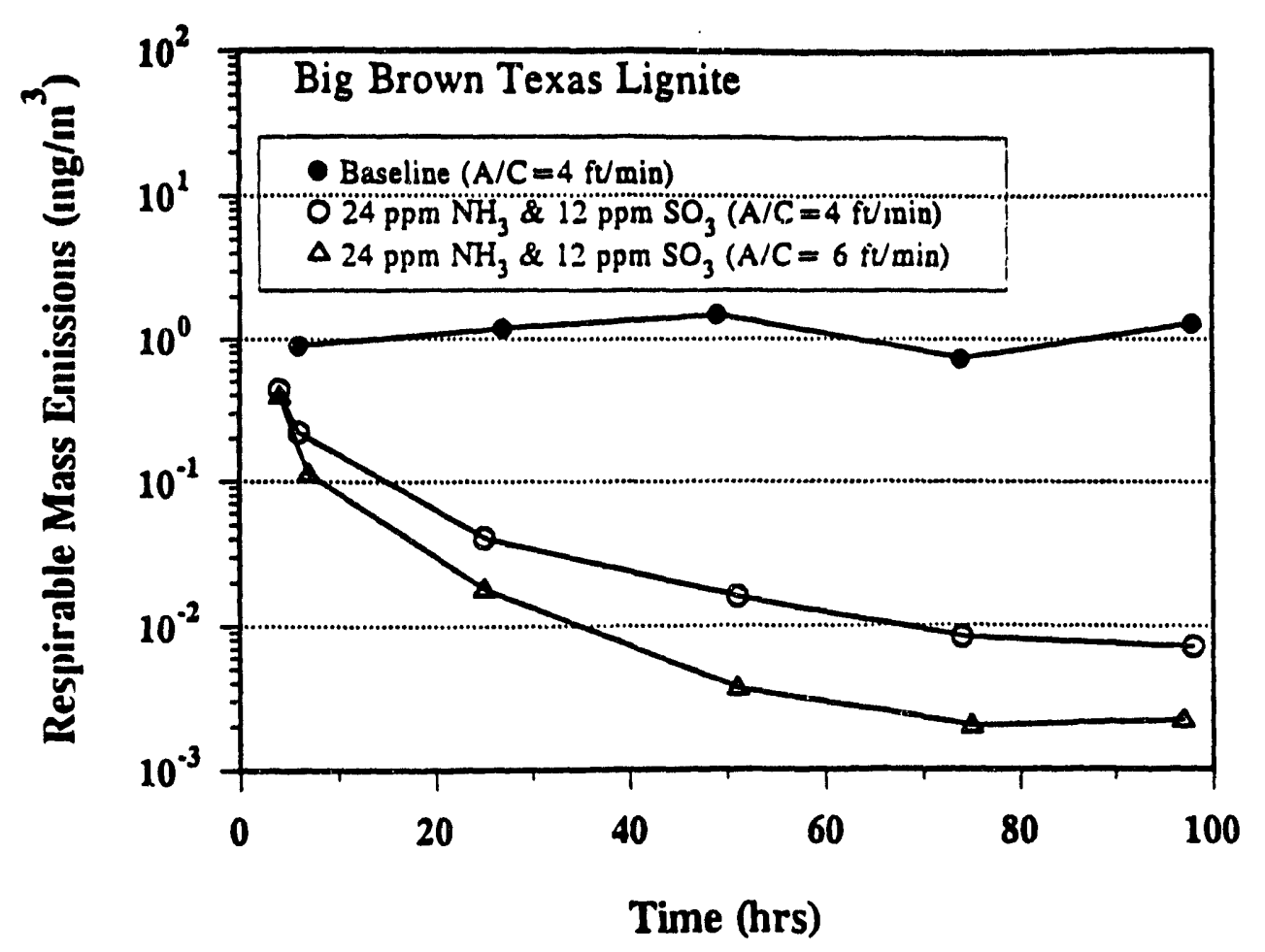

Figure 29. Effect of conditioning on average respirable mass emissions for 100-hour Big Brown tests for Runs 403, 404, and 405.

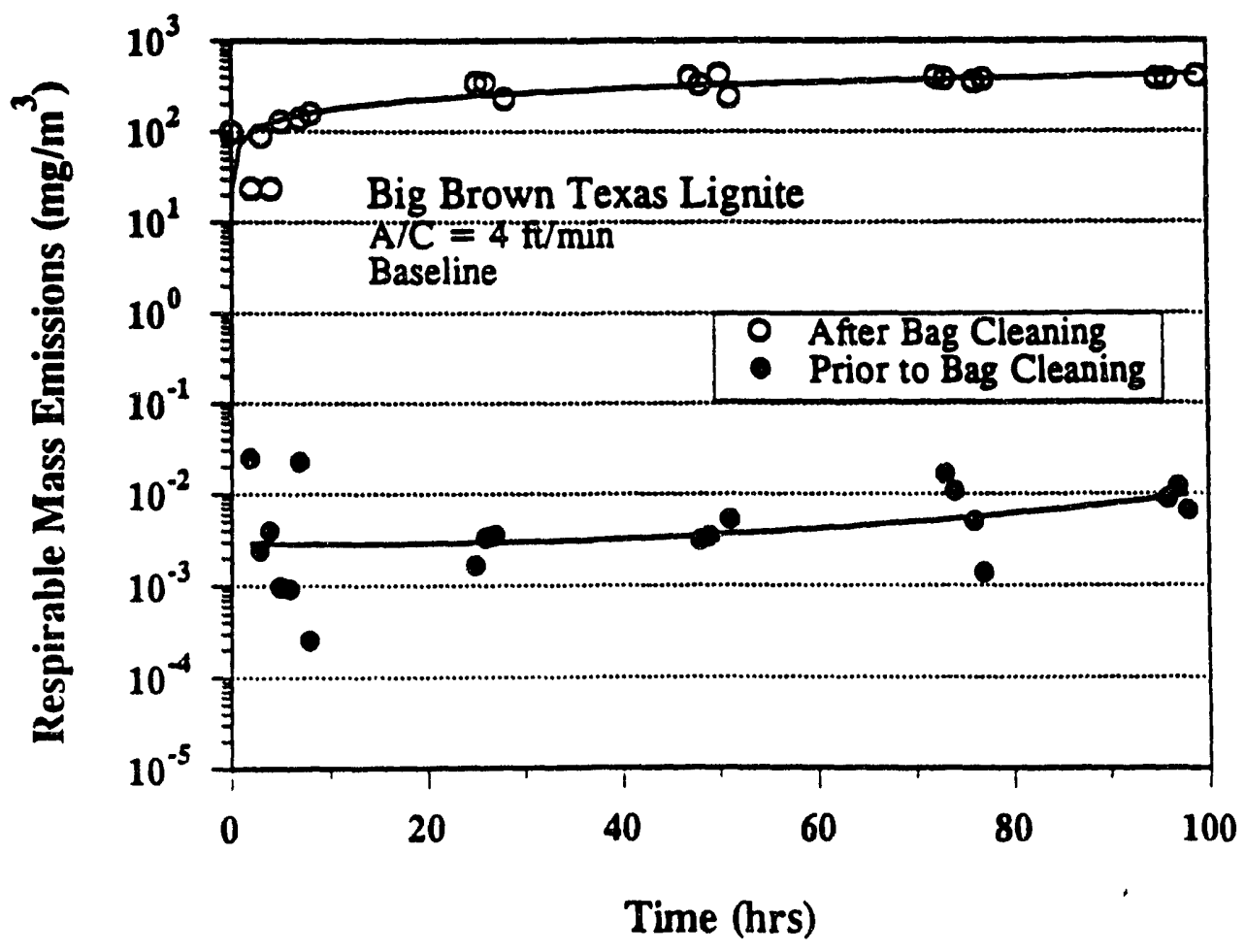

Figure 30. Respirable mass emissions before and after bag cleaning for the 100-hour baseline Run 403 with Big Brown coal. 


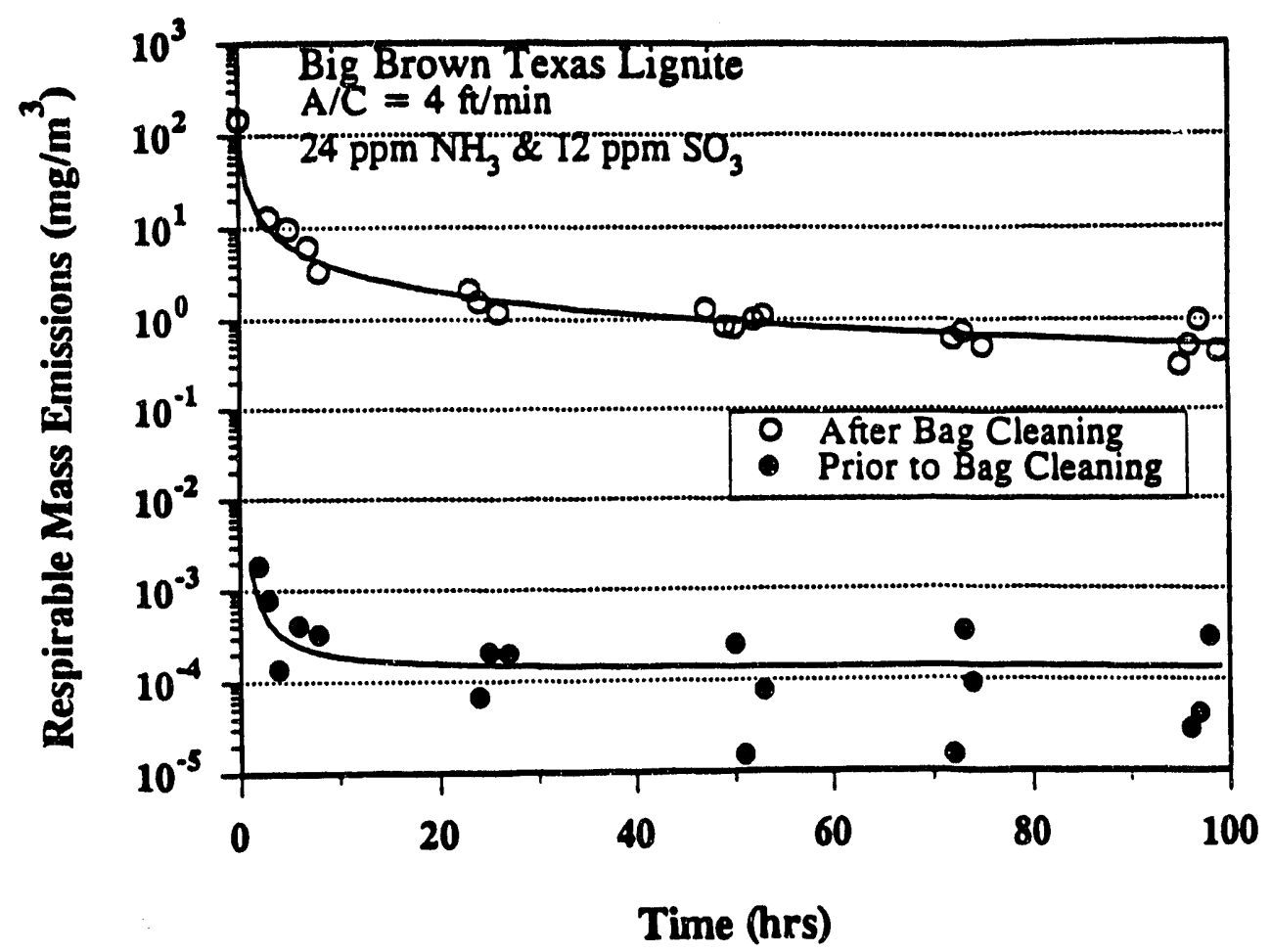

Figure 31. Respirable mass emissions before and after bag cleaning for the 100-hour conditioning Run 404 with Big Brown coal.

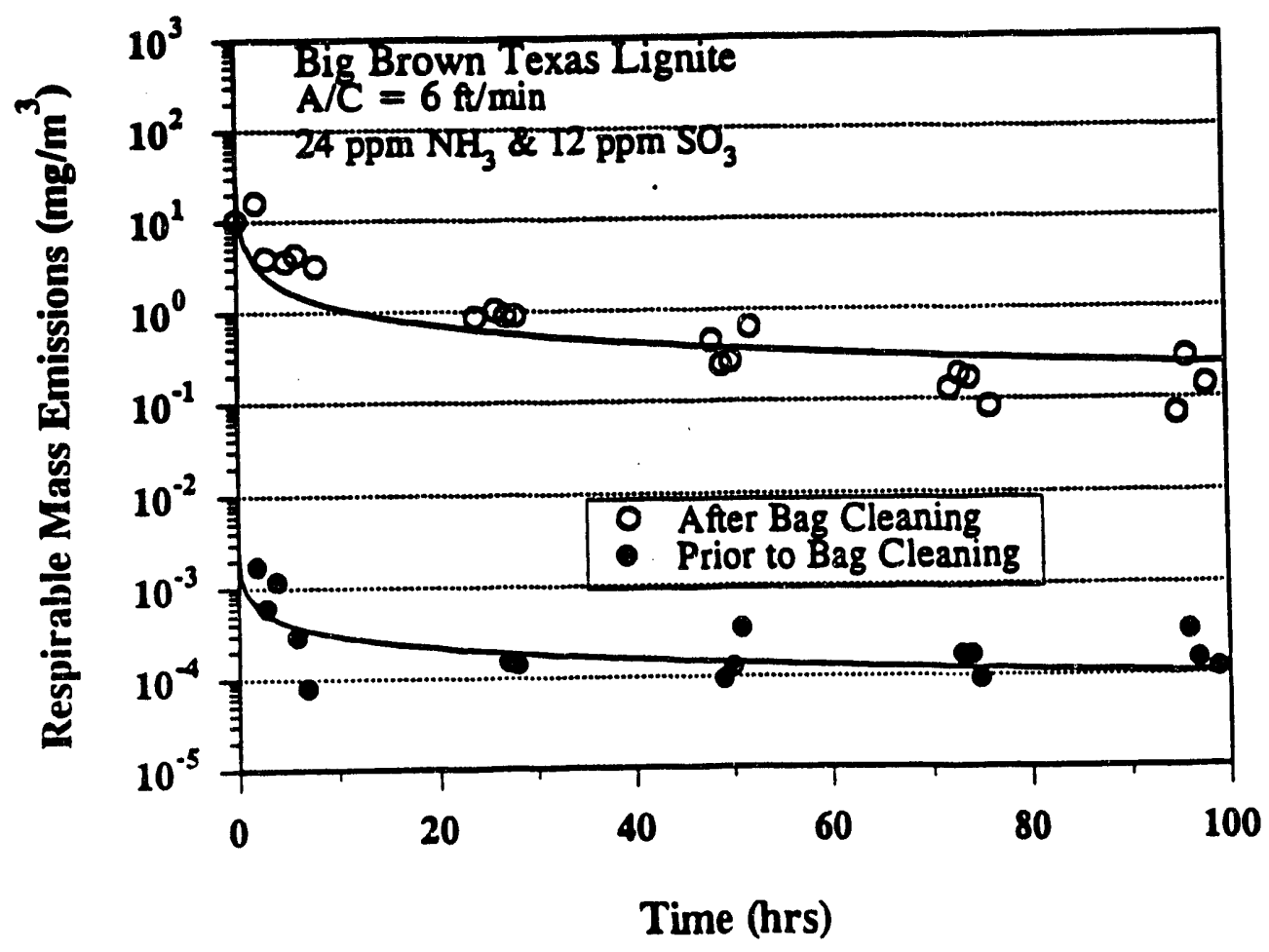

Figure 32. Respirable mass emissions before and after bag cleaning for the 100-hour conditioning Run 405 with Big Brown coal. 


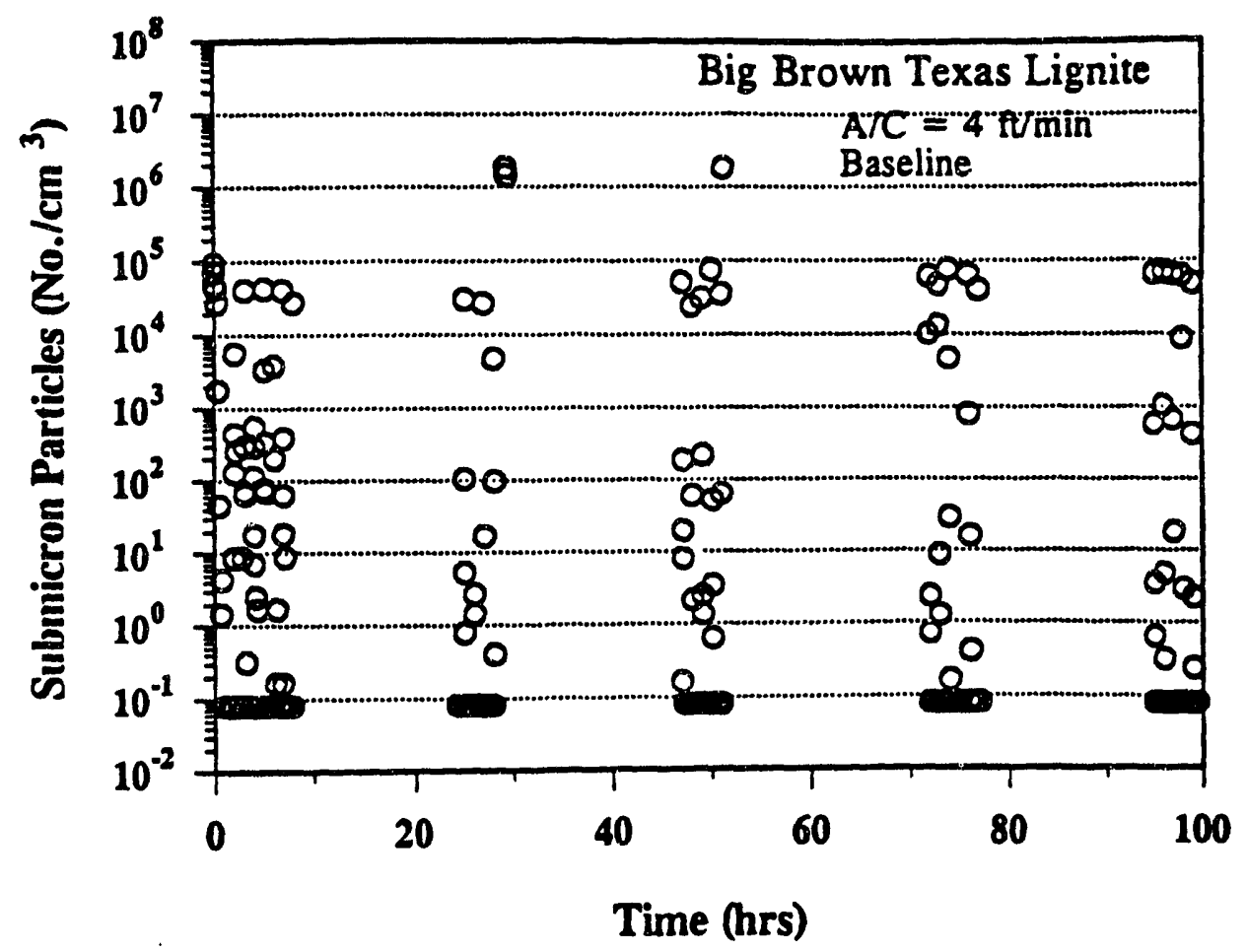

Figure 33. Range of submicron particle emissions for the 100-hour baseline Run 403 with Big Brown coal.

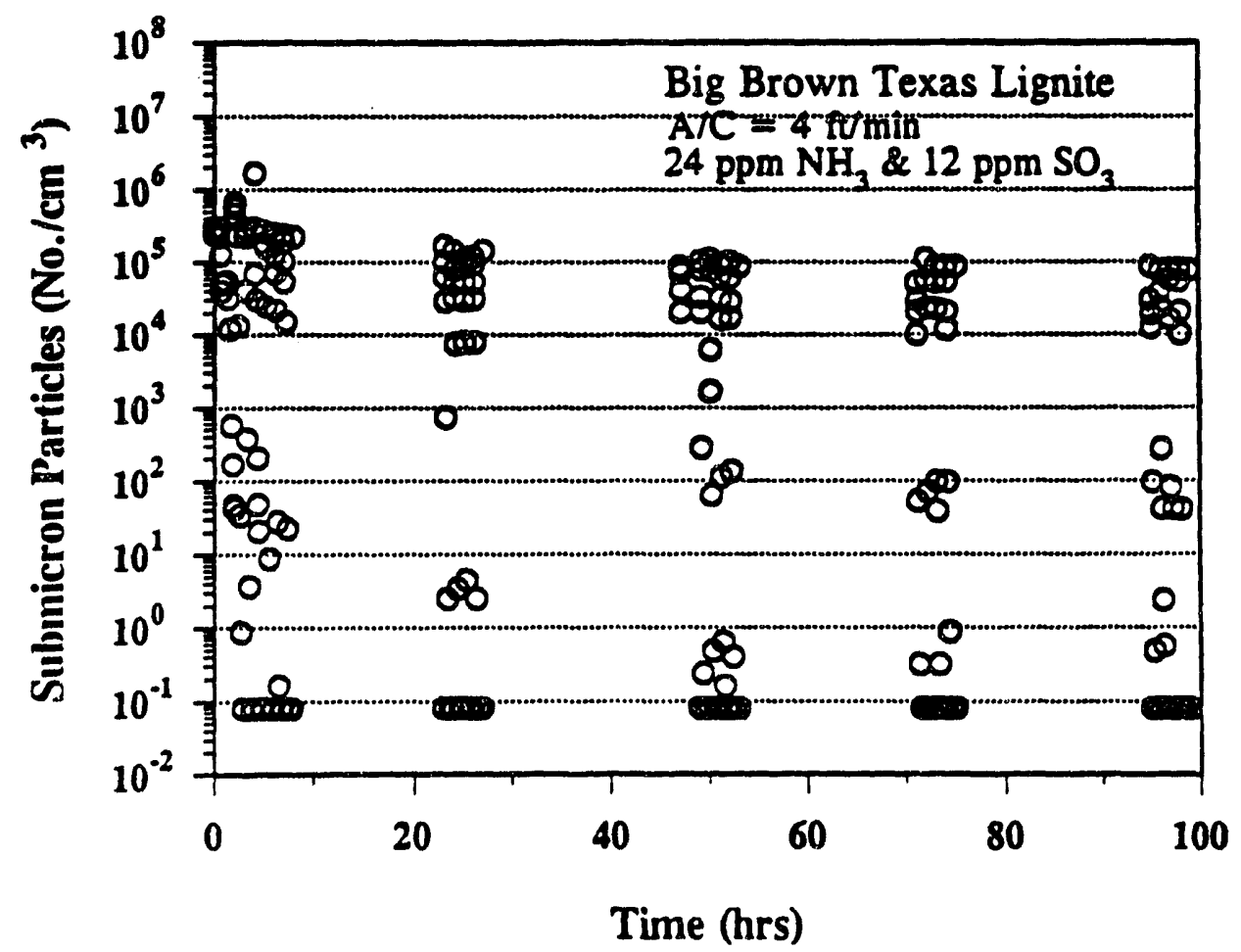

Figure 34. Range of submicron particle emissions for the 100-hour conditioning Run 404 with Big Brown coal. 


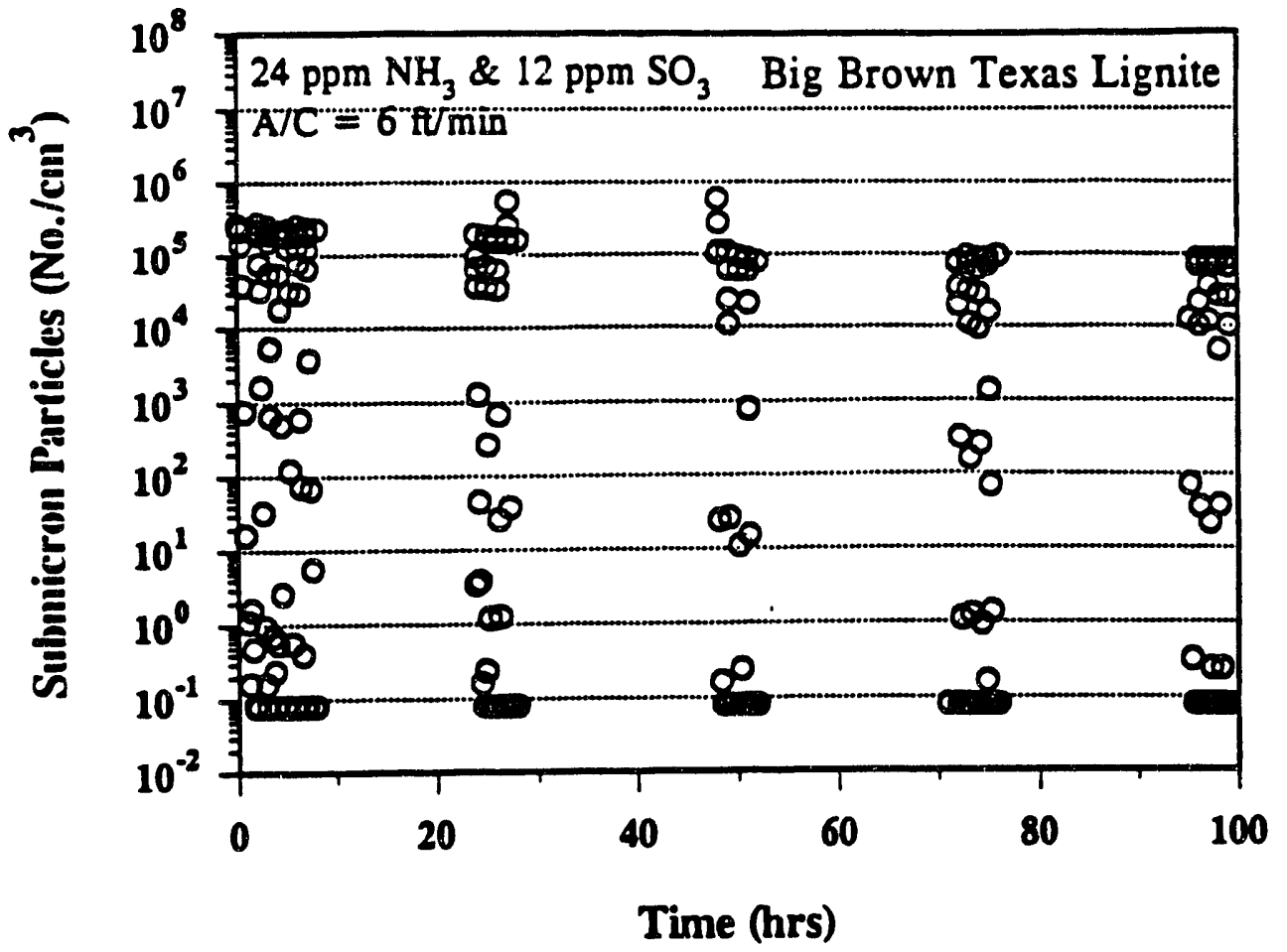

Figure 35. Range of subrnicron particle emissions for the 100-hour conditioning Run 405 with Big Brown coal.

bag cleaning, which means there is a smaller percentage of time between cleanings with open pores (when most of the emissions occur). Therefore, the net result was lower emissions for the higher $A / C$ ratio. However, if the bags were cleaned on a $\triangle P$ basis rather than on a time basis, emissions would likely have been about the same at both AVC ratios.

The range in submicron particle count, measured with the CNC, is shown in Figures 33 through 35 . The CNC actually read zero counts $/ \mathrm{cm}^{3}$ for many of the lower readings, but these are reported as 0.08 particles $/ \mathrm{cm}^{3}$, because the sensitivity limit of the CNC is 0.01 particle $/ \mathrm{cm}^{3}$. Since the sample delivered to the CNC is diluted 8:1 with particle-free air, all CNC readings were multiplied by a factor of 8 to obtain the actua' particle concentration in the flue gas. The submicron emissions ranged from about 0.08 to $10^{6}$ particles $/ \mathrm{cm}^{3}$ for both the baseline and conditioning tests. Since the CNC detects particles over the entire range from 0.01 to $1.0 \mu \mathrm{m}$, low CNC readings provide strong evidence that all submicron particle emissions are very low. At the lowest reading of 0.08 particles $/ \mathrm{cm}^{3}$, complete pore bridging has occurred, and the submicron collection efficiency is greater than $99.9999 \%$. The 
emissions that occur when there is complete pore bridging are probably due to gradual seepage of dust through the fabric and subsequent reentrainment of dust from the clean side of the fabric. When dust is reentrained, submicron particles will generally not be reentrained as individual particles. Data show that, prior to bag cleaning, submicron emissions were near zero for both the baseline and conditioned tests, but the respirable mass emissions (from 1 to $10 \mu \mathrm{m}$ ) were clearly higher for the baseline test. This indicates that significant reentrainment occurred for the baseline test, but not for the conditioning tests.

The pressure drop and particulate emissions data demonstrate the benefit of conditioning with Big Brown coal. Pressure drop and the corresponding $\mathrm{K}_{2}$ values were reduced by a factor of about three, and particulate emissions were reduced by two orders of magnitude. The EPA Method 5 measurements indicate that particulate emissions for the baseline test were $0.018 \mathrm{lb} / 10^{6} \mathrm{Btu}$, which does not provide much of a safety margin from the regulatory emission limit of $0.03 \mathrm{lb} / 10^{6} \mathrm{Btu}$. In addition, for the baseline case, there is little confidence that the A/C ratio could be increased beyond $4 \mathrm{ft} / \mathrm{min}$, without exceeding the regulatory limit. However, with conditioning, particulate emissions were substantially reduced for both $A / C$ ratios tested $\left(0.0005\right.$ to $\left.0.0014 \mathrm{lb} / 10^{6} \mathrm{Btu}\right)$, and the $\Delta \mathrm{P}$ was lower with conditioning at an $A / C$ ratio of $6 \mathrm{ft} / \mathrm{min}$ than the $\Delta P$ for the baseline test at an AVC ratio of $4 \mathrm{ft} / \mathrm{min}$. The explanation for reduced particulate emissions and pressure drop, which are discussed later in this report, involves changes in dust characteristics as a result of conditioning.

\subsubsection{0-hour Tests with Milner Coal}

Three 100-hour tests were completed with Milner coal in Task 3: a baseline test (Run 406) at an A/C ratio of $4 \mathrm{ft} / \mathrm{min}$ and conditioning tests at A/C ratios of 4 (Run 407) and $6 \mathrm{ft} / \mathrm{min}$ (Run 411). All three of these tests employed P84/Ryton fabric, and concentrations for the conditioning tests were $24 / 12 \mathrm{ppm}$ of $\mathrm{NH}_{3} / \mathrm{SO}_{3}$, as shown in the test matrix (Table 2).

Plots of $\angle F$ as a function of time for the three 100-hour Milner runs are shown in Figure 36. The bags were pulsed once every 30 minutes in each of these tests. Because of the very high ash content, the combustor had to be periodically shut down for ash cleanout, which resulted in about 70 hours of actual filtration time for Runs 406 and 407 . For Run 411 , almost 90 bours of filtration time were achieved by employing a different combustor bottom, which allowed for ash removal from the combustor without shutting down. The $\triangle \mathrm{P}$ data shown in Figure 36 are presented as continuous plots, ignoring the offline periods. Comparing the $\Delta P$ plots between the baseline and conditioned tests at an $A / C$ 


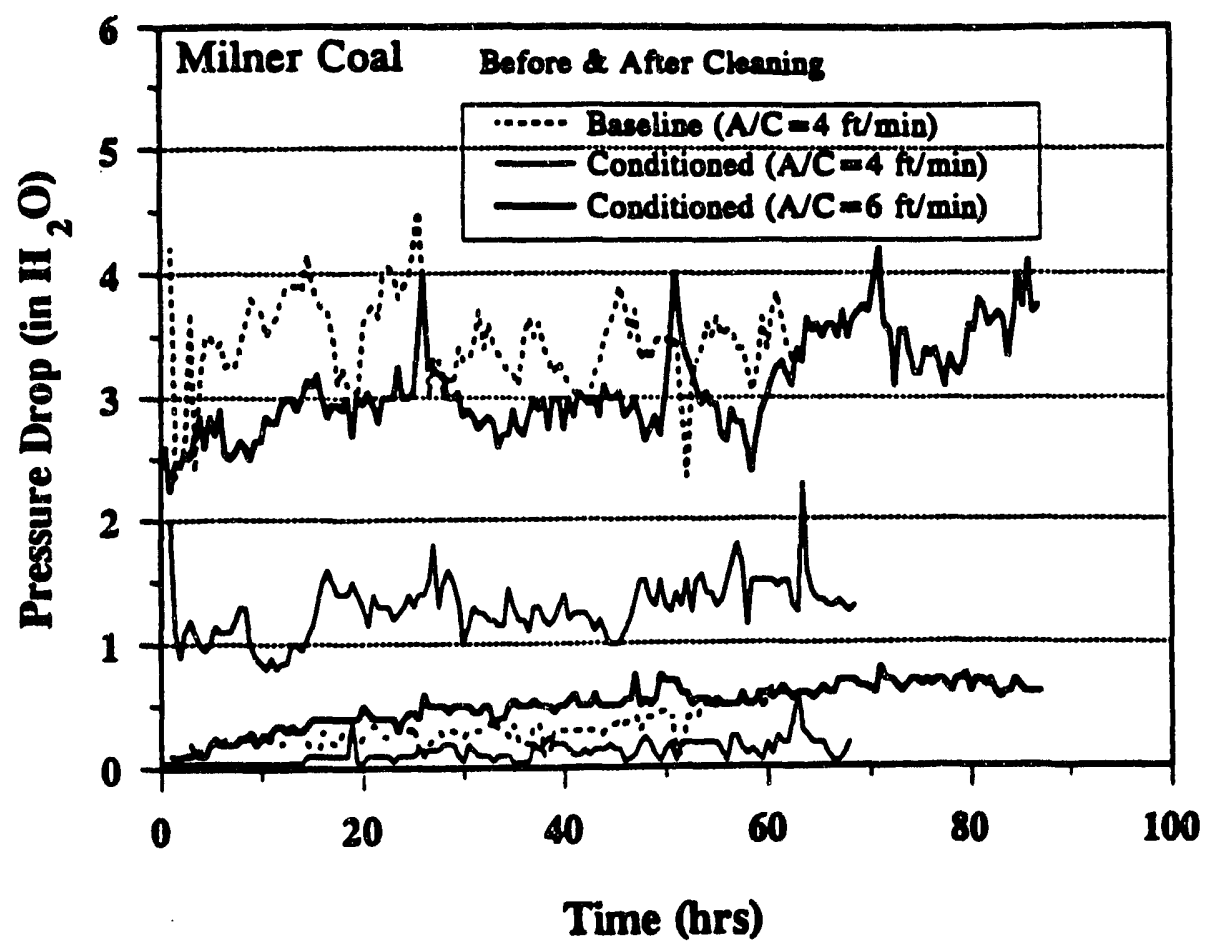

Figure 36. Effect of conditioning on baghouse pressure drop for 100-hour Milner tests for Runs 406, 407, and 411. Bags were pulsed every 30 minutes.

ratio of $4 \mathrm{ft} / \mathrm{min}$, the baseline $\Delta \mathrm{P}$ is about 2.5 times greater than the $\Delta \mathrm{P}$ for the conditioned test. Initial and effective $K_{2}$ values (from Table 8) are 2.3 and 2.4 times higher, respectively, for the baseline test. For the conditioned test at $6 \mathrm{ft} / \mathrm{min}$ (Run 411), the effective $K_{2}$ value was about 2.2 times lower than the effective $K_{2}$ value for the baseline test. A combination of an increase in A/C ratio from 4 to $6 \mathrm{ft} / \mathrm{min}$ and a decrease in $\mathrm{K}_{2}$ by a factor of 2.25 should result in identical $\triangle P$ plots for a constant dust loading and cleaning cycle. Figure 36 reveals that the $\Delta P$ with conditioning at $6 \mathrm{ft} / \mathrm{min}$ was slightly less than the baseline $\Delta P$ at $4 \mathrm{ft} / \mathrm{min}$. However, a somewhat lower dust loading for the conditioned test at $6 \mathrm{ft} / \mathrm{min}$ (see Table 8) accounts for the slightly lower $\Delta P$. All of the $\Delta P$ plots indicate a gradual trend of increasing $\triangle \mathrm{P}$ with time, which indicates that the tests were not long enough to establish steady-state operation.

Particulate emissions for the 100-hour tests with Milner coal are shown in Table 8 and in Figures 37 through 40 . Figure 37, which gives the integrated average respirable mass emissions as a function of run time, shows that, by the end of the tests, particulate emissions were almost two orders of magnitude lower with conditioning. The EPA Method 5 dustloading data also indicate that particulate emissions were significantly lower with conditioning. For the baseline case, emissions were already low at $0.0059 \mathrm{lb} / 10^{6} \mathrm{Btu}$, a 


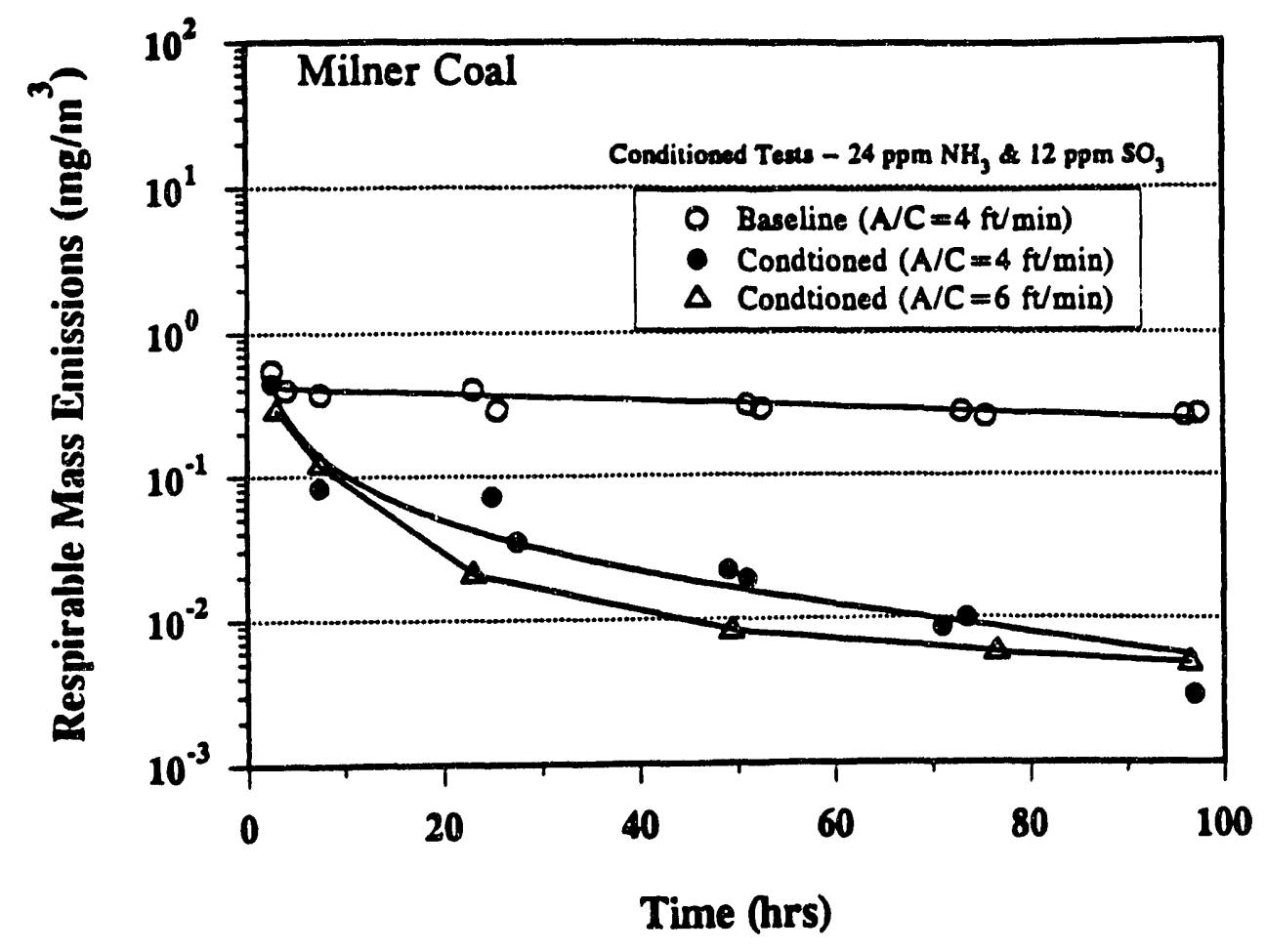

Figure 37. Effect of conditioning on average respirable mass emissions for 100-hour Milner tests for Runs 406, 407, and 411.

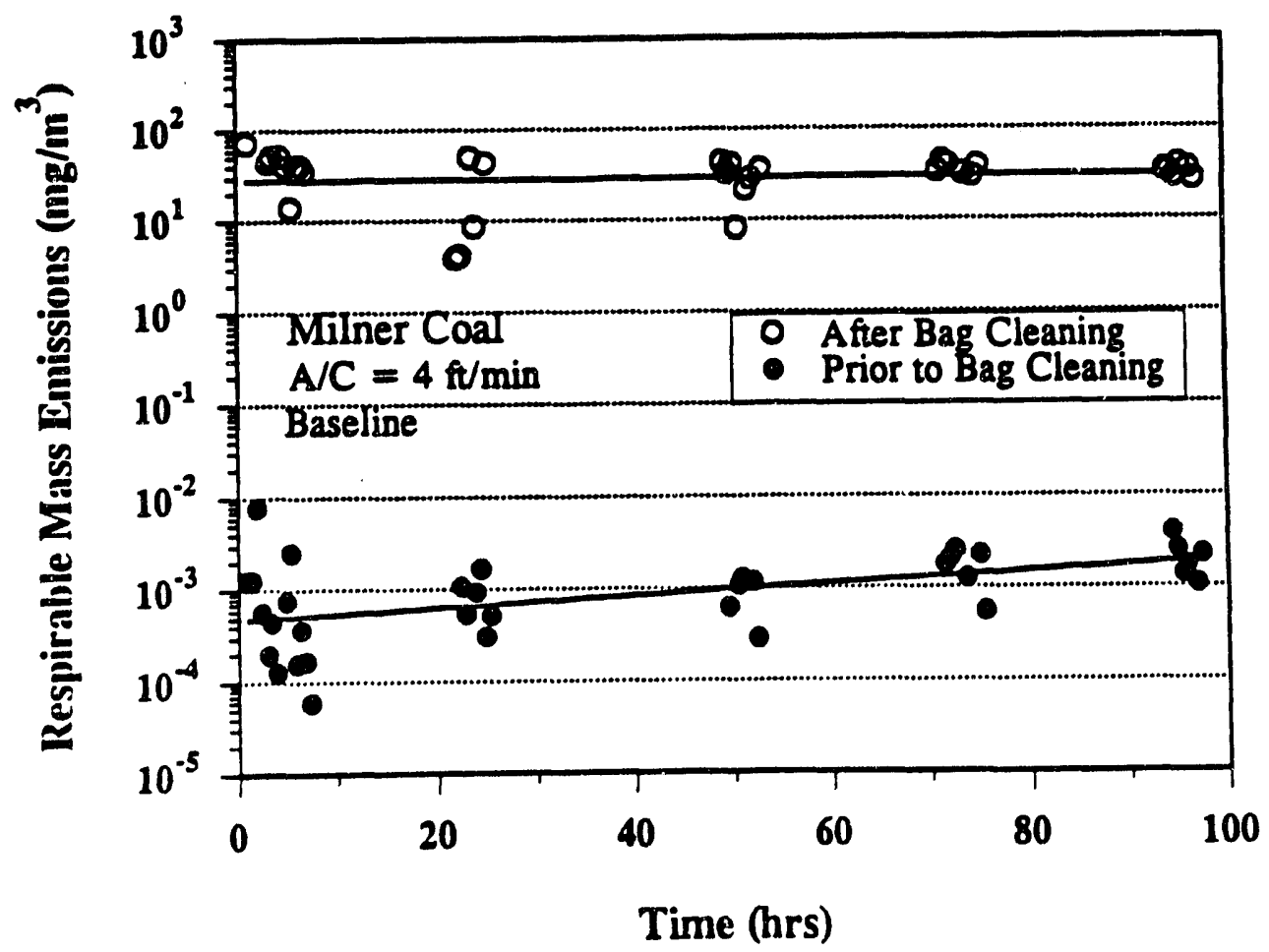

Figure 38. Respirable mass emissions before and after bag cleaning for the 100-hour baseline Run 406 with Milner coal. 


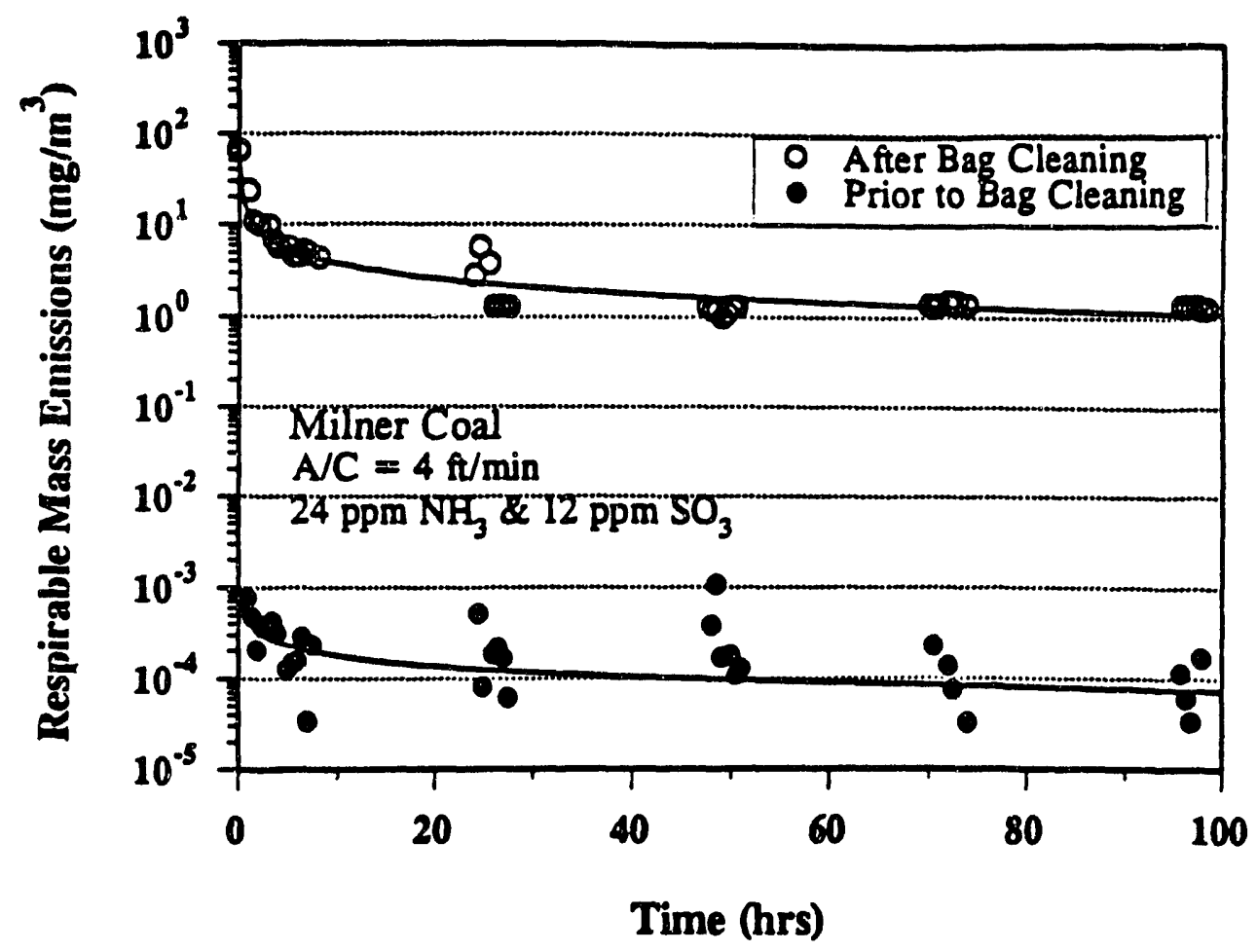

Figure 39. Respirable mass emissions before and after bag cleaning for the 100-hour conditioning Run 407 with Milner coal.

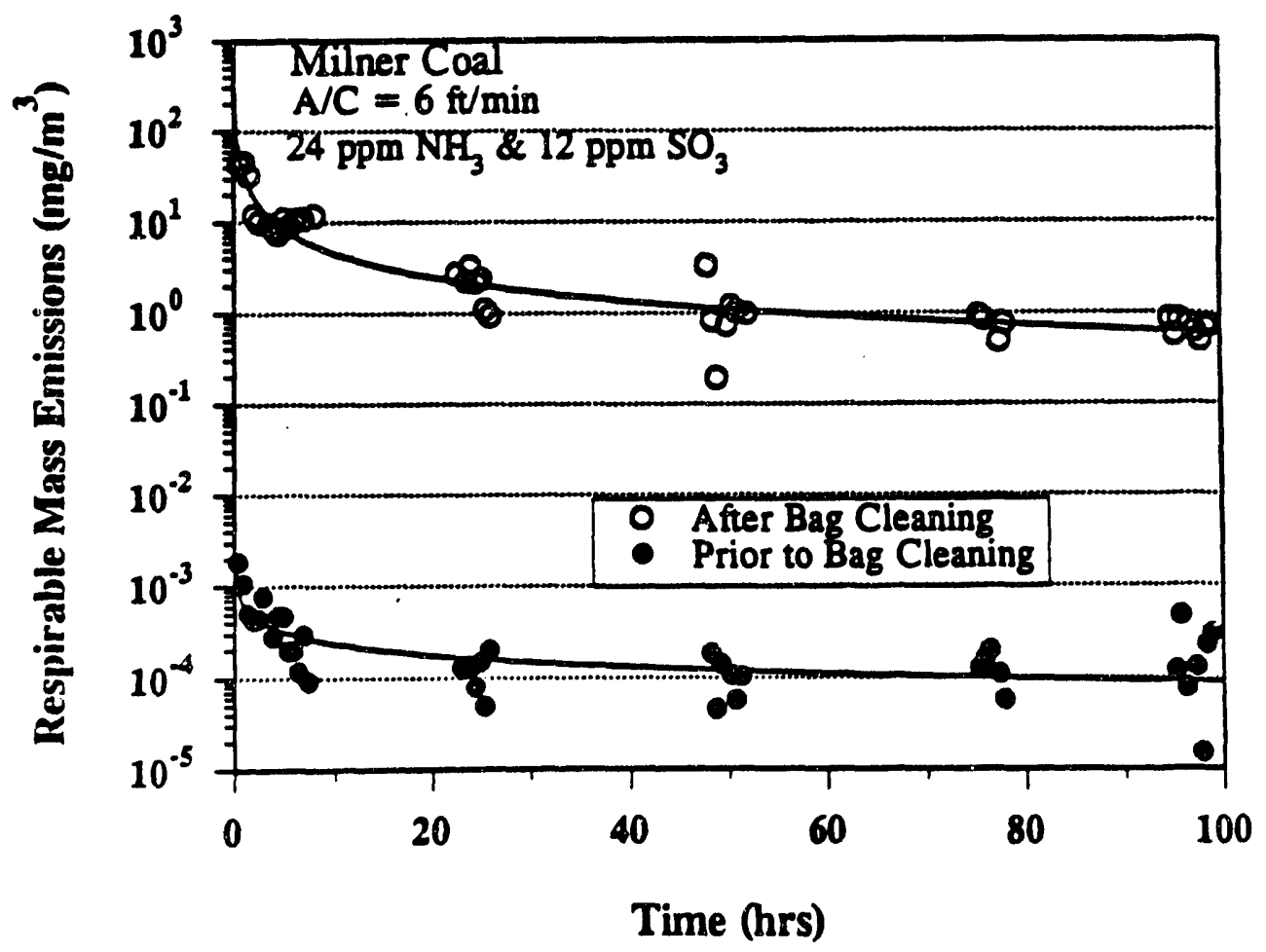

Figure 40. Respirable mass emissions before and after bag cleaning for the 100-hour conditioning Run 411 with Milner coal. 
factor of five times better than the regulatory limit of $0.03 \mathrm{lb} / 10^{6} \mathrm{Btu}$. The range in respirable mass measurements prior to bag cleaning to just after bag cleaning for these three runs is shown in Figures 38 through 40 . The submicron emissions data, shown in Figures 41 through 43 , indicate that the peak submicron emissions were higher with conditioning. This is not surprising, considering that the peak submicron emissions were only about 1000 particles $/ \mathrm{cm}^{3}$ for the baseline test. In cases where the baseline submicron particle count is low, the effect of conditioning will generally be to increase the submicron particle concentration because of the formation of some fine ammonium sulfate particles. If the bags are cleaned very well and there is only a light residual dust cake, the submicron emissions spike that occurs after bag cleaning may be higher with conditioning. However, conditioning generally facilitates rapid pore bridging, so this submicron emissions spike is short-lived, and the total submicron emissions are not a concern.

The pressure drop and particulate emissions data show that conditioning works well with Milner coal. $K_{2}$ values were reduced by a factor of 2 to 2.4 , and particulate emissions

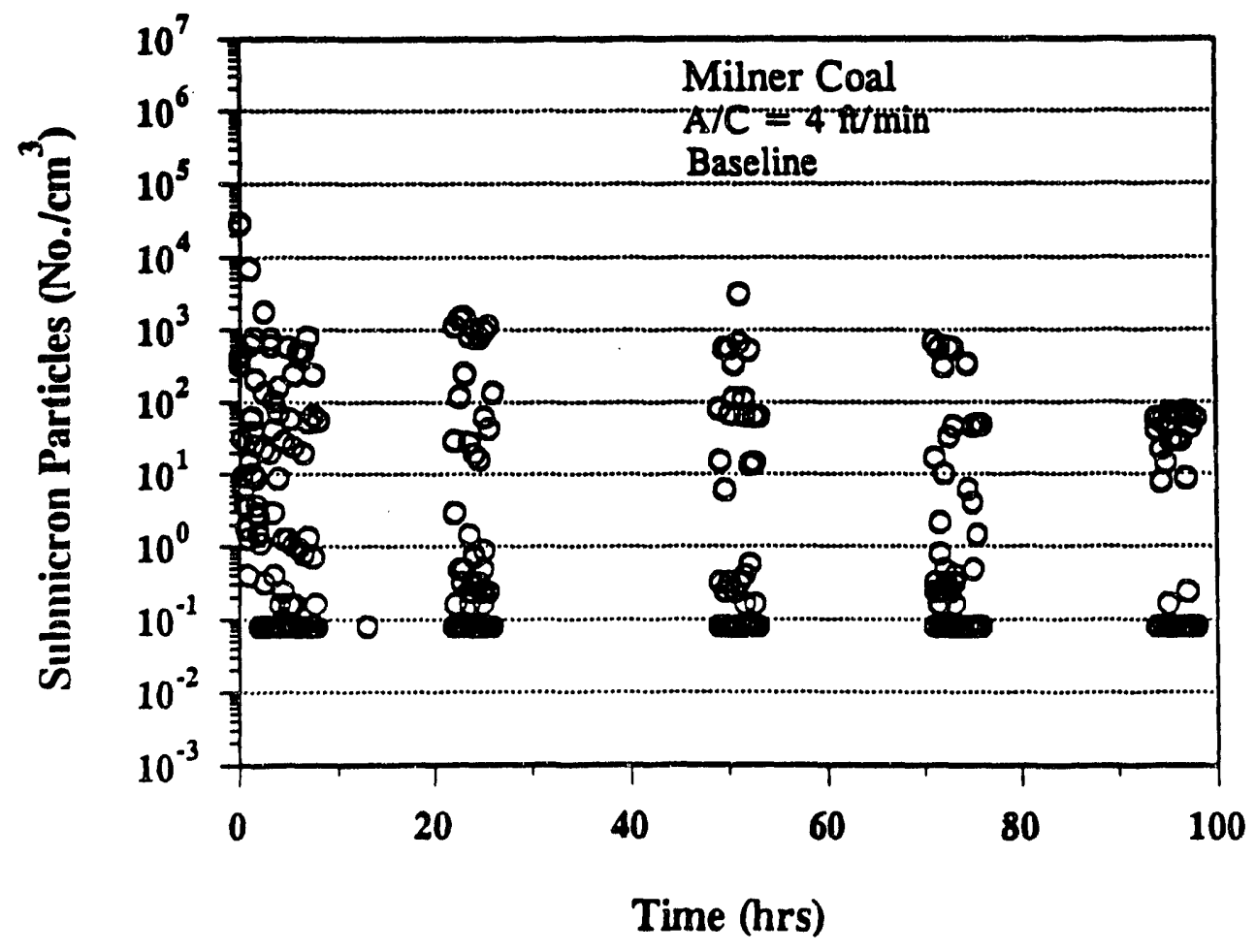

Figure 41. Range of submicron particle emissions for the 100-hour baseline Run 406 with Milner coal. 


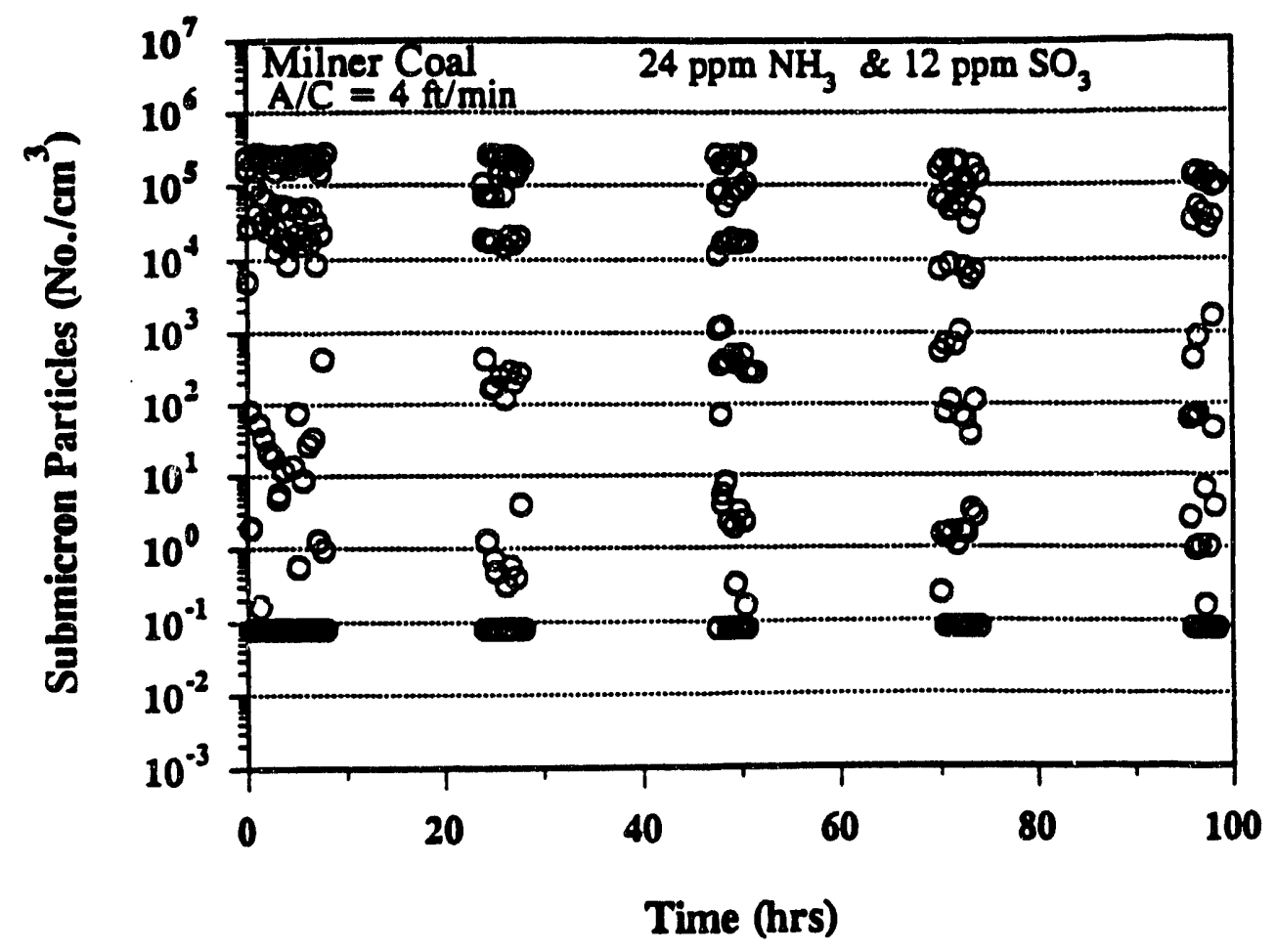

Figure 42. Range of submicron particle emissions for the 100-hour conditioning Run 407 with Milner coal.

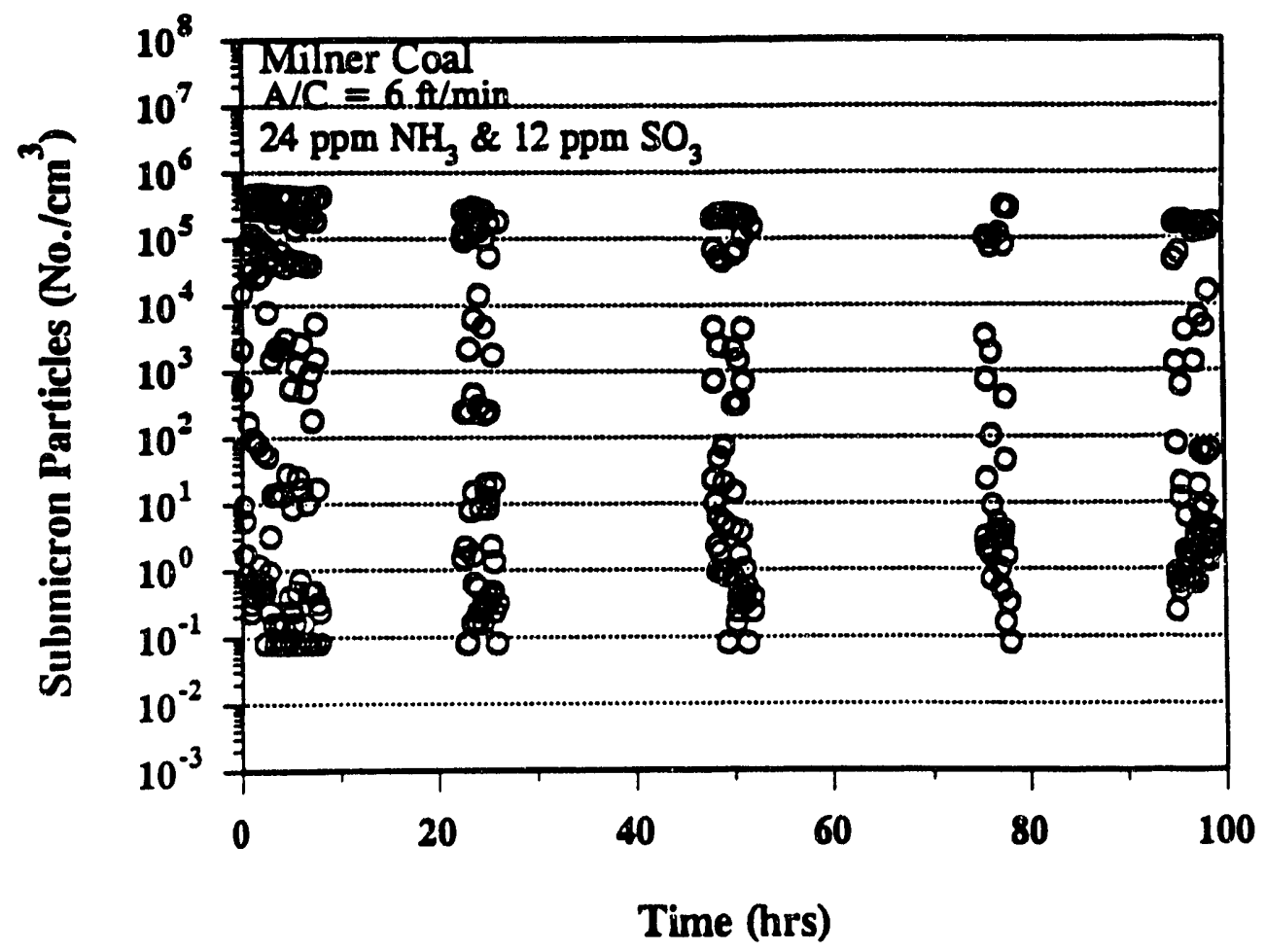

Figure 43. Range of submicron particle emissions for the 100-hour conditioning Run 411 with Milner coal. 
were reduced one to two orders of magnitude. Ash properties for the Milner tests are discussed later in this report.

\subsubsection{0-hour Tests with Black Thunder Coal}

The original test plan included only two 100-hour tests with Black Thunder coal: a baseline test at an AVC ratio of $4 \mathrm{ft} / \mathrm{min}$ and a conditioning test at an $A / C$ ratio of $6 \mathrm{ft} / \mathrm{min}$. It was thought that, if conditioning worked well for the other two coals at an A/C ratio of $6 \mathrm{ft} / \mathrm{min}$, it would also work well for the Black Thunder at an A/C ratio of $6 \mathrm{ft} / \mathrm{min}$. The baseline test (Run 409) was conducted without major difficulties. However, after less than 24 hours into the conditioning test (Run 410 ), it was obvious that the baghouse $\Delta P$ could not be adequately controlled, so the run was stopped. The reasons for the difficulty in bag cleaning were thought to be related to either the high conditioning agent concentrations (compared to the relatively low dust loading) or to the high AVC ratio. There was also the possibility that conditioning would simply not work with this coal. To address both of these possibilities, new bags were installed, the A/C ratio was reduced from 6 to $4 \mathrm{ft} / \mathrm{min}$, and the conditioning agent concentrations were reduced from $24 / 12 \mathrm{ppm}$ of $\mathrm{NH}_{3} / \mathrm{SO}_{3}$ to $12 / 6 \mathrm{ppm}$ of $\mathrm{NH}_{3} / \mathrm{SO}_{3}$ for the remainder of the 100 -hour test. The first part of the 100 -hour test at an A/C ratio of $6 \mathrm{ft} / \mathrm{min}$ was designated as Run 410A, and the last part of the test at an AVC ratio of $4 \mathrm{ft} / \mathrm{min}$ was designated as Run $410 B$. Since conditioning worked very well for Run 410B, an additional test was conducted at an AVC ratio of $6 \mathrm{ft} / \mathrm{min}$, but with conditioning agent concentrations of $12 / 6 \mathrm{ppm}$ of $\mathrm{NH}_{3} / \mathrm{SO}_{3}$ (Run 413). This last test was possible because Run 412 was terminated early as a result of pressure drop problems.

A comparison of the $\triangle \mathrm{P}$ plots for the three Black Thunder tests is shown in Figure 44. Comparing the baseline (Run 409) and conditioning (Run 410B) tests at an AVC ratio of $4 \mathrm{ft} / \mathrm{min}$, the $\Delta P$ for the baseline test is two to three times higher, which is also reflected in the $K_{2}$ values shown in Table 8 . For both tests, there is a trend of increasing $\Delta P$ with time, but the baseline $\Delta \mathrm{P}$ appears to be increasing more rapidly than the $\Delta \mathrm{P}$ with conditioning. Again, this is encouraging because, within the limits of the test period, no problems of residual dust cake buildup or bag cleaning are indicated. These results show that conditioning can be employed with Black Thunder coal to achieve a substantial reduction in pressure drop at a constant $A / C$ ratio. When the $A / C$ ratio was increased to $6 \mathrm{ft} / \mathrm{min}$ with conditioning (Run 413), there was a greater increase in $\Delta \mathrm{P}$ than the factor of 2.25 times increase expected from the increase in face velocity. The additional $\Delta \mathrm{P}$ increase is reflected in the higher $\mathrm{K}_{2}$ values for the test at $6 \mathrm{ft} / \mathrm{min}$. Since no baseline test was conducted at $6 \mathrm{ft} / \mathrm{min}$, a direct determination of the benefit of conditioning at the higher $\mathrm{A} / \mathrm{C}$ ratio cannot be 


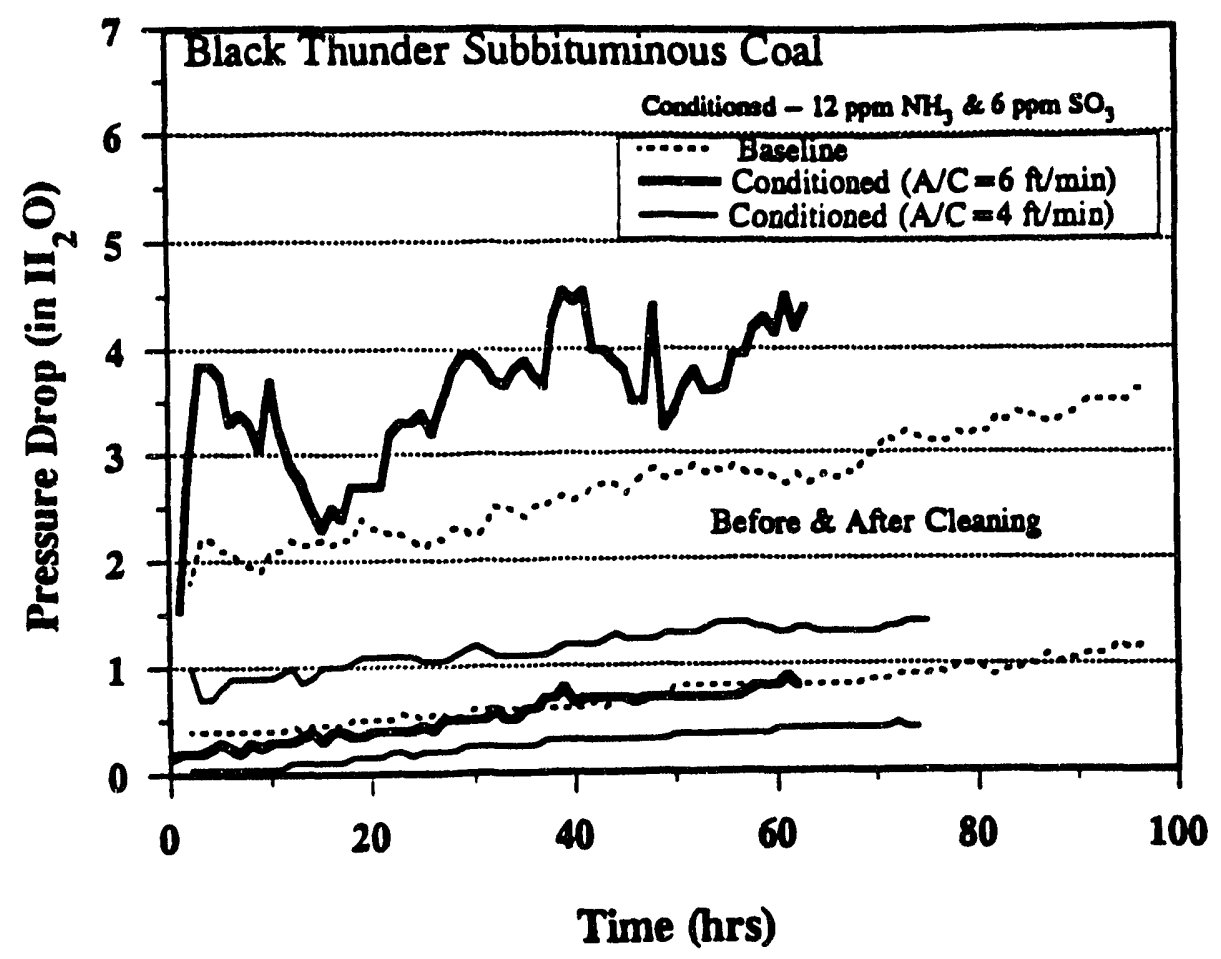

Figure 44. Effect of conditioning on baghouse pressure drop for 100-hour Black Thunder tests for Runs 409, 410B, and 413. Bags were pulsed once every hour.

made. However, the $K_{2}$ values with conditioning at $6 \mathrm{ft} / \mathrm{min}$ were still much lower than the $K_{2}$ values for the baseline test at $4 \mathrm{ft} / \mathrm{min}$. The difference in $K_{2}$ between baseline and conditioning tests, both conducted at $6 \mathrm{ft} / \mathrm{min}$, would likely have been greater, since $\mathrm{K}_{2}$ tends to increase with increasing velocity.

A plot of the $\triangle \mathrm{P}$ for Run $410 \mathrm{~A}$ (the first attempted conditioning test at an $\mathrm{A} / \mathrm{C}$ ratio of $6 \mathrm{ft} / \mathrm{min}$ with the higher conditioning agent concentrations of $24 / 12 \mathrm{ppm}$ of $\mathrm{NH}_{3} / \mathrm{SO}_{3}$ ), shown in Figure 45, indicates the problem that can occur when increasing the AVC ratio. The plot shows that $\Delta P$ was rising rapidly. To help control $\Delta P$, at 8 hours into the test, the bagcleaning frequency was increased from once per hour to once every $\mathbf{3 0}$ minutes. However, the $\triangle \mathrm{P}$ continued to increase, which corresponded to a buildup in the residual dust cake, as seen though the sight ports. At 12 hours into the test, the bags were pulsed off-line seven times to remove the residual dust cake, and the test was continued. However, the $\Delta \mathrm{P}$ again rose uncontrollably, so the test was terminated. No attempt was made to increase the pulse pressure or pulse duration to control pressure drop. These results indicated that conditioning with concentrations of $24 / 12 \mathrm{ppm}$ would not provide satisfactory results at this A/C ratio. The data from Run 413 , with $\mathrm{NH}_{3} / \mathrm{SO}_{3}$ concentrations of $12 / 6 \mathrm{ppm}$, indicated much better 


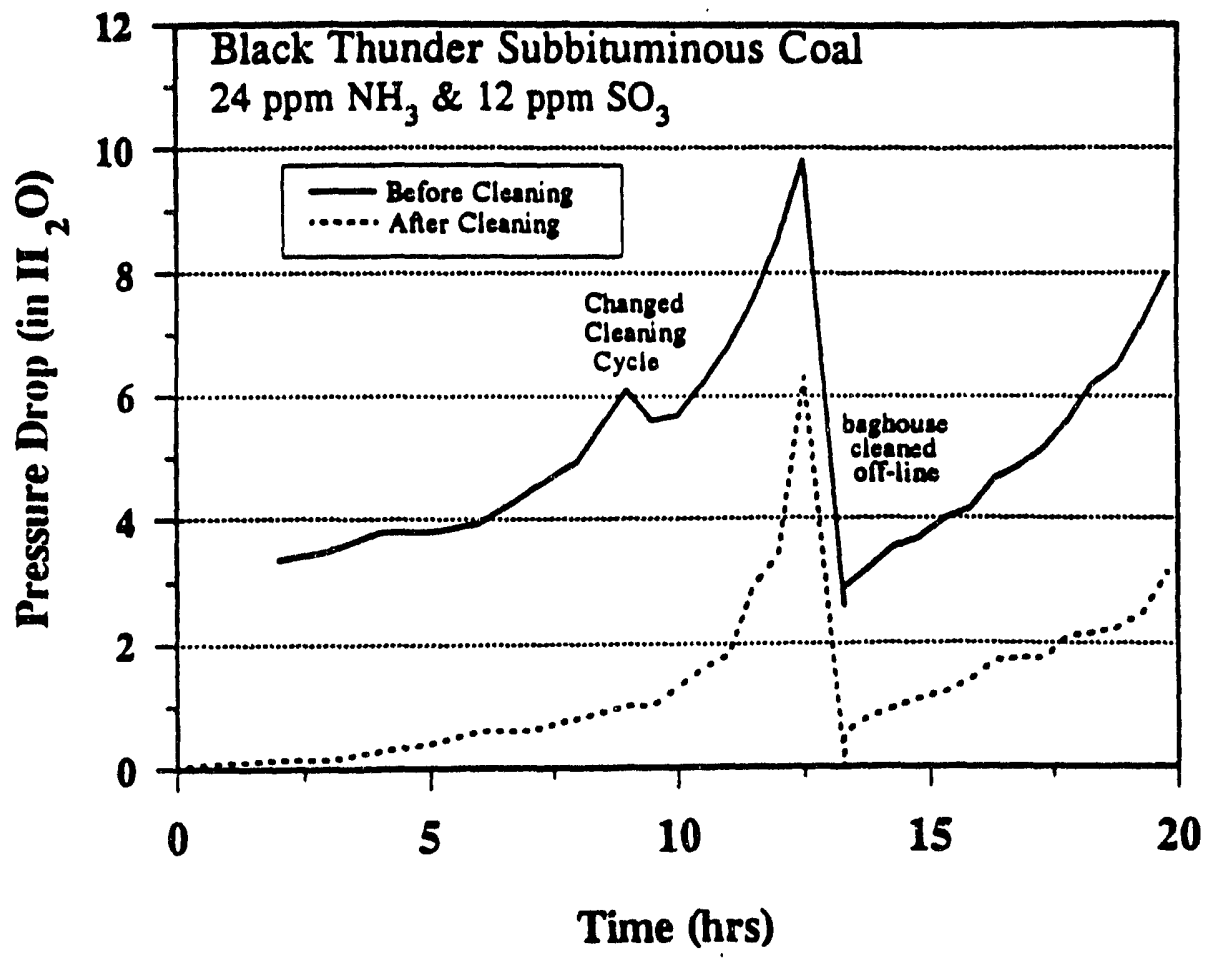

Figure 45. Effect of conditioning on baghouse pressure drop for Black Thunder test with $24 / 12 \mathrm{ppm}$ of $\mathrm{NH}_{3} / \mathrm{SO}_{3}$ for Run 410A. Bags were pulsed once per hour for the first 8 hours and once every 30 minutes for the remainder of the test.

results, but it appears that operating at an A/C ratio of $6 \mathrm{ft} / \mathrm{min}$ with the Black Thunder coal is difficult. This is somewhat surprising because the inlet dust loading was lowest with the Black Thunder coal. Discussion of dust properties (later in this report) will provide some insight into possible causes for this bag-cleaning difficulty, but the exact reasons are not clear.

Average respirable mass particulate emissions, shown in Figure 46, and the dustloading data from Tabie 8 both indicate very little effect of conditioning. However, emissions for both the baseline and conditioning tests were at least 35 times lower than the regulatory limit of $0.03 \mathrm{lb} / 10^{6} \mathrm{Btu}$. Respirable mass emissions for each of the tests are shown in Figures 47 through 49, and submicron particle counts are shown in Figures 50 through 53. From these graphs, it appears that, at an $\mathrm{A} / \mathrm{C}$ ratio of $6 \mathrm{ft} / \mathrm{min}$, both the respirable mass and submicron emissions did not reach as low a level before bag cleaning as did the emissions for the conditioning test at an $\mathrm{A} / \mathrm{C}$ ratio of $4 \mathrm{ft} / \mathrm{min}$. This may indicate some deterioration in performance with an increase in A/C ratio from 4 to $6 \mathrm{ft} / \mathrm{min}$, which is in contrast to the results for the Big Brown and Milner tests. They indicated no deterioration in particulate removal efficiency as a result of increased face velocity. When bag-cleaning 


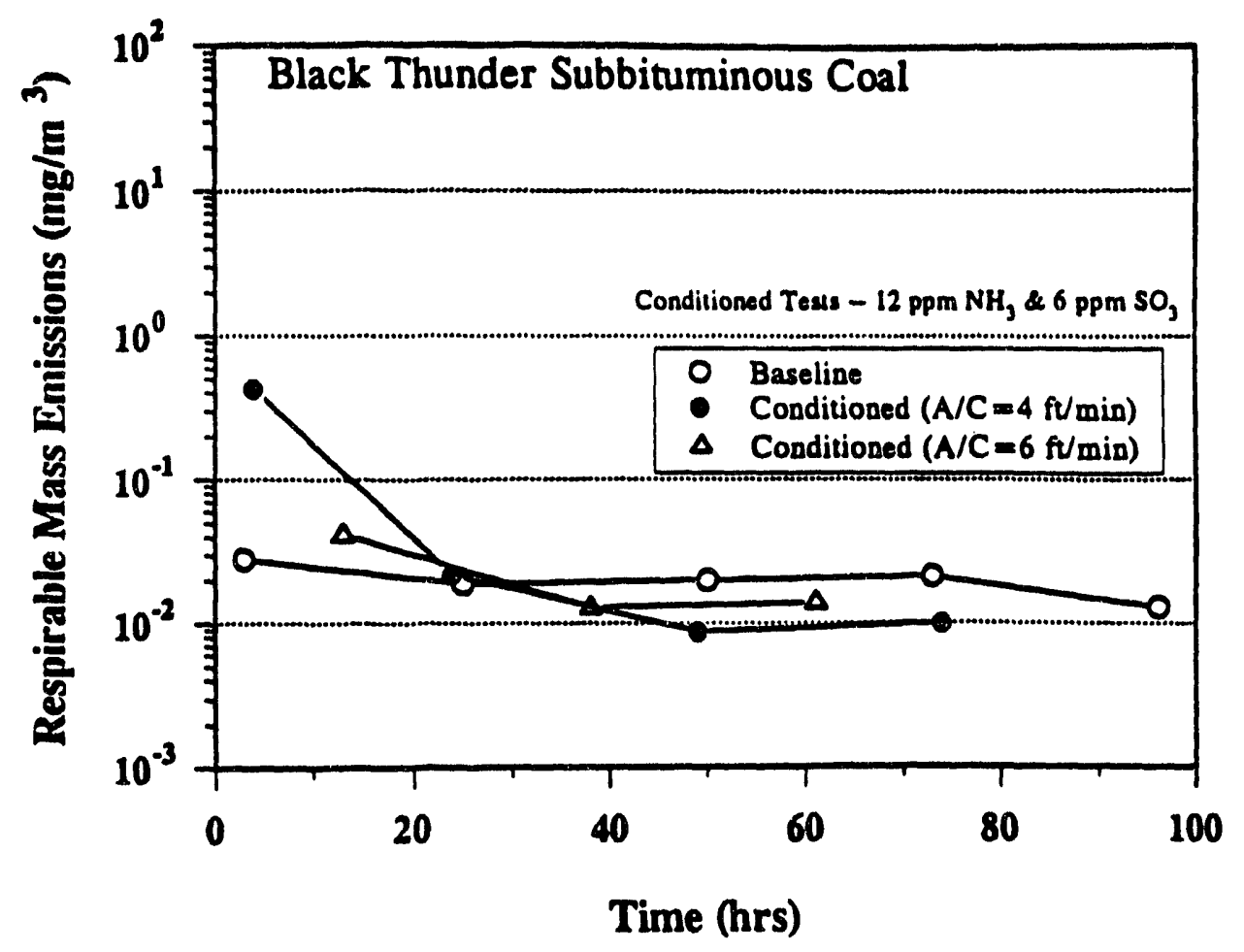

Figure 46. Effect of conditioning on average respirable mass emissions for 100-hour Black Thunder tests for Runs 409, 410B, and 413.

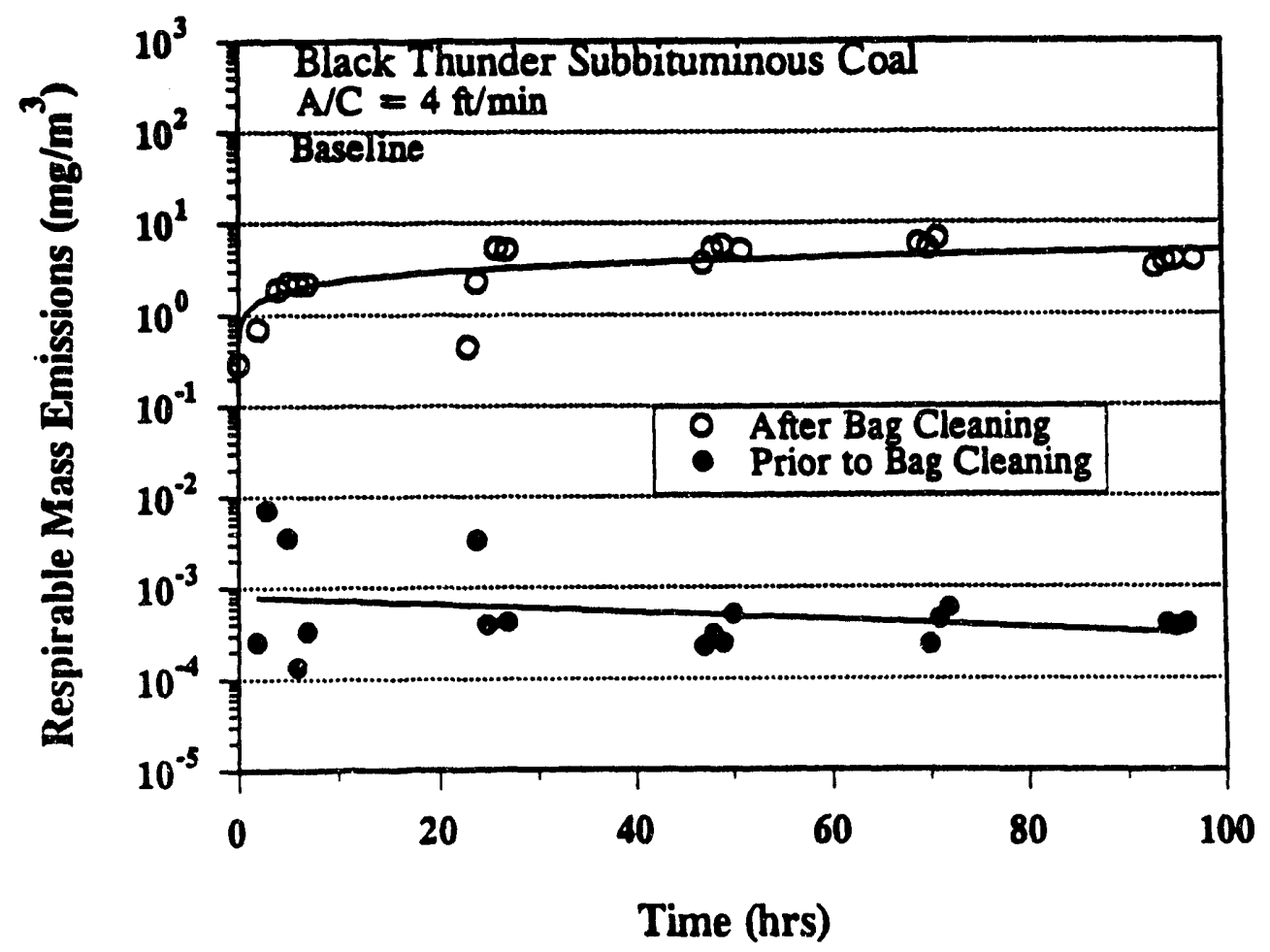

Figure 47. Respirable mass emissions before and after bag cleaning for the 100-hour baseline Run 409 with Black Thunder coal. 


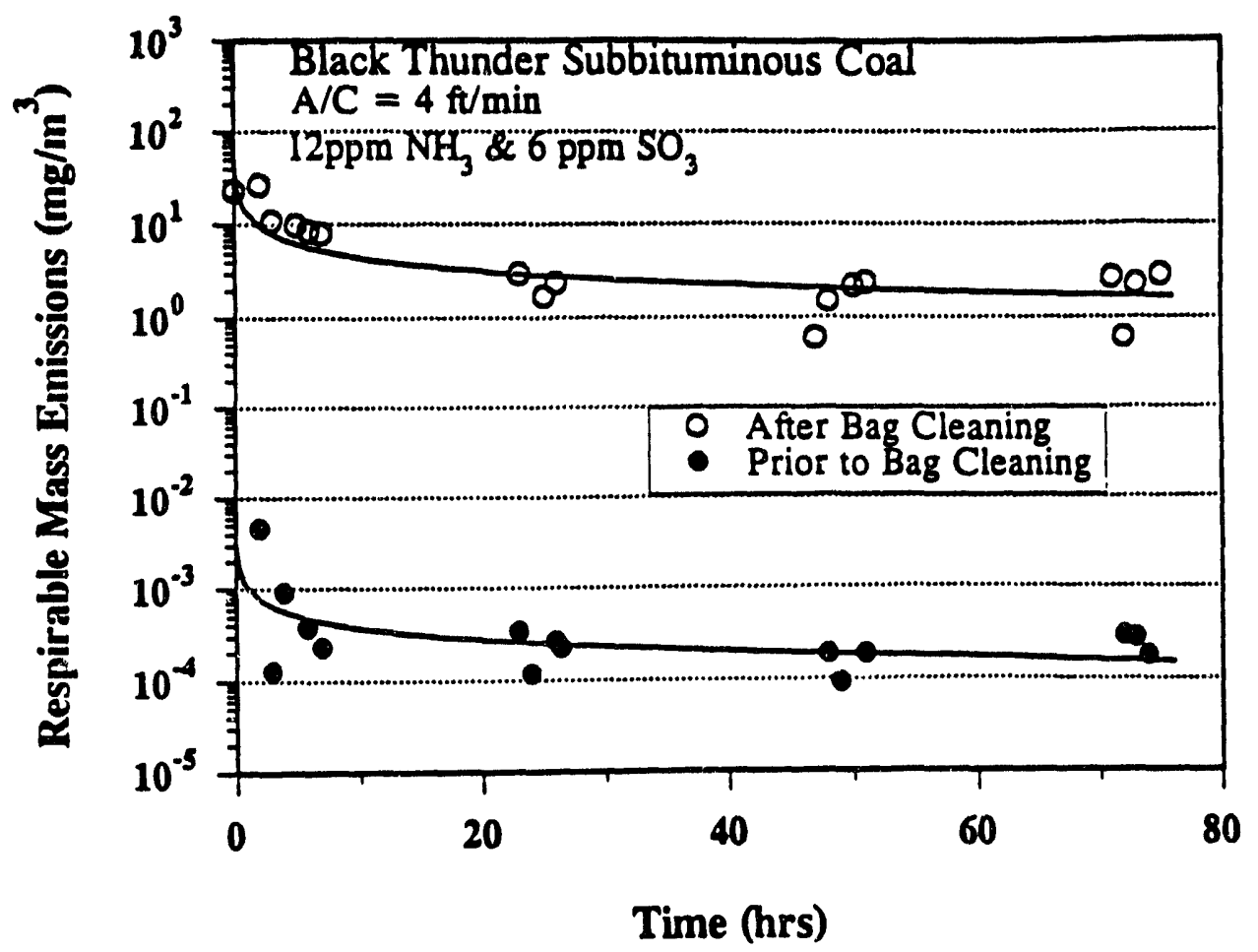

Figure 48. Respirable mass emissions before and after bag cleaning for the 100-hour conditioning Run 410B with Black Thunder coal.

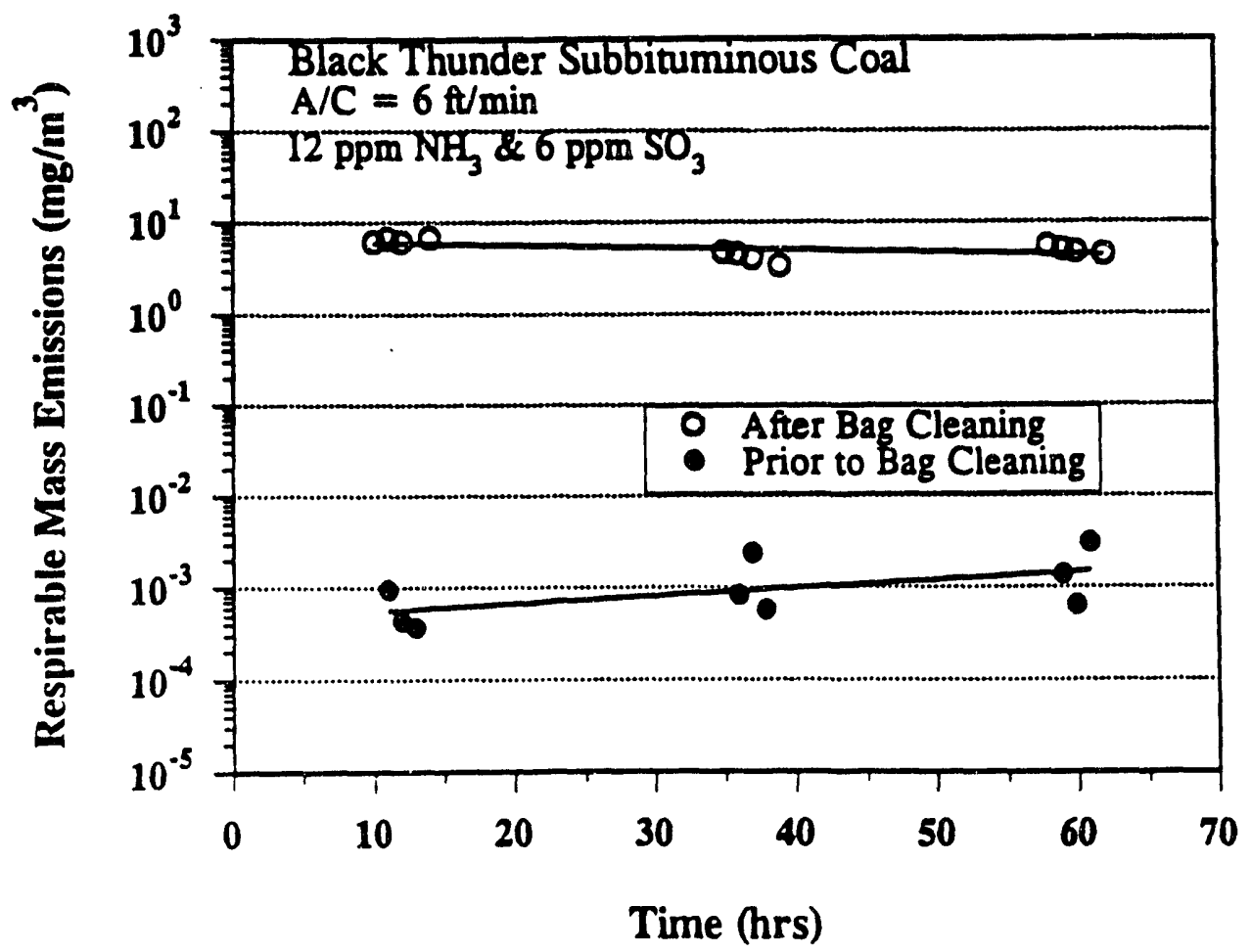

Figure 49. Respirable mass emissions before and after bag cleaning for the 100-hour conditioning Run 413 with Black Thunder coal. 


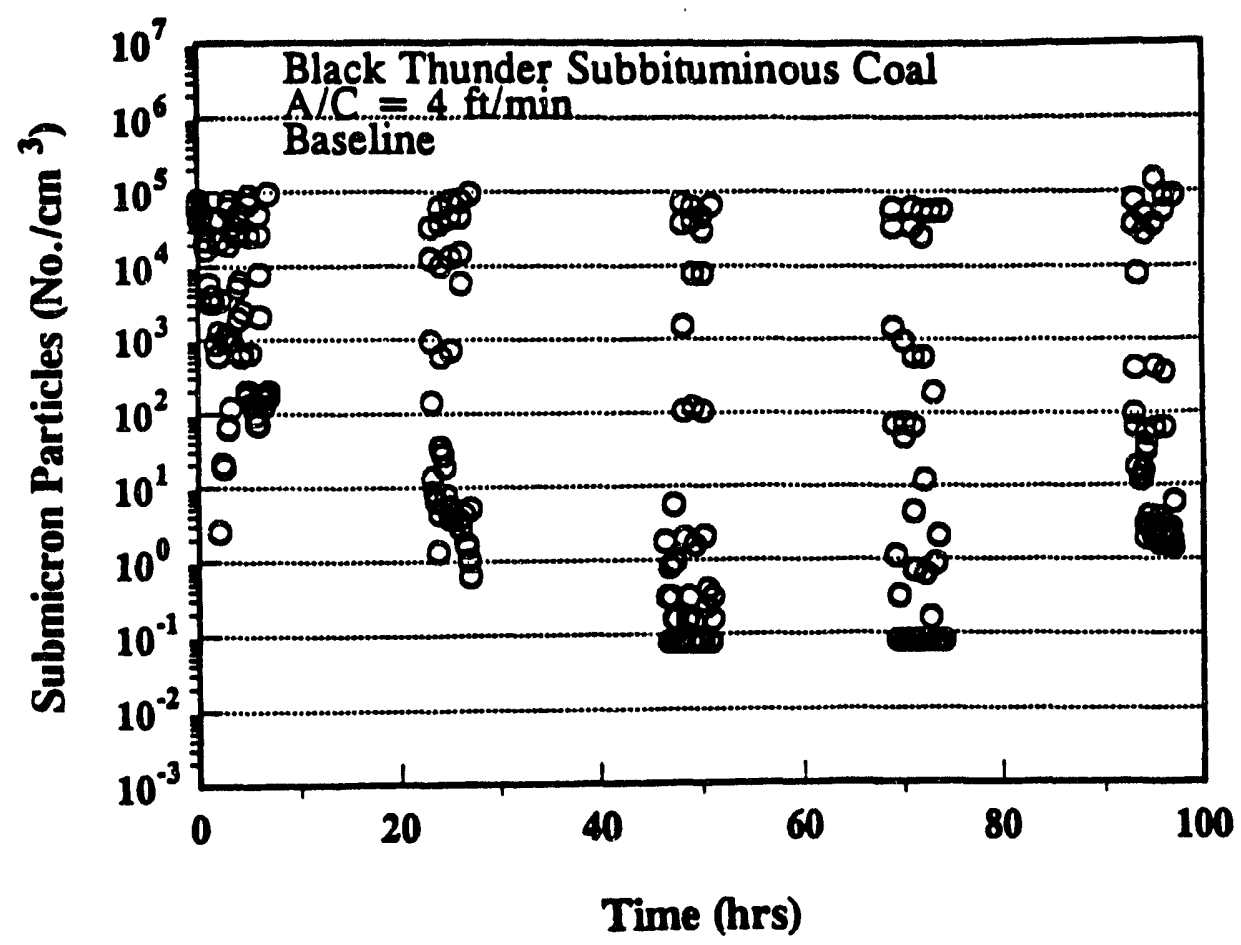

Figure 50. Range of submir ron particle emissions for the 100-hour baseline Run 409 with Black Thunder coal.

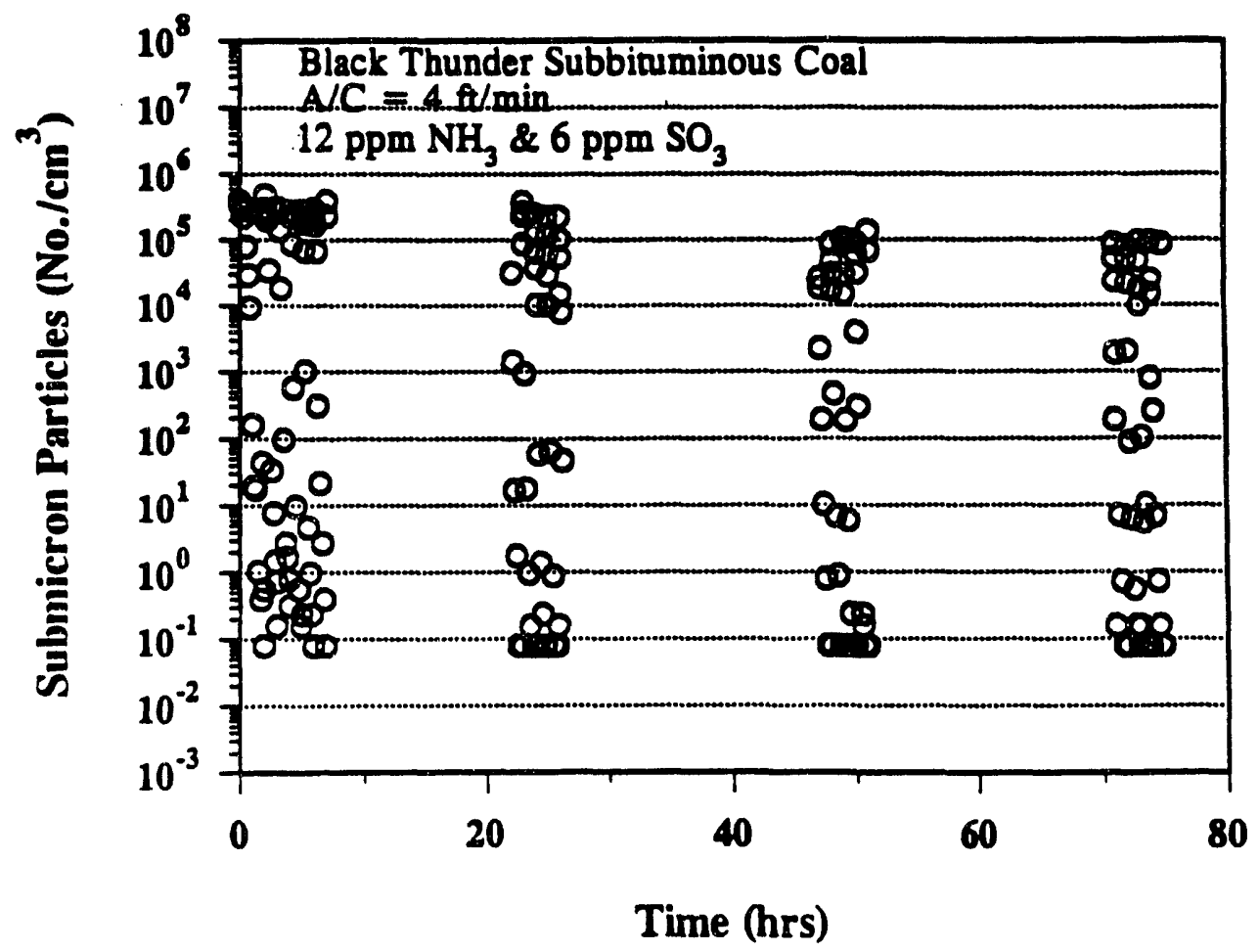

Figure 51. Range of submicron particle emissions for the 100-hour conditioning Run 410B with Black Thunder coal. 


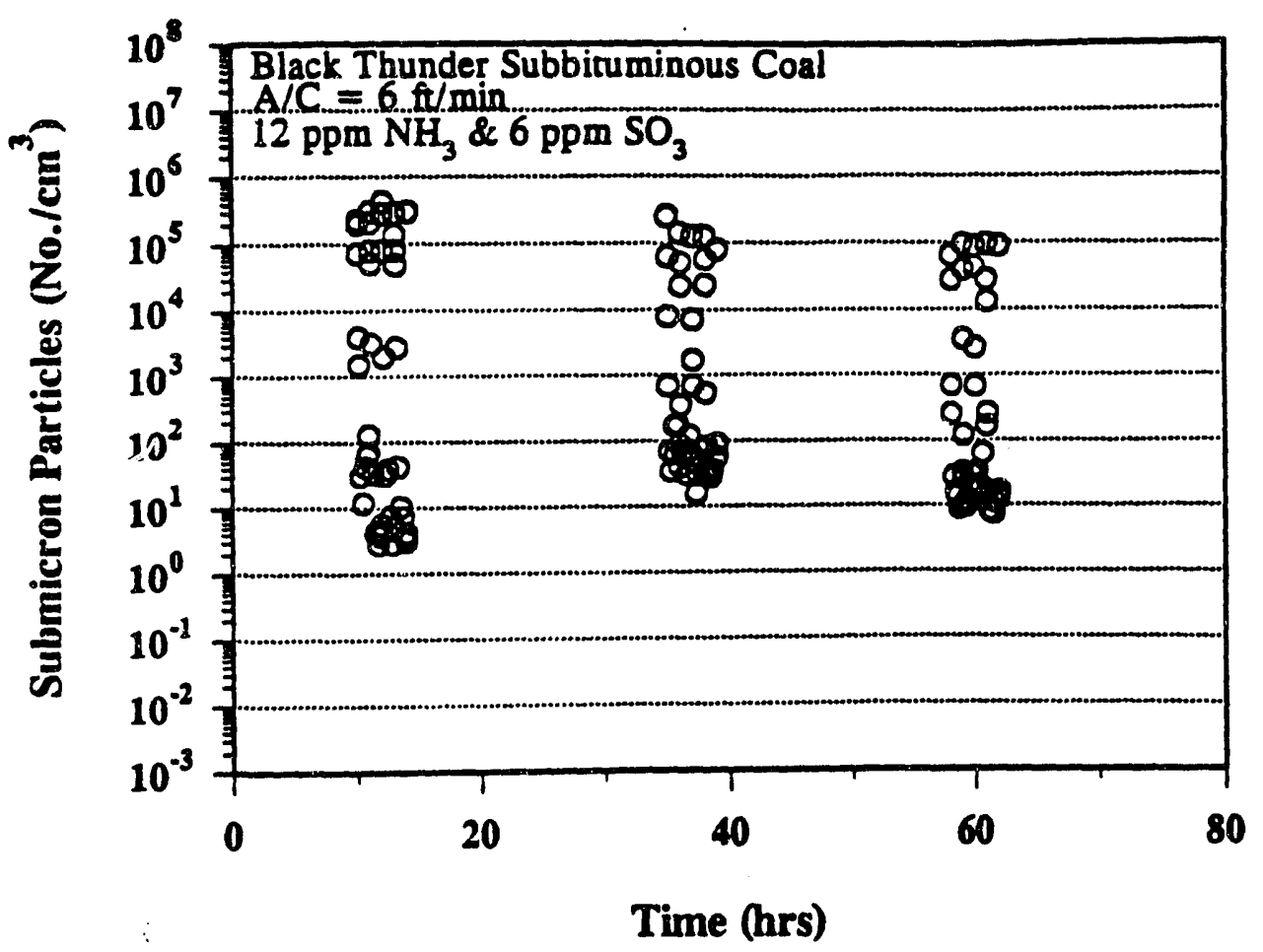

Figure 52. Range of submicron particle emissions for the 100-hour conditioning Run 413 with Black Thunder coal.

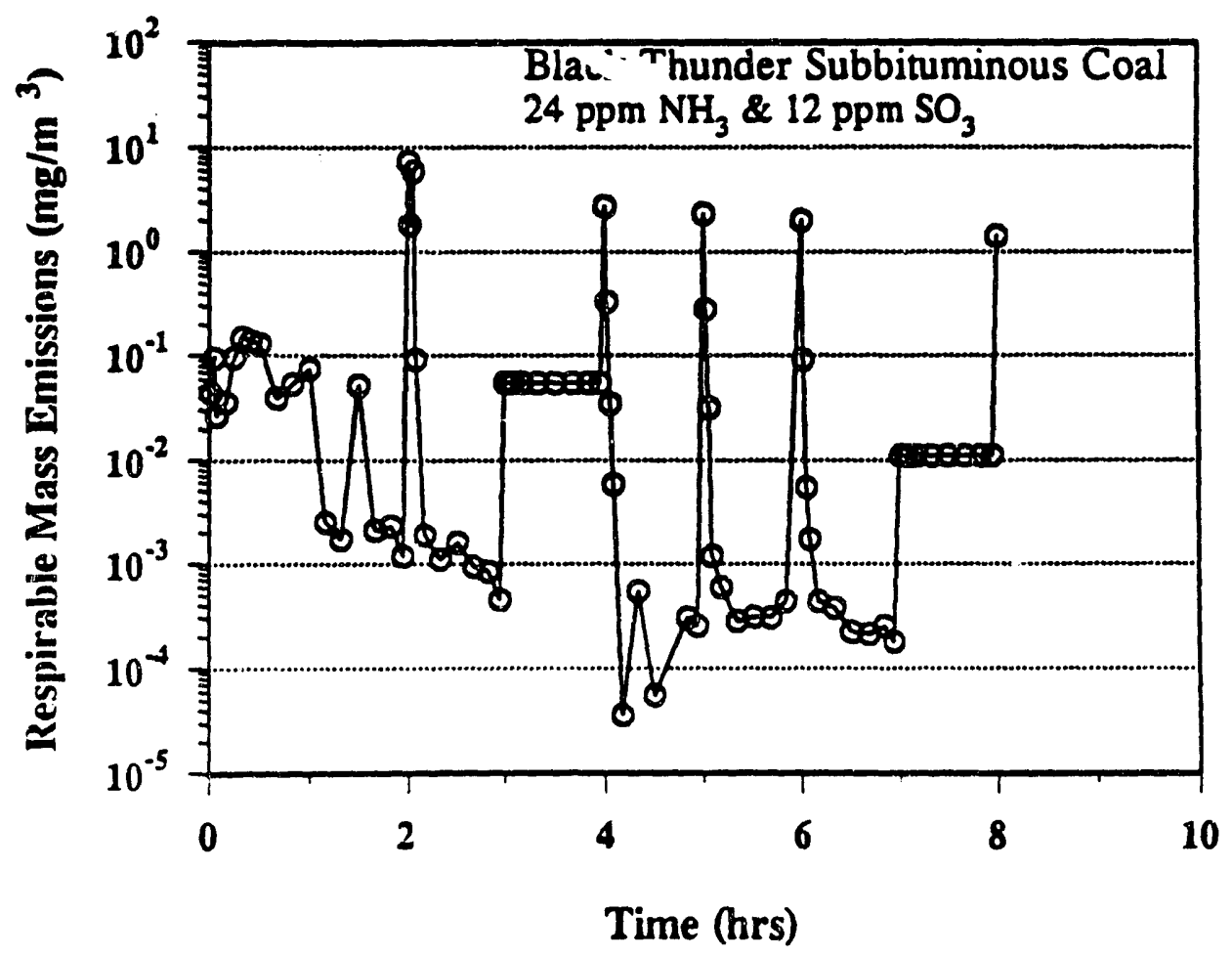

Figure 53. Respirable mass emissions for Black Thunder test with: $24 / 12 \mathrm{ppm}$ of $\mathrm{NH}_{3} / \mathrm{SO}_{3}$, Run 410A. 
problems occurred in Run 410A, particulate emissions remained low, as shown in Figures 53 and 54 and Table 8. Therefore, control of baghouse pressure drop appears to be more of a concem than particulate emissions for the Black Thunder coal using Ryton fabric.

\subsubsection{6-ft/min Tests with Big Brown Coal}

Five 8-hour tests at an A/C ratio of $16 \mathrm{ft} / \mathrm{min}$ using Ryton fabric were completed. The tests included baseline and conditioning runs with a normal dust loading and baseline and conditioning runs with a reduced dust loading. To achieve a reduced dust loading, the combustor was fired on natural gas while coal was fed at approximately $1 / 20$ th of the normal feed rate. Conditioning agent concentrations for the normal dust-loading conditioning test were 24/12 ppm of $\mathrm{NH}_{3} / \mathrm{SO}_{3}$, and for the reduced dust-loading conditioning tests, concentrations were $6 / 3 \mathrm{ppm}$ of $\mathrm{NH}_{3} / \mathrm{SO}_{3}$. One other major difference for these tests was off-line pulsing, in contrast to on-line pulsing employed for the other tests.

For the normal dust-loading baseline test (Run 399), the single 10-ft bag was cleaned every 10 minutes at the start of the run, but by 2.5 hours into the test, the cleaning interval

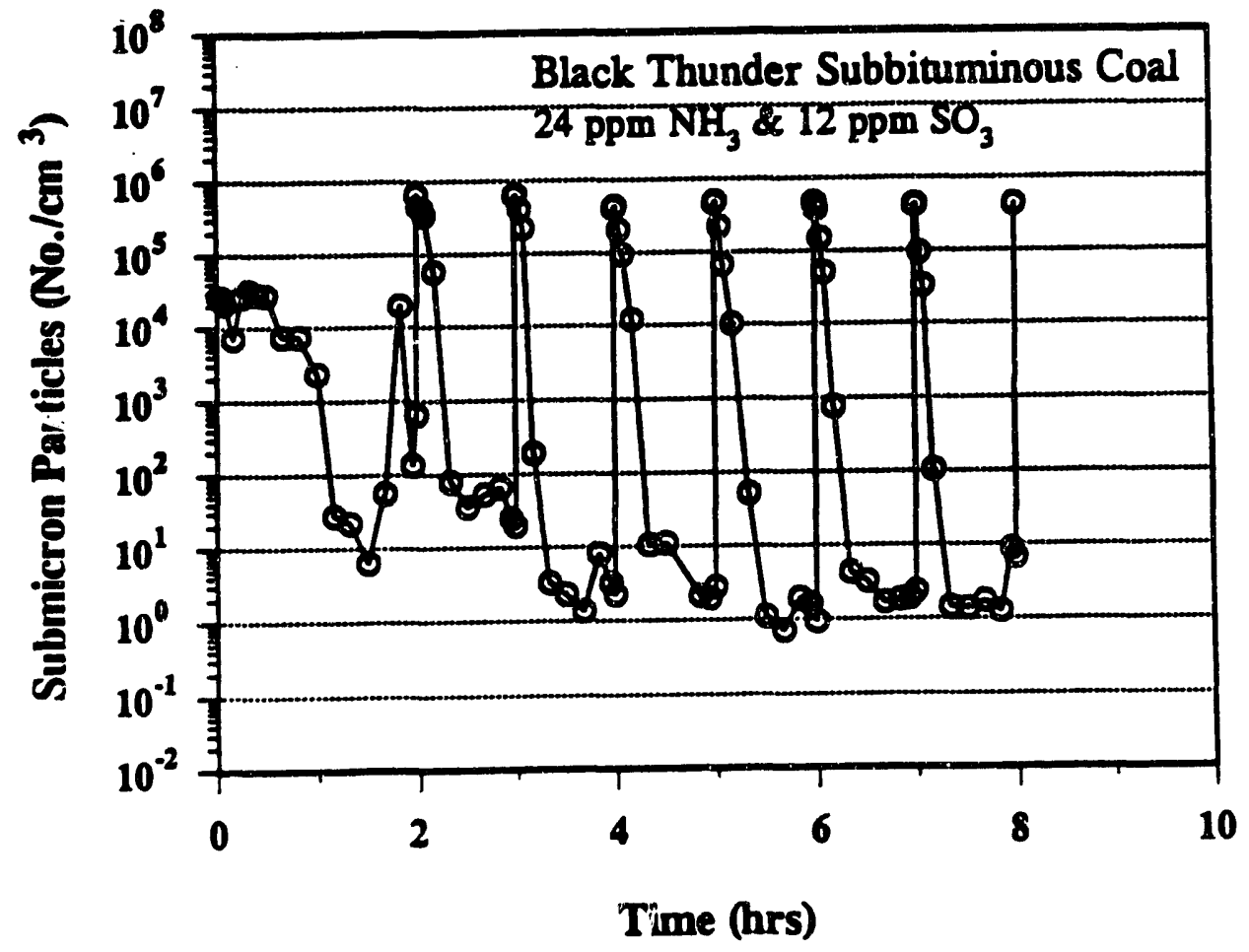

Figure 54. Range of submicron particle emissions for Black Thunder test with 24/12 ppm of $\mathrm{NH}_{3} / \mathrm{SO}_{3}$, Run 410A. 
had to be reduced to 5 minutes to control the pressure drop under 10 inches WC. After switching to 5-minute cleaning, pressure drop was initially 7 inches WC, but by the end of the 8-hour test, pressure drop was over 10 inches WC. With conditioning and normal dust loading (Run 400), the initial bag-cleaning interval was set at 20 minutes, but it was reduced to a 10-minute interval after 2 hours when the pressure drop exceeded 8 inches WC.

However, pressure drop gradually climbed again and reached 9 inches WC by 5.5 hours into the test. The cleaning interval was then set at 5 minutes, which resulted in a pressure drop of 6 inches WC for the remaining 2.5 hours of the 8-hour test (see Figure 55). Comparing the last 2.5 hours of each test shows a clear reduction in $\Delta \mathrm{P}$ with conditioning when the cleaning frequency was 5 minutes for both tests. The $K_{2}$ values, shown in Table 8 , are about two times lower with conditioning and are reasonably close to the $K_{2}$ values from the tests at 4 and $6 \mathrm{ft} / \mathrm{min}$.

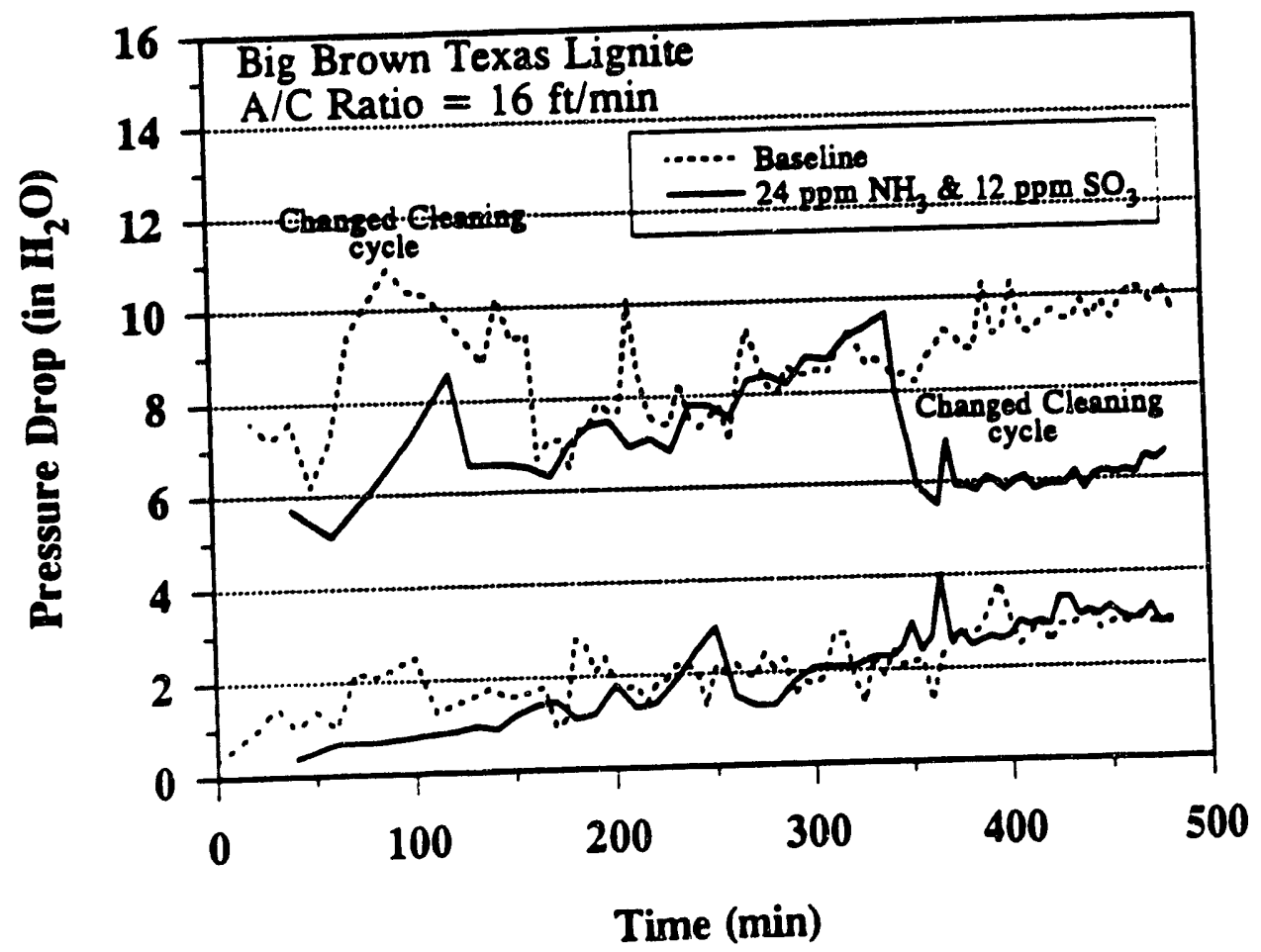

Figure 55. Effect of conditioning on baghouse pressure drop for 8-hour Big Brown tests with a full dust loading at an A/C ratio of $16 \mathrm{ft} / \mathrm{min}$ for Runs 399 and 400 . Bags were pulsed every 5 minutes during the last 2 hours of each test. 
Inspection of the bags after each test revealed almost no residual dust cake on the fabric surface for the baseline test, but there was some dust on the tube sheet, on the clean side of the bags, and on the cages, which indicated dust penetration into and through the bag. With conditioning, there was a heavier residual dust cake that was nodular and discontinuous. However, for the conditioning test, the residual dust cake appeared to be mainiy on the surface of the fabric, while, for the baseline test, the dust cake appeared to be packed into the fabric structure. One factor that may have contributed to the heavier residual dust cake with conditioning is the effect of taking the baghouse off-line for about 20 seconds each time the bag was pulsed. The ammonia and $\mathrm{SO}_{3}$ were injected into the duct just upstream of the baghouse at a location that is downstream of the inlet isolation valve. Since $\mathrm{NH}_{3}$ and $\mathrm{SO}_{3}$ were injected continuously, including the 20-second off-line periods, there was a 20-second period during each cleaning cycle when ammonia and $\mathrm{SO}_{3}$ were injected with no flue gas flow in the duct. Therefore, when flue gas was again introduced to the baghouse after bag cleaning, there was an initial surge of higher-concentration conditioning agents. The ash that was exposed to the higher concentrations of conditioning agents could bave been more sticky and adhered to the bag, causing a heavier dust cake weight. No attempt was made to increase the pulse pressure or duration to achieve better bag cleaning. However, at $16 \mathrm{ft} / \mathrm{min}$ with conditioning, higher pulsing energy may be necessary to adequately control the residual dust cake weight.

Average particulate emissions were about nine times lower with conditioning, achieving 99.97\% removal efficiency compared to nnly $\mathbf{9 9 . 7 9 \%}$ for the baseline test. However, by the end of the 8-hour tests, respirable mass emissions were about two orders of magnitude lower with conditioning, as shown in Figures 56 through 58. Therefore, conditioning resulted in a clear advantage for these full dust-loading tests at $16 \mathrm{ft} / \mathrm{min}$.

For the two reduced dust-loading tests, particulate emissions were as low as emissions with conditioning for the normal dust-loading test, but because of the much lower inlet dust loadings, the calculated collection efficiency was only 99.0 to $99.4 \%$. Respirable mass emissions for Runs 401 and 402 are shown in Figures 59 and 60 . A major bag blinding problem occurred for both the baseline (Run 401) and conditioning (Run 402) reduced dustloading tests. For the baseline test, the bag was pulsed after an initial filtration period of 3 hours when the pressure drop reached 6.5 inches WC. The bag cleaned down to 3 inches WC, but after only 20 minutes, pressure drop reached 7.5 inches WC, and the bag was pulsed again. This time the bag cleaned down to 5 inches WC and reached 8.5 inches WC after 15 minutes. The third time the bag was pulsed, the bag cleaned down to 7 inches WC, so the bag was taken off-line and pulsed 10 times. This brought the pressure drop down to 


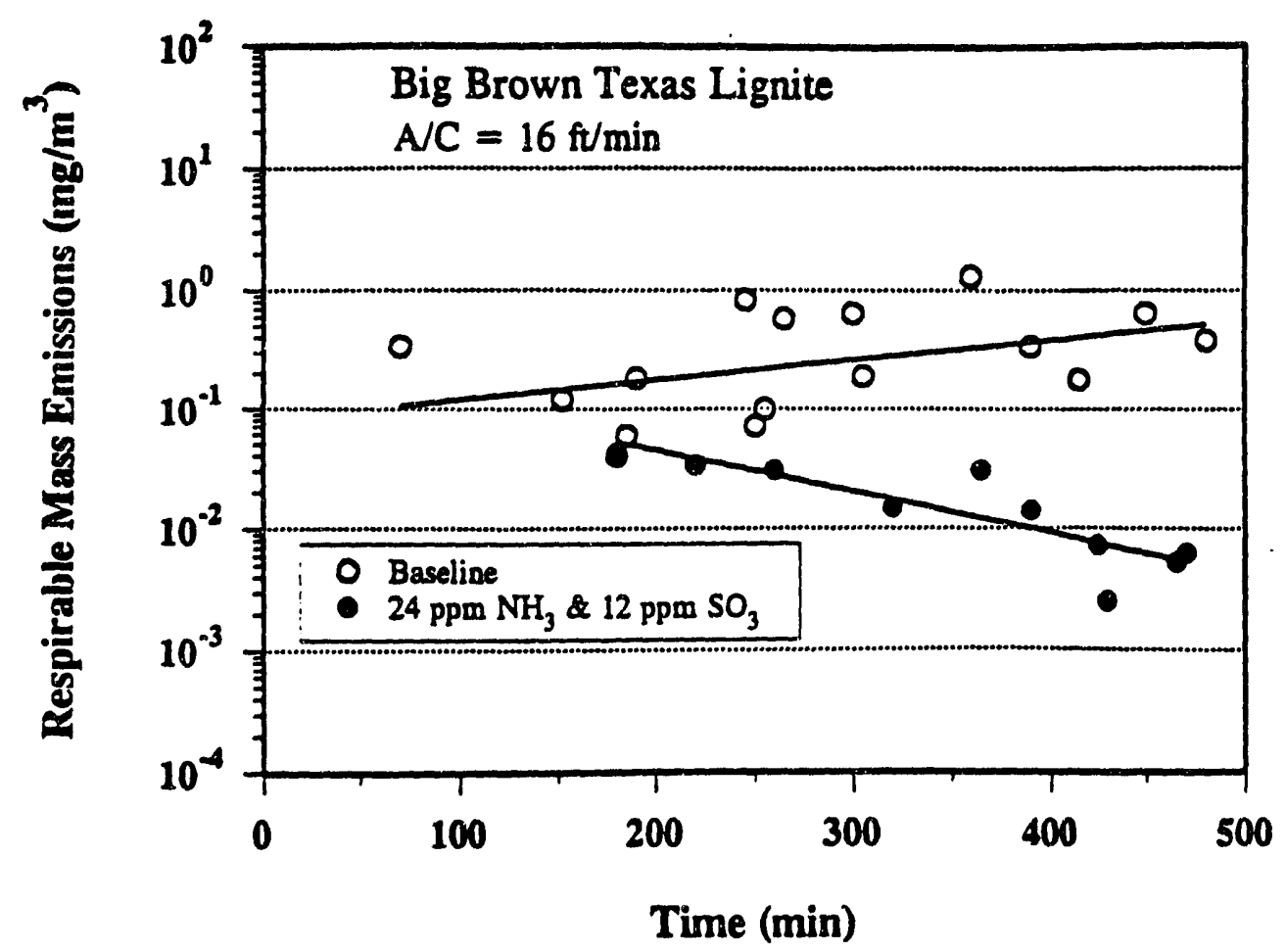

Figure 56. Effect of conditioning on average respirable mass emissions for 8-hour Big Brown tests with a full dust loading at an A/C ratio of $16 \mathrm{ft} / \mathrm{min}$ for Runs 399 and 400.

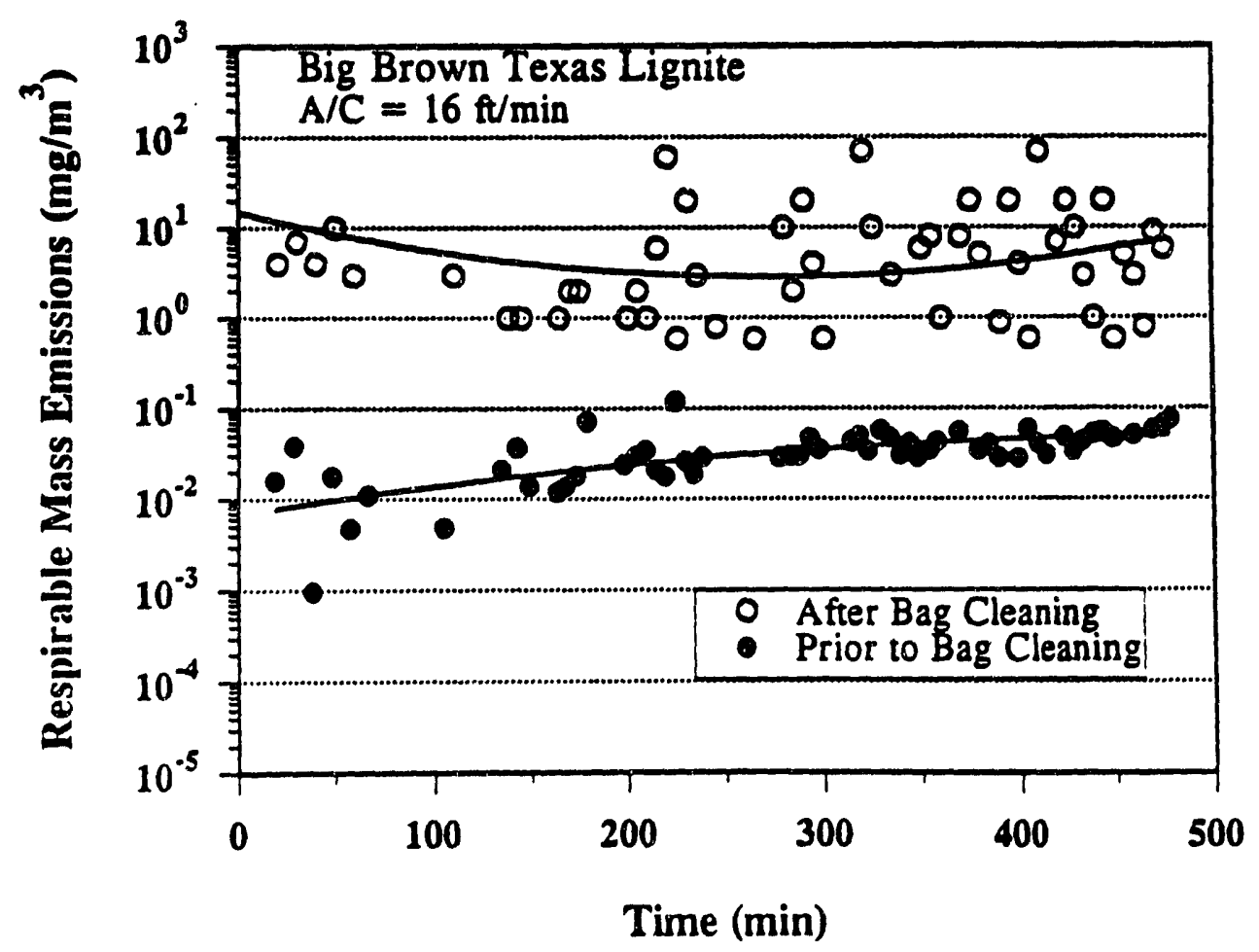

Figure 57. Respirable mass emissions before and after bag cleaning for the 8-hour baseline Big Brown test with a full dust loading at an A/C ratio of $16 \mathrm{ft} / \mathrm{min}$ for Run 399. 


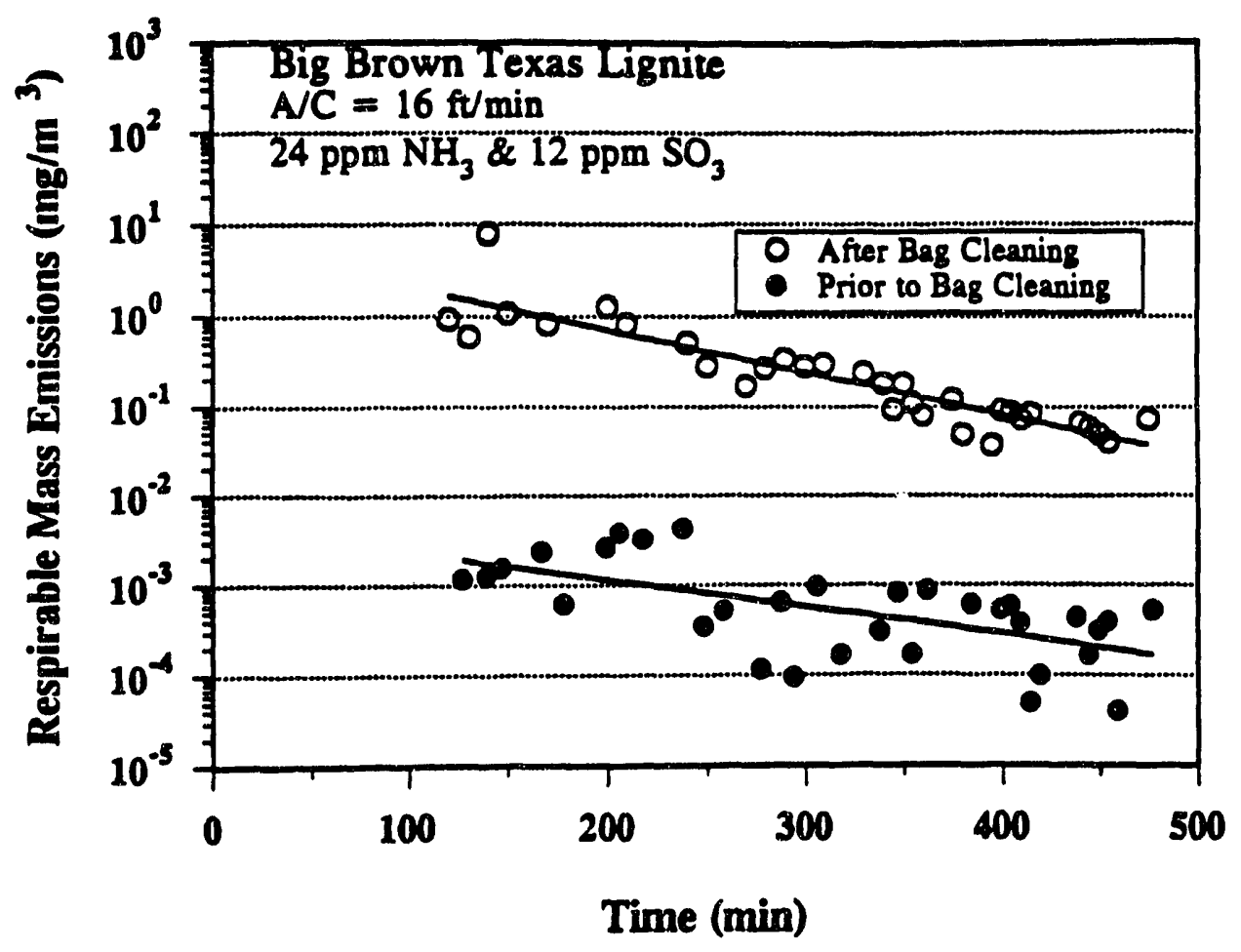

Figure 58. Respirable mass emissions before and after bag cleaning for the 8-hour Big Brown test with conditioning and with a full dust loading at an $\mathrm{A} / \mathrm{C}$ ratio of $16 \mathrm{ft} / \mathrm{min}$ for Run 400 .

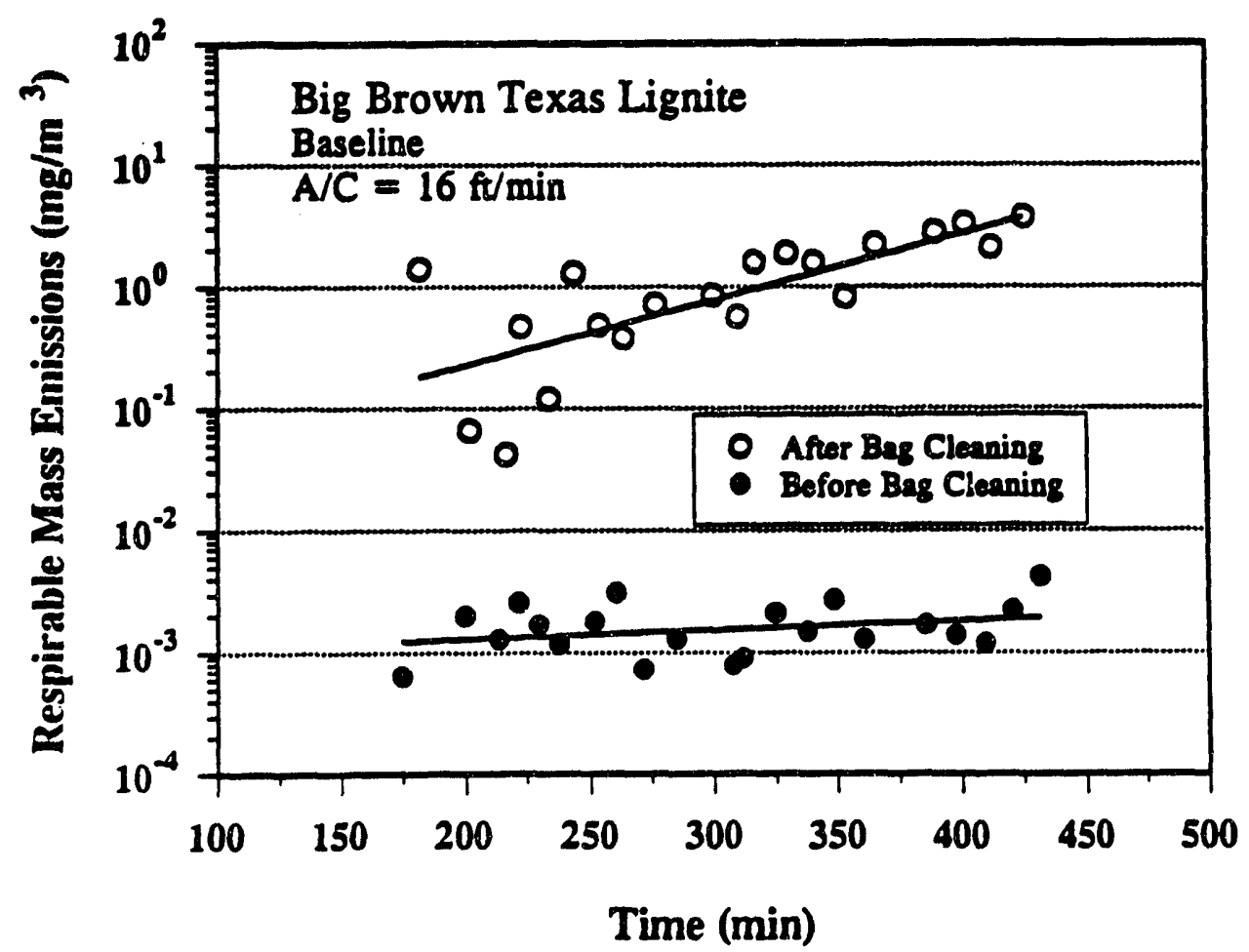

Figure 59. Respirable mass emissions before and after bag cleaning for the 8-hour baseline Big Brown test with a reduced dust loading at an A/C ratio of $16-\mathrm{ft} / \mathrm{min}$ for Run 401. 


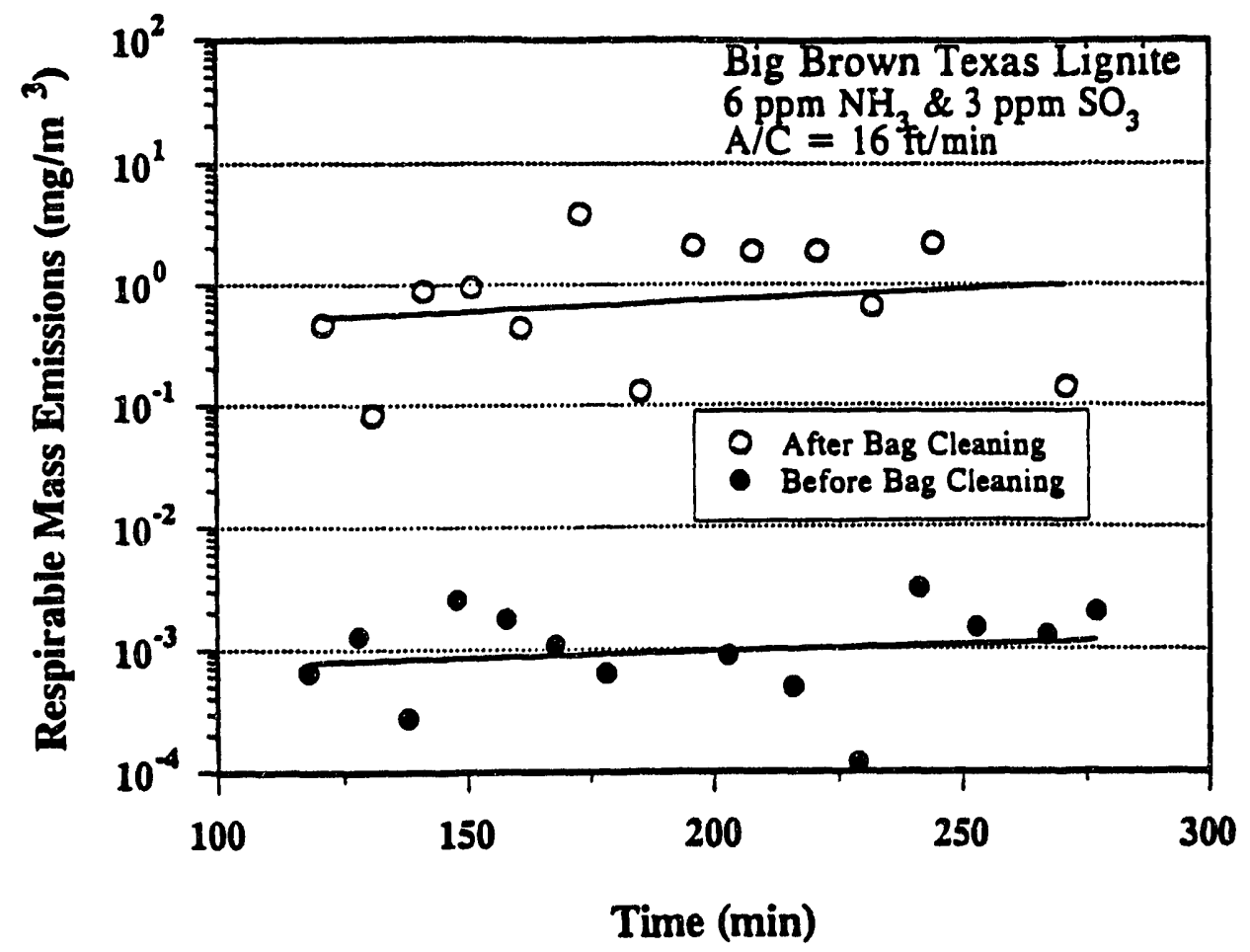

Figure 60. Respirable mass emissions before and after bag cleaning for the 8-hour Big Brown test with conditioning and a reduced dust loading at an $\mathrm{A} / \mathrm{C}$ ratio of $16 \mathrm{ft} / \mathrm{min}$ for Run 402.

3.5 inches, but it quickly climbed to 7.5 inches WC after 10 minutes of filtration. At this point, the pulse-air reservoir pressure was increased to $80 \mathrm{psig}$ (from the $40 \mathrm{psig}$ used previously), but the bag still would not clean with single off-line pulses. Finally, the bag was pulsed ten times off-line every 10 minutes, which resulted in the bag cleaning down to about 4 inches, but pressure drop climbed to over 10-inches WC after 10 minutes of filtration time. There was almost no dust cake visible on the surface of the fabric, so an explanation for the high pressure drop is that ash must have packed very tightly into the fabric structure, causing irreversible fabric blinding. For the reduced dust-loading test with conditioning (Run 402), results were very similar in that once high-pressure drop occurred, the bag could not be adequately cleaned even with increased pulse pressure and multiple off-line pulses.

Both the initial and effective $K_{2}$ values were very high, which is in agreement with the pressure drop data. The $\mathrm{K}_{2}$ value for the 3-hour initial filtration period for the baseline test was 35 inches of water-ft-min/lb, and the $\mathrm{K}_{2}$ value for the conditioned test was 48 inches of water-ft-min/lb. There is some uncertainty of the exact dust loading during the time period 
for which the $\mathrm{K}_{2}$ values were calculated, so no difference between them should be inferred. However, these $\mathrm{K}_{2}$ values are much higher than the initial $\mathrm{K}_{2}$ values for all of the full dustloading tests, including those conducted at $16 \mathrm{ft} / \mathrm{min}$ (see Table 8). By the end of the low dust-loading tests, the effective $K_{2}$ value was 255 inches of water-ft-min/lb for both the baseline and conditioned tests. These data indicate that pressure drop problems occurred from the start of the test and then grew progressively worse after pulsing was initiated. From the Carman-Kozeny $\mathrm{K}_{2}$ model, a higher $\mathrm{K}_{2}$ value must be caused either by a smaller particle size or a low porosity or a combination of both. First, consider the particle-size data.

Particle-size measurements of the fly ash included Coulter counter analysis of both the residual dust cake and baghouse hopper ash, and multicyclone sampling of the inlet fly ash. Coulter counter analysis of ash taken from the bags showed that the volumetric median diameter $(\mathrm{VMD})$ was $7.0 \mu \mathrm{m}$, which is in the range of 6 to $10 \mu \mathrm{m}$ for the VMD of residual dust cake from the other tests. Therefore, a smaller particle size of the residual dust cake is apparently not the explanation for bag blinding. The indicated VMD of the ash taken from the baghouse hopper for the low dust-loading tests was about $26 \mu \mathrm{m}$, which is larger than the range of 11 to $19 \mu \mathrm{m}$ for the VMD measured for the other tests. The 26- $\mu \mathrm{m}$ VMD measurement may not be valid because only a small amount of dust was collected in the hopper (150 to 200 grams for each test). The possibility exists that the sample could have been contaminated with residue from the baghouse hopper. Another contributing cause for the large VMD of the hopper ash is that the loss on ignition (LON) for these samples was $3.5 \%$ to $4 \%$ compared to $1 \%$ or less for the other tests (see Table 9). Higher LOI implies that unburned char was present in the ash, which may have biased the particle-size distribution toward larger sizes. Multicyclone analysis of the inlet fly ash indicated that the particle-size distribution consisted of a larger percentage of submicron particles than the previous full dust-loading tests with Big Brown coal, but this difference alone does not explain the blinding (graphs of multicyclone data are presented in Section 5.4.5.1). Therefore, a significantly smaller particle-size distribution does not appear to be the primary cause for the bag blinding and high $\mathrm{K}_{2}$ values.

If particle size is not the explanation, then low porosity or dense packing of the dust cake must have occurred. Greater dust cake packing is expected at a higher velocity; however, since the $K_{2}$ values for the full dust-loading test at $16 \mathrm{ft} / \mathrm{min}$ were not unreasonably high, the cause for the high $\mathrm{K}_{2}$ cannot be attributed only to the $16-\mathrm{ft} / \mathrm{min}$ face velocity. Rather, it appears that the combination of a very low dust loading and high velocity may be the cause. The particles that are collected are not protected by the rapid buildup of a dust 
cake and may be more susceptible to movement and packing after initial collection, leading to high $\mathrm{K}_{2}$ values.

There is also a question of whether the effectiveness of the bag cleaning is aggravated by the combination of high velocity and low dust loading. We know that some dust was removed from the bags during pulsing because of lowered pressure drop. The amount of dust on the bags (based on bag weights before and after the run) and the amount in the hopper were each about $50 \%$ of the total dust collected. Th 2 possibilities exist for the dust that was removed with pulsing: 1) it could be recollected on the bags, 2) it could collect on the walls of the baghouse vessel and hopper, or 3) it could fall to the hopper bottom. In the first case, even though pulsing was off-line, the 23-second off-line time would not be adequate for individual particles to fall to the hopper. For example, the gravitational settling velocity of a $10-\mu \mathrm{m}$ particle is only on the order of $1 \mathrm{~cm} / \mathrm{s}$. Therefore, if the dust is dispersed as individual particles after pulsing, these particles would not be expected to reach the hopper. For dust to reach the hopper after pulsing, sufficiently large agglomerates must remain intact for the dust to overcome the viscous drag of the flue gas. If the combination of a high velocity and low dust loading causes the particles to be more completely disbursed after pulsing, poor cleaning and eventual bag blinding may occur.

An additional factor that might contribute to dust cake packing and bag blinding is the cohesive nature of the ash. If cofiring of the coal with natural gas caused the fly ash to be significantly less cohesive, the results would be more easily explained. Unfortunately, not enough ash was generated to conduct tensile strength or porosity measurements on the bulk fly ash, so no data on cohesive properties are available.

One additional run was conducted at $16 \mathrm{ft} / \mathrm{min}$ with Big Brown coal to determine if precoating the bag with Neutralite might prevent bag blinding. Again, the combustor was fired on natural gas, supplemented with a coal feed rate of approximately $1 / 20$ th of the normal rate. This resulted in a dust loading at the baghouse inlet of 0.22 grains $/ \mathrm{scf}$. While the Neutralite ${ }^{\circledR}$ provided some initial benefit, after the bag was pulsed several times, it appeared that most of the Neutralite ${ }^{\star}$ was removed, and bag blinding again occurred. The bag blinding occurred for both the baseline and conditioning tests.

The bag was initially precoated with Neutralite while firing the combustor on $100 \%$ natural gas up to a $\Delta \mathrm{P}$ of 2.5 inches $\mathrm{WC}$. The test was started with a low $\mathrm{A} / \mathrm{C}$ ratio to help establish a dust cake without fabric blinding. Filtration on coal was started with an $A / C$ ratio of $4 \mathrm{ft} / \mathrm{min}$ for one hour followed by one hour at $6 \mathrm{ft} / \mathrm{min}$. At this point, the $\Delta \mathrm{P}$ was 
6 inches WC, primarily because of the Neutralite precoat, so the bag was pulsed off-line. Visual inspection of the bag through the sight ports indicated that almost all of the dust, including the Neutralite precoat, was removed by the pulse. The A/C ratio was then increased to 8,12 , and finally to $16 \mathrm{ft} / \mathrm{min}$. At this point, the decision was made to pulse the bag at 5 inches WC instead of on a time basis. After the first pulse at $16 \mathrm{ft} / \mathrm{min}$, an entire hour passed before reaching 5 inches WC, which indicated some continued benefit of the Neutralite. The time required to reach 5 inches WC for the next cleaning interval was only 30 minutes; the time required for the following interval was 20 minutes; and the time for the next cycle was reduced down to 12 minutes. This indicated that the benefit of Neutralite ${ }^{\oplus}$ was being lost with each successive cleaning cycle, and the bag was again blinding. After reaching 5 inches WC within 10 minutes, the bag was considered to be blinded because this is equivalent to an effective $K_{2}$ of about 75 inches of water-ft-min/lb. At this point, the bag was removed, hand-cleaned, and again precoated with Neutralite?. However, after about four or five cleaning cycles, the benefit of the Neutralite was quickly lost, and the bag had to be cleaned at least every 10 minutes to keep the $\Delta P$ below 5 inches WC. Precoating with Neutralite ${ }^{\circ}$ after hand-cleaning was tried several times, but each time blinding occurred after only four or five cleaning cycles. Tests were also conducted in which some Neutralite ${ }^{\circ}$ was added after each pulse, but this did not prevent bag blinding either. In cases where Neutralite ${ }^{\circ}$ was added simultaneously with the fly ash, the $\Delta P$ did not increase as fast; however, the add rate of the Neutralite had to be greater than the fly ash dust loading to prevent rapid $\Delta \mathrm{P}$ increase. Whenever the Neutralite was stopped, the benefit was quickly lost, apparently because most of the Neutralite was removed with bag pulsing.

A test was also conducted with $6 / 3 \mathrm{ppm}$ of $\mathrm{NH}_{3} / \mathrm{SO}_{3}$ with a Neutralite precoat, but no benefit of the conditioning was observed. A final test was attempted in which a Neutralite? precoat was used, but the coal feed rate was increased to the $16-\mathrm{lb} / \mathrm{hr}$ from the $4-\mathrm{lb} / \mathrm{hr}$ rate used in the earlier tests. However, fabric blinding again occurred after a few cleaning cycles. Since the Neutralite was not successful in preventing fabric blinding, the run was terminated, and the remainder of the week was used to perform another test with the Black Thunder coal (Run 413).

The reasons for the bag blinding with a low dust loading (achieved by cofiring with natural gas) remain somewhat of a mystery. Limited particle-size data do not indicate that the problem was caused by a smaller particle-size distribution. A sufficient amount of ash was not available from the first low dust-loading tests (Runs 401 and 402) to conduct cohesive measurements, and the ash from Run 412 was highly contaminated with Neutralite ${ }^{\Phi}$, 
so cohesive data are not available. Whether the cohesive properties of the dust from the low dust-loading tests were different than ash properties from the full dust-loading tests is not known. The remaining explanation is that, under very low dust-loading and high-velocity conditions, the ash is apparently more subject to packing, which leads to fabric blinding.

\subsubsection{Cohesive Properties and Ash Analyses}

\subsubsection{Particle Size}

Particle size was measured by two main methods: Coulter counter and 6-stage multicyclone. Typically, one Coulter counter analysis was completed on a hopper ash sample from each run. The Coulter counter data are presented as volumetric median diameters (VMD) in Table 9. The VMD of the hopper ash samples typically ranged from 12 to $16 \mu \mathrm{m}$, with one outlying at $19 \mu \mathrm{m}$. The Coulter counter analyses are fairly accurate, but caution must be exercised in interpreting differences in the VMD among the different runs. Since Coulter counter analysis requires only a very small sample (on the order of milligrams), a question exists on how representative the small sample is of the entire hopper ash sample. Multiple analyses would provide more information on the variability of the VMD within a given run, but multiple analyses were not completed. Therefore, no differences should be inferred in the VMD values for the hopper ash samples. The VMD values of the residual dust cake samples, however, were clearly smaller than the VMDs of the hopper ash samples and typically ranged from 6 to $8 \mu \mathrm{m}$, with one value at $10 \mu \mathrm{m}$. This indicates size fractionation occurred between the hopper ash and the residual dust cake ash, which could be the result of several effects. Larger particles might be more easily removed from the bags because the ratio of drag or inertial forces to cohesive forces is likely to be greater for larger particles. In addition, for the particles that are removed with pulsing, the larger particles are more likely to reach the hopper rather than be recollected $c n$ the bags. Both effects would tend to make the residual dust cake finer than the bulk hopper ash.

The multicyclone analyses are shown in Figures 61 through 64 as log-probability plots. A log-normal distribution curve was fit to the data, which is a straight line on a logprobability graph. The Big Brown and Milner multicyclone data from Task 3 agree closely with the Task 2 multicyclone data (Figures 61 and 62). A comparison of multicyclone results for the three coals, shown in Figure 63, indicates some differences in particle-size distribution. The Black Thunder ash has a greater percentage of submicron particles than the other ashes. Extrapolation of the data to the $50 \%$ cumulative mass point should provide the mass median aerodynamic diameter. For the Big Brown and Milner ashes, this aerodynamic 


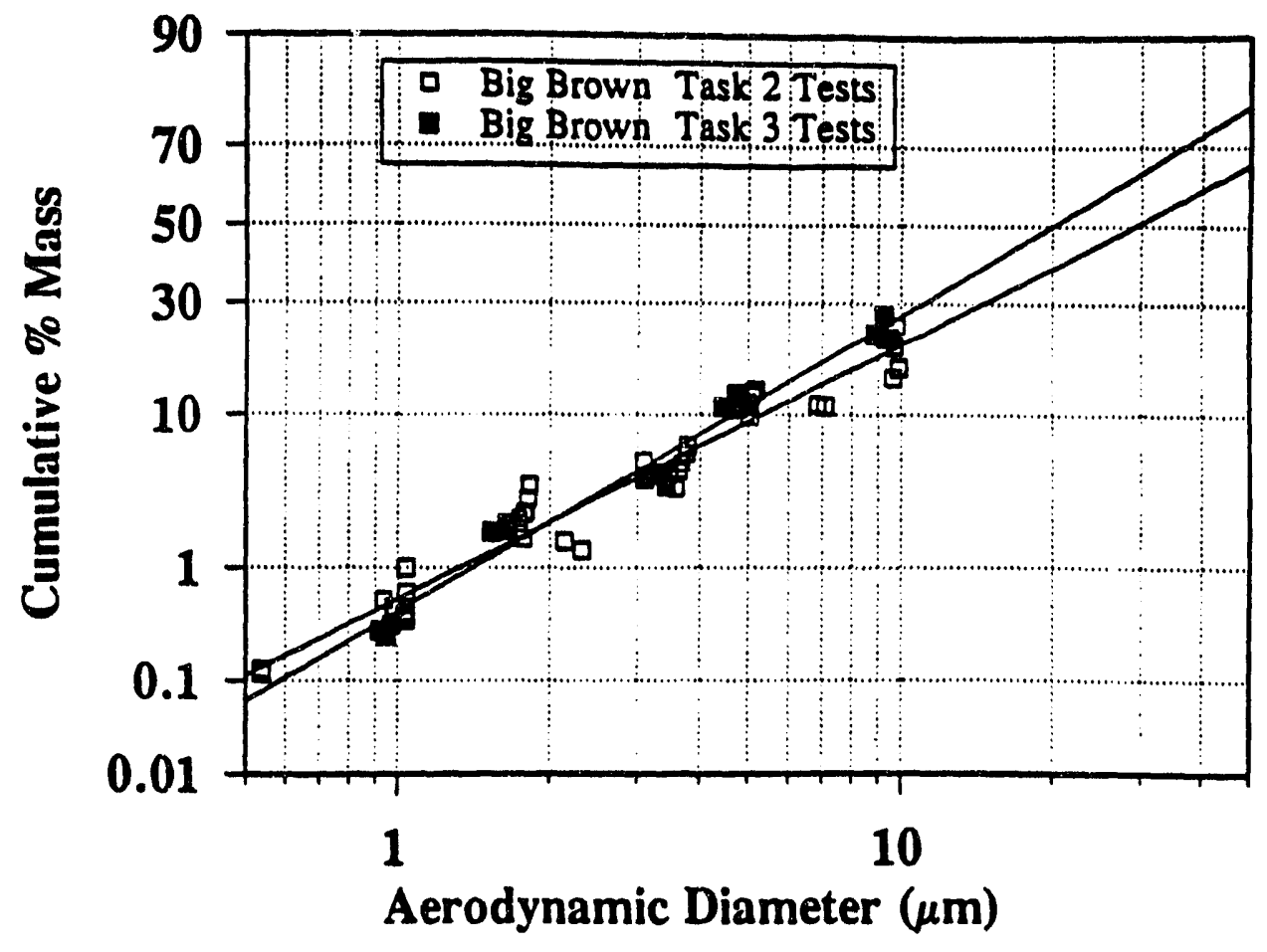

Figure 61. Particle-size distribution of Big Brown fly ash based on multicyclone sampling.

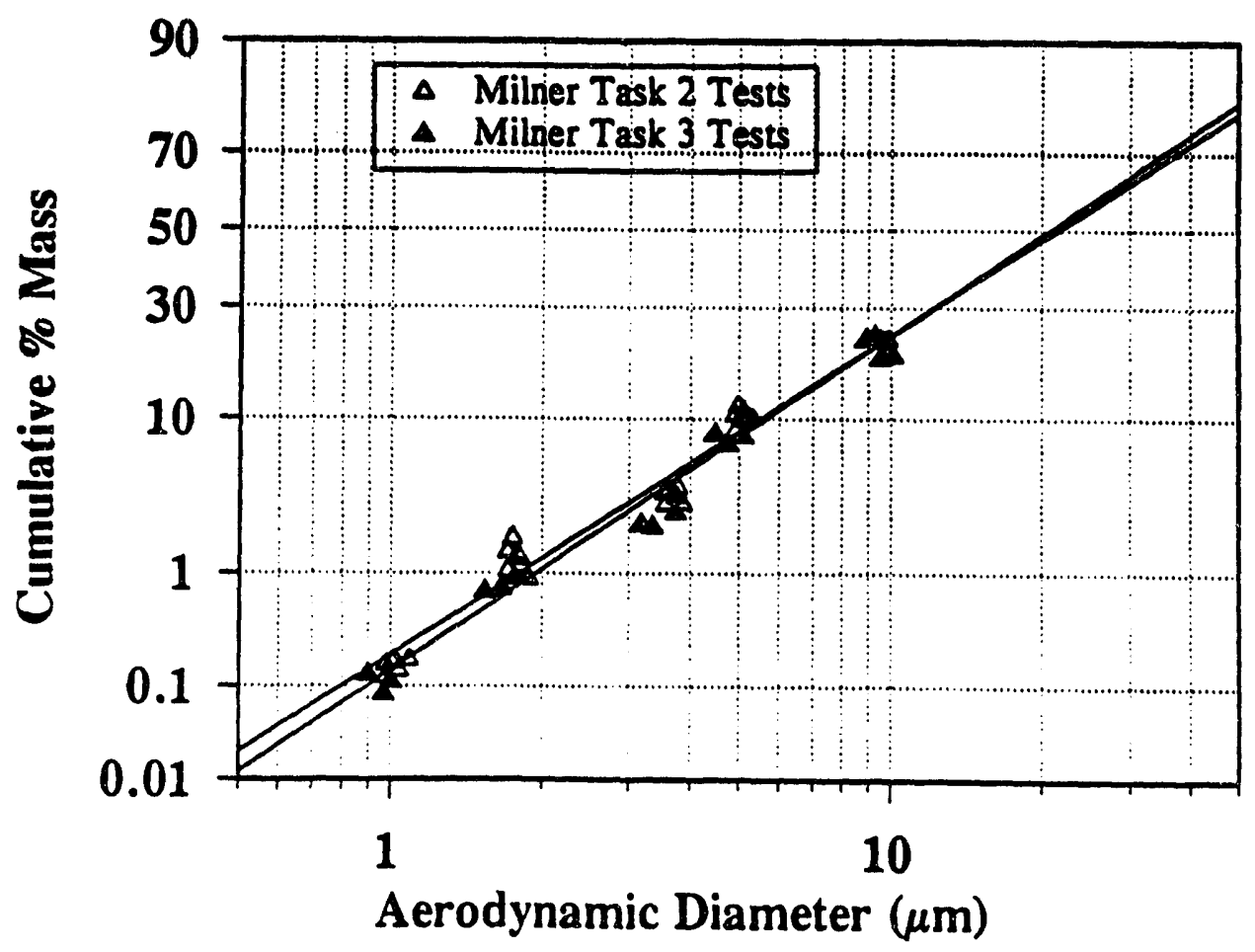

Figure 62. Particle-size distribution of Milner fly ash based on multicyclone sampling. 


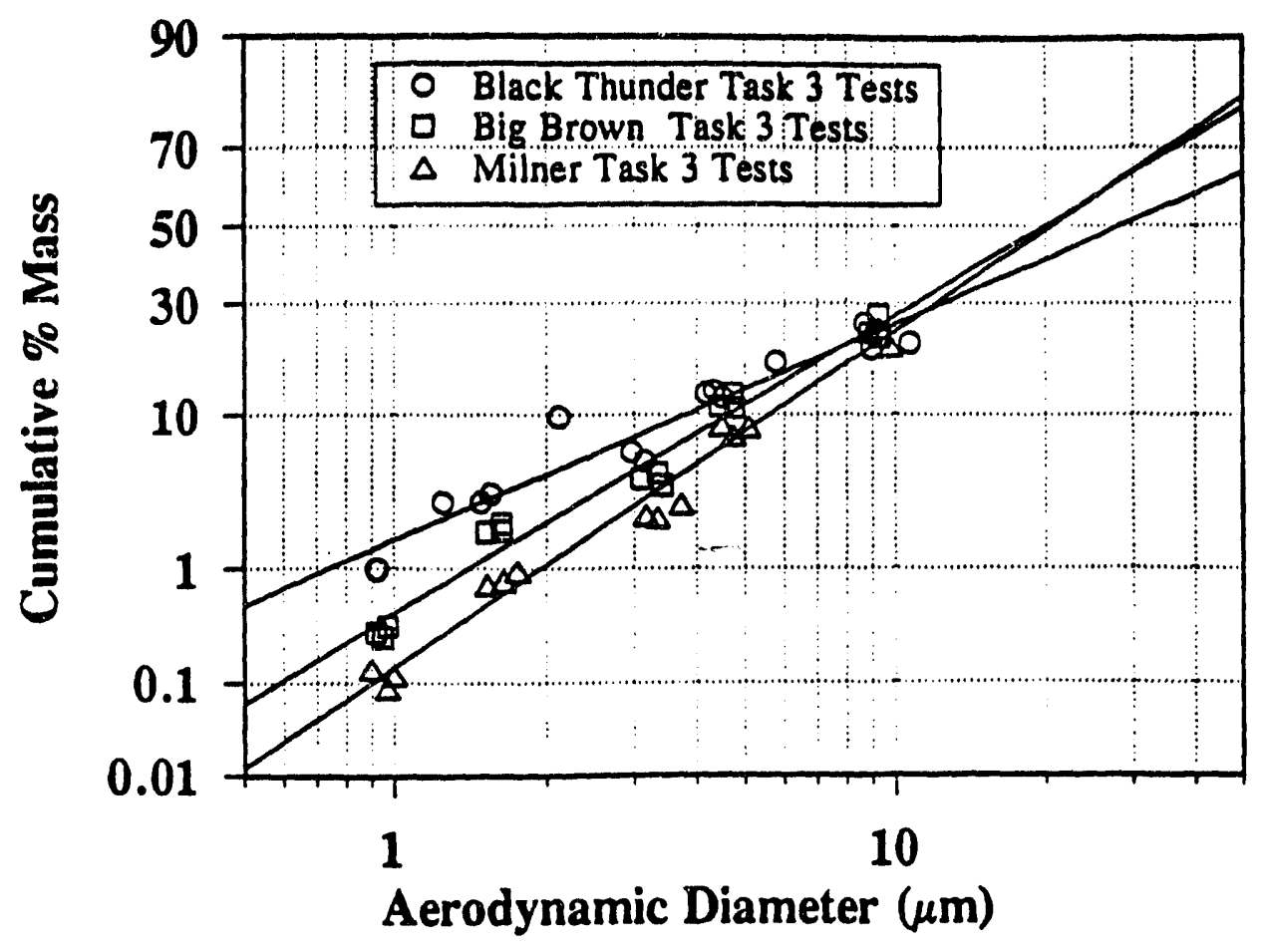

Figure 63. Comparison of particle-size distributions of Big Brown, Milner, and Black Thunder fly ash based on multicyclone sampling.

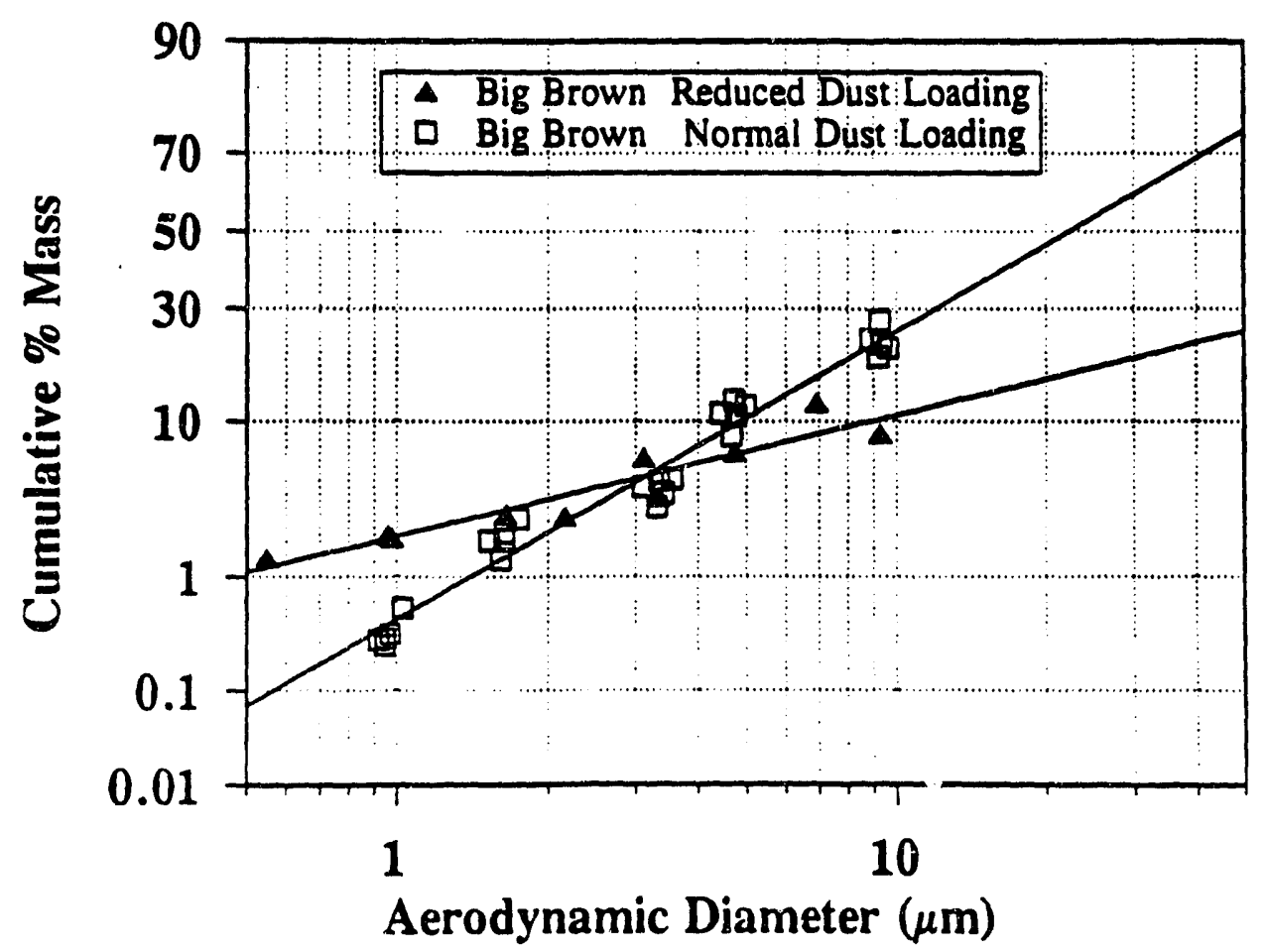

Figure 64. Comparison of particle-size distributions for normal and reduced dust-loading tests for Big Brown, based on multicyclone sampling. 
median diameter is about $20 \mu \mathrm{m}$, or about $13-\mu \mathrm{m}$ volumetric diameter, which agrees with the Coulter counter data (aerodynamic diameter can be converted to volumetric diameter by dividing by the square root of the particle density). The aerodynamic median diameter for the Black Thunder ash corresponds to a volumetric median diameter of about $17 \mu \mathrm{m}$, which is slightly higher than the $12-$ to $15-\mu \mathrm{m}$ range in volumetric median diameter determined by Coulter counter. Extrapolation of multicyclone data, however, is risky because about $80 \%$ of the ash is typically collected in the first cyclone, and no further information is available on the particle size of that $80 \%$ other than its being larger than the cut point of the first cyclone.

Both the mass median diameter and the width of the distribution (geometric standard deviation) are likely to have an effect on $K_{2}$. The highest $K_{2}$ occurred with the Black Thunder ash, which also had the greatest percentage of fine particles, and the lowest $\mathrm{K}_{2}$ occurred with the Milner ash, which had the smallest percentage of fine particles. Therefore, even though the median diameters of the three ashes are similar, the differences in the amount of fine particles may partially account for differences in $K_{2}$. Multicyclone results for the reduced dust-loading tests, shown in Figure 64, indicate a greater percentage of fine particles than the normal dust-loading tests. However, this difference alone does not appear to be the entire explanation for the mu:h higher $\mathrm{K}_{2}$ values for the reduced dustloading tests.

\subsubsection{Tensile Strength}

The primary dust characteristics that are likely to affect fabric filter performance include particle-size distribution and cohesive characteristics. The cohesive characteristics depend on factors such as chemical composition and particle morphology. The cohesive nature of the dust refers to the "stickiness" of the dust, or, more descriptively, the particleto-particle binding forces that exist in a dust cake. It is these relatively weak particle-toparticle forces that determine the pore-bridging ability of the dust and the resistance of the dust to reentrainment or gradual seepage through the fabric. These effects are important because they ultimately determine the fabric filter particulate collection efficiency. The resistance of the dust to packing and the ease of removing a dust cake from the fabric also depend on the particle-to particle forces and are important because they determine the pressure drop. The exact particle-to-particle forces depend on particle size, contact area, and chemicai composition. Subsequently, they are likely to vary widely within a given dust cake. Measurement of the distribution of individual particle-to-particle forces would be extremely difficult. A more straightforward approach would be to determine the average tensile strength of the dust, which can be considered to be a measure of the average particle-to- 
particle binding forces. For dusts with the same particle-size distribution, a comparison of tensile strengths at constant porosity should be an indication of their relative particle-toparticle binding forces.

Tensile strength as a function of porosity for the 100-hour Big Brown, Milner, and Black Thunder tests is shown in Figures 65 through 68. Based on multiple curve fit analysis, an exponential curve was fit to each data set of the form:

$$
\text { tensile strength }=a \exp ([-b][\% \text { porosity }])
$$

The physical significance of the coefficients in Equation 3 is not known. The curve fits simply facilitate extrapolation of the data so that comparisons in tensile strength can be made at constant porosity.

For the Big Brown tests (Figure 65), there is a significant shift in the tensile strength with conditioning toward higher porosity and higher tensile strength. For the Milner tests (Figure 66), there is also a significant shift toward higher porosity and higher tensile strength with conditioning, but the highest tensile strengths observed (under maximum compaction) were only about $4 \mathrm{~g}_{\mathrm{f}} / \mathrm{cm}^{2}$ compared to $18 \mathrm{~g}_{\mathrm{f}} / \mathrm{cm}^{2}$ for the conditioned Big Brown samples. For both Big Brown and Milner conditioning tests, the tensile strengths at a face velocity of $6 \mathrm{ft} / \mathrm{min}$ were somewhat higher than the tensile strengths at $4 \mathrm{ft} / \mathrm{min}$. In the 8-hour tests completed in Task 2, the highest tensile strengths were also observed at the higher $\mathrm{A} / \mathrm{C}$ ratios. Typically, when the $\mathrm{A} / \mathrm{C}$ ratio is increased, the bags are cleaned more often, and the exposure time of the ash to the flue gas is reduced. However, the bag-cleaning interval was held constant for both $\mathrm{A} / \mathrm{C}$ ratios, so differences in tensile strength would appear to be related to differences in face velocity, rather than other factors such as exposure time. There is no apparent reason why conditioning would have a greater effect on tensile strength at the higher $\mathrm{A} / \mathrm{C}$ ratio. The shift in the tensile strength curves with increasing $\mathrm{A} / \mathrm{C}$ ratio was much smaller than the significant shift in the tensile strength curves with conditioning for both the Big Brown and Milner tests. This indicates that the cohesive character of the ash was significantly changed and implies that the improvement in filtration performance was a direct result of the changed cohesive properties.

Figure 67 shows that the shift in the tensile strength curves for the Black Thunder tests was smaller than the shift for the Big Brown and Milner tests. For the Black Thunder tests, there was also a smaller improvement in fabric filter performance, which implies that the level of performance improvement correlates with the relative shift in the tensile strength 


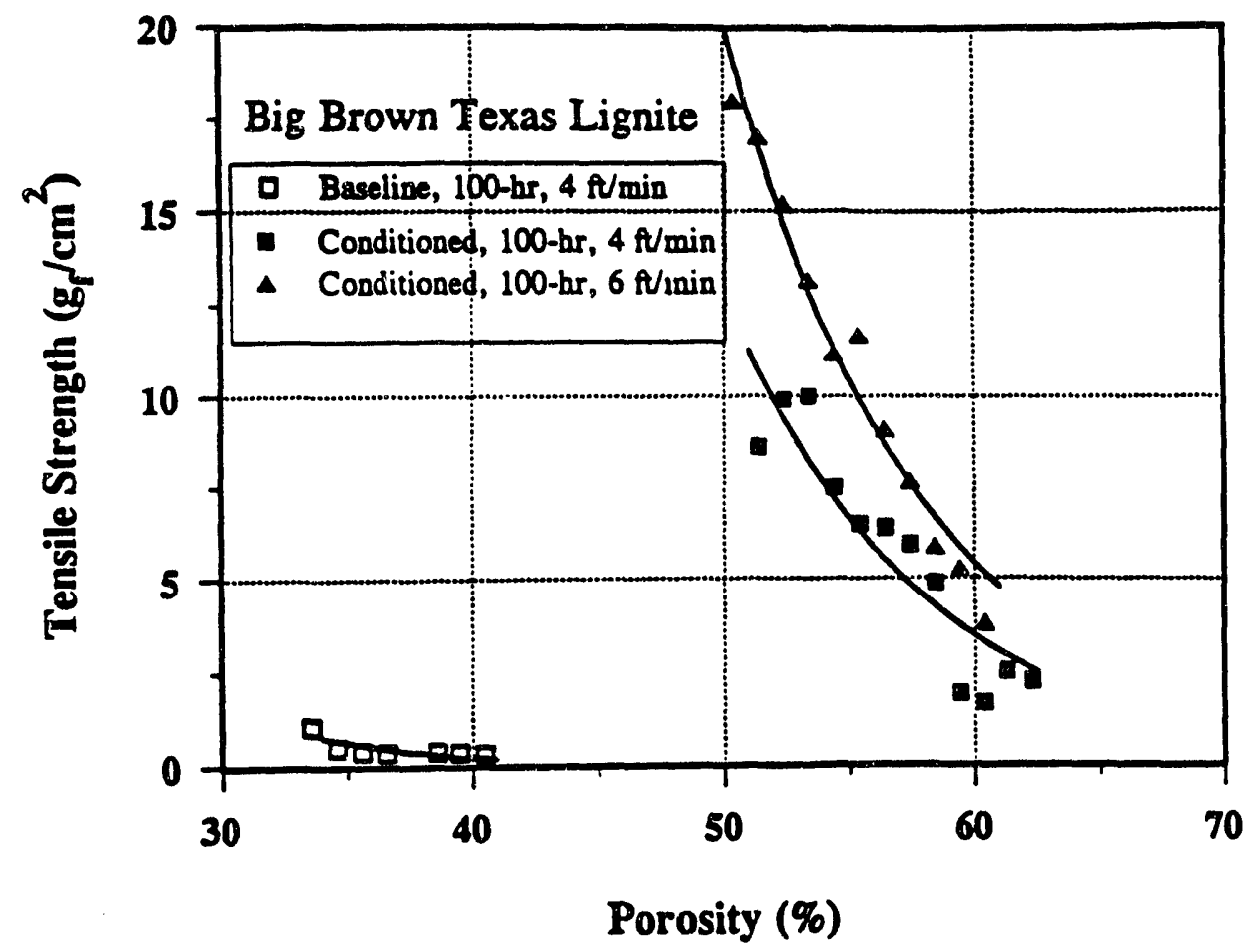

Figure 65. Effect of conditioning on fly ash tensile strength for 100-hour Big Brown tests.

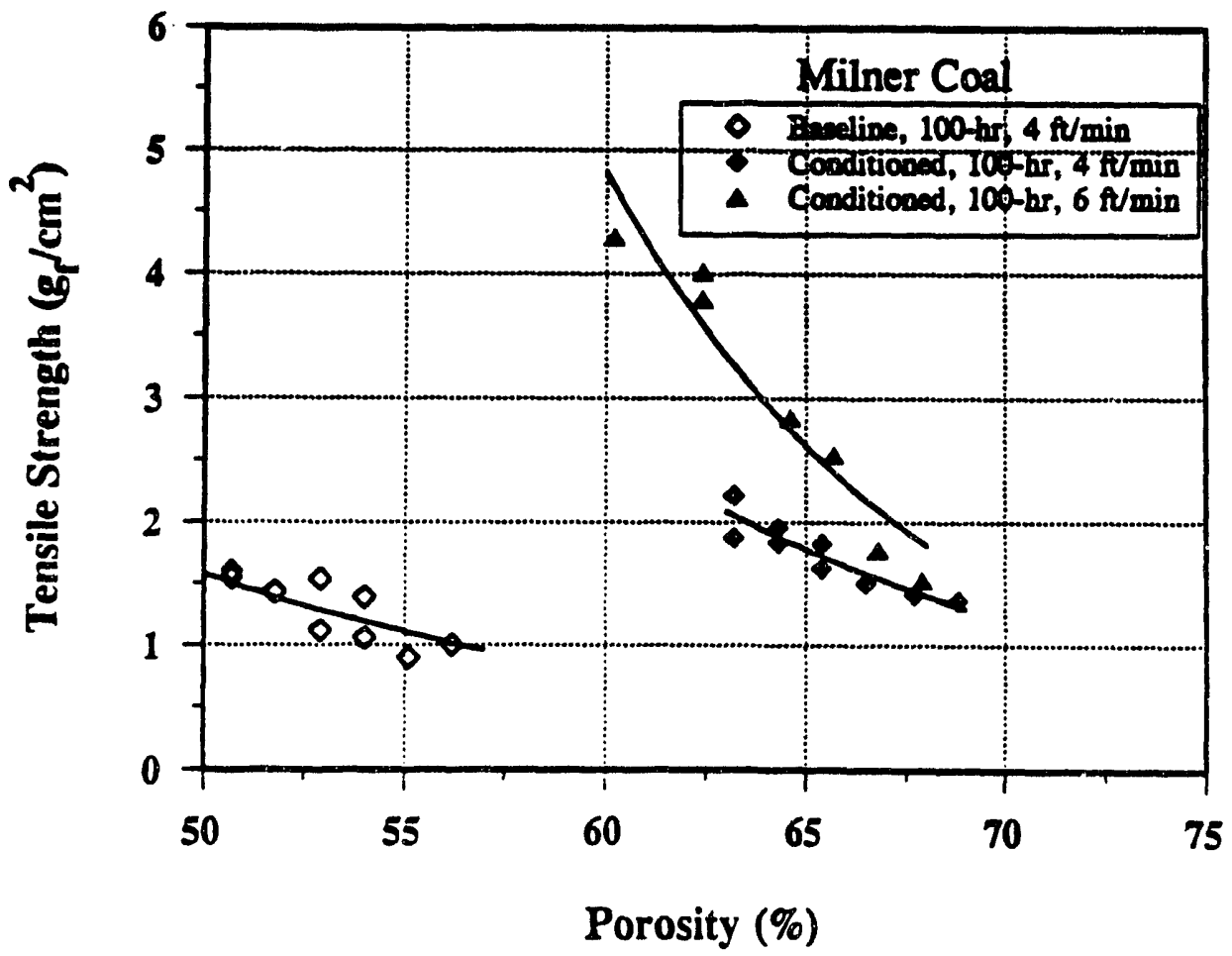

Figure 66. Effect of conditioning on fly ash tensile strength for 100-hour Milner tests. 


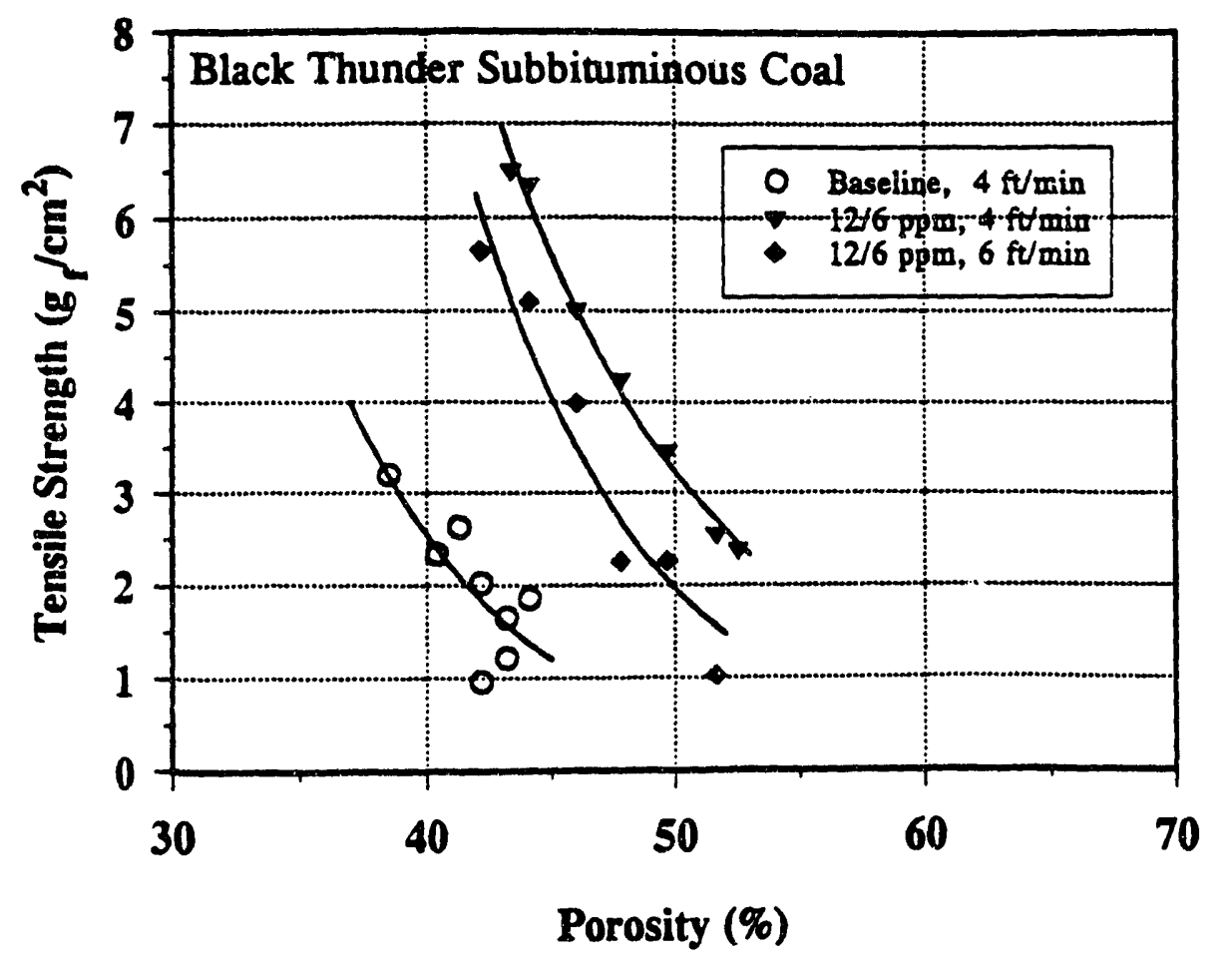

Figure 67. Effect of conditioning on fly ash tensile strength for 100-hour Black Thunder tests.

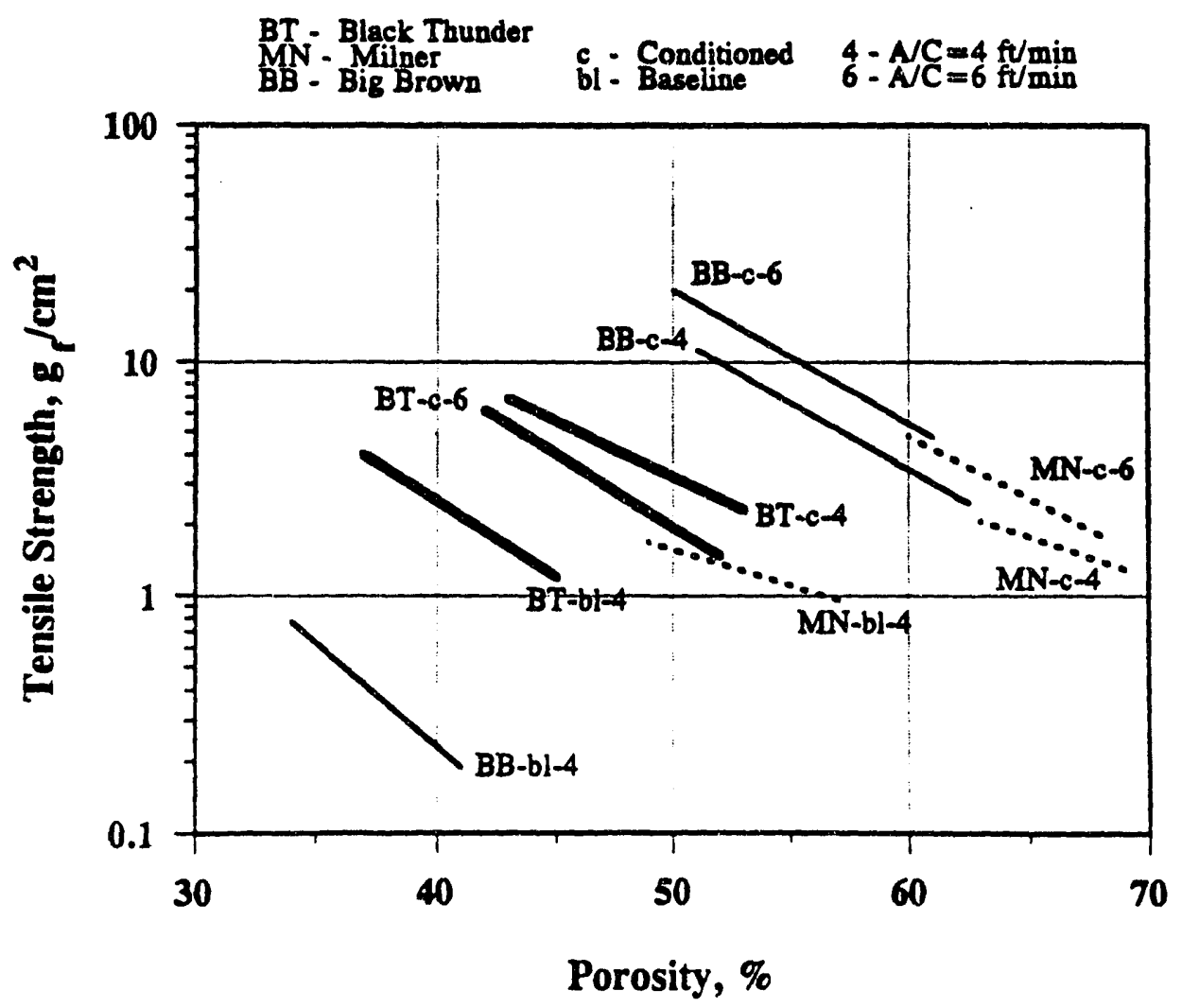

Figure 68. Comparison of fly ash tensile strengths for conditioned tests with Big Brown, Milner, and Black Thunder coals. 
curves. An obvious question is whether fabric filter performance can be predicted on the basis of tensile strength and/or porosity measurements. A comparison of the tensile strengths for the three baseline coals, given in Figure 69, indicates that the three ashes are distinctly different. Recall that the highest particulate emissions occurred for the baseline Big Brown run and the lowest particulate emissions occurred with the Black Thunder coal (see Figures 29, 37, and 46). The lowest particulate emissions appear to correlate with the highest tensile strength, which indicates that particulate emissions might be predicted from tensile strength. A question exists as to what porosity value or compaction force the tensile strength should be compared, but it appears that either the maximum or average tensile strength for each sample would provide a relative indication of particulate emissions. This correlation demonstrates the potential to predict filtration performance based on ash properties.

Tensile strength measurements, including the 8-hour tests in Task 2 and the $16-\mathrm{ft} / \mathrm{min}$ tests, are shown in Figures 70 through 72 . Figure 70 shows that the tensile strength for the conditioned ash from the normal dust-loading 16- $\mathrm{ft} / \mathrm{min}$ test was within the range of tensile strengths from the other 8-hour tests. This might indicate that tensile strength is not influenced by AVC ratio, as suggested previously; however, since the bag was cleaned much more frequently, a direct comparison cannot be made because of the possibility of residence time effects. For two of the Black Thunder tests, tensile strength of the residual dust cake ash was measured (Figure 72) to help determine why bag-cleaning problems occurred. Results show that tensile strength of the residual dust on the bags was considerably higher than the tensile strength of the corresponding hopper ash samples. The highest tensile strength was measured for the bag ash from Run 410B, where the conditioning concentrations were $12 / 6 \mathrm{ppm}$. This is surprising because the bag-cleaning problem occurred when concentrations were $24 / 12 \mathrm{ppm}$ in Run 410A. However, the residual dust cake was exposed to the flue gas for only 24 hours in Run 410A, compared to 75 hours in Run $410 \mathrm{~B}$. In addition, the median particle size of the residual dust: cake was somewhat smaller for Run 410B. The higher tensile strengths of the dust cake ash may be the result of both a smaller particle size and a longer time of exposure to the flue gas. The tensile strength of the hopper ash sample for Run 410A at $6 \mathrm{ft} / \mathrm{min}$, when bag cleaning occurred and conditioning concentrations were $24 / 12 \mathrm{ppm}$, was higher than the tensile strength for Run 413 at $6 \mathrm{ft} / \mathrm{min}$, when bag cleaning did not occur and conditioning concentrations were $12 / 6$ ppm. The higher tensile strength at the high conditioning concentrations was expected. However, the maximum tensile strength for Run 410A, when bag-cleaning problems occurred, was less than the maximum tensile strength of ash from the Big Brown tests when there were no bag-cleaning problems. This implies that other factors might also influence bag cleanability, but we do not know which dust cake had the highest actual tensile strength. 


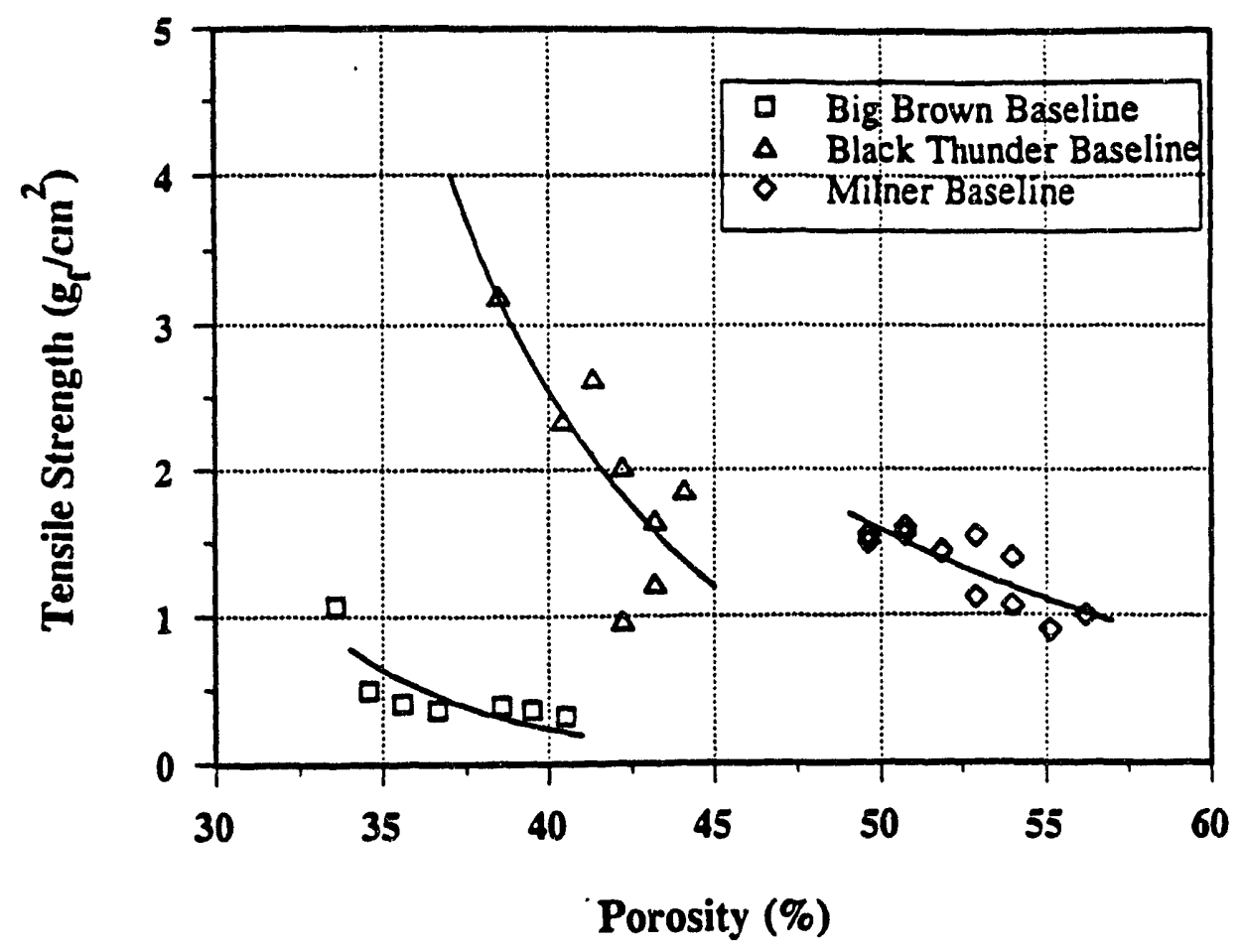

Figure 69. Comparison of fly ash tensile strengths for baseline tests with Big Brown, Milner, and Black Thunder coals.

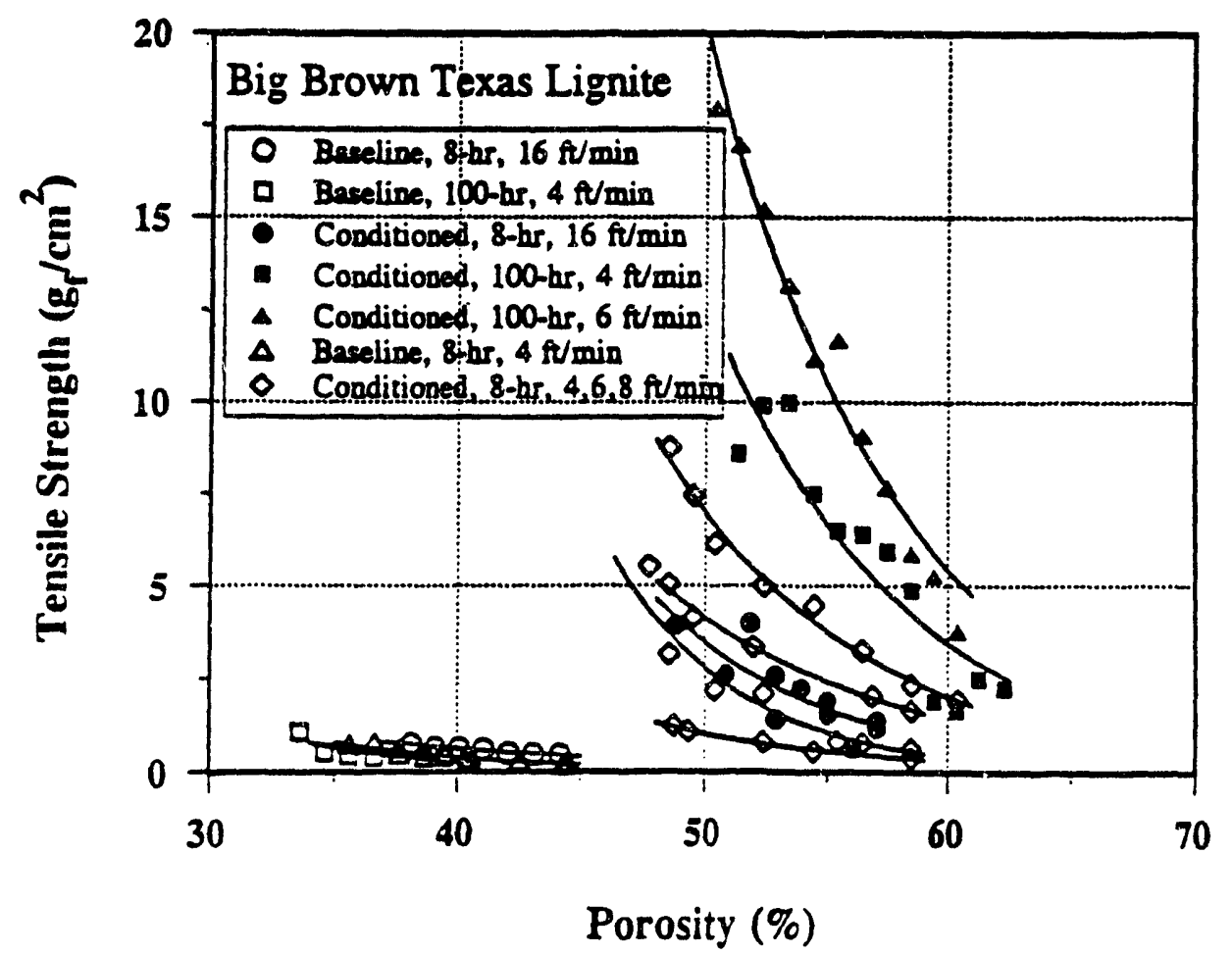

Figure 70. Fly ash tensile strengths for 100- and 8-hour Big Brown tests. 


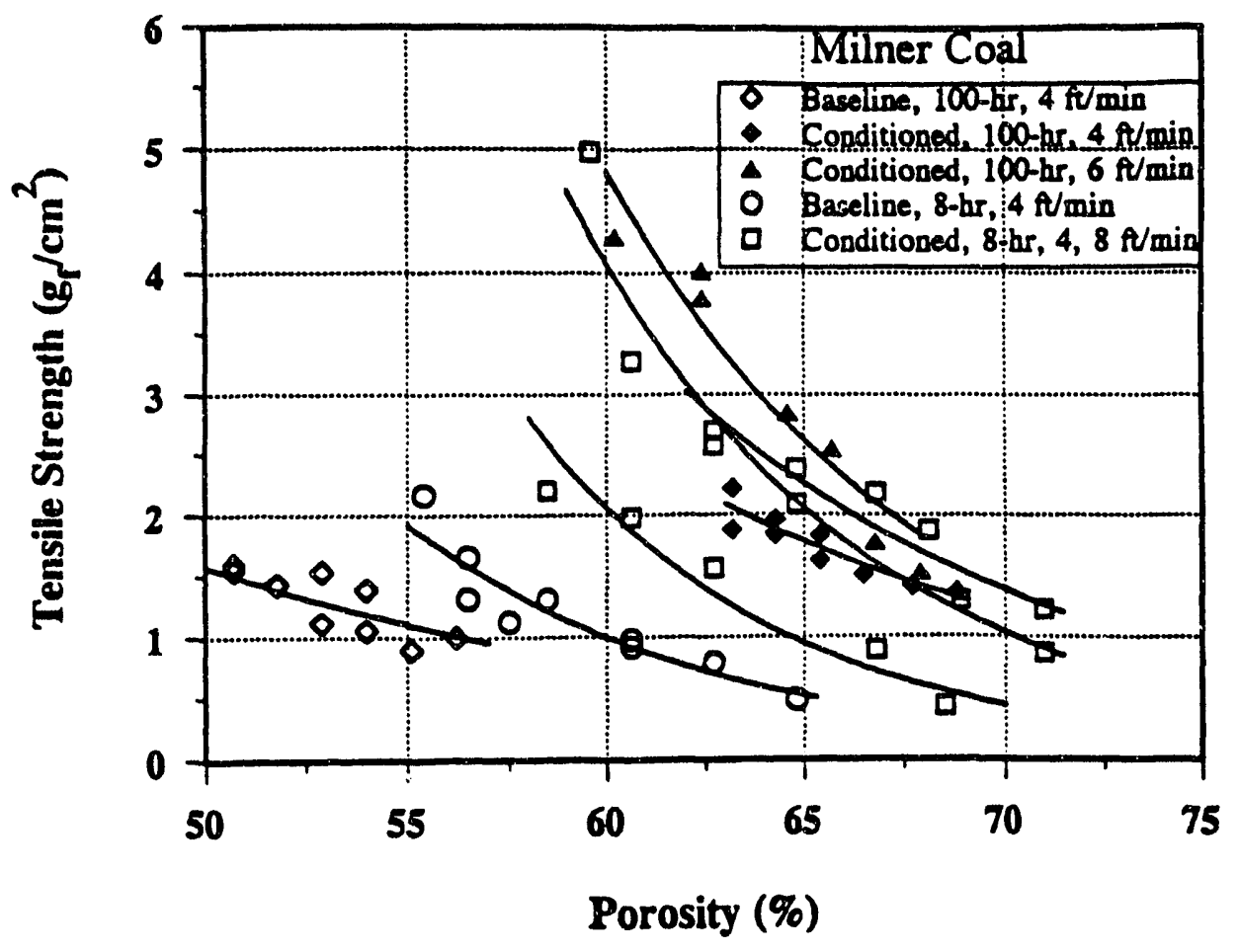

Figure 71. Fly ash tensile strengths for 100- and 8-hour Milner tests.

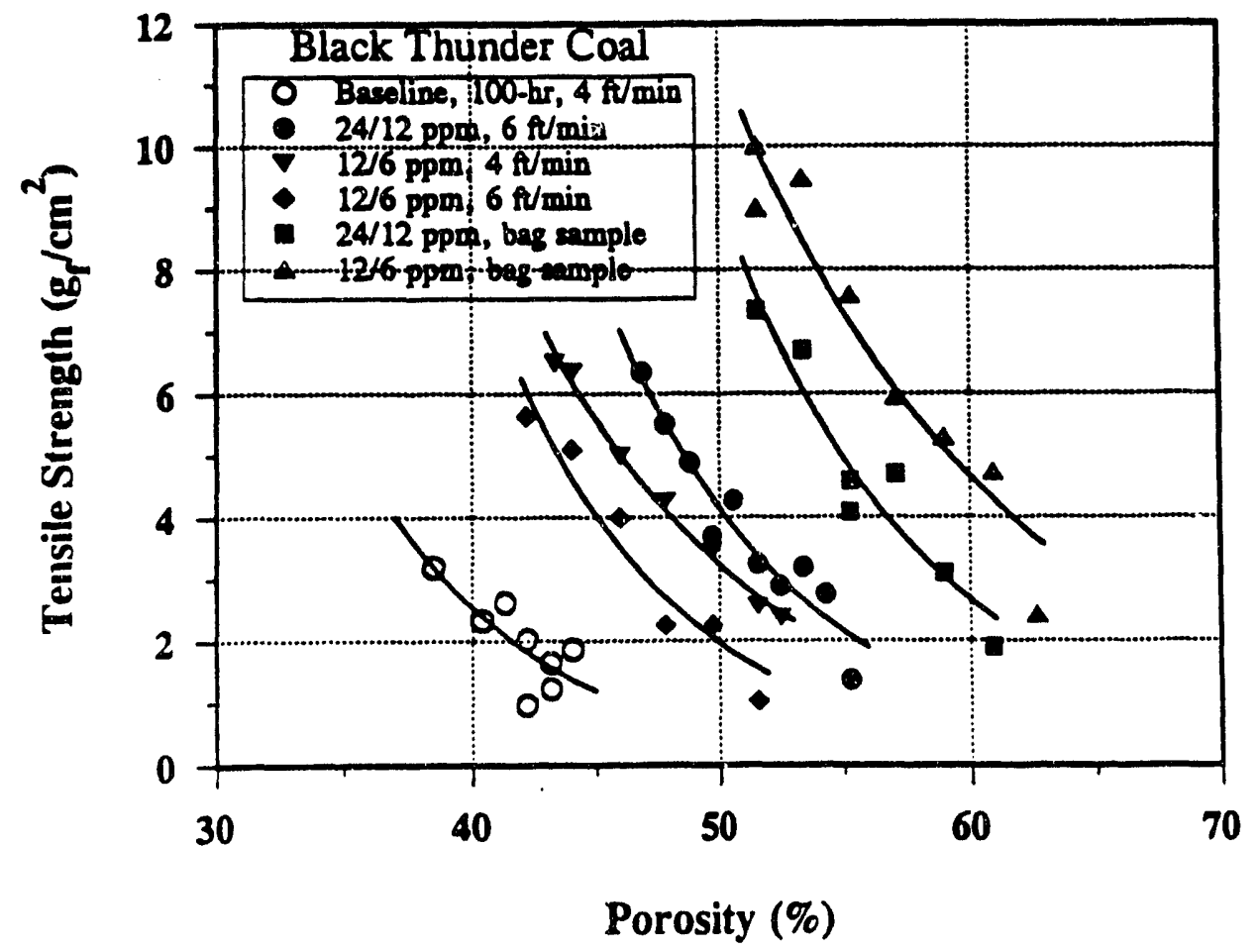

Figure 72. Comparison of tensile strengths of hopper ash and residual dust cake ash from the bags for Black Thunder tests. 
One of the difficulties in trying to correlate tensile strength with bag cleanability is the determination of the actual tensile strength of the dust cake. If the $\mathrm{K}_{2}$ of the dust cake is known and $\mathrm{K}_{2}$ can be measured in the laboratory as a function of porosity, the porosity of the dust cake can be determined indirectly. If the tensile strength of the fly ash is measured as a function of porosity, the tensile strength of the dust cake can be inferred. This approach assumes that the hopper ash and dust cake have similar particle-size distributions.

Laboratory measurements of $\mathrm{K}_{2}$ as a function of porosity are shown in Figures 73 through 76. These combined data from both baseline and conditioning runs for each coal are fit to the Carman-Kozeny equation for each plot. The Big Brown data all follow a single CarmanKozeny curve more closely than the Milner and Black Thunder data, but the dust cake porosity can be approximated from these curves if the $K_{2}$ of the dust cake is known. One of the causes for data scatter is small differences in particle-size distribution. Figure 76 shows the Carman-Kozeny curves fit to the three sets of data along with calculated Carman-Kozeny curves for monosized particles. Note that the differences in the curve fits are equivalent to only a $2-\mu \mathrm{m}$ spread in equivalent monosized diameter. Since the actual dusts have broad particle-size distributions, the equivalent Carman-Kozeny diameters cannot be predicted directly from the median particle diameters of the dusts. From the initial $\mathrm{K}_{2}$ values for the 100 -hour tests (corrected for the viscosity difference between $70^{\circ}$ and $300^{\circ} \mathrm{F}$ ) and the $K_{2}$ porosity curves in Figure 76, the porosities of the baseline and conditioned Big Brown dusts cakes were $63 \%$ and $77 \%$; the porosities of the baseline and conditioned Milner dust cakes were $80 \%$ and $85 \%$; and the porosities of the baseline and conditioned Black Thunder dust cakes were $66 \%$ and $72 \%$. These porosities are all much greater than the porosity range for which tensile strength data are available. Therefore, to infer the tensile strength of the dust cakes would require an extrapolation greater than the porosity range for which the tensile strength data exist. Because of the data scatter of the actual tensile strength data, such extrapolation would have too much uncertainty to provide valid tensile strengths of the dust cakes. From the available data, we cannot accurately infer the tensile strengths of the dust

cake. One conclusion that can be made, however, is that the actual dust cake tensile strength would be less than the lowest measured tensile strength for each ash sample.

\subsubsection{Porosity Measurements}

The aerated and packed porosity measurements are most likely related to the tensile strength, but may provide more direct information on the susceptibility of the dust to packing. Aerated and packed porosity data, given in Table 8, clearly show that one effect of conditioning is to make the ash less susceptible to packing. The aerated and packed porosity data are in good agreement as to the increase in porosity that occurs with conditioning. For 


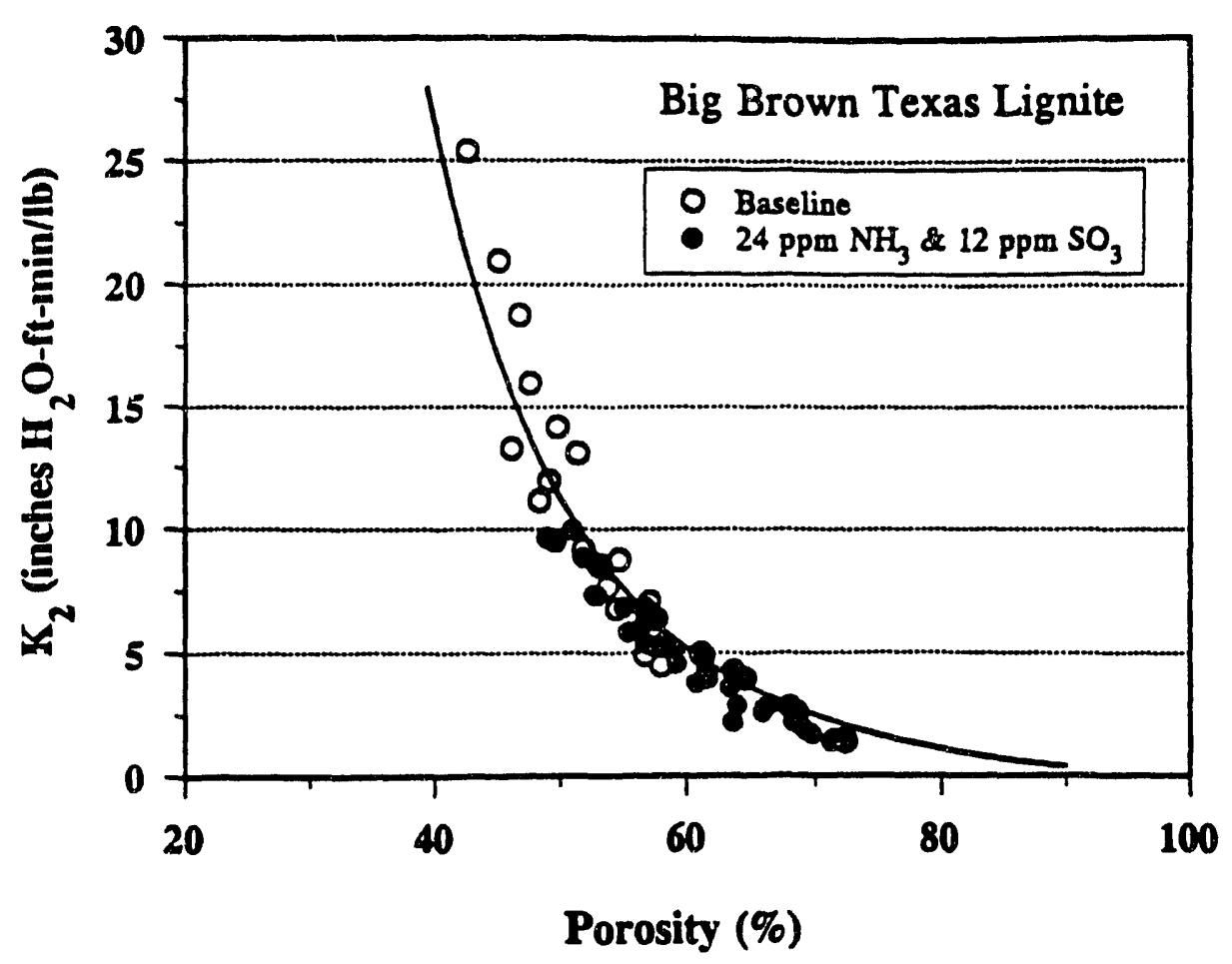

Figure 73. Laboratory measurement of $\mathrm{K}_{2}$ as a function of porosity with Carman-Kozeny equation fit to data for Big Brown tests.

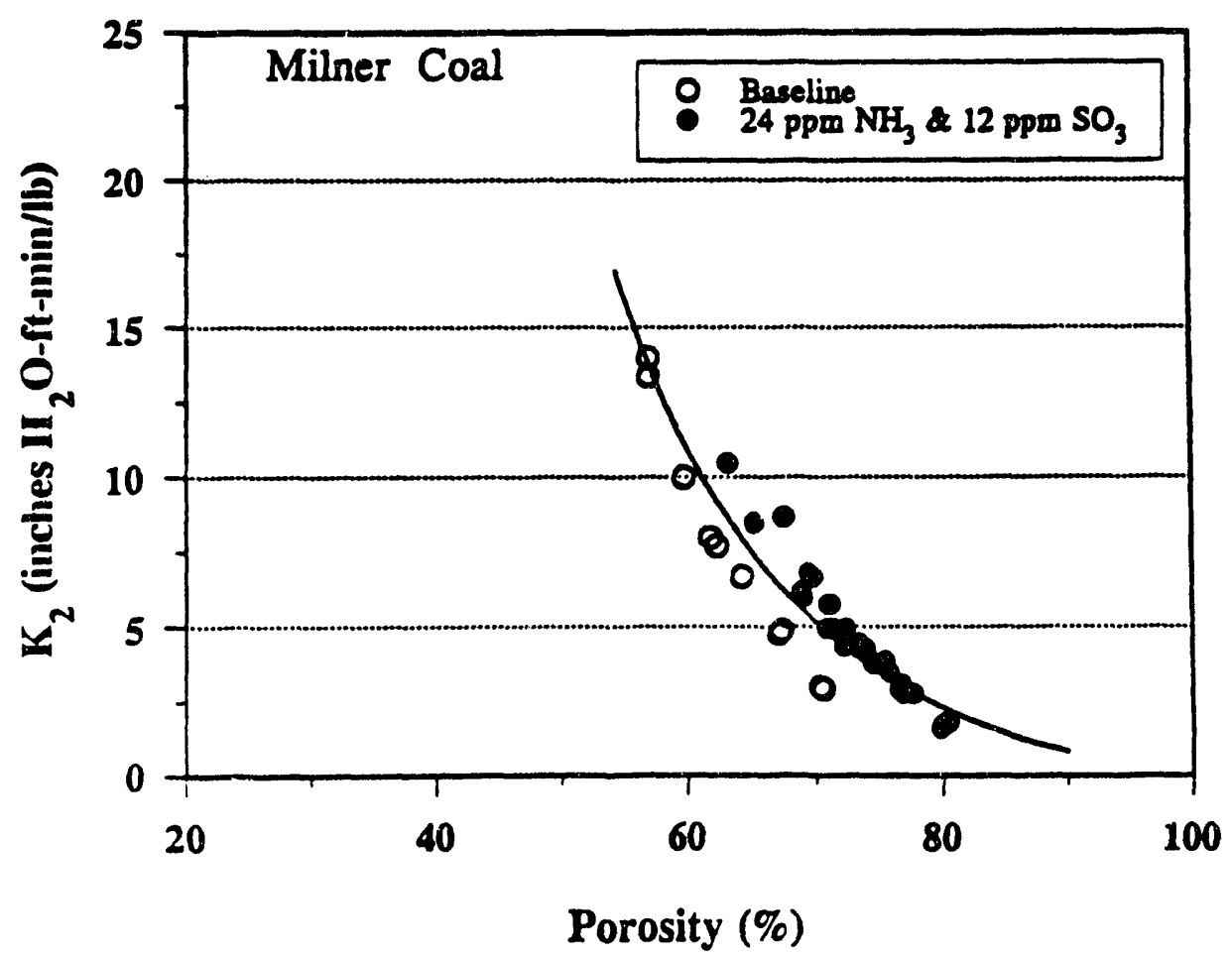

Figure 74. Laboratory measurement of $\mathrm{K}_{2}$ as a function of porosity with Carman-Kozeny equation fit to data for Milner tests. 


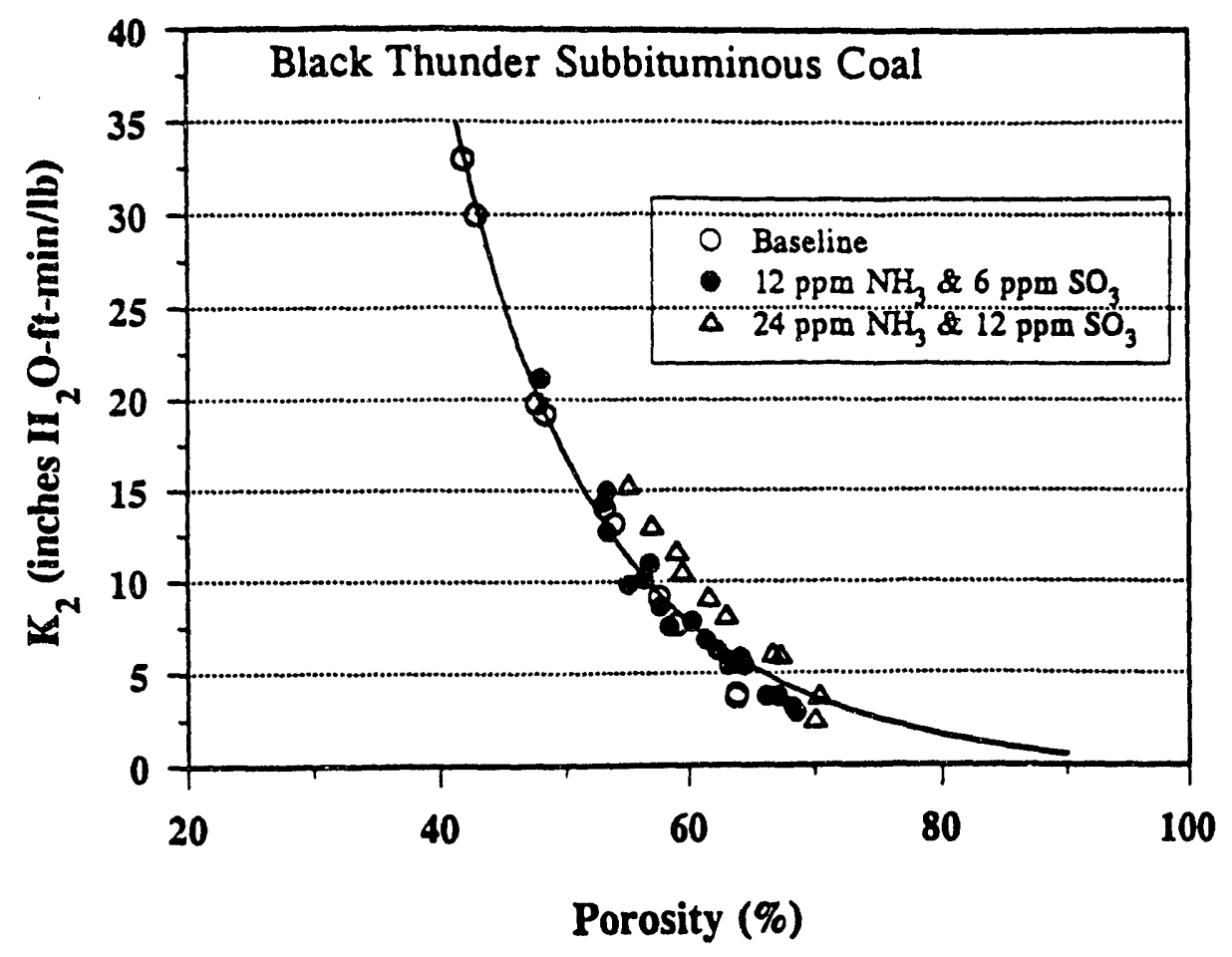

Figure 75. Laboratory measurement of $\mathrm{K}_{2}$ as a function of porosity with Carman-Kozeny equation fit to data for Black Thunder tests.

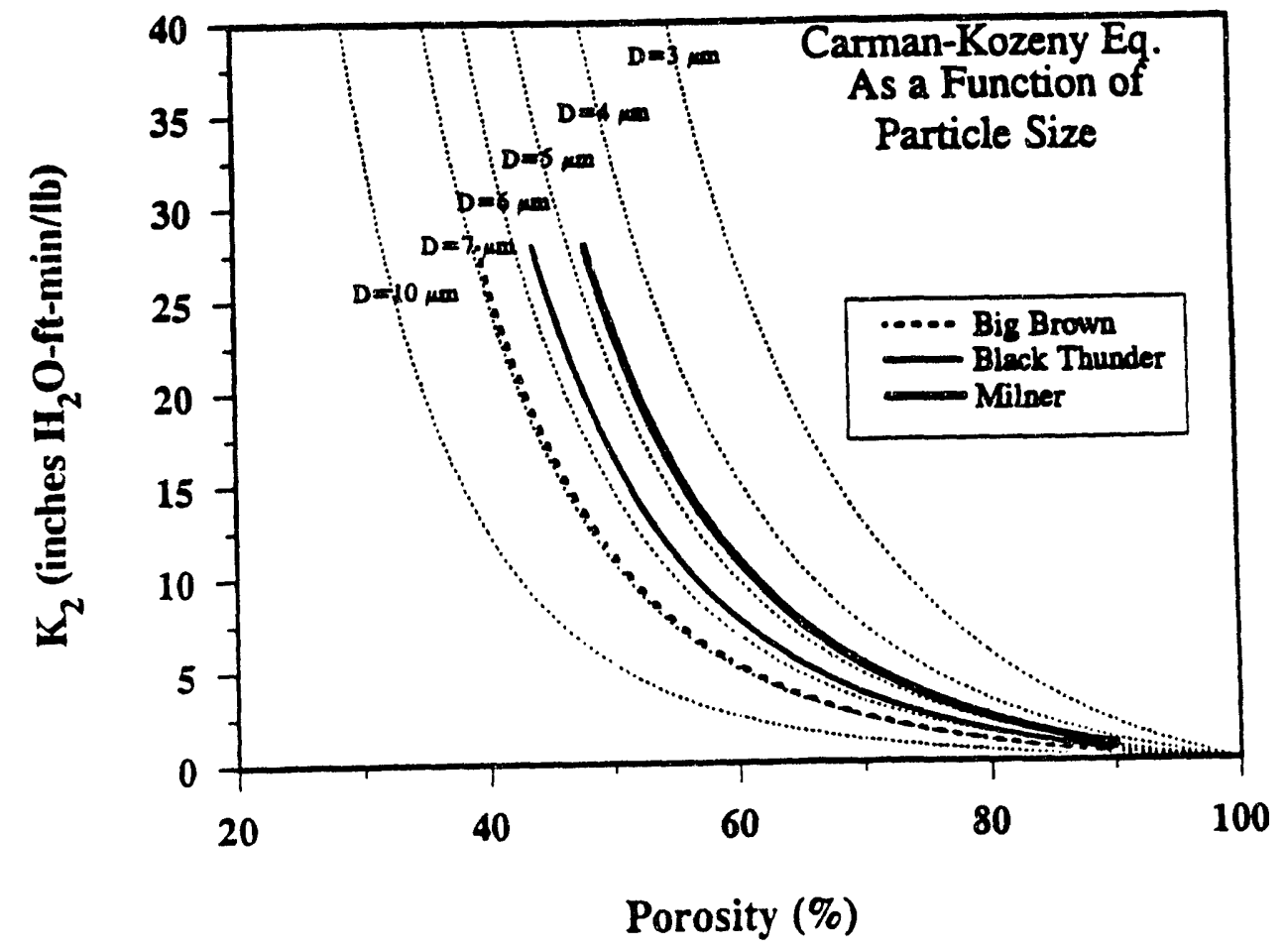

Figure 76. Comparison of $\mathrm{K}_{2}$ curves for Big Brown, Milner, and Black Thunder tests. 
example, the greatest increase in aerated and packed porosity that occurred with conditioning was with Big Brown coal, and these tests also resulted in the greatest decrease in $\mathrm{K}_{2}$. The smallest increase in aerated and packed porosity as a result of conditioning was with the Black Thunder tests, which also resulted in the smallest decrease in $\mathrm{K}_{2}$. The correlations between the aerated and packed porosity data and the initial $\mathrm{K}_{2}$ values from the 100-hour tests are shown in Figure 77, and the correlations for the effective $K_{2}$ values are shown in Figure 78. It appears that the packed porosity data provide a somewhat better correlation than the aerated porosity data. These correlations would likely not be valid, however, if the particle-size distributions varied significantly. The actual porosity of the dust cake is most closely represented by the aerated porosity measurements, rather than the packed porosity measurements. For example, with the Big Brown tests, the inferred porosities of the baseline and conditioned dust cakes were $63 \%$ and $77 \%$, compared to the aerated porosities of $58 \%$ and $76 \%$. For the Milner tests, the inferred dust cake porosities were $80 \%$ and $87 \%$, compared to aerated porosities of $71 \%$ and $83 \%$. For the Black Thunder tests, the inferred dust cake porosities were $66 \%$ and $72 \%$, compared to aerated porosities of $66 \%$ and $70 \%$. Therefore, the aerated and packed porosity measurements have three uses in relating ash properties to filtration performance. First, they appear to be good methods to quantify the effect of conditioning on ash properties; second, they correlate well with initial and effective $\mathrm{K}_{2}$ values; and third, the aerated porosity measurements provide an approximation of the actual dust cake porosity. Much more work is needed, however, to refine these correlatiois and to generalize them for a variety of dusts.

\subsubsection{Ammonia and Sulfate Analyses}

Elemental analysis of the hopper ash samples, determined by $x$-ray fluorescence, is shown in Table 9. The transfer of $\mathrm{SO}_{3}$ to the fly ash is shown by the increased sulfate in the conditioned samples compared to the baseline samples. However, this analysis is not sufficiently accurate to determine the amount of the injected $\mathrm{SO}_{3}$ that was transferred to the fly ash and does not include ammonia analysis.

Ammonia and soluble sulfate analyses (by ion chromatography) were conducted on the baghouse hopper ash samples and on the bag ash samples and are presented in Table 10. Since ammonium sulfate is highly soluble, this should be a valid determination of the amount of conditioning agents transferred to the fly ash. The ammonia in the ash and ammonia slip in the flue gas downstream from the baghouse should equal the amount of ammonia injected. For the Big Brown tests, the average of ten ammonia slip measurements was $0.83 \mathrm{ppm}$ and ranged from 0.27 to $1.84 \mathrm{ppm}$. For the Milner tests, the average of six 


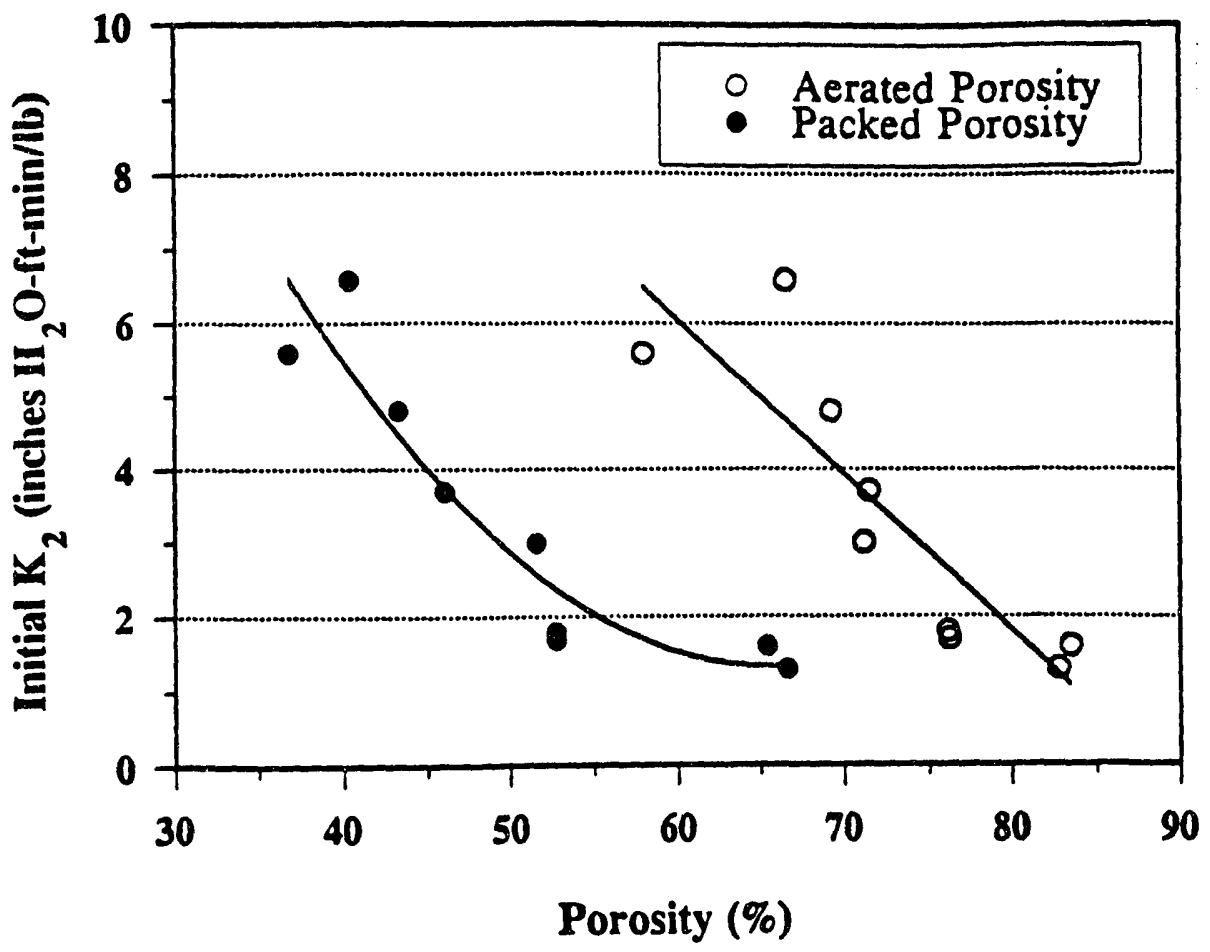

Figure 77. Correlation between initial $\mathrm{K}_{2}$ and aerated or packed porosity.

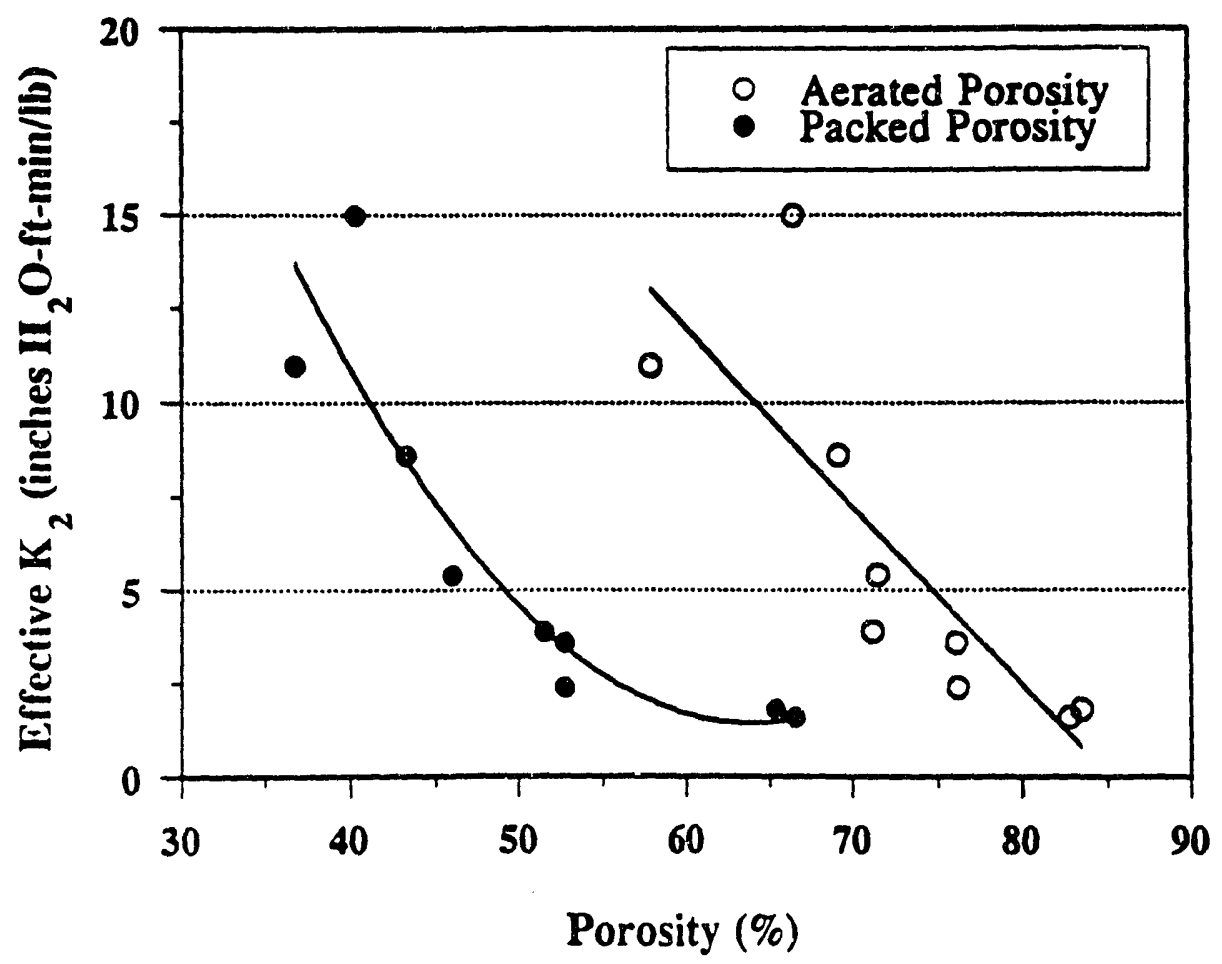

Figure 78. Correlation between effective $\mathrm{K}_{2}$ and aerated or packed porosity. 


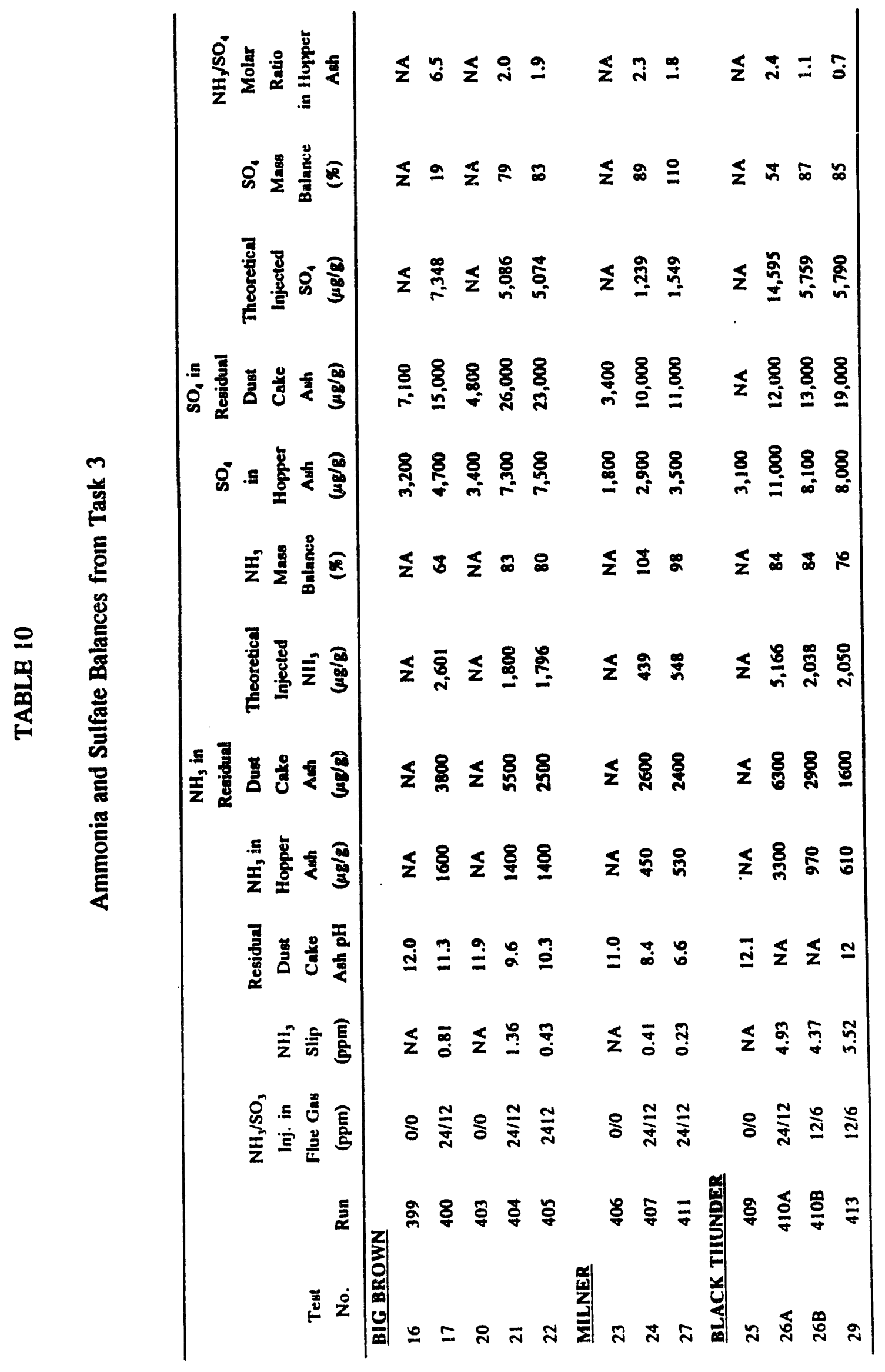


ammonia slip measurements was $0.18 \mathrm{ppm}$ and ranged from 0.10 to $0.31 \mathrm{ppm}$. For the Black Thunder tests, the average ammonia slip for seven measurements was noticeably higher at $4.9 \mathrm{ppm}$ and ranged from 4.3 to $6.7 \mathrm{ppm}$. This was true in spite of the fact that five of the seven ammonia slip measurements were conducted when the ammonia injection rate was only $12 \mathrm{ppm}$. Average ammonia slip values for each run are shown in Table 10.

For the Big Brown and Milner samples, most of the injected ammonia and $\mathrm{SO}_{3}$ was transferred to the fly ash, based on soluble ammonia and soluble sulfate analyses of hopper ash samples. There is uncertainty as to the sulfate transferred because there were also some soluble sulfates in the baseline ash samples. The baseline sulfate concentrations were subtracted from the sulfate soncentrations with conditioning to indirectly determine the amount of added sulfate. For the 100 -hour tests, the amount of the injected $\mathrm{SO}_{3}$ that was transferred to the fly ash ranged from $79 \%$ to $110 \%$. The uncertainty of the amount of injected $\mathrm{SO}_{3}$ of about $\pm 10 \%$ along with the uncertainty of the amount of baseline soluble sulfate means that the uncertainty of the sulfate balance is at least $\pm 10 \%$. For the 8-hour Big Brown test at $16 \mathrm{ft} / \mathrm{min}$ (Run 400) and the Black Thunder test at the highest injection rate (Run 410A), the soluble sulfate concentrations were much lower than expected. The ammonia mass balance was based on the ammonia slip and the ammonia in the hopper ash and ranged from $76 \%$ to $104 \%$ for all tests except Run 400 , for which the balance was $64 \%$. The ammonia balances should be more accurate than the sulfate balances because there is greater certainty of the amount of injected ammonia, and there is no background ammonia in the baseline ash. The ammonia and sulfate concentrations for the residual dust cake samples were from 2 to 5 times greater than the corresponding hopper ash samples. However, this difference is not surprising considering the large difference in particle size. Since the conditioning agents are likely to deposit on the available surface area, the ammonia and sulfate are expected to be more concentrated in the finer particles.

The measured ammonia-to-sulfate molar ratio for the 100 -hour Milner tests was close to $2: 1$, indicating that the product formed on the ash is ammonium sulfate. For the 100 -hour Big Brown tests, there was also a molar ratio of ammonia to sulfate of 2:1 for the hopper ash. However, the fly ash ammonia concentration, along with the 1 to $2 \mathrm{ppm}$ of ammonia slip, still leaves $4 \mathrm{ppm}$ of ammonia unaccounted for from the total of 24-ppm ammonia that was injected. Whether some off-gassing of the ammonia could occur in sample storage and handling or whether the lack of complete closure is due to analytical variability is not known.

For the Black Thunder samples, the ammonia analysis indicated that only about $30 \%$ to $50 \%$ of the ammonia was transferred to the fly ash, and the ammonia slips were 
correspondingly high. About 2 to $4 \mathrm{ppm}$ of the injected ammonia was unaccounted for. One other interesting effect that occurred with the Black Thunder samples was very low soluble sulfate values, on the basis of a 24-hour leaching test. Valid soluble sulfate concentrations can be obtained if the sulfate measurements are taken immediately after water extraction, but the soluble sulfate concentration slowly decreases with time. Apparently, insoluble sulfate complexes are slowly formed in solution. The molar ratio of ammonia to sulfate was closer to 1:1 for the 100-hour Black Thunder tests compared to a 2:1 ratio for the Big Brown and Milner tests. This implies that there could be a reaction between the fly ash and $\mathrm{SO}_{3}$ in the dust cake and offers an explanation for the high ammonia slip values. The high ammonia slip, 1:1 molar ratio of ammonia to sulfate, and the less significant effect of conditioning on baghouse performance for the Black Thunder tests are indications that the effectiveness of conditioning depends on fly ash chemistry.

In addition to measuring the ammonium and sulfate concentration, the $\mathrm{pH}$ of the residual dust cake ash was measured for eight of the 100-hour tests and two 8-hour tests (one gram ash in $100 \mathrm{ml}$ of water). As shown in Table 10, there is a decrease in the $\mathrm{pH}$ of the ash with $\mathrm{NH}_{3}$ and $\mathrm{SO}_{3}$ conditioning. As would be expected, the decrease in ash $\mathrm{pH}$ is directly related to the alkali content of the coal ash ( $\mathrm{Ca}, \mathrm{Mg}, \mathrm{Na}$, and $\mathrm{K})$. The Black Thunder, which had the highest alkali content (34.4\%) of the three coals tested, showed almost no decrease in $\mathrm{pH}$. Contrasting this to the Milner fly ash, with an alkali content of only $7.5 \%$, the $\mathrm{pH}$ dropped from 11 for the baseline test to 6.6 with conditioning. This is very near the $\mathrm{pH}$ of 5.5 for a $5 \%$ solution of pure ammonium sulfate. For the Big Brown coal, which has an intermediate alkali content (27.4\%), the $\mathrm{pH}$ dropped from 11.9 for the 100-hour baseline test to 9.6 for the 100-hour conditioned test. The decrease in $\mathrm{pH}$ also seems to be run-time-dependent. For the 8-hour test using Big Brown coal, the pH decreased only slightly, 12 for the baseline to 11.3 with conditioning. This indicates that there is an increase with time in the ammonium sulfate (bisulfate) content of the residual dust cake ash. This is consistent with the higher ammonia and sulfate concentration of the residual dust cake ash for the 100 -hour tests. What, if any, effects this may have on longterm operation is uncertain.

\subsubsection{Residual Dust Cake Weight}

Residual dust cake weights, given in Table 8, were determined by measuring the bag weights before and after the runs. After each 100-hour run, the whole tube sheet was lifted with the bags in place to allow for inspection of the bags and photographs of the residual dust cakes. The cages were then pulled from the bags, and the bags were removed from the 
botton of the tube sheet to minimize the amount of dust loss prior to weighing each bag. Photographs of the bags are shown in Figures 79 through 87 . The heaviest residual dust cakes occurred for the Big Brown tests, and the lightest cakes for the Milner tests. For the baseline Big Brown test (Run 403, shown in Figure 79), there was very little dust on the fabric surface over the entire length of the bags, but the dust was somewhat packed into the fabric structure. For Run 404 with conditioning at an $\mathrm{A} / \mathrm{C}$ ratio of $4 \mathrm{ft} / \mathrm{min}$, the weight of the residual cake was slightly lower, but the dust was very much on the fabric surface and somewhat nodular on the bottom half of the bags (Figure 80). For Run 405 with conditioning at $6 \mathrm{ft} / \mathrm{min}$, the cake was heavier and even more nodular on the bottom half of the bags. The top 8 inches of the bags with conditioning had a very heavy cake about $1 / 2$ inch thick. Some of this heavy cake fell off when the tube sheet was lifted, but it is clearly visible in the photographs. Apparently, the pulse results in little bag expansion or reverse flow at the very top of the bag, so this dust buildup may have occurred over all the runs.

For the Milner tests, the photographs show almost no residual dust cake for either the baseline or conditioning tests, which is in agreement with the bag weight data. In spite of the extremely high dust loading with the Milner coal, the ash characteristics apparently facilitate bag cleaning. However, a different fabric was used for the Milner (P84/Ryton), which may' also have had an effect on the dust cake release.

The bags were also fairly clean at the end of the Black Thunder tests, but there was some nodular structure on the bottom half of the bags. They were not as clean as for the Milner tests, but were cleaner than for the Big Brown conditioning tests, which is in agreement with the residual dust cake weights.

\subsection{CONCLUSIONS AND RECOMMENDATIONS}

\subsection{8-hour Tests with Milner and Big Brown Coals}

Results from the 8-hour tests showed that conditioning significantly reduced pressure drop and corresponding $\mathrm{K}_{2}$ at all concentrations tested. Results showed that conditioning worked well for both the Milner and Big Brown coals, even though the two coals had very different properties. This is an encouraging result and may be the most significant finding of the Task 2 tests, because it demonstrates the wide applicability of the conditioning process for improving baghouse performance. 

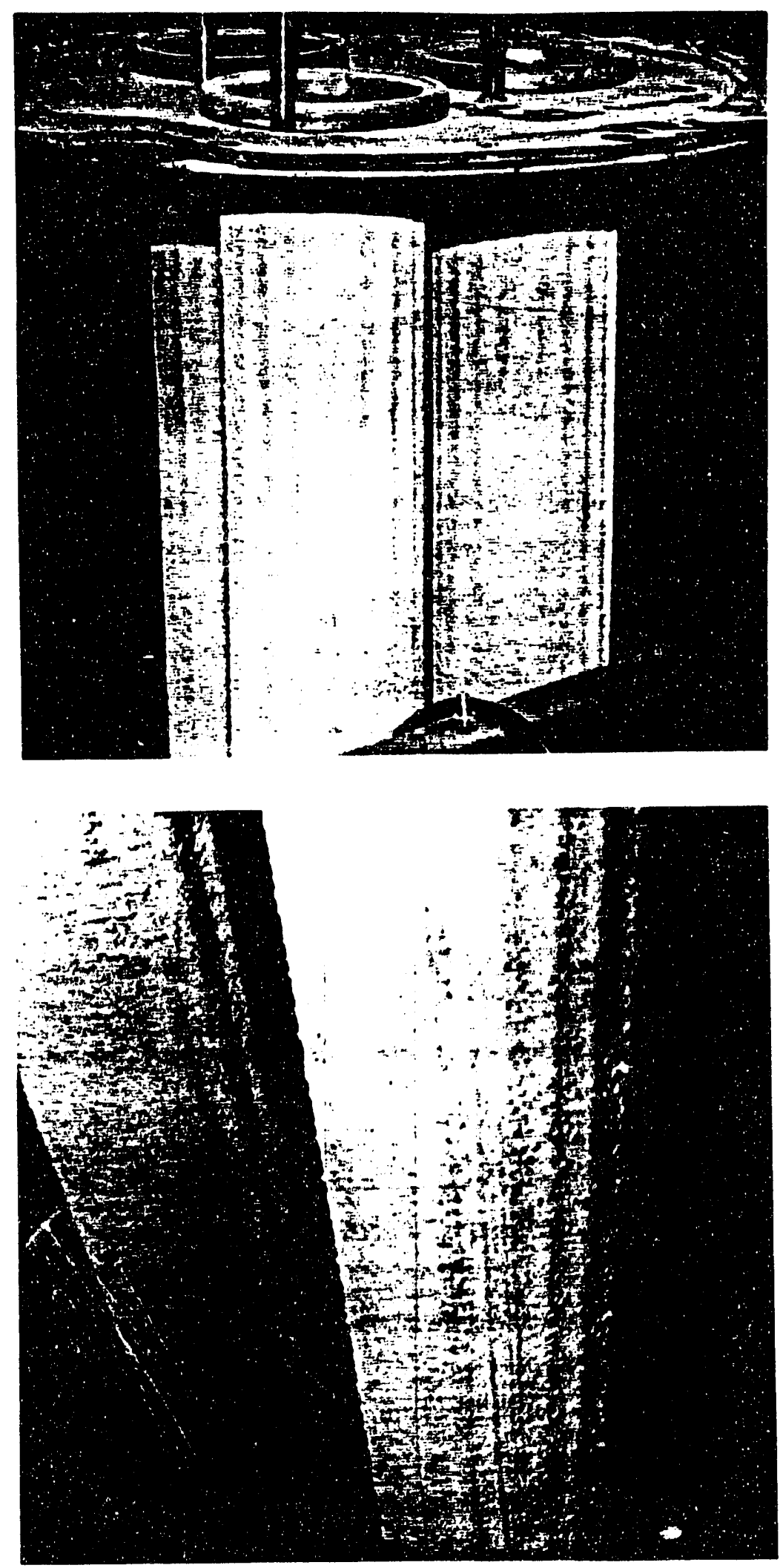

Figure 79. Residual dust cake at the end of the 100-hour baseline test with Big Brown coal for Run 403. 


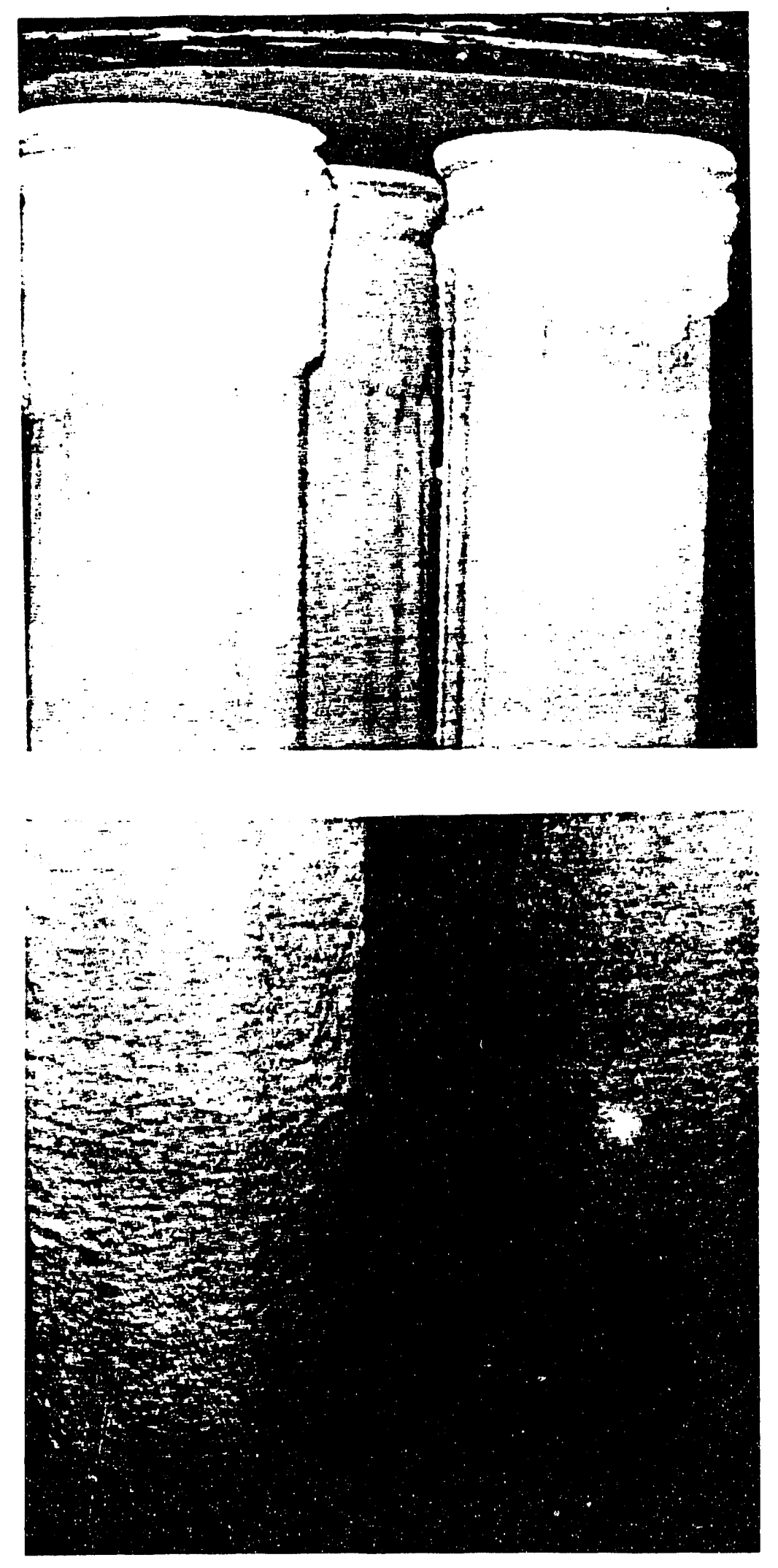

Figure 80. Residual dust cake at the end of the 100-hour conditioning test with Big Brown coal at an $\mathrm{A} / \mathrm{C}$ ratio of $4 \mathrm{ft} / \mathrm{min}$ for Run 404 . 

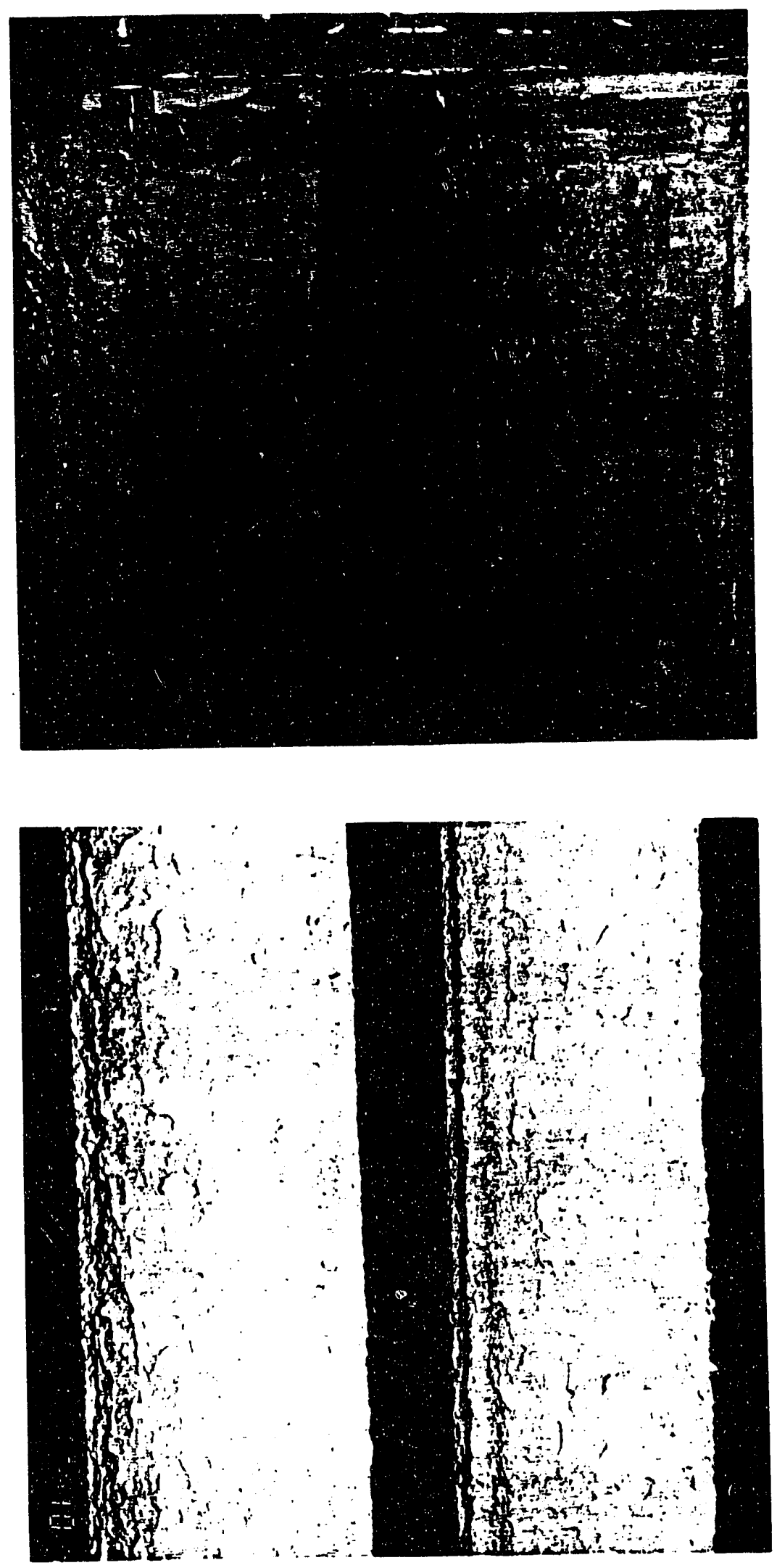

Figure 81. Residual dust cake at the end of the 100-hour conditioning test with Big Brown coal at an A/C ratio of $6 \mathrm{ft} / \mathrm{min}$ for Run 405 . 

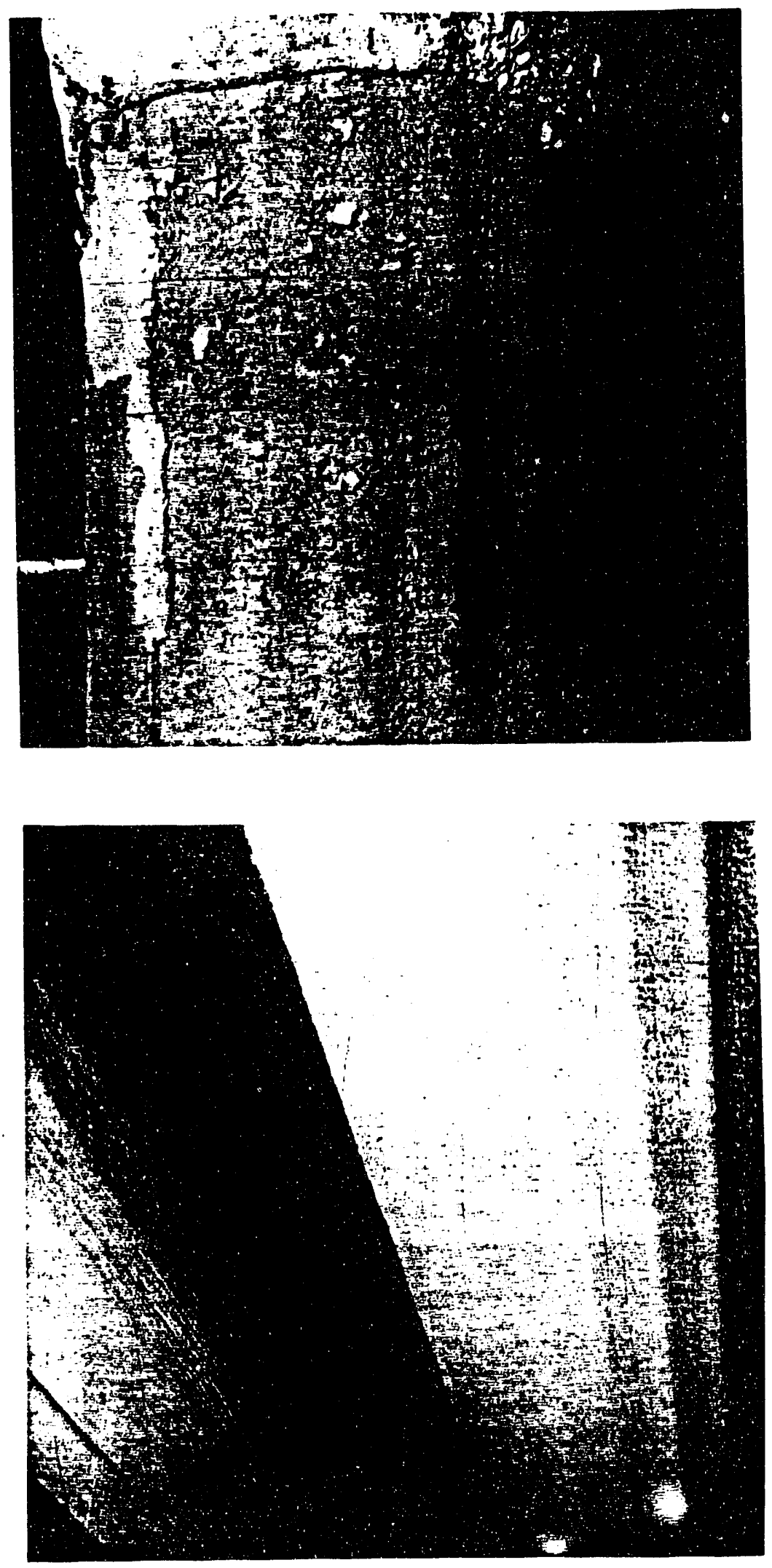

Figure 82. Residual dust cake at the end of the 100-hour baseline test with Milner coal for Run 406. 

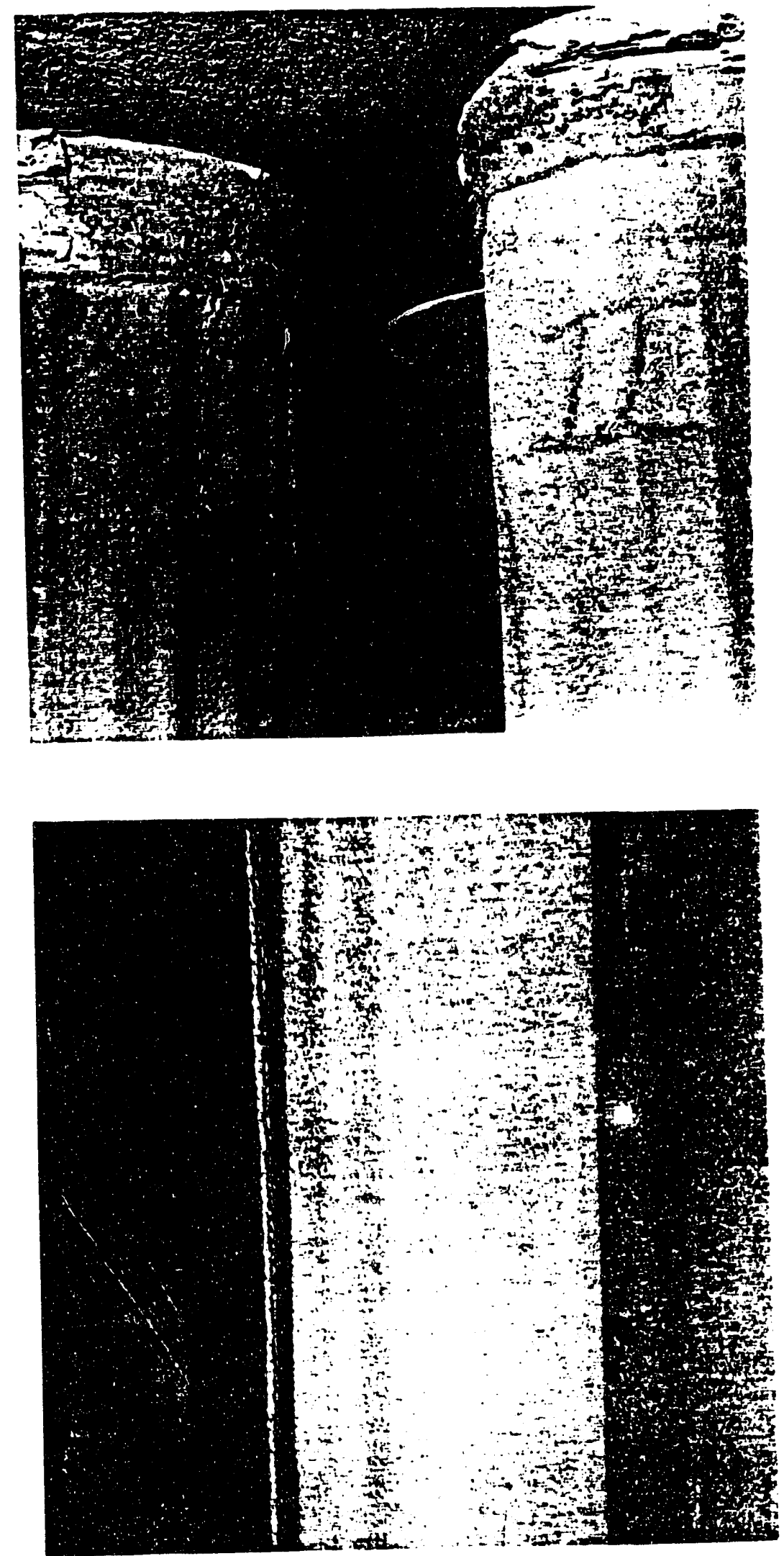

Figure 83. Residual dust cake at the end of the 100-hour conditioning test with Milner coal at an $\mathrm{A} / \mathrm{C}$ ratio of $4 \mathrm{ft} / \mathrm{min}$ for Run 407 . 

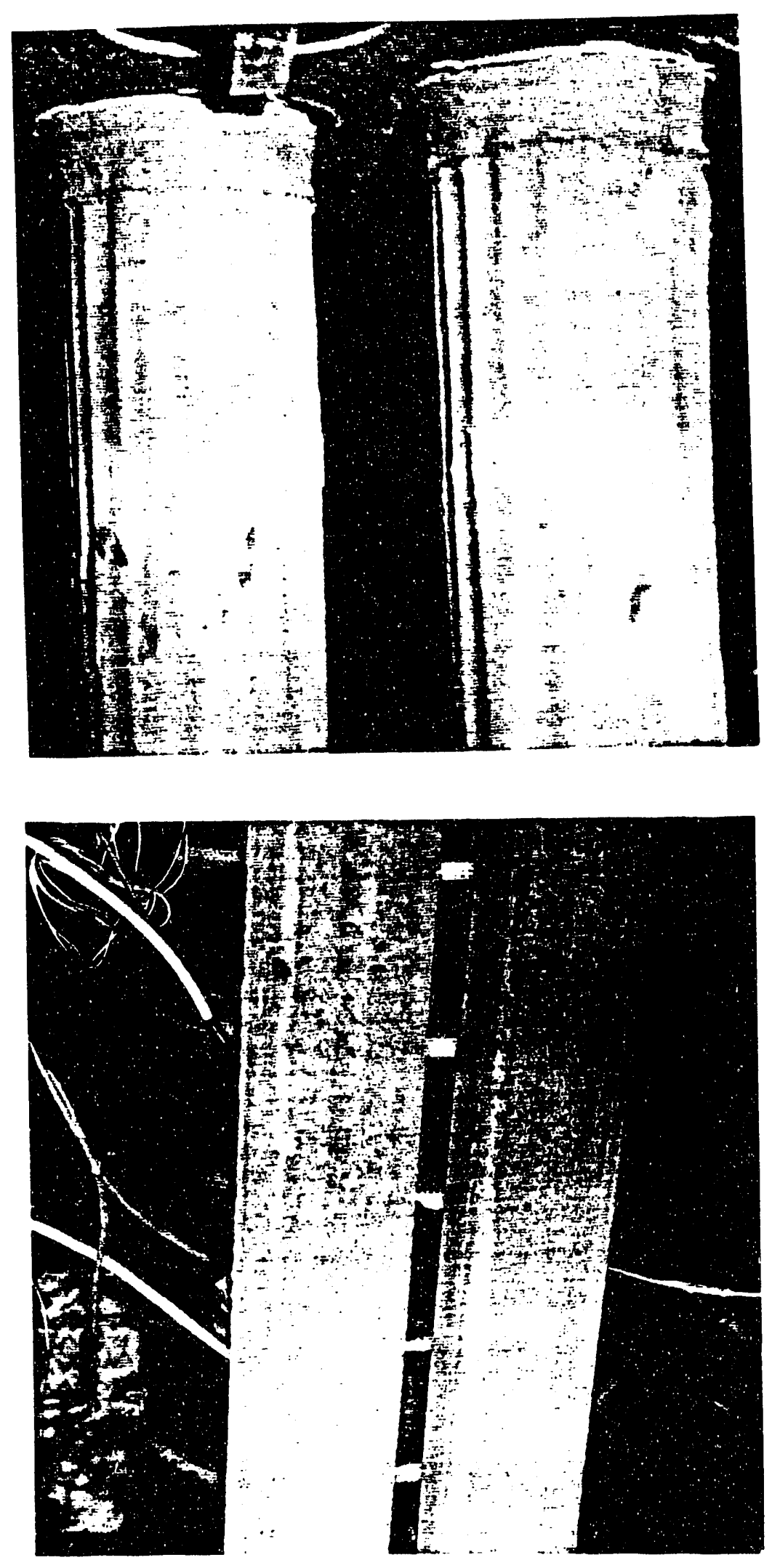

Figure 84. Residual dust cake at the end of the 100-hour conditioning test with Milner coal at an $\mathrm{A} / \mathrm{C}$ ratio of $6 \mathrm{ft} / \mathrm{min}$ for Run 411 . 

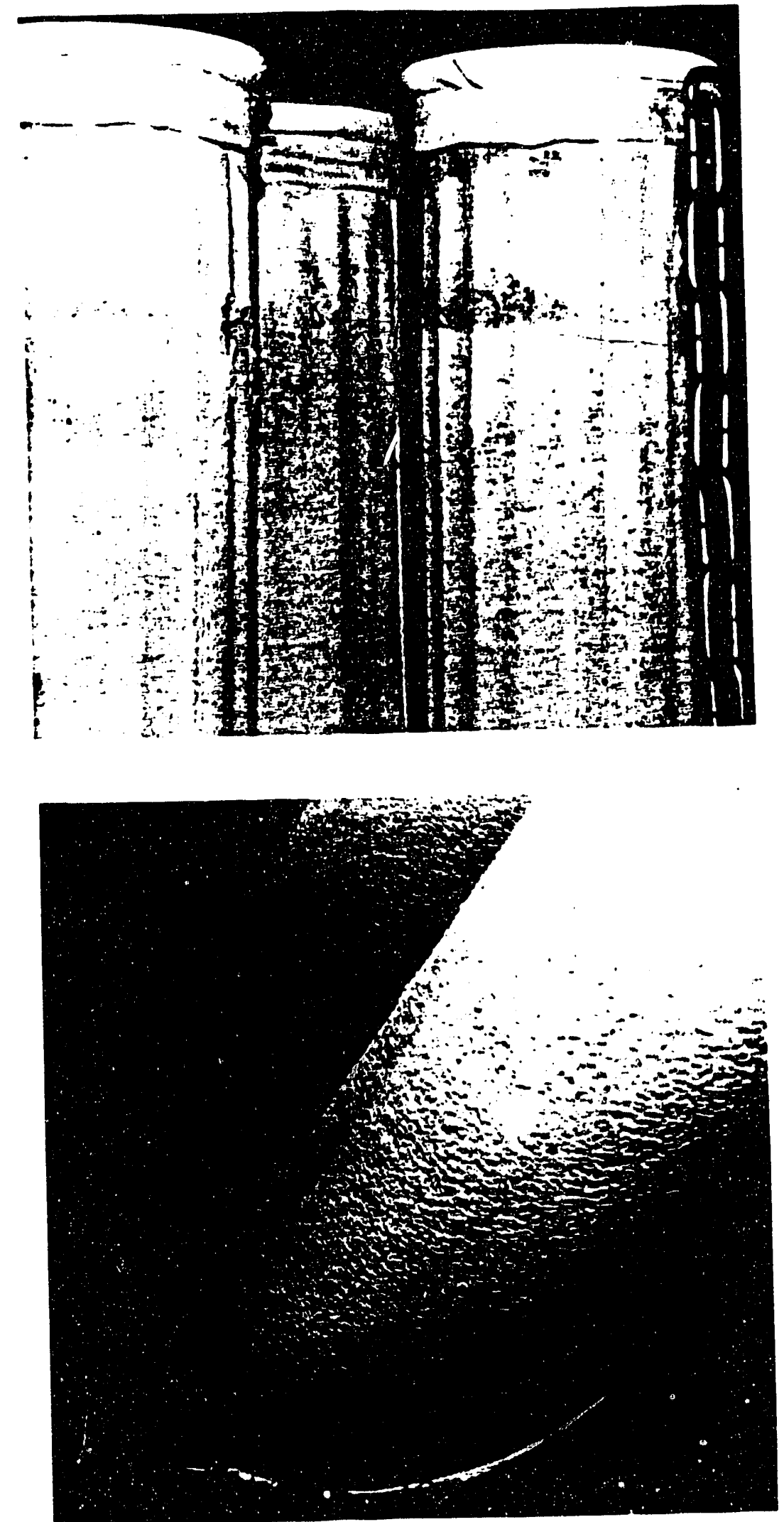

Figure 85. Residual dust cake at the end of the 100-hour baseline test with Black Thunder coal for Run 409. 

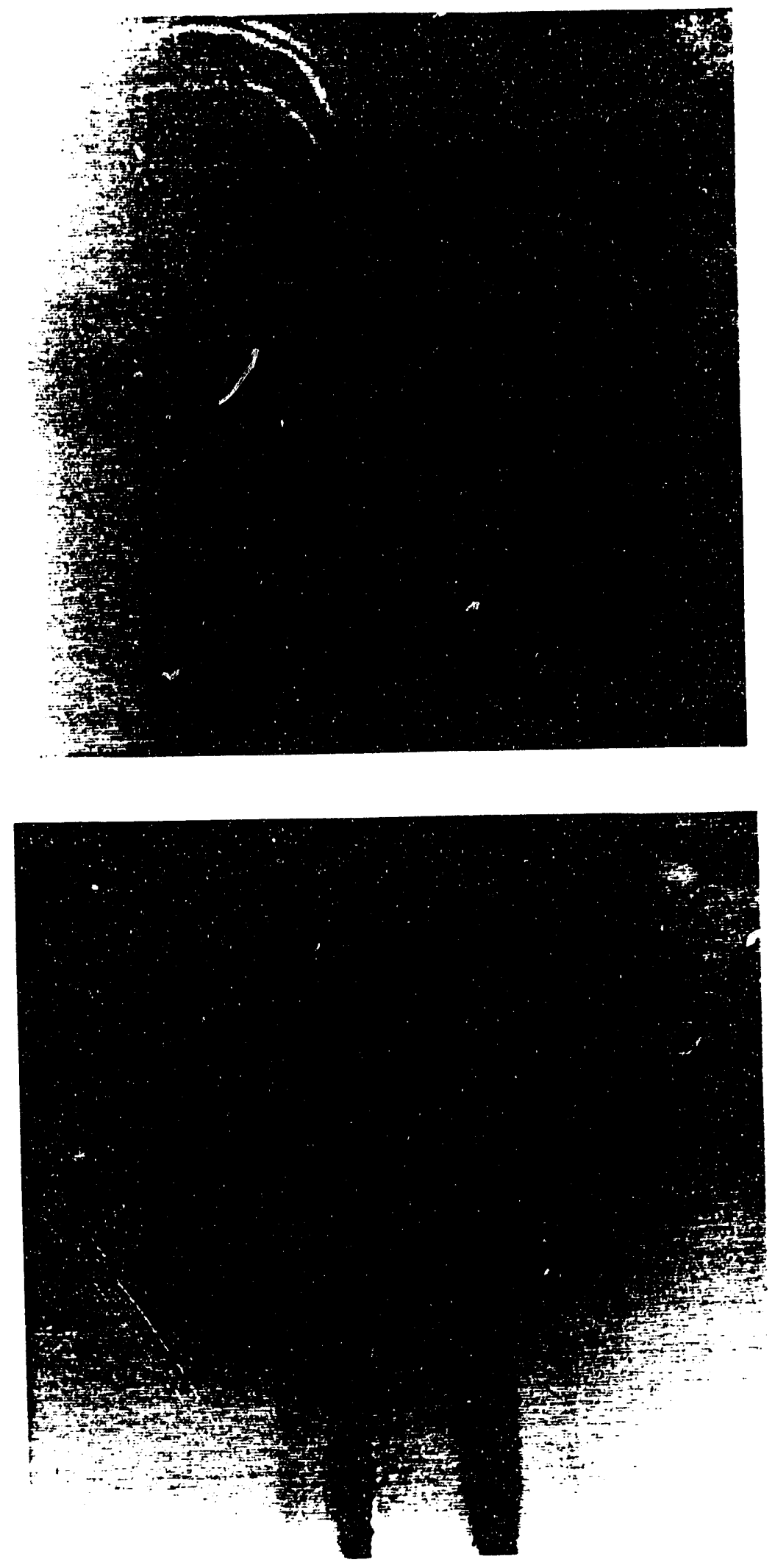

Figure 86. Residual dust cake at the end of the 100-hour conditioning test with Black Thunder coal at an $\mathrm{A} / \mathrm{C}$ ratio of $4 \mathrm{ft} / \mathrm{min}$ for Run $410 \mathrm{~B}$. 

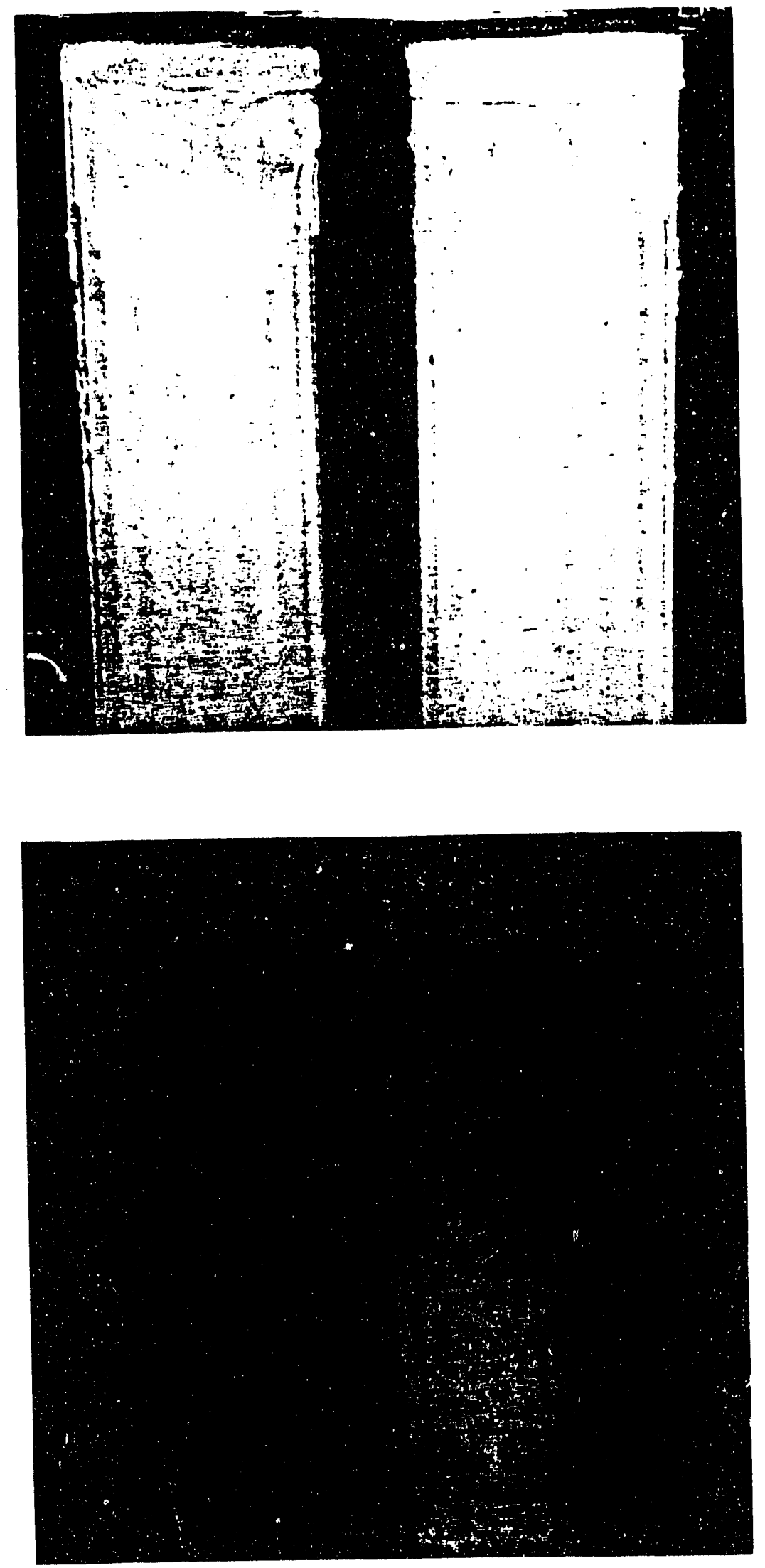

Figure 87. Residual dust cake at the end of the 100-hour conditioning test with Black Thunder coal at an A/C ratio of $6 \mathrm{ft} / \mathrm{min}$ for Run 413 . 
Results showed that conditioning was more effective for the woven glass fabric than for the Ryton felted fabric, but it was highly effective for both fabrics. Particulate emissions and pressure drop were both substantially reduced with the woven glass fabric with Big Brown coal at an A/C ratio of $4 \mathrm{ft} / \mathrm{min}$. With the Ryton fabric, pressure drop was substantially reduced, but particulate emissions were reduced only for the test at an $A / C$ ratio of $6 \mathrm{ft} / \mathrm{min}$. However, collection efficiency was already high at $99.99 \%$, and some additional reduction in particulate emissions would be likely if the bags were cleaned on a pressure drop basis rather than a constant time interval. Since pressure drop was reduced by over $50 \%$ for the Ryton fabric with conditioning, a longer cleaning cycle interval could have resulted in lower emissions because of fewer bag-cleaning spikes in a given time interval. However, the Ryton fabric already appears to provide adequate particulate collection efficiency at an A/C ratio of $4 \mathrm{ft} / \mathrm{min}$. For the Milner tests, there did not appear to be a significant difference in the performance improvement seen with conditioning between the Ryton and P84/Ryton fabrics.

Comparing the two Big Brown tests at an A/C ratio of $6 \mathrm{ft} / \mathrm{min}$ provides strong evidence that conditioning will greatly facilitate operation at high $\mathrm{A} / \mathrm{C}$ ratios. While no baseline tests were conducted at an A/C ratio of $8 \mathrm{ft} / \mathrm{min}$ for direct comparison, the highly successful results from conditioning tests at an A/C ratio of $8 \mathrm{ft} / \mathrm{min}$ for both coals further imply that this is a major benefit of conditioning. In general, conditioning provided a reasonable pressure drop and excellent particulate collection efficiency for both the Big Brown and Milner coals when the pulse-jet baghouse was operated with Ryton fabric up to an $\mathrm{A} / \mathrm{C}$ ratio of $8 \mathrm{ft} / \mathrm{min}$. Results imply that operation at even higher $\mathrm{A} / \mathrm{C}$ ratios should be possible when using ammonia and $\mathrm{SO}_{3}$ conditioning. The extent to which $\mathrm{A} / \mathrm{C}$ ratio can be increased with flue gas conditioning was further evaluated in Task 3 tests at an AVC ratio of $16 \mathrm{ft} / \mathrm{min}$.

The primary effect of conditioning on ash properties appears to be a significant increase in aerated and packed porosity. Conditioning produces an increase in the tensile strength at constant porosity, which implies that the particle-to-particle binding forces are increased.

While some new information was generated during Task 2 testing, the best concentrations to use remained somewhat uncertain. The Big Brown tests showed that significant performance improvement was achieved for all three concentrations tested, which is an encouraging result because it shows that performance improvement is not highly sensitive to exact concentrations of conditioning agents. Perhaps the most significant result of the conditioning agent concentration tests with Milner coal was the excellent performance 
improvement that was achieved with the relatively low concentrations tested, even though this was an extremely high-ash coal.

\subsection{0-hour Tests with Big Brown, Milner, and Black Thunder Coals}

Results of the 100-hour tests with Big Brown Coal and Ryton fabric showed that conditioning significantly reduced particulate emissions and pressure drop. With constant bag-cleaning frequency and a constant $A / C$ ratio of $4 \mathrm{ft} / \mathrm{min}$, conditioning resulted in a much lower baghouse $\Delta P$. With an increase in $A / C$ ratio to $6 \mathrm{ft} / \mathrm{min}$ while keeping the bagcleaning frequency constant, the $\Delta \mathrm{P}$ was lower than the $\Delta \mathrm{P}$ for the baseline test at an $\mathrm{A} / \mathrm{C}$ ratio of $4 \mathrm{ft} / \mathrm{min}$. These results demonstrate the significant benefits of using conditioning with Big Brown coal and Ryton fabric: a substantial reduction in particulate emissions and a substantial reduction in pressure drop (or the ability to operate at a higher AVC ratio without increasing pressure drop or bag-cleaning frequency). The improvements in fabric filter performance correlate strongly with a shift in the tensile strength-porosity curves and with increases in the aerated and packed porosity of the fly ash. The residual dust cake with conditioning was more on the surface of the fabric and somewhat thicker than for the baseline case. Since there were substantial changes in fabric filter performance and tensile strength with conditioning with the $24 / 12 \mathrm{ppm}$ of $\mathrm{NH}_{3} / \mathrm{SO}_{3}$, very likely the conditioning concentrations could be reduced somewhat while still retaining a significant benefit.

Conditioning also worked very well with the Milner coal and P8A/Ryton fabric, producing significant reductions in particulate emissions and pressure drop. With a constant bag-cleaning frequency, the $\Delta P$ with conditioning at an $A / C$ ratio of $6 \mathrm{ft} / \mathrm{min}$ was about the same as the $\Delta P$ for the baseline case at an $A C$ ratio of $4 \mathrm{ft} /$ min. One of the most encouraging results with the Milner tests was that the residual dust cake weight was very light for both the baseline and conditioning tests, and there was no evidence of potential bagcleaning problems. This indicates that the conditioning concentrations of $24 / 12 \mathrm{ppm}$ of $\mathrm{NH}_{3} / \mathrm{SO}_{3}$ were adequate to improve baghouse performance, but not too high to cause bagcleaning problems. The conditioning agent concentrations could likely be increased somewhat without a negative impact on bag cleanability, possibly resulting in even greater performance improvement. Similarly, conditioning agent concentrations could be somewhat reduced, while retaining a significant level of performance improvement.

Conditioning also resulted in some improvements in fabric filter performance with the Black Thunder coal, but not as substantial as with the other two coals. Pressure drop was reduced by about $50 \%$ with conditioning at an $A / C$ ratio of $4 \mathrm{ft} / \mathrm{min}$, but at an $A / C$ ratio of 6 
$\mathrm{ft} / \mathrm{min}$ with conditioning, the $\Delta \mathrm{P}$ was higher than the $\Delta \mathrm{P}$ for the baseline test at $4 \mathrm{ft} / \mathrm{min}$. Particulate emissions were not reduced for the conditioning tests, but emissions were already very low for the baseline test with Ryton fabric. Very likely, under other conditions such as with woven glass fabric, particulate emissions would be somewhat reduced. The shift in the fly ash tensile strength curves and the increases in aerated or packed porosity with Black Thunder coal were smaller than for the other coals. The ammonia slip was higher for the Black Thunder tests in spite of injecting only half of the ammonia concentration that was injected for the other coals. These results indicate that proper conditioning with Black Thunder coal may require smaller amounts of conditioning agents than the amounts used for the other coals. In addition, the ratio of ammonia to $\mathrm{SO}_{3}$ may have to be adjusted to minimize the ammonia slip.

\subsection{6-ft/min Tests with Big Brown Coal}

For the Big Brown normal dust-loading tests at an A/C ratio of $16 \mathrm{ft} / \mathrm{min}$ and off-line pulsing, conditioning resulted in a lower $\mathrm{K}_{2}$, but thee was also some buildup in residual dust cake weight. This implies that a more energetic pulse may be required to sufficiently dislodge the dust when conditioning is used at very high A/C ratios.

Big Brown tests with a dust loading of approximately $1 / 20$ th of normal at $16 \mathrm{ft} / \mathrm{min}$ with off-line pulsing resulted in bag blinding. Neither conditioning nor the use of Neutralite precoating was successful in preventing the bag blinding. The combination of very low dust loading and high velocity may allow the dust to pack tightly into the fabric structure, or the particulate properties may have been different because of different combustion conditions.

\subsection{Unresolved Issues and Areas for Future Research}

The optimum amounts of conditioning agents to use for all of the coals are not known. A 2:1 molar ratio of ammonia to $\mathrm{SO}_{3}$ was used for all of the tests, but it is not known if optimum performance is always achieved with a 2:1 molar ratio. A research need is to determine the maximum performance improvement that can be achieved by increasing conditioning agent concentrations beyond the highest level tested and to better determine a minimum performance improvement by reducing concentrations below the lowest level tested. Since only two concentrations were tested with the Milner coal, a question remains whether additional performance improvement can be achieved by increasing conditioning agent concentrations. One of the difficulties in trying to establish optimum performance improvement is that the characteristics of an ideal dust that provide the best combination of 
good pore-bridging ability, high porosity, and good bag cleanability are not known. A much better understanding of the relationships between the cohesive properties of dusts and filtration performance is needed before conditioning can be refined for optimum performance improvement.

The results clearly show the substantial benefits in fabric filter performance that can be achieved with conditioning. Longer-term testing is needed, however, to establish the effect of conditioning on the residual dust cake over an extended period. The chemistry of the process also needs further investigation so that possible chemical reactions between the conditioning agents and fly ash or the conditioning agents and the fabric could be predicted. Any potential effect on long-term fabric degradation also needs to be assessed.

The results from the $16-\mathrm{ft} / \mathrm{min}$ tests with a reduced dust loading were difficult to explain. More work is needed to determine if the combination of a high face velocity and a low dust loading is more likely to cause fabric blinding than a normal dust loading and high velocity, or if cofiring with coal and natural gas alters particulate properties to facilitate fabric blinding. In addition, it is not known whether conditioning would be effective with a very low dust loading by using different conditioning agent concentrations.

A question exists as to the effect, if any, that small amounts of ammonium sulfate may have on fly ash disposal and utilization. The concentration of ammonia on the fly ash was measured to be $0.1 \%$ to $0.3 \%$ (most likely in the form of ammonium sulfate). Three potential concerns are possible off-gassing of ammonia upon wetting of the fly ash, leaching characteristics of the ammonia or ammonia products, and the effect on fly ash utilization.

In an aqueous solution at a pH greater than 10, the ammonia is in the form of dissolved ammonia gas and would likely result in some off-gassing of ammonia into the air. Therefore, in the case of wetting of the fly ash or under very high-humidity conditions with high-calcium or high-sodium ashes, the possibility of a detectable ammonia odor exists. With dry fly ash handling and disposal, ammonia odor is not expected to be a problem.

ASTM leachate tests were not part of this study but have been conducted on fly ashes from previous baseline and conditioning tests. As expected, leachate concentrations of $\mathrm{NH}_{4}{ }^{+}, \mathrm{SO}_{4}{ }^{2-}$, and $\mathrm{NO}_{3}^{-}$were higher for the conditioned fly ashes. The $\mathrm{NO}_{3}{ }^{-}$is apparently the result of oxidation of some of the ammonia. Nitrate in groundwater is regulated by the primary drinking water standards; however, the contribution of nitrate from conditioned fly ash to overall nitrates is likely to be very small compared to major contributors such as 
agricultural sources. Soluble sulfates are typically found in fly ash so the addition of a small amount of soluble $\mathrm{SO}_{4}{ }^{2-}$ should not change disposal considerations. $\mathrm{NH}_{4}{ }^{+}$is not normally found in fly ash, but apparently there are no regulations that would require special disposal methods for fly ash containing small amounts of ammonia. One interesting result of the leaching tests was that selenium concentration in the leachate was reduced by about $75 \%$ which implies that conditioning inhibits the leaching of selenium. The mechanism, however, is not clear, and this result needs to be verified.

Fly ashes have been used extensively for cement replacement in concrete. The effect of the ammonia on the pozzolonic activity of the fly ash is not known. The concentration and chemical form of the ammonia on the fly ash and the specific use will likely determine whether small amounts of ammonia on fly ash will significantly affect utilization. Research is needed on the effect of ammonia on fly ash disposal and utilization, not only for flue gas conditioning applied to fabric filtration, but also for other processes such as $\mathrm{NO}_{\mathrm{x}}$ control by selective catalytic reduction which result in ammonia on fly ash.

\subsection{REFERENCES}

1. Miller, S.J.; Laudal, D.L. "Real-Time Measurement of Respirable Particulate Emissions from a Fabric Filter," In Particulate and Multiphase Processes, Vol. 2, Contamination Analysis and Control; Ariman, T., Ed.; Hemisphere Pub. Corp., 1987, p 663.

2. Miller, S.J.; Laudal, D.L. "Particulate Removal Enhancement of a Fabric Filter Using Flue Gas Conditioning," Presented at the Third EPRI Conference on Fabric Filter Technology for Coal-Fired Power Plants, Scottsdale, AZ, Nov. 19-21, 1985.

3. Laudal, D.L.; Miller, S.J. "Flue Gas Conditioning for Improved Baghouse Perfornance," In Proceedings of the Sixth Symposium on the Transfer and Utilization of Particulate Control Technology; EPRI CS-4918, Nov. 1986, Vol. 3, p 14-1.

4. Miller, S.J.; Laudal, D.L. "Flue Gas Conditioning for Improved Fine Particle Capture in Fabric Filters: Comparative Technical and Economic Assessment," In Low-Rank Coal Research Final Report, Vol. II, Advanced Research and Technology Development; DOE/FC/10637-2414 (DE87006532), Apr. 1987.

5. Miller, S.J.; Laudal, D.L. "Fine Particulate Emissions: Flue Gas Conditioning for Improved Fine-Particle Capture in Fabric Filters," Final Technical Report for the Period Apr. 1, 1987, through Mar. 31, 1988; DE-FC21-86MC10637, Grand Forks, ND, August 1988. 
6. Laudal, D.L.; Miller, S.J. "Flue Gas Conditioning for Baghouse Performance Improvement with Low-Rank Coals," In Proceedings of the Fourteenth Biennial Lignite Symposium on the Technology and Utilization of Low-Rank Coals; University of North Dakota Energy and Environmental Research Center, Grand Forks, ND, 1987.

7. Miller, S.J.; Laudal, D.L.; Kim, S.S. "Mechanisms of Fabric Filter Performance Improvement with Flue Gas Conditioning," In Proceedings of the Seventh EPA/EPRI Symposium on the Transfer and Utilization of Particulate Control Technology; EPRI GS-6208, Feb. 1989, Vol. 2, pp 25-1.

8. Miller, S.J. "Flue Gas Conditioning for Fabric Filter Performance Improvement," Final Project Report for Contract No. DE-AC22-88PC88866 for Pittsburgh Energy Technology Center, Dec. 1989.

9. Miller, S.J.; Laudal, D.L. "Enhancing Baghouse Performance with Conditioning Agents: Basis, Developments, and Economics," In Proceedings of the Eighth Particulate Control Symposium; EPRI GS-7050, Nov. 1990, Vol. 2, p 23-1.

10. Miller, S.J.; Laudal, D.L; Chang, R.L. "Flue Gas Conditioning for Improving PulseJet Baghouse Performance," Presented at the Ninth Particulate Control Symposium, Williamsburg, VA, Oct. 15-18, 1991.

11. Miller, S.J.; Heidt, M.K.; Laudal, D.L.; Weber, G.F. "Flue Gas Cleanup," Semiannual Report for the Period Jan. 1, 1992 - Jun. 30, 1992 for Contract No. DEFC21-86MC10637, Jul. 1992. 

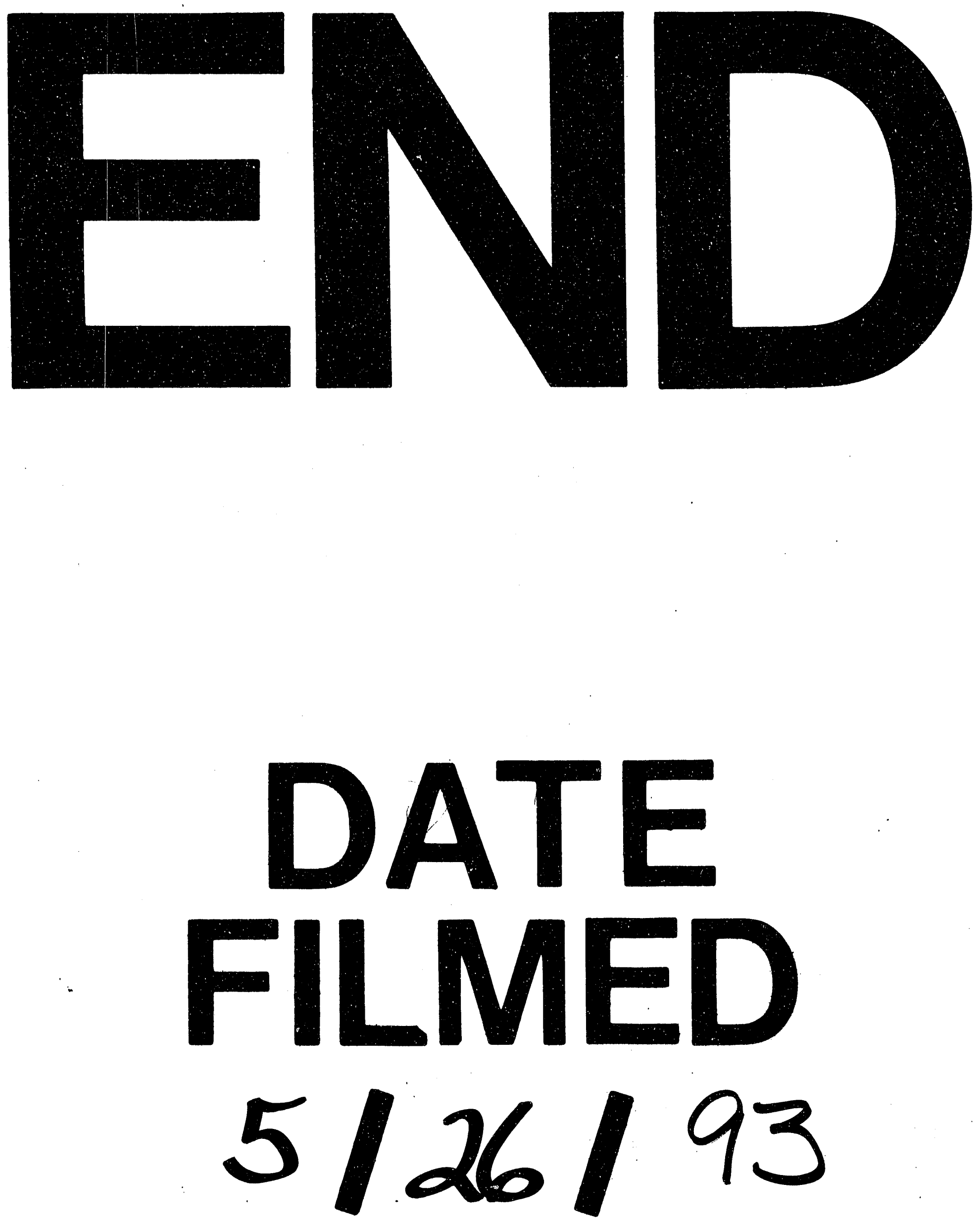

1 


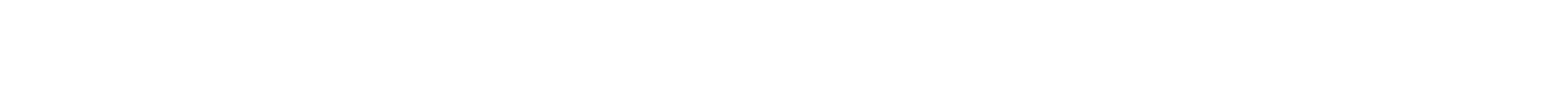

